UNIVERSIDADE DE SÃO PAULO

FACULDADE DE ECONOMIA, ADMINISTRAÇÃO E CONTABILIDADE DE RIBEIRÃO PRETO

DEPARTAMENTO DE ECONOMIA

PROGRAMA DE PÓS-GRADUAÇÃO EM ECONOMIA APLICADA

VICTOR AZAMBUJA GAMA

\title{
Uma análise de relação entre violência e proficiência escolar no município de São Paulo
}

Orientador: Prof. Dr. Luiz Guilherme Dácar da Silva Scorzafave 
Profa. Dra. Sueli Vilela

Reitora da Universidade de São Paulo

Prof. Dr. Rudinei Toneto Júnior

Diretor da Faculdade de Economia, Administração e Contabilidade de Ribeirão Preto

Prof. Dr. Walter Beluzzo Júnior

Chefe do Departamento de Economia 


\section{Uma análise de relação entre violência e proficiência escolar no município de São Paulo}

Dissertação apresentada ao Programa de PósGraduação em Economia Aplicada da Faculdade de Economia, Administração e Contabilidade de Ribeirão Preto da Universidade de São Paulo como requisito para obtenção do título de Mestre em Economia.

Área de concentração: Economia Aplicada Orientador: Prof. Dr. Luiz Guilherme Dácar da Silva Scorzafave 
AUTORIZO A REPRODUÇÃO E DIVULGAÇÃO TOTAL OU PARCIAL DESTE TRABALHO, POR QUALQUER MEIO CONVENCIONAL OU ELETRÔNICO, PARA FINS DE ESTUDO E PESQUISA, DESDE QUE CITADA A FONTE.

Gama, Victor Azambuja.

Uma análise de relação entre violência e proficiência escolar no município de São Paulo. Ribeirão Preto, 2009.

113 p.; $30 \mathrm{~cm}$

Dissertação de Mestrado, apresentada à Faculdade de Economia, Administração e Contabilidade de Ribeirão Preto da Universidade de São Paulo.

Orientador: Scorzafave, Luiz Guilherme Dácar da Silva.

1. Economia. 2. Violência. 3. Proficiência escolar. 4. São Paulo. 


\section{FOLHA DE APROVAÇÃO}

Victor Azambuja Gama

Uma análise de relação entre violência e proficiência escolar no município de São Paulo.

Dissertação apresentada ao Programa de PósGraduação em Economia Aplicada da Faculdade de Economia, Administração e Contabilidade de Ribeirão Preto da Universidade de São Paulo como requisito para obtenção do título de Mestre em Economia.

Área de concentração: Economia Aplicada

Aprovado em:

Banca Examinadora

Prof. Dr. Luiz Guilherme Dácar da Silva Scorzafave

Instituição: Faculdade de Economia, Administração e Contabilidade de Ribeirão Preto - FEARP/USP

Assinatura:

Prof. Dr.

Instituição:

Assinatura:

Prof. Dr.

Instituição:

Assinatura: 


\section{DEDICATÓRIA}

Aos meus pais, pela paciência e apoio incondicional não apenas no período de elaboração desse trabalho, mas em todas as atividades em que estive comprometido. Ao verdadeiro Deus, sempre próximo, atento e disposto a me auxiliar. 


\section{AGRADECIMENTOS}

Meus sinceros agradecimentos ao prof. Dr. Luiz Guilherme, sempre presente, com infinita paciência e ânimo incontestável. Eu recomendo! 
"Deus é o meu rochedo, nele confiarei; o meu escudo, e a força da minha salvação, o meu alto retiro, e o meu refúgio. O meu Salvador, da violência me salvas". 


\section{RESUMO}

GAMA, V. A. Uma análise de relação entre violência e proficiência escolar no município de São Paulo. 113 f. Dissertação (Mestrado) - Faculdade de Economia, Administração e Contabilidade de Ribeirão Preto, Universidade de São Paulo, Ribeirão Preto, 2009.

De acordo com a literatura internacional, a violência é considerada um sério problema, em especial, para crianças e adolescentes. O motivo é que a exposição à violência no início do ciclo da vida pode constituir-se não só em um fator degenerativo da saúde, mas também, em um fenômeno que pode solapar o acúmulo de capital humano e, portanto, afetar a formação social e econômica da vítima. Tendo em vista a importância desse link teórico, o objetivo do presente estudo é analisar a relação entre violência e proficiência escolar no município de São Paulo. Para a consecução dessa proposta de trabalho, serão utilizadas as ocorrências criminais arranjadas por distritos policiais da SEADE (Fundação Sistema Estadual de Análise de Dados), Prova Brasil 2005 que oferece informações de desempenho escolar e da condição socioeconômica dos alunos avaliados, Censo Escolar 2005 que coleta informações de professores e escolas, e variáveis socioeconômicas arranjadas por distritos da capital (distritos populacionais) levantados pelo Censo Demográfico 2000. A análise econométrica mostrou que alunos da quarta série de escolas públicas de regiões violentas têm desempenho melhor em matemática e português para três das seis categorias de crime usadas. Ademais, encontramos evidências de que a violência afeta mais os alunos da cauda superior da distribuição de notas.

Palavras-chave: Economia. Violência. Proficiência escolar. São Paulo. 


\begin{abstract}
GAMA, V. A. An analysis of relationship between violence and school proficiency in the city of São Paulo. 113 f. Dissertação (Mestrado) - Faculdade de Economia, Administração e Contabilidade de Ribeirão Preto, Universidade de São Paulo, Ribeirão Preto, 2009.

According to international literature, violence is considered a serious problem, especially for children and adolescents. The reason is that exposure to violence at the beginning of the life course can be not only a degenerative health factor, but also, a phenomenon that can harm the accumulation of human capital and thus affect the social and economical formation of the victim. Because of the importance of this theorical link, the purpose of this study is to analyze the relationship between violence and school proficiency in the city of São Paulo. To reach this aim, we use criminal occurrences arranged by police districts of the SEADE (Fundação Sistema Estadual de Análise de Dados), Prova Brasil 2005 that offers information of school performance and socioeconomic conditions of the evaluated students, Censo Escolar 2005 that collects information about teachers and schools, and socioeconomic variables arranged by capital districts (population districts) administered by Censo Demográfico 2000. The econometric analysis showed that students in fourth grade of public schools in violent areas have better performance in mathematics and portuguese for three of the six categories of crime used. Moreover, we found evidence that the violence affects more the students of the upper tail distribution of scores.
\end{abstract}

Keywords: Economy. Violence. School proficiency. São Paulo. 


\section{LISTA DE TABELAS}

Tabela 1 - Média, desvio padrão das notas e indicadores de violência.

Tabela 2 - Correlações entre as categorias de violência

Tabela 3 - Correlações entre notas, notas médias por escola e indicadores de violência.

Tabela 4 - Características dos alunos e testes de diferenças de média.

Tabela 5 - Background familiar e testes de diferenças de média.

Tabela 6 - Características das escolas e testes de diferenças de média......

Tabela 7 - Características dos professores e testes de diferenças de média.

Tabela 8 - Média e desvio padrão das características dos distritos da capital. 48

Tabela 9 - Testes de diferenças de média das variáveis inerentes ao controle de variáveis omitidas e efeito de pares.

Tabela 10 - A associação entre violência e proficiência escolar em matemática.

Tabela 11 - A associação entre violência e proficiência escolar em português.

Tabela A1 - A associação entre crimes contra a pessoa e notas de matemática. 72

Tabela A2 - A associação entre crimes contra o patrimônio e notas de matemática. .75

Tabela A3 - A associação entre crimes violentos e notas de matemática. .78

Tabela A4 - A associação entre ameaças e notas de matemática.

Tabela A5 - A associação entre roubo consumado e notas de matemática.....

Tabela A6 - A associação entre furto consumado e notas de matemática......

Tabela A7 - A associação entre crimes contra a pessoa e notas de português. .90

Tabela A8 - A associação entre crimes contra o patrimônio e notas de português

Tabela A9 - A associação entre crimes violentos e notas de português. .96

Tabela A10 - A associação entre ameaças e notas de português

Tabela A11 - A associação entre roubo consumado e notas de português.... 102 
Tabela A12 - A associação entre furto consumado e notas de português

Tabela A13 - Relação entre crimes contra a pessoa e proficiência escolar em matemática ao longo da distribuição de notas.

Tabela A14- Relação entre crimes contra o patrimônio e proficiência escolar em matemática ao longo da distribuição de notas.

Tabela A15 - Relação entre crimes violentos e proficiência escolar em matemática ao longo da distribuição de notas.

Tabela A16 - Relação entre ameaças e proficiência escolar em matemática ao longo da distribuição de notas.

Tabela A17 - Relação entre roubo consumado e proficiência escolar em matemática ao longo da distribuição de notas.

Tabela A18 - Relação entre furto consumado e proficiência escolar em matemática ao longo da distribuição de notas.

Tabela A19 - Relação entre crimes contra a pessoa e proficiência escolar em português ao longo da distribuição de notas.

Tabela A20- Relação entre crimes contra o patrimônio e proficiência escolar em português ao longo da distribuição de notas.

Tabela A21 - Relação entre crimes violentos e proficiência escolar em português ao longo da distribuição de notas

Tabela A22 - Relação entre ameaças e proficiência escolar em português ao longo da distribuição de notas

Tabela A23 - Relação entre roubo consumado e proficiência escolar em português ao longo da distribuição de notas.

Tabela A24 - Relação entre furto consumado e proficiência escolar em português ao longo da distribuição de notas..... 


\section{SUMÁRIO}

1. INTRODUÇÃO

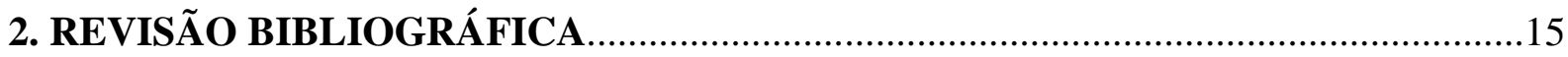

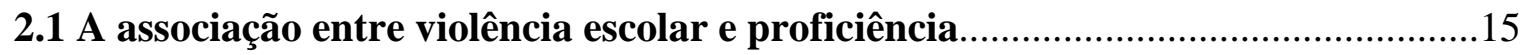

2.2 A associação entre violência genérica e proficiência............................................18

3. DADOS, METODOLOGIA E ESTATÍSTICAS DESCRITIVAS...............................28

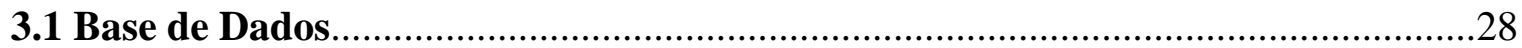

3.2 Metodologia

3.2.1 Variáveis dependentes e variáveis explicativas de interesse.................................30

3.2.2 Medidas relacionadas às características dos alunos.............................................31

3.2.3 Medidas de background familiar..........................................................................3

3.2.4 Medidas relacionadas às características das escolas............................................34

3.2.5 Medidas relacionadas às características dos professores.....................................34

3.2.6 Medidas relacionadas às características dos distritos da capital........................35

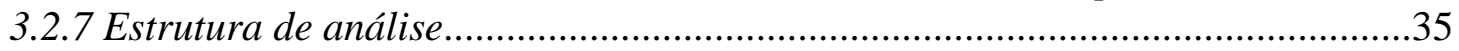

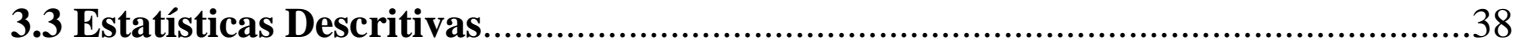

3.3.1 Notas, notas médias e indicadores de violência................................................39

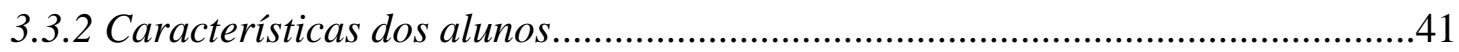

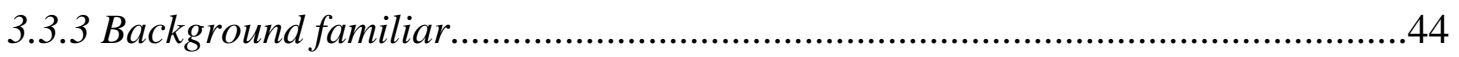

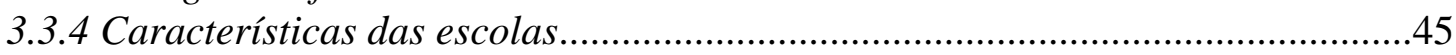

3.3.5 Características dos professores....................................................................4

3.3.6 Características dos distritos da capital.........................................................48

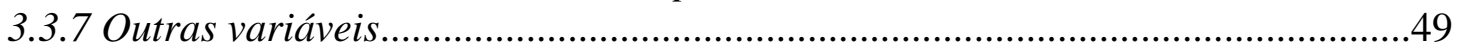

4. RESULTADOS

4.1 A associação entre violência e proficiência escolar em matemática........................52

4.1.1 Mínimos Quadrados Ordinários para as notas de matemática............................52

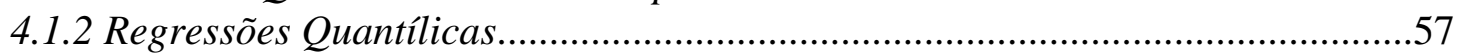

4.2 A associação entre violência e proficiência escolar em português............................58

4.2.1 Mínimos Quadrados Ordinários para as notas de português..............................58

5. CONCLUSÕES

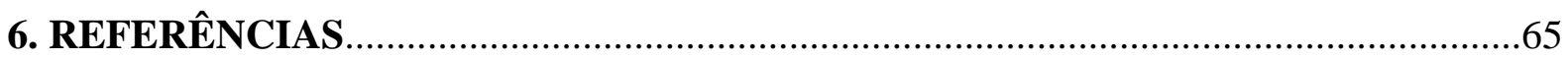

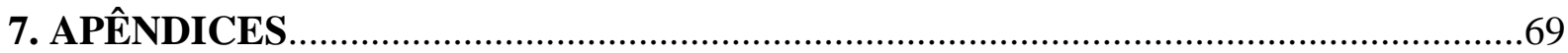

7.1 Definições e construção das variáveis explicativas....................................................69

7.2 Tabelas com os resultados obtidos por mínimos quadrados ordinários.................72

7.3 Tabelas com os resultados obtidos pelas regressões quantílicas.............................107 


\section{INTRODUÇÃO}

A educação sob a perspectiva do investimento em capital humano é considerada um fator fundamental para o crescimento econômico no longo prazo (ROMER, 2006). Nesse sentido, a melhoria da educação constitui-se não somente em uma estratégia que afeta o desenvolvimento de habilidades e ganhos individuais, mas também em um elemento de promoção do bem-estar socioeconômico (HANUSHEK E WOESSMANN, 2007).

Considerando os resultados obtidos pelo Programa Internacional de Avaliação de Alunos $(\mathrm{PISA})^{1}$ o Brasil ocupa uma das últimas colocações no ranking de proficiência em matemática e em leitura nas provas de 2003 e 2006. Esses resultados evidenciam que o Brasil tem um longo caminho a percorrer no processo de melhoria da qualidade de ensino. Logo, compreender os fatores determinantes do desempenho dos alunos brasileiros é tarefa de extrema relevância para o desenvolvimento de ações que levem a melhoria da educação brasileira.

Um outro problema encontrado no cenário brasileiro é a violência. Para se ter uma dimensão desse problema, entre 1992 e 2002, a taxa de homicídios geral cresceu cerca de $33 \%$ e os homicídios de jovens cresceram aproximadamente 40\% (IPEADATA, 2009). Waiselfisz (2006) retratou com detalhes o mapa da violência juvenil entre os anos de 1994 e 2004 e mostra a profundidade do problema no caso brasileiro. Dentre 84 países o Brasil em 2004 ocupou a terceira posição no ranking de violência juvenil com a taxa de 51,7 homicídios em cem mil jovens, sendo que essa taxa é mais de cem vezes superior que as da Áustria, Inglaterra, Egito e Japão.

\footnotetext{
${ }^{1}$ O PISA é um programa internacional de avaliação comparada, que tem por objetivo construir indicadores que possam representar a qualidade dos sistemas educacionais entre os países participantes, avaliando a proficiência dos alunos que possuem em torno de quinze anos de idade.
} 
A simultaneidade dos fenômenos da falta de qualidade educacional e da violência nos leva a questionar se não haveria alguma relação entre eles? É possível que a violência seja um fator determinante do desempenho escolar? Por quais mecanismos a violência poderia afetar a performance dos estudantes?

A violência é considerada um dos fatores de risco mais preocupantes para o desenvolvimento emocional, comportamental e social de crianças e adolescentes. Isso ocorre, pois nessa faixa etária os efeitos da exposição à violência são mais traumáticos devido à limitação dos recursos mentais necessários para se compreender esses eventos (SIEGER et al., 2004). Ademais, existem evidências indicando que quando a exposição a práticas violentas ocorre no início do ciclo da vida, poderão existir sérias consequiências em termos de distúrbios ao desenvolvimento pessoal e socioeconômico das vítimas (MACMILLAN, 2001).

Os efeitos ocasionados por experiências com atos violentos são extremamente nocivos quando as vítimas (ou testemunhas) são crianças e adolescentes. Em primeiro lugar, a exposição à violência pode afetar diretamente a saúde das vítimas. Indivíduos que presenciaram algum evento traumático podem apresentar sintomas de depressão, ansiedade, aflição, stress, dificuldade em se concentrar, preocupações excessivas com a segurança, dificuldade em dormir e outros comportamentos destrutivos como o uso de substâncias e tentativas de suicídio, os quais contribuem diretamente para a degradação do bem estar físico e psicológico. Em segundo lugar, a vitimização pode ser caracterizada como um importante fator que antecede futuros desvios de conduta, envolvimento criminal e associação com delinqüentes. Em terceiro lugar, a exposição à violência pode prejudicar a consecução de metas educacionais e socioeconômicas. É consenso na literatura internacional que crianças e adolescentes que foram vítimas da violência ou que sofrem pressão por residirem em um 
ambiente hostil e de extrema insegurança tendem a ter pior desempenho escolar. ${ }^{2}$ Em conseqüência, pode haver comprometimento da formação de capital humano e das perspectivas no momento de ingresso no mercado de trabalho.

A literatura internacional especializada na relação entre violência e desempenho escolar possui duas vertentes bem definidas. Na primeira, estão os estudos que abordaram essa relação sob a perspectiva da violência escolar, isto é, a violência que ocorre nos domínios físicos da escola e vizinhança. Na segunda, são compreendidos os trabalhos que analisaram o tema em pauta sob o ponto de vista do conceito genérico de violência ${ }^{3}$. O presente trabalho se insere nessa segunda linha e seu objetivo é analisar a associação entre violência e proficiência dos alunos da quarta série das escolas públicas da cidade de São Paulo. Especificamente, o intuito é investigar qual a relação entre a violência da região em que as escolas estão localizadas e o desempenho dos alunos dessas instituições. A escolha do município de São Paulo como região a ser estudada, se deve a disponibilidade de dados relativos a diversas categorias criminais que estão organizadas por distritos policiais. Além disso, escolhemos os alunos da quarta série, pois acreditamos que crianças dessa faixa de idade estariam mais propícios a serem vítimas de violência do que serem geradores de atos violentos.

Além dessa introdução, o trabalho está organizado em mais quatro capítulos. No segundo capítulo, será revisada a literatura que disserta sobre o tema em estudo. No terceiro, serão apresentados os dados utilizados, a metodologia de análise e as estatísticas descritivas da nossa amostra no que diz respeito às ocorrências de violência, características dos alunos, background familiar, características das escolas, dos professores e dos distritos da capital. No quarto, serão apresentados os resultados e, por fim, as conclusões.

\footnotetext{
${ }^{2}$ Para maiores detalhes sobre os efeitos da exposição à violência sobre crianças e adolescentes, consultar: Gorman-Smith e Tolan (1998), Osofsky (1999), Margolin e Gordis (2000), Overstreet (2000), Ceballo et al. (2001), Ward et al. (2001), Salzinger et al. (2002), Scarpa (2003), Aisenberg e Ell (2005), e Jones (2007).

${ }^{3}$ Essas duas linhas de pesquisa serão abordadas mais detalhadamente no capítulo seguinte.
} 


\section{REVISÃO BIBLIOGRÁFICA}

Este capítulo tem por finalidade discutir a literatura que associa violência e desempenho escolar. Esse campo do conhecimento possui dois grupos bem definidos de trabalhos. O primeiro analisa essa relação no âmbito da violência escolar (que ocorre no interior ou nas imediações da escola) e que pode ser caracterizada pelas seguintes práticas: (i) agressão física entre ou contra alunos e professores, (ii) assédio sexual, (iii) intimidações, (iv) ameaças físicas ou verbais, (v) depredação do patrimônio dos alunos e das escolas, (vi) tráfico de drogas, (vii) ação de gangues, (viii) uso e porte de armas.

O segundo grupo de trabalhos foca a violência em geral - denominada pela literatura de community violence - que se trata da exposição freqüente e contínua das pessoas a qualquer tipo de violência, seja como testemunhas, vítimas ou pelo conhecimento das vítimas. Essa exposição ocorre no ambiente externo ao domicílio e, portanto, pode assumir os mais diversos tipos de ocorrências, como por exemplo: exposição ao uso de armas, esfaqueamentos, tráfico de drogas, brigas, roubos e etc.

Devido a essa diferenciação conceitual do termo violência, torna-se importante descrever quais aspectos mais importantes diferenciam os estudos, suas metodologias, dados e resultados.

\subsection{A associação entre violência escolar e proficiência}

Figlio (2005) abordou a questão da violência escolar sob a perspectiva mais "amena" da indisciplina. Para analisar a associação entre indisciplina e desempenho escolar, foram utilizadas informações de uma escola localizada na Flórida/EUA. Primeiramente, 
estimou-se um modelo básico que empregou como variável dependente, a notas dos alunos e como variável explicativa de interesse, o número de suspensões. Para contornar um possível problema de simultaneidade, o autor propôs como variável instrumental para os indivíduos indisciplinados, o número de alunos que possuíam nomes os quais geralmente seriam dados a meninas. $\mathrm{O}$ autor adotou essa estratégia, pois foi constatado que esses alunos tendiam a um comportamento contraproducente no contexto escolar. Além disso, observou que os desvios de conduta, instrumentalizados pelos nomes dos garotos se associavam positivamente com os problemas de disciplina e negativamente com o desempenho escolar.

Kinsler (2006) incluiu nessa discussão os efeitos da suspensão sobre a indisciplina e sobre a proficiência. Para a consecução desse trabalho, utilizou dados da Education Research Data Center (NCERDC) que coleta informações inerentes à educação no estado da Carolina do Norte/EUA. Inicialmente, foram estimados modelos de equilíbrio dinâmico para o comportamento, proficiência e suspensão dos alunos do ensino fundamental. Assim como no trabalho anterior, também foi encontrada uma associação negativa entre indisciplina e proficiência. Ademais, observou que a suspensão diminui a indisciplina e não prejudicou a performance dos estudantes.

Por sua vez, Grogger (1997) abordou os efeitos da violência escolar sobre a conclusão do ensino médio e superior. Nas escolas em que a violência constituiu-se um problema moderado, os alunos tiveram uma probabilidade de concluir o ensino médio 5,1 pontos percentuais menor do que alunos de escolas sem violência. É importante destacar que esses resultados foram obtidos, mesmo controlando por raça, características dos estudantes que aumentam a propensão à violência, background familiar, características das escolas e características da região. Já em termos de salários, escolas com violência moderada pagavam 2,4\% a mais para os professores do que escolas sem violência. 
Coleman (1998) examinou a relação entre violência escolar e proficiência em leitura e matemática de alunos americanos da oitava série por meio de uma análise cross-section. A pesquisa foi realizada com base na National Educational Study que fornece dados a respeito das características dos estudantes e background, além de três medidas de violência: (i) indisciplina e briga com outros alunos, (ii) exposição a roubos, tráfico de drogas, ameaças ou dano, (iii) percepção dos alunos sobre o grau de violência escolar. Os resultados indicaram uma associação negativa (embora não significativa) entre violência escolar e proficiência dos estudantes.

Combinando dados da Montreal Longitudinal Study e Studies in Education Policy, Ferris e Leung (2002) dissertaram sobre a relação entre o tamanho da escola (número de alunos da escola) e violência juvenil. De acordo com o modelo proposto pelos autores, certas características contribuíram para o aumento da probabilidade de ocorrer violência nas escolas, tais como: família desagregada, amigos delinqüentes e escolas de baixa qualidade educacional. Além disso, também foi observado que o tamanho da escola (número de alunos) constituiu-se em um fator determinante da violência escolar. Apesar de não haver análises de regressão com o intuito de investigar a relação entre violência e desempenho escolar, foram realizadas algumas considerações a respeito desse tema. O tamanho da escola, segundo os autores, é um atributo que se associa positivamente com a frustração, desistência e violência escolar e, portanto, contribui para a degradação do ambiente de aprendizagem. Logo, esse ponto de vista defendido pelos autores confronta a hipótese de que grandes escolas são necessárias para o incremento da proficiência escolar. Apesar disso, advertem que escolas populosas devem possuir outras qualidades que nem sempre são observáveis, mas que podem compensar os fatores negativos anteriormente citados.

Ammermueller (2007) analisou os determinantes da vitimização e os efeitos da violência escolar sobre a performance dos estudantes em onze países da Europa utilizando 
dados da Trends in International Mathematics and Science Study (TIMSS) e National Child Development Study (NCDS). Para a oitava série, meninas e estudantes de cidades de pequeno porte estiveram menos propensos a serem vítimas da violência escolar. Para a quarta série, alunos imigrantes é um atributo que aumentou a possibilidade de vitimização, enquanto alunos com alto background social é uma característica que potencializou negativamente a probabilidade de ser vítima. Por fim, o autor também concluiu que a violência afetou negativamente o desempenho escolar.

No Brasil, Severnini (2007) utilizou os indicadores de violência escolar levantados pelo SAEB 2003 (Sistema de Avaliação da Educação Básica) e verificou que os alunos que freqüentaram escolas mais violentas tiveram, em média, pior desempenho em português e matemática. Constatou ainda uma associação indireta entre violência e proficiência escolar por meio da rotatividade dos professores. Isso quer dizer que a violência se relacionou positivamente com a rotatividade dos docentes.

\subsection{A associação entre violência genérica e proficiência}

Hurt et al. (2001), Delaney-Black et al. (2002) e Ratner et al. (2006) são trabalhos internacionais que possuem algumas características em comum: analisaram a associação entre exposição a violência, sintomas da vitimização (estresse e ansiedade), comportamento (autoestima e sensação de segurança) e desempenho escolar para crianças afro-americanas de seis a sete anos e utilizaram dados longitudinais. Para obter medidas de percepção da violência e segurança/proteção, estes estudos realizaram entrevistas para caracterizar a freqüência, grau e a categoria dos eventos que as crianças presenciaram. Em outras palavras, aplicou-se um questionário com 20 itens denominado de "Coisas que você viu e ouviu", o qual compreendeu 
uma lista de categorias de violência que vão desde a ouvir tiroteios, testemunhar brigas e esfaqueamentos até a ver cadáveres. As medidas de proficiência são oriundas da Wechsler Primary and Preschool Scale of Intelligence-Revised (WPPSI-R) e Test of Early Reading Ability - Second Edition (TERA-2).

O primeiro dos trabalhos assinalados, teve por objetivo documentar a exposição à violência, registrar os sintomas dessa exposição, e analisar a associação entre violência, sintomas e comportamento (auto-estima). A amostra foi providenciada pela National Institute on Drug Abuse, projeto fundado para estudar crianças de seis a sete anos de idade que potencialmente foram expostas ao uso de drogas e álcool durante a gestação. É necessário ressaltar que os demais testes de avaliação emocional, social e de performance escolar, foram realizados quando as crianças alcançaram à idade escolar. Para examinar os sintomas de estresse e auto-estima foram utilizados os métodos Levonn, Culture-Free Self-Esteem Inventory - Second Edition (CFSEI-2), Version of Children's Distress Symptoms (CCDSPRV), Parent Report Form e Teacher Report Form. O Levonn é um questionário de quarenta itens que relaciona a experiência da criança ao comportamento expresso em figuras por um personagem chamado Levonn. O CFSEI-2 é um questionário de respostas sim/não que tem por intuito avaliar a percepção das crianças sobre auto-valorização, qualidade dos relacionamentos, capacidade de consecução de metas escolares e relacionamento com os pais. Nesse sentido, altas pontuações no CFSEI-2 indicam elevada auto-estima por parte das crianças. Já a CCDS-PRV, Parent Report Form e a Teacher Report Form são questionários dirigidos, respectivamente, a pessoa responsável pela criação, aos pais e professores com a finalidade de avaliar os níveis de estresse das crianças. Os resultados mostraram que a exposição à violência esteve positivamente relacionada à baixa performance escolar, sintomas de ansiedade e baixa auto-estima. 
Delaney-Black et al. (2002) investigaram a relação entre exposição à violência, estresse e desempenho escolar. Assim como no trabalho anterior, a amostra estudada foi fornecida pela National Institute on Drug Abuse e os levantamentos sobre os níveis de estresse das crianças também foram levantados pelo método Levonn. Diferentemente, nesse estudo houve a preocupação de controlar variáveis que potencialmente interferiram de forma biológica ou ambiental (ambiente de criação) nos resultados de proficiência das crianças. Dessa forma, foram incluídas por meio da Hollings-head 2-factor index informações que relataram se houve ou não o uso de substâncias proibidas por parte da mãe durante o período de gravidez. Também foram inseridos dados sobre a capacidade cognitiva maternal ou da pessoa responsável pela criação por meio da escala de QI medido pela Wechsler Adult Intelligence Scale - Revised (WAIS-R). Por fim, foi incluída uma medida de ambiente domiciliar disponibilizada pela Home Observation for Measurement of the Environment (HOME). Empregando essas informações, verificou-se que a exposição à violência esteve negativamente associada ao QI das crianças. Foi encontrada também uma associação negativa (embora não significativa) entre estresse e QI. Por fim, observou-se que a exposição à violência e as medidas de estresse das crianças se relacionaram negativamente com a capacidade de leitura das mesmas.

Já Ratner et al. (2006) tinham o propósito de examinar as relações entre exposição à violência, sensações de segurança/proteção e testes de conhecimento. A amostra estudada compreendeu filhos(as) de mulheres que receberam assistência pré-natal e foram continuamente examinadas pelos hospitais da cidade de Detroit/EUA. Além das variáveis de proficiência utilizadas nos trabalhos anteriores, foram incluídas medidas de desempenho escolar em matemática e em leitura administradas pela Metropolitan Achievement Test (MAT). Também foi adicionada uma medida padronizada de avaliação dos estudantes (grade point average - GPA) realizada pelas escolas públicas de Detroit. Assim como no trabalho de 
Delaney-Black et al. (2002), também houve a preocupação de controlar variáveis que potencialmente interferiram nos resultados de proficiência das crianças. Por essa razão, foram empregadas medidas de uso de drogas e de álcool durante a gestação, índices de qualidade do ambiente domiciliar provenientes de uma versão modificada da HOME e dados sobre a capacidade cognitiva maternal ou da pessoa responsável pela criação por meio da escala de QI medido pela WAIS-R. Diferentemente dos trabalhos anteriores, foram adicionadas informações parentais sobre níveis de estresse, de coesão e adaptação familiar, e informações sobre à auto-estima das crianças. Os resultados mostraram que a vitimização se associou negativamente às medidas de proficiência, enquanto que a sensação de segurança/proteção se relacionou positivamente com as capacidades cognitivas das crianças.

Apesar de algumas diferenças metodológicas, nota-se que o cerne desses trabalhos consistiu em esquadrinhar os mecanismos biológicos, emocionais e comportamentais que poderiam afetar a proficiência das crianças. Nesse contexto, a exposição à violência foi abordada do ponto de vista patológico e as análises proferidas visaram essencialmente o ramo da pediatria. Por essa razão, as informações de background socioeconômico da família, das escolas e da região em que as crianças viveram não foram devidamente consideradas. Tal questão é de suma importância, pois as famílias estudadas poderiam ser aquelas que estiveram mais expostas à violência em ocasião das desvantagens proporcionadas pelo baixo background, fato que estaria afetando as medidas de proficiência das crianças. Tal hipótese pode ser fundamentada no trabalho de Hurt et al. (2001), o qual destacou que no momento de registro das mães e de suas crianças na National Institute on Drug Abuse, todas as mães eram consideradas de baixo status socioeconômico de maneira que estavam recebendo assistência médica estatal. Portanto, a amostra foi selecionada e os autores ignoraram completamente os efeitos do viés de seleção na estimação dos efeitos da violência. Outra crítica, diz respeito ao processo de levantamento das medidas de percepção da violência que não considerou a 
localização geográfica da família no contexto em que foi realizado o estudo. Em outras palavras, pode ser que as famílias coletadas para as amostras estudadas fossem residentes de áreas tipicamente violentas, fato que resultou em uma percepção unanimemente maior do fenômeno. Por fim, também se deve considerar a violência não somente como um fator degenerativo da saúde, mas também como um fenômeno que afeta a formação social e econômica da vítima. Nesse sentido, é recomendável a leitura preliminar de Macmillan e Hagan (2004).

O trabalho de Macmillan e Hagan (2004) construiu um encadeamento teórico e discutiu o processo pela qual a exposição à violência na infância pode constituir-se em um evento que causa desvantagem no processo de estabelecimento das condições socioeconômicas futuras da vítima. Segundo os autores, esse mecanismo pode se concretizar pelo fato da violência ser um fenômeno que afeta o desempenho escolar e, consequentemente, o acúmulo de capital intelectual das vítimas. Dessa maneira, a violência pode gerar efeitos negativos em termos de consecução de metas sociais e econômicas, como por exemplo: participação no mercado de trabalho, status ocupacional, premiações ou aumento da remuneração salarial e possibilidade de alcançar postos de trabalho mais qualificados. Enfim, a vitimização na adolescência sob a perspectiva desses autores sugere um potencial detrimento da renda futura da vítima. Em seguida, utilizando dados da NYS (amostra familiar dos Estados Unidos) que abrange informações de adolescentes entre onze e dezessete anos, foram estimados uma série de modelos com o intuito de explorar as seguintes questões: (i) investigar quais fatores de risco explicam a vitimização de um adolescente por meio do método MQO, (ii) verificar pelo mesmo método, quais são as variáveis determinantes do desempenho escolar, ou mais especificamente, que fatores afetam o comportamento e o investimento de tempo e energia nas atividades escolares, (iii) analisar pelo método Logit as consequências socioeconômicas da vitimização na transição para a idade adulta. Os resultados 
obtidos corroboraram o link teórico proposto pelos autores entre experiência com atos violentos e consecução de metas socioeconômicas. Isso quer dizer que a violência prejudicou o desempenho escolar, a eficiência educacional, a participação no mercado de trabalho e as possibilidades salariais na idade adulta.

No âmago da discussão que associa violência e desempenho escolar, ainda resta considerar uma questão primordial que não foi levantada nos trabalhos de Hurt et al. (2001), Delaney-Black et al. (2002), Ratner et al. (2006) e parcialmente discutida por Macmillan e Hagan (2004), qual seja, a importância e o papel do background ou das características socioeconômicas inerentes às pessoas e do meio onde vivem. Seguindo essa linha de raciocínio, Aizer (2007) destacou que é preciso considerar o fato de que crianças vítimas da violência possuem algumas características em comum, como por exemplo: são em sua maioria negras, pobres e são de famílias com baixa educação. A partir dessa hipótese, a autora investigou se é a exposição à violência ou as medidas de desvantagens que são responsáveis pela baixa performance escolar. Mais detalhadamente, ela procurou responder a seguinte pergunta: é a violência que agrava a proficiência ou é o caso em que pessoas com piores condições de background que são aquelas que mais estão expostas à violência e, portanto, possuem pior desempenho escolar? Para responder essa questão, foram utilizados os dados sobre as famílias e medidas de desempenho escolar contidas na Los Angeles Family and Neighborhood Study (LA FANS). Os indicadores de violência foram coletados do banco de dados do Hospital da Califórnia que possui medidas de violência na vizinhança (taxas de assalto), medidas de violência em grupo (se a criança conhece algum membro de gang) e outras medidas como o testemunho de tiroteios ou se o indivíduo foi assaltado no último ano. A técnica econométrica usada foi a de efeitos fixos para contornar o problema de não observação de características inerentes aos bairros e famílias por parte do pesquisador. Ao controlar essas características foi verificado que o impacto da violência sobre o desempenho 
escolar das crianças diminuiu. Assim, a autora concluiu que foram as características das pessoas expostas os fatores mais responsáveis pelo decréscimo da proficiência observada.

Henrich et al. (2004) também investigaram os efeitos da exposição à violência sobre o desempenho escolar e sensação de segurança em uma amostra de 759 alunos dos Estados Unidos por intermédio de uma análise cross-section. Dados referentes às características dos alunos, informações sobre o testemunho de práticas violentas, vitimização, apoio familiar e índices de pobreza, foram coletados na Social and Health Assessment (SAHA). As medidas utilizadas de desempenho escolar como notas em testes de leitura, matemática e escrita foram construídas pela Connecticut Mastery Test (CMT). Em oposição aos demais trabalhos, esse estudo concluiu que a vitimização não esteve relacionada a baixos níveis de proficiência. Entretanto, a vitimização se associou negativamente à sensação de segurança nas escolas somente para meninos que relataram ter falta de apoio familiar.

O Trabalho de Bowen e Bowen (1999) é importante no sentido de que ele reuniu as duas linhas de pesquisa do tema em pauta. O objetivo desse estudo foi examinar conjuntamente a percepção dos estudantes sobre a exposição à violência na escola e na vizinhança, e os efeitos dessa exposição em relação à proficiência e comportamento escolar (freqüência nas aulas e evasão de problemas disciplinares). Os dados utilizados foram coletados pela Louis Harris and Associates Inc. e pela School Success Profile (SSP). A amostra estudada compreendeu um total de 1.828 alunos do ensino fundamental e médio, correspondendo a um total de noventa e três escolas públicas. Nesse estudo, as variáveis independentes de interesse são as medidas de violência no bairro e na escola.

As medidas de violência no bairro foram compreendidas por dois indicadores. O primeiro se relacionou a um índice de percepção de comportamento contraproducente de grupos, caracterizado por: (i) envolvimento com a polícia, (ii) uso de drogas, (iii) relação com gangues e (iv) ingestão de bebidas alcoólicas. O segundo indicador de violência no bairro 
correspondeu a um índice de experiência pessoal com tal evento. Foi perguntado aos estudantes se alguma vez nos últimos trinta dias houve os seguintes incidentes no bairro: (i) roubo, (ii) depredação da casa ou da residência do vizinho, (iii) venda de drogas, (iv) se alguém coagiu o aluno a infringir a lei, (v) se alguém ameaçou o estudante com uma arma, (vi) se alguém ofereceu ao aluno bebidas alcoólicas.

Em relação à violência na escola, também foram utilizadas duas medidas. A primeira se relacionou à percepção dos estudantes no que diz respeito as seguintes ocorrências: (i) brigas, (ii) roubos, (iii) destruição da propriedade escolar, (iv) uso de álcool, (v) uso de drogas, (vi) porte de armas, (vii) agressão física a professores, (viii) agressão verbal a professores, (ix) desentendimento entre alunos de diferentes raças, (x) briga de gangues e (xi) assédio sexual. Já a segunda contemplou cinco indicadores de percepção sobre a exposição dos alunos a comportamentos considerados perigosos na escola. Foi perguntado aos estudantes se nos últimos trinta dias (i) houve briga com um outro aluno, (ii) caso houve medo de que alguém poderia machucá-lo ou incomodá-lo na escola, (iii) decidiu ficar em casa por medo de que alguém poderia machucá-lo ou incomodá-lo na escola, (iv) percebeu algum conhecido portando arma na escola e (v) se foi atacado por alguém que usava arma na escola.

As variáveis dependentes foram compreendidas pelas medidas de desempenho escolar, frequiência nas aulas e comportamento na aula. Os resultados obtidos pela análise de regressão, mostraram que tanto a violência escolar como a violência na vizinhança se relacionaram negativamente com o desempenho escolar, freqüências nas aulas e com a evasão de problemas disciplinares. Outro resultado importante foi à constatação de que os efeitos da exposição à violência na vizinhança foram mais significativos que os efeitos da violência no contexto escolar.

Com a discussão dos pontos fundamentais que nortearam os trabalhos apresentados nesse capítulo, pode-se concluir, primeiramente, que tanto a violência escolar como a 
violência nos bairros é um fenômeno conhecido e bem caracterizado pelos pesquisadores. Em segundo lugar, os trabalhos aqui apresentados são registros de que a exposição à violência constitui-se em um problema crescente e percebido pelas crianças, adolescentes e estudiosos. Em terceiro, com exceção dos trabalhos de Coleman (1998) e Henrich et al. (2004), a literatura em geral mostrou evidências que a exposição à violência tanto na esfera escolar como na vizinhança é um fenômeno que afetou o desempenho escolar dos indivíduos analisados. Um fator que difere entre as duas linhas de pesquisa da violência além da abordagem distinta do conceito, é o fato de alguns trabalhos da linha de estudos da violência geral destacar com maior veemência considerações sobre o comportamento escolar e estado psicológico (ansiedade, estresse e sensação de segurança) das vítimas. Por fim, é preciso ressaltar que a maioria desses trabalhos não considerou as características territoriais e socioeconômicas da região onde residiam os indivíduos amostrados.

Uma das vantagens do estudo aqui desenvolvido é o uso de indicadores de violência representados pelo número de ocorrências de crime registradas por cada distrito policial da cidade de São Paulo. Argumentamos que essas medidas de crime representam uma proxy mais direta da violência que ocorre nas diferentes regiões do município. Com isso, espera-se captar de forma mais significativa às regiões que são mais e menos violentas, tendo em vista que a cidade de residência da amostra a ser estudada possui um porte territorial e demográfico extremamente considerável. Uma outra vantagem é o uso de informações socioeconômicas por distritos da capital (distritos populacionais) e por região de pertencimento da escola. Tais informações são extremamente importantes a fim de controlar fatores heterogêneos inerentes as diferentes regiões analisadas. Destaca-se também no presente estudo, uma abordagem ampla dos fatores determinantes do desempenho escolar ao considerar cinco categorias de variáveis: características dos alunos, background familiar, características das escolas, professores e dos distritos da capital. Um outro diferencial é a atenção concedida à 
possibilidade de existir heterogeneidade na reação dos alunos frente à violência. A idéia básica é que estudantes mais determinados tendem a absorver menos os fatores que afetam negativamente a aprendizagem. Com o propósito de investigar essa possível discrepância dos efeitos da violência, será analisado no presente estudo o impacto que a violência exerce ao longo da distribuição da proficiência escolar. Por fim, pode-se associar a temática de trabalho aqui desenvolvida aos estudos que tratam do tema "neighborhoods effects", Apesar de os dados não estarem arranjados por bairros, a formatação das informações em distritos policiais e distritos da capital permitem uma análise similar, isto é, estudar que características das diferentes áreas da cidade podem afetar a proficiência das crianças e adolescentes.

\footnotetext{
${ }^{4}$ Para maiores detalhes sobre essa literatura, consultar: Brooks-Gunn et al. (1993), Ross (2000), Ainsworth (2002), Browning e Cagney (2002), Sampson, Morenoff e Gannon-Rowlev (2002).
} 


\section{DADOS, METODOLOGIA E ESTATÍSTICAS DESCRITIVAS}

Este capítulo tem por intuito apresentar, a base de dados, a metodologia utilizada na pesquisa, bem como a exposição das estatísticas descritivas da amostra estudada em relação às ocorrências de violência, características dos alunos, background familiar, características das escolas, dos professores e dos distritos da capital. Ademais, serão tecidas as primeiras considerações sobre a associação entre a violência e desempenho escolar.

\subsection{Base de Dados}

Os dados são provenientes de quatro fontes. As ocorrências criminais foram coletadas no site da SEADE (Fundação Sistema Estadual de Análise de Dados), órgão vinculado ao governo do Estado de São Paulo. O site disponibiliza uma série de informações organizadas por temas, como por exemplo: administração pública, economia, educação, saneamento, saúde, trabalho e população. Na seção "justiça e segurança”, a Fundação SEADE em parceria com a SSP (Secretaria de Estado dos Negócios da Segurança Pública) disponibiliza um acervo de dados, e um conjunto de textos e informações inerentes à justiça e segurança pública. As ocorrências criminais estão organizadas em séries históricas construídas a partir de registros policiais. Portanto, é possível obter o número de ocorrências das mais diversas categorias de crime entre os anos de 1984 a 2005 que podem ser arranjadas por município ou por distritos policiais. Além das ocorrências de violência, também são aproveitadas as informações sobre a população dos distritos policiais e a distância das escolas em relação ao centro da cidade de São Paulo (Praça da Sé). 
O Centro de Estudos da Metrópole (CEM) é responsável pelo desenvolvimento de estudos sobre temas relacionados aos processos de urbanização e metropolização de São Paulo, Rio de Janeiro e Salvador. Com essa perspectiva de trabalho, as pesquisas realizadas por essa instituição abrangem diversas áreas, tais como: políticas públicas, segregação, pobreza, redes sociais, religião, emprego e desemprego, habitação, práticas culturais e comportamento eleitoral. No site do CEM, mais precisamente na seção "banco de dados" é possível ter acesso às informações georeferenciadas organizadas nos seguintes temas: demografia, desigualdade social, divisão territorial, educação, eleições, empresas, logradouros e saúde. No presente estudo, serão utilizados dados sobre o rendimento e escolaridade das pessoas responsáveis pelos domicílios que foram levantados pelo Censo Demográfico de 2000.

Informações sobre a proficiência escolar e das condições socioeconômicas dos alunos foram obtidas por meio da Prova Brasil de 2005. O objetivo dessa avaliação é, por intermédio de provas de português e matemática aplicadas aos alunos de quarta e oitava séries das escolas públicas brasileiras em área urbana, obter uma medida de desempenho escolar daqueles que participaram. É importante ressaltar que a avaliação é quase universal, isto é, abrange todas as escolas públicas com mais de vinte alunos na classe. Por fim, também serão utilizados os dados do Censo Escolar 2005 que é responsável pelo levantamento detalhado de informações sobre os professores e de todas as escolas públicas e privadas do Brasil.

Uma limitação dos dados é o fato de que a base de dados oriunda do CEM se refere ao ano de 2000, enquanto as demais são de 2005. 


\subsection{Metodologia}

O objetivo principal do presente estudo é analisar a associação entre a violência da região em que as escolas públicas da cidade de São Paulo estão localizadas e o desempenho escolar dos alunos da quarta série. Contudo, também consideramos uma série de outras variáveis explicativas para a promoção de um estudo aprofundado dos determinantes do desempenho escolar.

\subsubsection{Variáveis dependentes e variáveis explicativas de interesse}

No estudo aqui desenvolvido, trabalharemos com duas variáveis dependentes diferentes: as notas de matemática e português dos alunos que participaram da Prova Brasil 2005. A variável explicativa de interesse é a violência. Como proxy da violência da região em que se localizam as escolas, serão utilizados os números de ocorrências de diferentes categorias criminais registradas por cada distrito policial no ano de 2005 . No total, foram selecionadas seis categorias criminais pelo critério da freqüência (maior número de ocorrências registradas pelos distritos policiais) e por serem modalidades que, em geral, envolvem práticas violentas. Além disso, escolhemos tipos de crimes que podem causar deterioração do estado físico e emocional das vítimas. A partir desses critérios, as seis categorias de violência escolhidas são: “(i) crimes contra a pessoa: ofensa causada à integridade do ser humano, (ii) crimes contra o patrimônio: ofensa ao interesse patrimonial, que é, por sua vez, um complexo de relações jurídicas, com valor pecuniário, (iii) furto consumado: ato de subtrair, para si ou para outrem, coisa alheia móvel, (iv) roubo consumado: ato de subtrair coisa móvel alheia, para si ou para outrem, mediante grave ameaça ou 
violência contra a pessoa, ou depois de havê-la, por qualquer meio, reduzido à impossibilidade de resistência” (SEADE, 2008). “(v) ameaça: comportamento ou gesto intimidativo, (vi) crimes violentos: categoria de crime caracterizada pelo total de homicídios dolosos, roubos, latrocínios, estupros e extorsões mediante seqüestro" (SECRETARIA DE SEGURANÇA PÚBLICA DE SÃO PAULO, 2008). É preciso destacar que todas as escolas foram associadas a seu distrito policial e cada indicador de violência foi ajustado de tal forma a representar uma taxa de ocorrência por cem mil habitantes.

Para facilitar a compreensão da utilização das demais variáveis explicativas, essas foram organizadas em cinco grupos de variáveis: (i) características dos alunos, (ii) background familiar, (iii) características das escolas, (iv) características dos professores e (v) características socioeconômicas dos distritos da capital ${ }^{5}$. Para verificar as definições e a construção dessas variáveis, consultar o quadro A1 do apêndice.

Nas subseções a seguir, faremos uma breve descrição da motivação do emprego das variáveis explicativas, nos casos em que essa não é óbvia.

\subsubsection{Medidas relacionadas às características dos alunos}

Para captar possíveis efeitos da defasagem idade-série sobre a proficiência, incorporamos as variáveis de reprovação e sete dummies de idade ${ }^{6}$. Como proxy do esforço do aluno, inserimos a variável tempo de tv (Em dia de aula, quanto tempo você gasta assistindo tv?). Quanto maior é o dispêndio de tempo assistindo tv, menor deve ser o comprometimento com as atividades escolares e, consequentemente, pior o desempenho acadêmico.

\footnotetext{
${ }^{5}$ A Prefeitura de São Paulo divide a cidade em Sub-Prefeituras e essas em distritos (distritos da capital), que é uma subdivisão territorial diferente daquela dos distritos policiais Assim, como em nosso trabalho algumas variáveis estão disponíveis apenas por distritos da capital, cada escola foi associada a seu respectivo distrito da capital.

${ }^{6}$ Ferrão, Beltrão e Santos (2002).
} 
Nosso objetivo com a variável abandono (Você já abandonou a escola durante o período de aulas e ficou fora da escola o resto do ano?) é verificar se os alunos que já abandonaram a escola no passado têm pior desempenho pelo não acompanhamento das disciplinas ministradas. Além disso, alunos que abandonaram as escolas podem sentir maiores dificuldades de reintegração ao sistema de ensino em termos de (i) tempo necessário para a consolidação do processo de inclusão social no ambiente escolar e (ii) em termos de esforço necessário para recuperar os hábitos indispensáveis para o acompanhamento das aulas, como por exemplo, tempo de estudo em casa. As variáveis trabalho fora de casa (Você trabalha fora de casa?) e trabalho doméstico (Em dia de aula, quanto tempo você gasta fazendo trabalhos domésticos em casa?) foram inseridas para averiguar se a substituição de tempo de estudo por essas atividades, ocasiona uma piora no desempenho escolar.

A variável início na escola tem por finalidade apurar se crianças que entraram mais cedo na escola (maternal e pré-escola), possuem melhores notas se comparadas às crianças que entraram mais tarde (primeira série), pela possibilidade daquelas terem desenvolvido com antecedência as suas capacidades cognitivas. Em relação a variável estudou na mesma escola (Desde a primeira série você estudou sempre nessa mesma escola?), o objetivo é inquirir se há benefícios em termos de perfomance escolar para os alunos que permaneceram na mesma escola se comparados aos alunos que já estudaram em outras escolas públicas ou em relação àqueles que já estudaram em escolas particulares. A variável mora com pai ou mãe (Você mora com quem?) será usada com a finalidade de investigar se a presença da figura paterna ou materna é um fator que estimula o aluno a obter uma melhor proficiência. Em relação a variável mora com quantas pessoas (Quantas pessoas moram com você?) que é constituída por cinco dummies, foi empregada para se averiguar como diferentes faixas de números de pessoas no convívio domiciliar se associam com o desempenho dos alunos. 
Adicionamos a variável futuro (Quando você terminar o ensino fundamental, você pretende: ) para captar as expectativas do aluno com relação ao seu futuro: se pretende continuar estudando, ou começar a trabalhar após o fim do ensino fundamental ou estudar e trabalhar simultaneamente. É uma variável importante, pois a motivação do aluno, variável não observada, deve ter alta correlação com a variável futuro, já que os mais motivados devem ter maior expectativa de continuar na escola. Já com a variável deixado de lado (Você se sente deixado de lado na sala de aula?), o nosso intento é obter uma proxy da auto-estima do aluno e analisar como o estado psicológico do mesmo no meio escolar se associa com a proficiência. Por fim, temos a variável bolsa família (Você participa do programa BolsaFamília?) que será utilizada para investigar se o background socioeconômico do aluno afeta a sua nota individual. Cabe destacar que essa variável também capta o background familiar, já que é uma proxy de pobreza.

\subsubsection{Medidas de background familiar}

Em relação ao background familiar foram incorporadas as variáveis livros (Em sua casa existe uma estante com mais de vinte livros?) e computador (Em sua casa tem um computador?) que representam instrumentos materiais e de condições de estudo oferecidos pela família que podem auxiliar e melhorar a aprendizagem dos estudantes. Ademais, incluindo a variável apoio aos estudos (Seus pais ou seus responsáveis incentivam você a estudar:) será analisado no presente trabalho não só a importância da presença física dos pais (mora com pai ou mãe), mas também a influência direta que os pais ou pessoas próximas podem exercem sobre a proficiência por meio de estímulos ao estudo. Também serão 
incluídas quatro dummies para a escolaridade da mãe a fim de examinar a relação entre os diferentes níveis de escolaridade da figura materna e o desempenho escolar do filho(a).

\subsubsection{Medidas relacionadas às características das escolas}

Em relação às características das escolas, construímos a variável tamanho da sala. A motivação para a inclusão dessa variável baseia-se na tentativa de captar o fenômeno conhecido como "efeito classe", o qual é amplamente considerado no ramo da economia da educação. $^{7}$

As variáveis municipal e ensino médio foram inclusas para verificar como as escolas municipais e estaduais, e escolas que também possuem ensino médio, respectivamente, se associam com as notas dos alunos. Adicionamos também nesse grupo, variáveis que são consideradas proxies da infra-estrutura da escola (laboratório de informática, laboratório de ciências, biblioteca, sala de leitura e uso de computadores em sala de aula). Finalmente, a variável distância em relação ao centro que mede a proximidade da escola em relação ao centro da cidade (Praça da Sé) servirá como proxy da situação sócio-econômica da região da escola, tendo em mente que as escolas mais periféricas devem ter público mais carente.

\subsubsection{Medidas relacionadas às características dos professores}

O grupo referente às características dos professores, possui as seguintes variáveis: (i) corrige tarefas de matemática (O professor corrige a lição de casa de matemática?) e corrige

\footnotetext{
${ }^{7}$ Ver Lazear (1999), Krueger (2003) entre outros.
} 
tarefas de português (O professor corrige a lição de casa de língua portuguesa?), (ii) proporção de professores com ensino superior. A primeira é uma proxy para a motivação do professor com a atividade de ensino. A segunda foi introduzida para observar os efeitos da qualificação dos professores sobre a performance dos estudantes.

\subsubsection{Medidas relacionadas às características dos distritos da capital}

Na tentativa de controlar alguns fatores heterogêneos inerentes às diferentes regiões da cidade de São Paulo, serão utilizadas duas variáveis socioeconômicas arranjadas por distritos da capital, subdivisões territoriais do município de São Paulo. A primeira variável diz respeito à escolaridade média em anos de estudo dos responsáveis pelos domicílios de cada distrito. A segunda está relacionada a um índice de pobreza, ou mais especificadamente, a proporção de pessoas responsáveis pelos domicílios particulares permanentes que não possuem rendimento ou que possuem rendimento menor do que um salário mínimo. Cabe destacar que o município de São Paulo possui noventa e sete distritos.

\subsubsection{Estrutura de análise}

Tendo em vista que o nosso objetivo é analisar a associação entre a violência geral e o desempenho escolar e como outras variáveis também podem explicar a proficiência, estimamos a seguinte equação:

$$
Y_{\text {itep }}=\phi \text { Const. }+\alpha V_{p}+\lambda \text { Alunos }_{\text {tep }}+\beta \text { Background }_{\text {tep }}+\delta \text { Escola }_{e p}+\theta \text { Professores }_{\text {tep }}+\text { DistritosCapital }_{\text {ec }}+\varepsilon_{\text {itep }}
$$


em que $Y_{\text {itep }}$ é o desempenho escolar do aluno $i$, da turma $t$, da escola $e$ que está na região de abrangência do distrito policial $p . V_{p}$ é o indicador de violência do distrito policial $p$. Alunos $_{\text {itep }}$ representa uma matriz com todas as variáveis relacionadas às características do aluno $i$. Background $d_{\text {itep }}$ incorpora todas as variáveis de background familiar do aluno $i$. Escola $_{e p}$ engloba as variáveis que congregam as características da escola $e$. Professores itep $_{\text {é }}$ uma matriz com as variáveis de características dos professores e, por fim, Distritos Capital $_{e c}$ é uma matriz que emprega as variáveis relacionadas as características socioeconômicas dos distritos da capital.

A equação acima será estimada inicialmente por Mínimos Quadrados Ordinários. Contudo, cabe um comentário quanto ao coeficiente do índice de violência. Pode haver um problema de endogeneidade entre a violência e o desempenho escolar.

$\mathrm{O}$ viés de simultaneidade pode surgir quando a violência afeta o desempenho escolar, ao mesmo tempo em que o desempenho escolar gera violência. Entretanto, pode-se argumentar que o viés de simultaneidade seja mais plausível quando são considerados os alunos da oitava série. Tal hipótese se sustenta no fato de que adolescentes com a idade na faixa de catorze anos e que possuem pior desempenho, estão mais propícios a se comportarem de forma improdutiva e, consequentemente, estariam mais aptos (fisicamente e psicologicamente) a gerar violência se comparados aos alunos de idade próxima aos dez anos (quarta série). Caso aceitarmos a hipótese de que os alunos da quarta série com pior proficiência são incapazes de influenciar o nível de violência, a suposição do viés de simultaneidade pode ser descartada no presente estudo.

Já o viés de omissão de variáveis não observáveis, ocorre em virtude do ingresso de um aluno em uma determinada escola ser um processo ligado a decisões familiares que por sua vez, não é aleatório. Em outras palavras, pais mais preocupados com a qualidade 
educacional e com a segurança de seus filhos procuram escolas que atendam a suas exigências e critérios de ensino, que se localizam em regiões com melhor infra-estrutura e com menos violência, mesmo tendo que arcar com custos monetários e não monetários (i.e. distância da escola em relação ao local de domicílio). Por essa razão, escolas com qualidade superior de ensino e mais seguras, tendem a atrair e a manter melhores alunos. Por outro lado, escolas que se situam em regiões com maior violência podem expulsar os alunos com melhor desempenho (SEVERNINI, 2007).

Mesmo acreditando que nossa estimação não sofre de viés de simultaneidade, utilizamos indicadores defasados de violência em uma de nossas especificações econométricas para reforçar os resultados. Em relação ao problema de variáveis omitidas, seguimos a estratégia de Severnini (2007), ou seja, incluímos duas variáveis que são proxies da participação dos pais na vida escolar de seus filhos e da atratividade da escola (quadro A1 do apêndice). Elas são: (i) reunião de pais (Com que freqüência seus pais ou seus responsáveis vão à reunião de pais?): acreditamos que quanto maior é a freqüência dos pais ou responsáveis nas reuniões escolares, maior é o interesse dos mesmos em debater assuntos pertinentes aos problemas da escola e, principalmente, discutir o processo de ensino e aprendizagem; (ii) livros didáticos devolvidos por aluno: essa variável pode refletir o comprometimento e a responsabilidade dos alunos com a manutenção das condições de ensino em suas escolas. Nesse sentido, essa medida representa uma qualidade da escola mesmo que a decisão de devolver o livro seja proveniente de uma decisão simplesmente individual ou fruto da administração escolar.

Por fim, destacamos o fenômeno do peer effect (efeito de pares), o qual também exerce um importante papel analítico nos estudos que se dedicam à análise do desempenho escolar. Sucintamente, o efeito de pares existe quando o comportamento de um aluno é afetado por sua interação com os demais colegas (WINSTON E ZIMMERMAN, 2003). 
Entretanto, não é aconselhável usar o próprio desempenho dos colegas no exame de proficiência como medida desse efeito, pois pode haver viés de simultaneidade devido à influência que um aluno exerce nos demais. Dessa forma, seguimos a estratégia de MenezesFilho (2007) e inserimos a variável escolaridade dos pais dos colegas, que capta a escolaridade média dos pais da turma, como medida representativa do efeito de pares.

Cabe destacar que a análise realizada por meio de MQO permite estimar o efeito das variáveis explicativas apenas na média condicional de proficiência. Entretanto, pode ser que a resposta dos alunos a situações de violência seja diferente em outras partes da distribuição condicional de notas. Assim, alunos com melhor desempenho podem sofrer menos os efeitos da violência que os demais. Com o objetivo de avaliar essa questão, estimamos regressões quantílicas com a finalidade se observar como os indicadores de violência se associam com a proficiência escolar ao longo da distribuição de notas ${ }^{8}$.

\subsection{Estatísticas Descritivas}

A amostra em estudo compreende o total de 103.658 alunos da quarta série de escolas estaduais e municipais da cidade de São Paulo. Para apresentar os primeiros resultados da análise da associação entre violência e proficiência e para melhor compreender as características dessa amostra, essa seção será dividida em sete subseções.

\footnotetext{
${ }^{8}$ Para maiores detalhes sobre regressões quantílicas, consultar Koenker e Hallock (2001).
} 


\subsubsection{Notas, notas médias e indicadores de violência}

De acordo com a tabela 1, percebe-se que a média observada para a nota de matemática é superior a média de português. Em relação às médias dos indicadores de violência, os valores apresentados na tabela 1 representam as médias da taxas de ocorrência por cem mil habitantes no ano de 2005 considerando noventa e três distritos policiais.

Ainda na tabela 1, verifica-se que crimes contra o patrimônio é a categoria que apresentou a maior taxa média de ocorrência por cem mil habitantes $(2.976,27)$. Por outro lado, ameaças é o tipo de violência que apresentou a menor taxa $(228,03)$.

Observando o valor máximo das taxas de ocorrência, constatou-se que o $3^{\circ} \mathrm{DP}$ localizado no bairro Santa Efigênia apresentou as maiores taxas para crimes contra a pessoa $(5.679,61)$, crimes violentos $(13.875,05)$, ameaças $(1.251,91)$ e roubo consumado $(9.911,32)$. Já o $1^{\circ} \mathrm{DP}$ - Sé registrou as maiores taxas para crimes contra o patrimônio $(40.101,62)$ e furto consumado $(19.845,77)$. Com essas informações, conclui-se que os distritos policiais que registraram o maior número de ocorrência de violência para as categorias aqui apresentadas abrangem as regiões que estão localizadas no centro do município de São Paulo.

Tabela 1 - Média, desvio padrão das notas e indicadores de violência

\begin{tabular}{ccccc}
\hline Variável & Média & $\begin{array}{c}\text { Desvio- } \\
\text { padrão }\end{array}$ & Mín. & Máx. \\
\hline Nota de matemática & 176,22 & 41,1 & 78,1 & 330,65 \\
\hline Nota de português & 171,02 & 44,32 & 74,84 & 324,62 \\
\hline Crimes contra a pessoa (por 100 mil hab.) & 850,88 & 423,61 & 358,38 & $5.679,61$ \\
\hline Crimes contra o patrimônio (por 100 mil hab.) & $2.976,27$ & $2.589,75$ & 801,55 & $40.101,62$ \\
\hline Crimes Violentos (por 100 mil hab.) & $1.780,83$ & $1.024,82$ & 619,31 & $13.875,05$ \\
\hline Ameaças (por 100 mil hab.) & 228,03 & 109,36 & 79,58 & $1.251,91$ \\
\hline Roubo consumado (por 100 mil hab.) & 866,82 & 704,01 & 239,85 & $9.911,32$ \\
\hline Furto consumado (por 100 mil hab.) & 763,23 & 946,86 & 237,51 & $19.845,77$ \\
\hline
\end{tabular}

Fonte: Elaboração própria com base nos dados da Prova Brasil 2005 e SEADE.

No que diz respeito ao valor mínimo das taxas de ocorrência por cem mil habitantes, observou-se que o $85^{\circ} \mathrm{DP}$ - Jardim Mirna apresentou as menores taxas para crimes contra a 
pessoa $(358,38)$, crimes contra o patrimônio $(801,55)$, crimes violentos $(619,31)$, roubo consumado $(239,85)$ e furto consumado $(237,51)$. O $98^{\circ}$ DP - Jardim Miriam apresentou a menor taxa para ameaças $(79,58)$.

A tabela 2 apresenta as correlações entre as taxas de ocorrência de violência por cem mil habitantes. Todas as correlações são positivas e estatisticamente significantes a $5 \%$. Portanto, regiões que tinham elevado nível de ocorrência de uma determinada categoria de crime tenderiam a ter elevada incidência das demais.

Observa-se também que há grande correlação entre roubo consumado e crimes violentos (97\%), roubo consumado e crimes contra o patrimônio (96\%), e crimes violentos e crimes contra o patrimônio (96\%). A menor correlação é entre roubo consumado e ameaças $(63 \%)$.

Tabela 2 - Correlações entre as categorias de violência

\begin{tabular}{|c|c|c|c|c|c|c|}
\hline $\begin{array}{c}\text { Por } 100 \text { mil } \\
\text { hab. }\end{array}$ & $\begin{array}{c}\text { Crimes contra } \\
\text { a pessoa }\end{array}$ & $\begin{array}{c}\text { Crimes contra o } \\
\text { patrimônio }\end{array}$ & $\begin{array}{c}\text { Crimes } \\
\text { Violentos }\end{array}$ & Ameaças & $\begin{array}{c}\text { Roubo } \\
\text { consumado }\end{array}$ & $\begin{array}{c}\text { Furto } \\
\text { consumado }\end{array}$ \\
\hline $\begin{array}{c}\text { Crimes contra a } \\
\text { pessoa }\end{array}$ & $\mathrm{X}$ & & & & & \\
\hline $\begin{array}{l}\text { Crimes contra o } \\
\text { patrimônio }\end{array}$ & $0,83^{*}$ & $\mathrm{X}$ & & & & \\
\hline $\begin{array}{c}\text { Crimes } \\
\text { Violentos }\end{array}$ & $0,82 *$ & $0,96^{*}$ & $\mathrm{X}$ & & & \\
\hline Ameaça & $0,93 *$ & $0,72 *$ & $0,72 *$ & $\mathrm{X}$ & & \\
\hline $\begin{array}{c}\text { Roubo } \\
\text { consumado }\end{array}$ & $0,76^{*}$ & $0,96^{*}$ & $0,97 *$ & $0,63 *$ & $\mathrm{X}$ & \\
\hline $\begin{array}{c}\text { Furto } \\
\text { consumado }\end{array}$ & $0,76^{*}$ & $0,92 *$ & $0,84^{*}$ & $0,66^{*}$ & $0,88^{*}$ & $X$ \\
\hline
\end{tabular}

Fonte: Elaboração própria com base nos dados da Prova Brasil 2005 e SEADE.

*significante a $5 \%$

A tabela 3 mostra as correlações entre notas dos alunos, notas médias por escola e as taxas de ocorrência de violência por cem mil habitantes. Nota-se que todas as correlações são positivas e estatisticamente significantes a 5\%. Apesar das correlações serem pequenas, percebe-se que os valores que envolvem as médias das notas por escolas são maiores se comparados aos valores envolvendo as notas por alunos. Dentre as categorias de violência, crimes contra o patrimônio apresentam as maiores correlações em ambas as disciplinas tendo 
em vista as notas dos alunos e as notas médias por escola. Já a categoria furto consumado é aquela que apresenta as menores correlações considerando conjuntamente as notas dos alunos e as notas médias por escola em ambas as disciplinas.

Tabela 3 - Correlações entre notas, notas médias por escola e indicadores de violência

\begin{tabular}{ccccc}
\hline & \multicolumn{2}{c}{ Matemática } & \multicolumn{2}{c}{ Português } \\
\hline Por 100 mil hab. & Nota dos alunos & Média por escola & Nota dos alunos & Média por escola \\
\hline $\begin{array}{c}\text { Crimes contra a } \\
\text { pessoa }\end{array}$ & $0,074^{*}$ & $0,232^{*}$ & $0,079^{*}$ & $0,24^{*}$ \\
\hline $\begin{array}{c}\text { Crimes contra o } \\
\text { patrimônio }\end{array}$ & $0,091^{*}$ & $0,288^{*}$ & $0,093^{*}$ & $0,28^{*}$ \\
\hline Crimes Violentos & $0,091^{*}$ & $0,286^{*}$ & $0,092^{*}$ & $0,273^{*}$ \\
\hline Ameaças & $0,072^{*}$ & $0,229^{*}$ & $0,075^{*}$ & $0,235^{*}$ \\
\hline Roubo consumado & $0,078^{*}$ & $0,248^{*}$ & $0,08^{*}$ & $0,241^{*}$ \\
\hline Furto consumado & $0,053^{*}$ & $0,176^{*}$ & $0,056^{*}$ & $0,177^{*}$ \\
\hline
\end{tabular}

Fonte: Elaboração própria com base nos dados da SEADE e Prova Brasil 2005.

*significante a $5 \%$.

No entanto, observa-se que as correlações não proporcionam os sinais esperados: regiões mais violentas apresentaram melhor desempenho na Prova Brasil. Logo, deve-se salientar que as correlações não levam em consideração outros fatores que podem estar afetando a determinação da proficiência.

\subsubsection{Características dos alunos}

Na tabela 4 são apresentadas às estatísticas descritivas relacionadas às características dos alunos. Nessa tabela assim como as demais apresentadas nas próximas subseções, consta o percentual de alunos relacionados a cada especificação. Entretanto, é preciso salientar que para algumas variáveis a soma do percentual não é cem por cento, pois a diferença é causada pelos alunos que não responderam as perguntas do questionário sócio-econômico da Prova Brasil. 
Tabela 4 - Características dos alunos e testes de diferenças de média (continua)

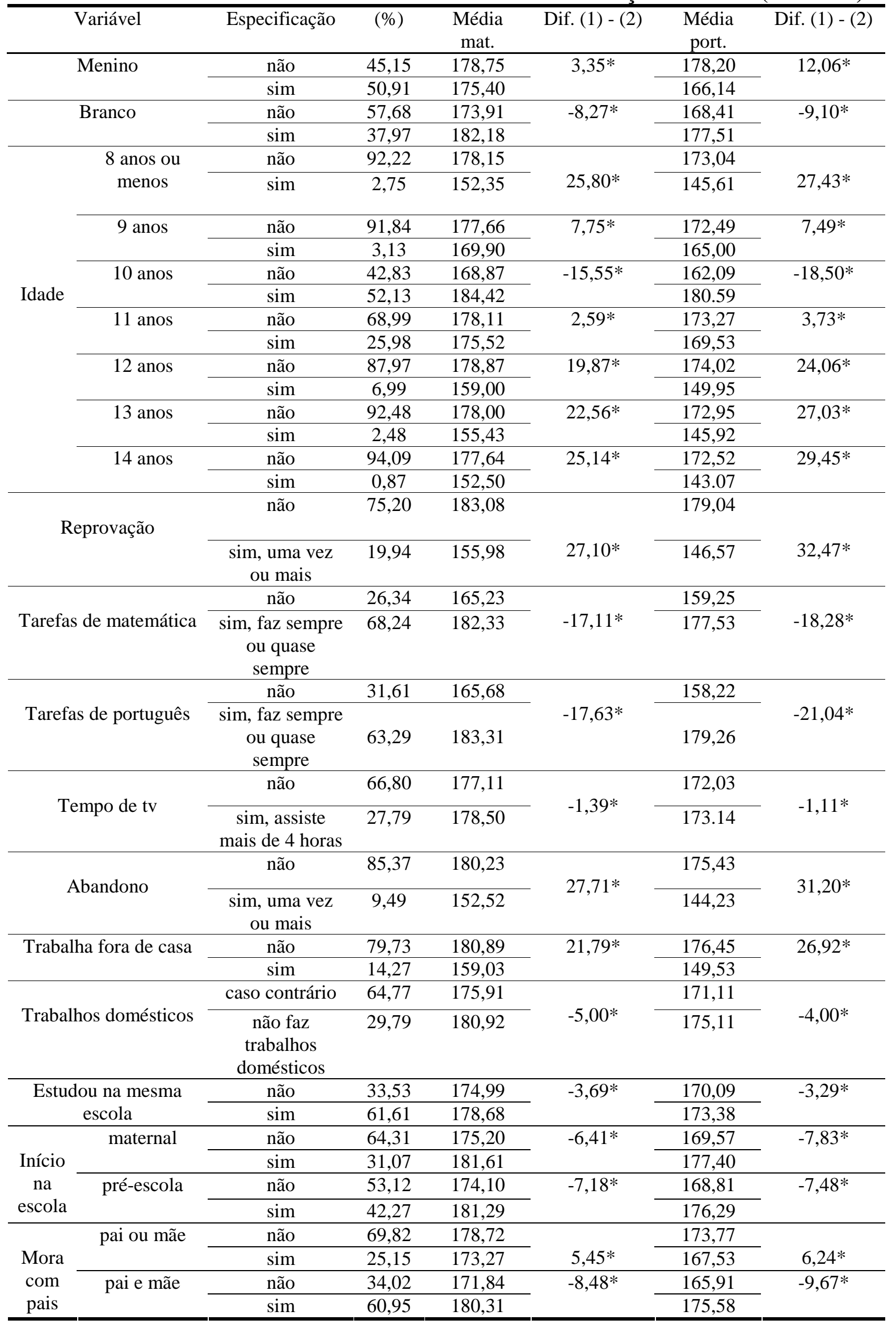


Tabela 4 - Características dos alunos e testes de diferenças de média (conclusão)

\begin{tabular}{|c|c|c|c|c|c|c|c|}
\hline \multicolumn{2}{|c|}{ Variável } & Especificação & $(\%)$ & Média & Dif. (1) - (2) & Média & Dif. (1) - (2) \\
\hline \multirow{11}{*}{$\begin{array}{c}\text { Mora com } \\
\text { quantas } \\
\text { pessoas }\end{array}$} & \multirow{3}{*}{$\begin{array}{c}\text { sozinho(a) } \\
\text { ou com } \\
\text { mais } 1 \\
\text { pessoa } \\
\end{array}$} & não & 90,36 & 177,81 & \multirow{3}{*}{$10,96 *$} & 172,66 & \multirow{3}{*}{$10,98^{*}$} \\
\hline & & sim & 5,35 & 166,85 & & 161,68 & \\
\hline & & & & & & & \\
\hline & \multirow{2}{*}{$\begin{array}{l}\text { com mais } \\
2 \text { pessoas }\end{array}$} & não & 85,48 & 176,29 & \multirow[t]{2}{*}{$-8,46^{*}$} & 170,77 & \multirow[t]{2}{*}{$-11,88 *$} \\
\hline & & $\operatorname{sim}$ & 10,23 & 184,75 & & 182,65 & \\
\hline & \multirow{2}{*}{$\begin{array}{l}\text { com mais } \\
3 \text { pessoas }\end{array}$} & não & 77,20 & 174,72 & \multirow{2}{*}{$-12,81 *$} & 169,14 & \multirow{2}{*}{$-15,01 *$} \\
\hline & & $\operatorname{sim}$ & 18,50 & 187,53 & & 184,15 & \\
\hline & \multirow{2}{*}{$\begin{array}{c}\text { com mais } \\
4 \text { ou } 5\end{array}$} & não & 57,49 & 177,07 & \multirow[t]{2}{*}{$-0,32$} & 172,09 & \multirow[t]{2}{*}{0,12} \\
\hline & & $\operatorname{sim}$ & 38,22 & 177,39 & & 171,97 & \\
\hline & \multirow{2}{*}{$\begin{array}{c}\text { com mais } \\
6 \text { ou } 8 \\
\text { pessoas }\end{array}$} & não & 78,97 & 178,69 & \multirow{2}{*}{$8,51 *$} & 173,89 & \multirow{2}{*}{$10,57 *$} \\
\hline & & $\operatorname{sim}$ & 16,74 & 170,18 & & 163,32 & \\
\hline \multirow{6}{*}{$\begin{array}{c}\text { Futuro } \\
\text { (Quando } \\
\text { você } \\
\text { terminar o } \\
\text { ensino } \\
\text { fundamental, } \\
\text { você } \\
\text { pretende:) }\end{array}$} & \multirow{2}{*}{$\begin{array}{c}\text { Ainda não } \\
\text { sei }\end{array}$} & não & 67,40 & 178,30 & \multirow{2}{*}{$2,65^{*}$} & 173,39 & \multirow{2}{*}{$3,43 *$} \\
\hline & & $\operatorname{sim}$ & 27,27 & 175,65 & & 169,96 & \\
\hline & \multirow{2}{*}{$\begin{array}{l}\text { Somente } \\
\text { estudar }\end{array}$} & não & 73,54 & 178,47 & \multirow{2}{*}{$4,18 *$} & 173,41 & \multirow{2}{*}{$4,54^{*}$} \\
\hline & & $\operatorname{sim}$ & 21,14 & 174,29 & & 168,87 & \\
\hline & \multirow{2}{*}{$\begin{array}{l}\text { Continuar } \\
\text { estudando } \\
\text { e trabalhar }\end{array}$} & não & 57,53 & 173,11 & \multirow{2}{*}{$-11,28 *$} & 167,20 & \multirow{2}{*}{$-13,25^{*}$} \\
\hline & & $\operatorname{sim}$ & 37,15 & 184,39 & & 180,45 & \\
\hline \multirow{2}{*}{\multicolumn{2}{|c|}{ Deixado de lado }} & não & 78,80 & 180,71 & \multirow[b]{2}{*}{$19,41^{*}$} & 175,86 & \multirow[b]{2}{*}{$21,16^{*}$} \\
\hline & & $\begin{array}{l}\text { sim, muitas } \\
\text { vezes }\end{array}$ & 15,61 & 161,30 & & 154,70 & \\
\hline \multirow{2}{*}{\multicolumn{2}{|c|}{ Bolsa família }} & não & 74,41 & 181,30 & \multirow[t]{2}{*}{$17,42^{*}$} & 176,66 & \multirow[t]{2}{*}{$19,82 *$} \\
\hline & & $\operatorname{sim}$ & 18,37 & 163,88 & & 156,85 & \\
\hline
\end{tabular}

Fonte: Elaboração própria com base nos dados da Prova Brasil 2005.

*significante a $5 \%$.

Nota-se que as meninas apresentaram melhor desempenho tanto em português quanto em matemática. Observa-se também que a diferença entre a média das notas de português das meninas em relação à média dos meninos é bastante considerável. Percebe-se que os alunos repetentes ou que abandonaram a escola, apresentaram na média desempenho muito inferior se comparados aos demais. No que diz respeito à amostra de estudantes que fizeram sempre ou quase sempre à lição de casa, tanto de matemática $(68,24 \%)$ como de português $(63,29 \%)$ foram melhor do que os demais estudantes. Constata-se que alunos que entraram no maternal $(31,07 \%)$ e na pré-escola $(42,27 \%)$, e que estudaram sempre na mesma escola $(61,61 \%)$ também apresentaram melhor desempenho escolar se comparados aos demais estudantes. 
Já o grupo de alunos que moravam com a mãe ou com o pai $(25,15 \%)$, apresentou pior proficiência em relação aos demais. Por outro lado, estudantes que moravam com ambos (pai e mãe) $(60,95 \%)$ conseguiram melhores notas em relação aos outros estudantes. No que diz respeito às dummies da variável futuro, nota-se que boa parte dos alunos ainda não sabia o que fazer ao terminar o ensino fundamental $(27,27 \%)$. Outros $21,14 \%$ pretendiam somente estudar e outros $37,15 \%$ esperavam continuar estudando e trabalhar. Assim como aqueles que não sabiam, os estudantes que pretendiam somente estudar tiveram pior proficiência escolar. Aqueles que queriam continuar estudando e trabalhar se relacionaram positivamente com o desempenho escolar.

De acordo com o esperado, observa-se que os alunos que notificaram se sentir deixado de lado muitas vezes em sala de aula $(15,61 \%)$, conseguiram na média, notas inferiores se comparados aos demais estudantes. Por fim, em relação a variável proxy do background socioeconômico dos alunos, nota-se que na presente amostra 18,37\% dos alunos foram contemplados com a bolsa família. Entretanto, os alunos em questão foram aqueles que apresentaram desempenho muito inferior em relação aos que não foram beneficiados. Esses resultados mostram que a bolsa foi concedida para os alunos que possivelmente eram mais desprovidos de condições econômicas e, consequentemente, tinham piores notas.

\subsubsection{Background familiar}

A tabela 5 apresenta as variáveis de background familiar e mostra que além do incentivo educacional que pode ser proveniente do aparato literário e de recursos computacionais, a participação dos pais na vida escolar de seus filhos bem como a escolaridade da mãe estiveram positivamente relacionadas com a proficiência escolar. 
Tabela 5 - Background familiar e testes de diferenças de média

\begin{tabular}{|c|c|c|c|c|c|c|c|}
\hline \multicolumn{2}{|c|}{ Variável } & Especificação & $(\%)$ & Média Mat. & Dif. (1) - (2) & $\begin{array}{c}\text { Média } \\
\text { port. }\end{array}$ & Dif. (1) - (2) \\
\hline \multirow{2}{*}{\multicolumn{2}{|c|}{ Livros }} & não & 55,79 & 176,12 & \multirow[t]{2}{*}{$-3,18 *$} & 170,61 & \multirow[t]{2}{*}{$-4,03 *$} \\
\hline & & sim & 38,63 & 179,30 & & 174,64 & \\
\hline \multirow{2}{*}{\multicolumn{2}{|c|}{ Computador }} & não & 63,34 & 175,78 & \multirow[t]{2}{*}{$-4,64 *$} & 170,24 & \multirow[t]{2}{*}{$-5,78 *$} \\
\hline & & sim & 31,56 & 180,43 & & 176,02 & \\
\hline \multirow{2}{*}{\multicolumn{2}{|c|}{ Apoio aos estudos }} & não & 7,17 & 157,63 & \multirow[t]{2}{*}{$-21,10$} & 148,72 & \multirow[t]{2}{*}{$-25,16$} \\
\hline & & $\operatorname{sim}$ & 88,64 & 178,74 & & 173,87 & \\
\hline \multirow{8}{*}{$\begin{array}{l}\text { Escola- } \\
\text { ridade } \\
\text { da mãe }\end{array}$} & $\begin{array}{c}\text { Nunca } \\
\text { estudou } \\
\text { ou não }\end{array}$ & não & 86,61 & 178,64 & \multirow[t]{2}{*}{$14,74 *$} & 173,66 & \multirow[t]{2}{*}{$16,61 *$} \\
\hline & $\begin{array}{l}\text { compl.a } \\
4^{\mathrm{a}} \text { série }\end{array}$ & $\operatorname{sim}$ & 8,55 & 163,90 & & 157,04 & \\
\hline & \multirow{2}{*}{$\begin{array}{c}4^{\mathrm{a}} \text { série, } \\
\text { mas não } \\
\text { compl. } \\
8^{\mathrm{a}} \text { série }\end{array}$} & não & 72,04 & 177,70 & \multirow{2}{*}{$1,58^{*}$} & 172,58 & \multirow{2}{*}{$1,69 *$} \\
\hline & & $\operatorname{sim}$ & 23,12 & 176,12 & & 170,88 & \\
\hline & \multirow{2}{*}{$\begin{array}{c}8^{a} \text { série, } \\
\text { mas não } \\
\text { compl. } \\
\text { ensino } \\
\text { médio }\end{array}$} & não & 80,51 & 177,17 & \multirow{2}{*}{$-0,93 *$} & 172,04 & \multirow{2}{*}{$-0,80 *$} \\
\hline & & $\operatorname{sim}$ & 14,66 & 178,11 & & 172,84 & \\
\hline & \multirow{2}{*}{$\begin{array}{l}\text { ensino } \\
\text { médio, } \\
\text { mas não } \\
\text { compl. } \\
\text { a Facul. }\end{array}$} & não & 80,99 & 174,85 & \multirow{2}{*}{$-16,57^{*}$} & 169,31 & \multirow{2}{*}{$-19,13^{*}$} \\
\hline & & $\operatorname{sim}$ & 14,18 & 191,42 & & 188,44 & \\
\hline
\end{tabular}

Fonte: Elaboração própria com base nos dados da Prova Brasil 2005.

*significante a $5 \%$.

\subsubsection{Características das escolas}

A tabela 6 apresenta as estatísticas descritivas relacionadas às características das escolas. De acordo com os dados, os alunos das escolas estaduais $(26,25 \%)$ tiveram na média um desempenho muito superior tanto em matemática como em português se comparados aos alunos das escolas municipais. Por sua vez, alunos que freqüentaram escolas que também tinham ensino médio $(6,96 \%)$ apresentaram melhor rendimento escolar em comparação aos alunos de escolas que não tinham. Esses dois últimos resultados se contrapõem a duas políticas adotadas pelo Estado de São Paulo nos anos 90: separar as escolas por níveis de ensino e municipalização do ensino básico. 
Em relação aos efeitos da existência de laboratórios de informática e ciências, os resultados não foram os esperados. $\mathrm{O}$ conjunto de alunos que pertenceu às escolas que não tinham laboratório de informática $(16,34 \%)$ e de ciências $(74,93 \%)$ conseguiu melhor desempenho em ambas as disciplinas em relação aos alunos de escolas que tinha esses laboratórios. Alunos que estudavam em escolas que utilizavam os computadores em sala de aula (2,66\%), apresentaram melhor desempenho se comparados aos alunos de escolas que não possibilitavam acesso a computadores em sala de aula. Por fim, observa-se que os alunos de escolas que participavam de algum programa educativo apresentaram melhor performance se comparados aos alunos de escolas que não participavam de programas com objetivo educacional.

Tabela 6 - Características das escolas e testes de diferenças de média

\begin{tabular}{|c|c|c|c|c|c|c|}
\hline Variável & Especificação & $(\%)$ & $\begin{array}{l}\text { Média } \\
\text { mat. }\end{array}$ & Dif. (1) - (2) & $\begin{array}{l}\text { Média } \\
\text { port. }\end{array}$ & Dif. (1) - (2) \\
\hline \multirow[t]{2}{*}{ Municipal } & não & 26,25 & 185,70 & \multirow[t]{2}{*}{$12,91^{*}$} & 183,85 & \multirow[t]{2}{*}{$17,49^{*}$} \\
\hline & $\operatorname{sim}$ & 72,43 & 172,79 & & 166,36 & \\
\hline \multirow[t]{2}{*}{ Ensino Médio } & não & 91,73 & 176,06 & \multirow[t]{2}{*}{$-2,34 *$} & 170,63 & \multirow[t]{2}{*}{$-5,41 *$} \\
\hline & $\operatorname{sim}$ & 6,96 & 178,39 & & 176,04 & \\
\hline \multirow{2}{*}{$\begin{array}{l}\text { Laboratório de } \\
\text { informática }\end{array}$} & não & 16,34 & 183,76 & \multirow[t]{2}{*}{$9,04 *$} & 181,06 & \multirow[t]{2}{*}{$12,04^{*}$} \\
\hline & $\operatorname{sim}$ & 82,34 & 174,72 & & 169,02 & \\
\hline \multirow[t]{2}{*}{ Laboratório de ciências } & não & 74,93 & 176,47 & \multirow[t]{2}{*}{$1,05^{*}$} & 171,41 & \multirow[t]{2}{*}{$1,64 *$} \\
\hline & $\operatorname{sim}$ & 23,76 & 175,42 & & 169,77 & \\
\hline \multirow[t]{2}{*}{ Biblioteca } & não & 91,07 & 176,59 & \multirow[t]{2}{*}{$4,75^{*}$} & 171,47 & \multirow[t]{2}{*}{$5,92 *$} \\
\hline & $\operatorname{sim}$ & 7,61 & 171,83 & & 165,55 & \\
\hline \multirow[t]{2}{*}{ Sala de leitura } & não & 15,31 & 176,71 & \multirow[t]{2}{*}{0,57} & 172,62 & \multirow[t]{2}{*}{$1,90 *$} \\
\hline & $\operatorname{sim}$ & 83,38 & 176,13 & & 170,72 & \\
\hline \multirow{2}{*}{$\begin{array}{c}\text { Uso de computadores em } \\
\text { sala de aula }\end{array}$} & não & 96,03 & 176,02 & \multirow[t]{2}{*}{$-7,32 *$} & 170,71 & \multirow[t]{2}{*}{$-11,47 *$} \\
\hline & $\operatorname{sim}$ & 2,66 & 183,35 & & 182,18 & \\
\hline \multirow[t]{2}{*}{ Programas educacionais } & não & 7,17 & 174,84 & \multirow[t]{2}{*}{$-1,49 *$} & 169,44 & \multirow[t]{2}{*}{$-1,70^{*}$} \\
\hline & $\operatorname{sim}$ & 91,51 & 176,33 & & 171,14 & \\
\hline
\end{tabular}

Fonte: Elaboração própria com base nos dados do Censo Escolar 2005.

*significante a $5 \%$.

Com relação à variável distância em relação ao centro que mede a proximidade das escolas em relação ao centro do município de São Paulo (Praça da Sé), verificou-se a média de 16,09 km e um desvio-padrão de 5,96. O menor valor observado para a distância é de 0,72 km, enquanto a distância máxima é de 41,82 km. De acordo com o esperado, a correlação entre essa variável e as notas de matemática foi negativa $(-10,9 \%)$ e significante a $5 \%$, assim 
como a correlação entre a distância e as notas de português $(-10,6 \%)$. Isso significa que quanto mais distante estavam as escolas do centro, pior foi o desempenho escolar médio dos alunos.

\subsubsection{Características dos professores}

A tabela 7 apresenta duas variáveis que tentam captar a importância que o professor exerce sobre a proficiência escolar. $\mathrm{O}$ fato de o professor corrigir a tarefa implica em um comprometimento com o aprendizado da classe e em um estímulo para que os alunos estudem. Segundo os dados, o grupo de alunos que notificou ter professores que corrigiam sempre ou quase sempre as lições de matemática $(67,49 \%)$ e português $(65,75 \%)$ tiveram desempenho muito superior em matemática e português, respectivamente, em comparação aos demais alunos.

Tabela 7 - Características dos professores e testes de diferenças de média

\begin{tabular}{|c|c|c|c|c|c|c|}
\hline Variável & Especificação & $(\%)$ & $\begin{array}{c}\text { Média } \\
\text { mat. }\end{array}$ & Dif. (1) - (2) & $\begin{array}{l}\text { Média } \\
\text { port. }\end{array}$ & Dif. (1) - (2) \\
\hline \multirow{4}{*}{$\begin{array}{l}\text { Corrige tarefas de } \\
\text { matemática }\end{array}$} & não & & & \multirow{4}{*}{$-11,72^{*}$} & & \multirow{4}{*}{$-12,40^{*}$} \\
\hline & & 26,99 & 169,23 & & 163,60 & \\
\hline & sim, sempre & & & & & \\
\hline & $\begin{array}{c}\text { ou quase } \\
\text { sempre }\end{array}$ & 67,49 & 180,95 & & 176,00 & \\
\hline \multirow{2}{*}{$\begin{array}{l}\text { Corrige tarefas de } \\
\text { português }\end{array}$} & não & 28,92 & 169,74 & \multirow[b]{2}{*}{$-11,18^{*}$} & 163,74 & \multirow[b]{2}{*}{$-12,40 *$} \\
\hline & $\begin{array}{l}\text { sim, sempre } \\
\text { ou quase } \\
\text { sempre }\end{array}$ & 65,75 & 180,92 & & 176,14 & \\
\hline
\end{tabular}

Fonte: Elaboração própria com base nos dados da Prova Brasil 2005.

*significante a $5 \%$.

Outra variável inserida no grupo das características dos professores é a proporção de professores com ensino superior. A média observada foi de $18,48 \%$ e o desvio-padrão assumiu o valor de 7,45. O mínimo é zero enquanto o valor máximo assumido por essa 
variável é 49\%. Já as correlações, foram significativas considerando o coeficiente de significância de 5\%, contudo, os sinais não foram os esperados. As correlações entre a proporção de professores e notas tiveram sinal negativo: $-2,2 \%$ para matemática e $-2,7 \%$ para português.

\subsubsection{Características dos distritos da capital}

A tabela 8 apresenta as estatísticas descritivas para as variáveis relacionadas aos distritos da capital. Percebe-se que a média para a variável de escolaridade foi de 6,74 anos de estudo, enquanto a média para a variável de pobreza foi de $19 \%$, ou seja, existiam $19 \%$ de domicílios em São Paulo abaixo da linha da pobreza. De acordo com o previsto, a escolaridade média das pessoas responsáveis pelos domicílios particulares em anos de estudo se associou positivamente com as notas de matemática $(12,17 \%)$ e de português $(12,34 \%)$, além de serem significantes a 5\%. As correlações entre o índice de pobreza e as notas de matemática e português são significativas a $5 \%$ e negativas conforme o esperado. A correlação entre o índice de pobreza e a nota de matemática foi de $-13,16 \%$, enquanto o valor inerente à correlação entre o índice de pobreza e as notas de português foi de -12,76\%.

Tabela 8 - Média e desvio padrão das características dos distritos da capital

\begin{tabular}{ccccc}
\hline Variável & Média & $\begin{array}{c}\text { Desvio- } \\
\text { padrão }\end{array}$ & Mín. & Máx. \\
\hline Escolaridade média em anos de estudo & 6,74 & 1,34 & 4,30 & 13,19 \\
\hline Índice de pobreza & 0,19 & 0,05 & 0,05 & 0,47 \\
\hline
\end{tabular}

Fonte: Elaboração própria com base nos dados do Censo Escolar 2005.

*significante a $5 \%$. 


\subsubsection{Outras variáveis}

A tabela 9 mostra a frequiência, a média de notas e os testes de diferença de média para as variáveis reunião de pais e escolaridade dos pais dos colegas que serão usadas, respectivamente, para o controle do viés de variáveis omitidas e para captar o efeito de pares. De acordo com os dados, os alunos que tinham pais que foram quase sempre ou sempre às reuniões apresentaram um desempenho escolar muito superior em relação aos demais.

Em termos de escolaridade dos pais dos colegas, observa-se que os estudantes que tinham pai e mãe com ensino superior completo conseguiram, na média, notas superiores em relação aos demais alunos que não tinham pais com esse atributo. Por fim, a taxa de livros didáticos devolvidos por aluno que também será utilizada para controlar o viés de variáveis omitidas apresentou a média de 4,16 livros devolvidos por aluno com um desvio-padrão de 4,59. Já as correlações com as notas de matemática e português, são significativas considerando o nível de significância de $5 \%$ e positivas de acordo com o esperado. A correlação envolvendo a nota de matemática foi de $8,23 \%$, enquanto a correlação com as notas de português foi de $10,34 \%$.

Tabela 9 - Testes de diferenças de média das variáveis inerentes ao controle de variáveis omitidas e efeito de pares

\begin{tabular}{|c|c|c|c|c|c|c|}
\hline Variável & Especificação & $(\%)$ & $\begin{array}{l}\text { Média } \\
\text { mat. }\end{array}$ & Dif. (1) - (2) & $\begin{array}{l}\text { Média } \\
\text { port. }\end{array}$ & $\begin{array}{l}\text { Dif. (1) - } \\
(2)\end{array}$ \\
\hline \multirow[b]{3}{*}{ Reunião de pais } & não & & & & & \\
\hline & & 28,20 & 167,74 & \multirow[b]{2}{*}{$-14,46^{*}$} & 160,73 & \multirow[b]{2}{*}{$-17,23 *$} \\
\hline & $\begin{array}{c}\text { sim, quase sempre ou } \\
\text { sempre }\end{array}$ & 64,56 & 182,21 & & 177,96 & \\
\hline \multirow[b]{3}{*}{$\begin{array}{c}\text { Escolaridade dos pais } \\
\text { dos colegas }\end{array}$} & caso contrário & & & \multirow{3}{*}{$-5,27 *$} & & \multirow{3}{*}{$-5,66^{*}$} \\
\hline & & 85,48 & 175,45 & & 170,18 & \\
\hline & $\begin{array}{c}\text { pai e a mãe } \\
\text { completaram a } \\
\text { faculdade }\end{array}$ & 14,52 & 176.22 & & 175,84 & \\
\hline
\end{tabular}

Fonte: Elaboração própria com base nos dados da Prova Brasil 2005.

*significante a $5 \%$. 
Em suma, para as variáveis relacionadas às características dos alunos os sinais das correlações com o desempenho em matemática e em português se deram conforme o esperado, exceto para a variável tempo de tv. De acordo com a tabela 4, alunos que assistiam tv mais de 4 horas em dia de aula apresentaram melhor desempenho na média em ambas as disciplinas. Em relação ao background familiar, os resultados foram bastante intuitivos. A tabela 5 mostrou que o aparato literário, os recursos computacionais e o incentivo dos pais se correlacionaram positivamente com as notas dos alunos. Ademais, observou-se que quanto mais elevada era à escolaridade das mães, melhor foi o desempenho dos alunos. No que diz respeito à infra-estrutura de ensino oferecido pelas escolas, os resultados não se deram conforme o esperado. Os alunos que estudavam em escolas que tinham laboratório de informática e de ciências, sala de leitura e biblioteca tinham pior proficiência escolar. Diferentemente, as correlações entre as notas e a distância das escolas em relação ao centro se deram conforme o esperado, elas são significativas e negativas. A variável proporção de professores com ensino superior também não se associou da forma esperada com as notas de matemática e português. Já as características sócio-econômicas da região da escola (escolaridade média em anos de estudo e índice de pobreza) apresentaram a correlação esperada com a proficiência. Por fim, os resultados das estatísticas descritivas para as variáveis de controle para o viés de variáveis omitidas e para captar o efeito de pares também não fugiram do esperado.

Diante esses resultados, sendo eles previstos ou não, é importante realizar a análise de regressão para se tentar inferir a relação de causalidade entre as medidas de violência e a proficiência. 


\section{RESULTADOS}

Este capítulo apresenta os resultados da análise de relação entre violência e proficiência escolar. Com o intuito de se testar a robustez dos resultados, foram construídas sete especificações diferentes para o conjunto de regressores.

No modelo 1, iniciaremos as análises por meio de uma regressão simples de proficiência na medida de violência. No modelo 2, controlamos adicionalmente pelas características dos alunos. Em seguida, incorporamos também as variáveis de background familiar. Após isso, incluímos sucessivamente as características das escolas e dos professores, dos distritos da capital, a escolaridade dos pais dos colegas, reunião de pais e taxa de livros devolvidos por aluno. Por fim, com o modelo 7 o nosso intuito é controlar um potencial viés de simultaneidade inserindo no modelo anterior as variáveis defasadas para os indicadores de violência.

Consideramos nas estimações dos desvios padrões das estimativas dos parâmetros desses modelos, o fato de as informações inerentes às escolas serem iguais para todos os alunos que pertenceram à mesma instituição escolar. Portanto, incluímos nas regressões a idéia de clusters com o intuito de corrigir o desvio-padrão das regressões.

Também foram estimadas regressões quantificas nas quais o vetor de variáveis explicativas corresponde àquelas do modelo 6 (especificação completa) para os seguintes percentis da distribuição de notas: 5, 10, 25, 50, 75, 90 e 95. 


\subsection{A associação entre violência e proficiência escolar em matemática}

\subsubsection{Mínimos Quadrados Ordinários para as notas de matemática}

A tabela 10 apresenta somente os coeficientes relacionados aos indicadores de violência. Nota-se que todos são positivos e pequenos. Percebe-se também que o valor dos coeficientes diminui - e na maioria dos casos deixa de ser significativo - à medida que se acrescentam regressores. Dentre os coeficientes significantes, a categoria ameaças é aquela que apresenta maior efeito sobre a proficiência (modelos 1, 2, 3 e 4). Portanto, os resultados obtidos não são os esperados e, consequentemente, não corroboram a hipótese de que a violência na região em que a escola se situa afetou nocivamente a proficiência escolar.

Tabela 10 - A associação entre violência e proficiência escolar em matemática

\begin{tabular}{|c|c|c|c|c|c|c|c|}
\hline Variáveis & Modelo 1 & Modelo 2 & Modelo 3 & Modelo 4 & Modelo 5 & Modelo 6 & Modelo 7 \\
\hline $\begin{array}{l}\text { Crimes } \\
\text { contra a } \\
\text { pessoa }\end{array}$ & $\begin{array}{c}0,007 * * * \\
(0,000)\end{array}$ & $\begin{array}{c}0,005^{* * *} * \\
(0,001)\end{array}$ & $\begin{array}{c}0,005 * * * \\
(0,001)\end{array}$ & $\begin{array}{c}0,002 * * \\
(0,001)\end{array}$ & $\begin{array}{c}0,000 \\
(0,001)\end{array}$ & $\begin{array}{c}0,000 \\
(0,001)\end{array}$ & $\begin{array}{c}0,000 \\
(0,001)\end{array}$ \\
\hline $\begin{array}{c}\text { Crimes } \\
\text { contra o } \\
\text { patrimônio }\end{array}$ & $\begin{array}{c}0,001 * * * \\
(0,000)\end{array}$ & $\begin{array}{c}0,001 * * * \\
(0,000)\end{array}$ & $\begin{array}{c}0,001 * * * \\
(0,000)\end{array}$ & $\begin{array}{c}0,001 * * * \\
(0,000)\end{array}$ & $\begin{array}{l}0,000^{*} \\
(0,000)\end{array}$ & $\begin{array}{l}0,000 * \\
(0,000)\end{array}$ & $\begin{array}{l}0,000^{*} \\
(0,000)\end{array}$ \\
\hline $\begin{array}{l}\text { Crimes } \\
\text { violentos }\end{array}$ & $\begin{array}{c}0,004 * * * \\
(0,000)\end{array}$ & $\begin{array}{c}0,003 * * * \\
(0,000)\end{array}$ & $\begin{array}{c}0,003 * * * \\
(0,000)\end{array}$ & $\begin{array}{c}0,002 * * * \\
(0,000)\end{array}$ & $\begin{array}{l}0,001 * * \\
(0,000)\end{array}$ & $\begin{array}{l}0,001 * * \\
(0,000)\end{array}$ & $\begin{array}{l}0,001 * * \\
(0,000)\end{array}$ \\
\hline Ameaças & $\begin{array}{c}0,027 * * * \\
(0,001)\end{array}$ & $\begin{array}{c}0,019 * * * \\
(0,003)\end{array}$ & $\begin{array}{c}0,018 * * * \\
(0,003)\end{array}$ & $\begin{array}{l}0,006^{*} \\
(0,003)\end{array}$ & $\begin{array}{c}0,000 \\
(0,003)\end{array}$ & $\begin{array}{c}0,000 \\
(0,003)\end{array}$ & $\begin{array}{c}0,001 \\
(0,003)\end{array}$ \\
\hline $\begin{array}{c}\text { Roubo } \\
\text { consumado }\end{array}$ & $\begin{array}{c}0,005^{* * * *} \\
(0,000)\end{array}$ & $\begin{array}{c}0,004 * * * \\
(0,001)\end{array}$ & $\begin{array}{c}0,003 * * * \\
(0,001)\end{array}$ & $\begin{array}{c}0,002 * * * \\
(0,001)\end{array}$ & $\begin{array}{c}0,001 \\
(0,001)\end{array}$ & $\begin{array}{c}0,001 \\
(0,001)\end{array}$ & $\begin{array}{l}0,001 * \\
(0,001)\end{array}$ \\
\hline $\begin{array}{c}\text { Furto } \\
\text { consumado }\end{array}$ & $\begin{array}{c}0,002^{* * * *} \\
(0,000)\end{array}$ & $\begin{array}{l}0,002 * * \\
(0,001)\end{array}$ & $\begin{array}{l}0,002 * * \\
(0,001)\end{array}$ & $\begin{array}{c}0,001 \\
(0,001)\end{array}$ & $\begin{array}{c}0,000 \\
(0,000)\end{array}$ & $\begin{array}{c}0,000 \\
(0,000)\end{array}$ & $\begin{array}{c}0,000 \\
(0,000)\end{array}$ \\
\hline
\end{tabular}

Fonte: Elaboração própria com base nos dados da SEADE, Prova Brasil 2005, Censo Escolar 2005 e Censo Demográfico 2000.

$* * *$ significante a $1 \% * *$ significante a $5 \% *$ significante a $10 \%$

Para a apresentação dos efeitos das demais variáveis explicativas, iremos nos concentrar na análise das estimações que utilizam à categoria crimes contra a pessoa (tabela A1 do apêndice). Tomamos essa decisão, pois os resultados obtidos para as demais categorias 
de crimes e notas de matemática são muito semelhantes aos da tabela $\mathrm{A} 4 \mathrm{em}$ termos de sinal e significância, e estão nas tabelas A2 a A6 do apêndice.

Um primeiro resultado interessante que se encontra ao analisar a tabela A1 é que à medida que se incorporam mais variáveis explicativas não há mudança expressiva nas estimativas dos coeficientes.

Quando controlamos para as características dos alunos percebe-se que duas variáveis não são estatisticamente significantes em qualquer um dos modelos considerados. Elas são: a variável proxy para o esforço do aluno (tempo de tv) e estudou na mesma escola. A tabela A4 mostra que os meninos e os brancos apresentaram na média melhor proficiência em matemática se comparados às meninas e aos não-brancos, respectivamente.

No que diz respeito às dummies de idade, nota-se que alunos mais jovens ( 8 anos de idade) tiveram notas mais baixas que os demais. Já o coeficiente da variável dummy que representa o grupo de alunos que está na faixa de idade esperada para a quarta série (10 anos de idade), apresentou a maior magnitude em relação às demais especificações da variável idade. A partir dessa faixa, a performance escolar diminuiu gradativamente a medida que a idade aumenta.

Como era de se esperar, alunos que reprovaram, abandonaram, que ficaram afastados durante o ano e que trabalhavam fora de casa tiveram pior desempenho se comparados aos alunos que não apresentaram esses atributos. Além disso, estudantes que não fazem trabalhos domésticos, que eram comprometidos com a realização das tarefas de matemática e que entraram no maternal e na pré-escola obtiveram melhores notas de matemática que os demais.

Contudo, é interessante observar que os alunos que entraram mais cedo (maternal e pré-escola) na escola conseguiram notas muito superiores em comparação aos alunos que entraram mais tarde (primeira série). 
Observa-se que alunos que moravam com o pai ou com a mãe tiveram piores notas de matemática em comparação àqueles que moravam com ambos ou que moravam com outras pessoas. Verifica-se também que quanto mais pessoas moravam no domicílio, pior era o desempenho do aluno, cabendo destacar que o grupo base eram alunos que moravam com mais de oito pessoas no domicílio. Um outro resultado interessante é que alunos que moravam sozinhos ou com mais uma pessoa tiveram piores notas que aqueles que moravam com mais duas pessoas.

Em relação à variável futuro, cabe a observação de que os coeficientes das dummies referentes aos alunos que não sabiam o que fazer e aqueles que pretendiam continuar estudando após a conclusão do ensino fundamental assumiram valores bastante próximos. O ponto fundamental nesse caso, tendo em vista que o grupo base (pretendem somente trabalhar) teve o pior desempenho é que o grupo de alunos que desejavam estudar e trabalhar após o término do ensino fundamental, apresentou um desempenho muito superior em termos de notas em relação às demais especificações da variável futuro. Isso pode significar que tal atributo esteja captando características não observáveis e que podem contribuir substancialmente para o melhor aproveitamento escolar. É possível que os alunos que desejavam desempenhar duas atividades (estudo e trabalho) mutuamente após o término do ensino fundamental fossem aqueles mais ambiciosos, preparados, esforçados e conscientes dos fatores necessários para a consecução de metas escolares e socioeconômicas.

Já a variável deixado de lado que reflete o estado emocional do aluno no ambiente escolar apresenta o sinal esperado. Além disso, a magnitude do coeficiente é elevada, demonstrando que esse atributo foi um fator importante para o processo de aprendizado. Por fim, os alunos beneficiados pelo programa Bolsa-Família apresentaram um rendimento inferior em termos de notas se comparados aos alunos não contemplados. Esse resultado 
reflete o fato de que a bolsa foi concedida às crianças de famílias pobres que acabam tendo um pior desempenho que os demais indivíduos.

No que diz respeito as variáveis de background familiar, todos os coeficientes são significativos e possuem os sinais esperados. Alunos que tinham um aparato literário (livros) e que eram contemplados por recursos computacionais (computador) apresentaram melhores notas de matemática. Ademais, o incentivo dos pais à vida escolar (apoio aos estudos) também se constituiu em uma qualidade que afetou positivamente o desempenho. Ao analisar os efeitos que a escolaridade das mães exerce sobre as notas dos alunos, os resultados também indicam uma relação direta entre a proficiência dos filhos e a escolaridade materna, pelo menos até aquelas que não completaram faculdade.

Ao controlar por características das escolas, observa-se que a maior parte das dummies referentes ao tamanho da sala não são estatisticamente significantes em nenhum dos modelos especificados. A situação se mantém para as variáveis que são consideradas no presente trabalho como proxies da infra-estrutura de ensino e aprendizagem (laboratório de informática, laboratório de ciências e biblioteca) com exceção da variável sala de leitura que apresenta coeficientes com sinais positivos (conforme o esperado), mas significantes apenas para os modelos 4 e 5. Já a variável programas educacionais não explicou o desempenho em matemática em nenhum dos modelos citados. Examinando as variáveis que apresentaram coeficientes significantes, nota-se que os alunos de salas que compreendiam de dezesseis a vinte alunos, e salas que abarcavam de vinte e um a vinte e cinco alunos apresentaram notas inferiores se comparados aos estudantes de turmas com menos de dez indivíduos (grupo base).

Os alunos que estudaram em escolas municipais tiveram notas inferiores que aqueles das escolas estaduais. Já alunos de escolas que também tinham ensino médio apresentaram pior desempenho que aqueles de escolas que não tinham ensino médio, resultado contrário ao 
obtido na análise descritiva. Assim, os resultados das regressões parecem apoiar a política de separação das escolas por níveis de ensino, não havendo evidência a favor da municipalização.

Por fim, temos a variável distância em relação ao centro que apresentou uma associação negativa com as notas conforme o esperado. Entretanto, o coeficiente é significativo somente para o modelo 4.

Considerando o controle por características dos professores, observa-se que os alunos que eram ensinados por professores que corrigiam sempre ou quase sempre as tarefas de matemática conseguiram melhores notas de matemática se comparados aos demais. Por outro lado, a variável proporção de professores com ensino superior não apresentou coeficientes significantes em nenhum dos modelos.

Ao controlar por características dos distritos da capital, verifica-se que a variável escolaridade média em anos de estudo, referente à região onde a escola está localizada, não afetou a proficiência em matemática. No entanto, o índice de pobreza, mais especificamente, a proporção de chefes que não tinham rendimento ou que recebiam até um salário mínimo na região em que a escola se encontra apresentou coeficientes significantes e negativos (conforme o esperado) em todos os modelos em que essa variável consta. É importante destacar que essa variável apresentou o maior coeficiente dentre as variáveis explicativas da tabela A1. Assim, a redução na incidência de pobreza em um ponto percentual eleva aproximadamente, em média, as notas em 38 pontos na escala da Prova Brasil.

Considerando a variável escolaridade dos pais dos colegas utilizada com a motivação de captar o efeito de pares, observa-se que os coeficientes são significantes e apresentam os sinais esperados, isto é, são positivos. Por fim, temos as variáveis reunião de pais e taxa de livros didáticos devolvidos por aluno inseridas nas regressões com o intuito de 
controlar o viés de variáveis omitidas. Nota-se que somente a primeira é significante e apresentou uma associação positiva com as notas como era de se esperar.

De modo geral, os resultados dessa seção, corroboram aqueles encontrados em Menezes-Filho (2007), Barros et al. (2001) e Waltenberg (2005), embora esses autores não tenham incorporado à violência como regressor. Além disso, é preciso considerar que os dois últimos utilizaram variáveis que são qualitativamente diferentes daquelas empregadas no presente estudo. Em relação ao trabalho de Menezes-Filho (2007) que utilizou os dados do SAEB 2003, os resultados são similares aos encontrados nessa seção, com exceção da variável mora com pai ou mãe. Barros et al. (2001) observaram que a renda (individual, da família e da região) e a escolaridade (dos pais e da população) foram fatores importantes na consecução de metas escolares. Já Waltenberg (2005), verificou que o efeito de pares (ocupação dos pais dos colegas) e o atraso escolar (medida análoga a nossa variável reprovação) também foram importantes no processo de aprendizado dos alunos.

\subsubsection{Regressões Quantílicas}

Seguiremos com a nossa análise desenvolvendo a questão da heterogeneidade na resposta dos alunos à violência. Os resultados obtidos para investigar a associação entre os indicadores de violência e proficiência escolar em matemática ao longo da distribuição de notas são apresentados nas tabelas A13 a A18 do apêndice.

Nesse contexto, observa-se que as regressões que envolveram as categorias crimes contra a pessoa (tabela A13) e ameaças (tabela A16) não apresentam coeficientes significantes ao longo da distribuição de notas, assim como os coeficientes obtidos por MQO. Em contrapartida, as regressões que empregaram as categorias crimes contra o patrimônio, 
crimes violentos e roubo consumado apresentaram em geral coeficientes significantes e positivos para todos os quantis. Apesar de ser mínima a diferença entre os coeficientes, notase que a violência tem efeito maior sobre alunos da cauda superior da distribuição da proficiência em matemática.

\subsection{A associação entre violência e proficiência escolar em português}

\subsubsection{Mínimos Quadrados Ordinários para as notas de português}

Nessa seção, serão apresentados os resultados inerentes à relação da violência com as notas de português. A tabela 11 apresenta somente os coeficientes relacionados aos indicadores de violência. Os resultados seguem conforme as regressões que empregaram as notas de matemática, isto é, os coeficientes continuam sendo todos positivos e pequenos. Além disso, os valores destes diminuem quando o número de variáveis explicativas aumenta e a significância também varia de acordo com a composição de variáveis. Logo, esses resultados também não corroboram a hipótese de que a violência constitui-se em um fenômeno prejudicial à proficiência escolar.

A categoria ameaças continua sendo aquela que apresenta os coeficientes com maior correlação (modelos 1, 2, 3 e 4), enquanto a modalidade crimes contra o patrimônio também apresenta nesse caso a menor correlação com as notas de português. Uma diferença fundamental entre os coeficientes obtidos nas regressões que envolvem as notas de matemática (tabela 10) em relação às regressões que utilizam as notas de português (tabela 11) é que no último caso os indicadores de violência apresentaram coeficientes ligeiramente maiores. 
Tabela 11 - A associação entre violência e proficiência escolar em português

\begin{tabular}{|c|c|c|c|c|c|c|c|}
\hline Variáveis & Modelo 1 & Modelo 2 & Modelo 3 & Modelo 4 & Modelo 5 & Modelo 6 & Modelo 7 \\
\hline $\begin{array}{l}\text { Crimes } \\
\text { contra } \\
\text { pessoas }\end{array}$ & $\begin{array}{c}0,008 * * * \\
(0,000)\end{array}$ & $\begin{array}{c}0,006^{* * * *} \\
(0,001)\end{array}$ & $\begin{array}{c}0,006^{* * * *} \\
(0,001)\end{array}$ & $\begin{array}{c}0,002 * * * \\
(0,001)\end{array}$ & $\begin{array}{c}0,001 \\
(0,001)\end{array}$ & $\begin{array}{c}0,001 \\
(0,001)\end{array}$ & $\begin{array}{c}0,001 \\
(0,001)\end{array}$ \\
\hline $\begin{array}{c}\text { Crimes } \\
\text { contra o } \\
\text { patrimônio }\end{array}$ & $\begin{array}{c}0,002 * * * \\
(0,000)\end{array}$ & $\begin{array}{c}0,001 * * * \\
(0,000)\end{array}$ & $\begin{array}{c}0,001 * * * \\
(0,000)\end{array}$ & $\begin{array}{c}0,001 * * * \\
(0,000)\end{array}$ & $\begin{array}{c}0,000 * * \\
(0,000)\end{array}$ & $\begin{array}{c}0,000 * * \\
(0,000)\end{array}$ & $\begin{array}{l}0,000 * * \\
(0,000)\end{array}$ \\
\hline $\begin{array}{c}\text { Crimes } \\
\text { violentos }\end{array}$ & $\begin{array}{c}0,004 * * * \\
(0,000)\end{array}$ & $\begin{array}{c}0,003 * * * \\
(0,000)\end{array}$ & $\begin{array}{c}0,003 * * * \\
(0,000)\end{array}$ & $\begin{array}{c}0,002 * * * \\
(0,000)\end{array}$ & $\begin{array}{l}0,001 * * \\
(0,000)\end{array}$ & $\begin{array}{l}0,001 * * \\
(0,000)\end{array}$ & $\begin{array}{c}0,001 * * * \\
(0,000)\end{array}$ \\
\hline Ameaças & $\begin{array}{c}0,031 * * * \\
(0,001)\end{array}$ & $\begin{array}{c}0,021 * * * \\
(0,003)\end{array}$ & $\begin{array}{c}0,020 * * * \\
(0,003)\end{array}$ & $\begin{array}{c}0,008 * * * \\
(0,003)\end{array}$ & $\begin{array}{c}0,003 \\
(0,003)\end{array}$ & $\begin{array}{c}0,003 \\
(0,003)\end{array}$ & $\begin{array}{c}0,004 \\
(0,003)\end{array}$ \\
\hline $\begin{array}{c}\text { Roubo } \\
\text { consumado }\end{array}$ & $\begin{array}{c}0,005^{* * *} * \\
(0,000)\end{array}$ & $\begin{array}{c}0,004 * * * \\
(0,001)\end{array}$ & $\begin{array}{c}0,004 * * * \\
(0,001)\end{array}$ & $\begin{array}{c}0,002 * * * \\
(0,001)\end{array}$ & $\begin{array}{l}0,001 * \\
(0,001)\end{array}$ & $\begin{array}{l}0,001 * \\
(0,001)\end{array}$ & $\begin{array}{l}0,001 * * \\
(0,001)\end{array}$ \\
\hline $\begin{array}{c}\text { Furto } \\
\text { consumado }\end{array}$ & $\begin{array}{c}0,003^{* * *} * \\
(0,000)\end{array}$ & $\begin{array}{c}0,002 * * \\
(0,001)\end{array}$ & $\begin{array}{c}0,002 * * \\
(0,001)\end{array}$ & $\begin{array}{l}0,001 * \\
(0,001)\end{array}$ & $\begin{array}{c}0,000 \\
(0,000)\end{array}$ & $\begin{array}{c}0,000 \\
(0,000)\end{array}$ & $\begin{array}{c}0,000 \\
(0,000)\end{array}$ \\
\hline
\end{tabular}

Fonte: Elaboração própria com base nos dados da SEADE, Prova Brasil 2005, Censo Escolar 2005 e Censo Demográfico 2000.

$* * *$ significante a $1 \% * *$ significante a $5 \% *$ significante a $10 \%$

Para a apresentação dos demais resultados também iremos nos concentrar na análise das estimações que empregam a categoria crimes contra a pessoa (tabela A7 do apêndice). Seguiremos com essa estratégia, pois os resultados para as outras modalidades de violência e notas de português que estão nas tabelas A8 a A12 são muito similares aos da tabela A7. Contudo, nessa seção enfatizaremos as diferenças entre os resultados obtidos por meio das regressões que utilizam as notas de matemática e aquelas que usam as notas de português, por intermédio da comparação dos dados da tabela A7 (crimes contra a pessoa x português) com os resultados dispostos na tabela A1 (crimes contra a pessoa x matemática).

Ao considerar as demais variáveis explicativas, também é oportuna a mesma observação destacada na exposição das informações contidas na tabela A1, ou seja, que os coeficientes em geral não mudam muito à medida que se inserem novos blocos de regressores.

Iniciando a apresentação dos resultados, nota-se que diferentemente dos modelos que utilizam as notas de matemática (tabela A1), quando controlamos para as características dos alunos a tabela A7 mostra que a variável tempo de tv continua não sendo estatisticamente significante. Percebe-se também que os meninos apresentaram um desempenho inferior em 
português se comparados às meninas e os brancos superaram os não-brancos em termos de notas em português.

Uma outra novidade apresentada pela tabela A7 diz respeito ao fato de que alunos que estudaram sempre na mesma escola tiveram piores notas de português que os demais. Para as demais variáveis de atributo dos alunos, bem como para as de background familiar os resultados também são, de forma geral, similares àqueles apresentados pela tabela A1 em termos de sinal e significância.

Para as variáveis ensino médio e sala de leitura os resultados apresentados na tabela A7 divergem em termos de significância ao mudar a composição de variáveis explicativas, mas não no que diz respeito ao sinal daqueles observados na tabela A1. Para as demais variáveis relacionadas às características das escolas e dos professores, os resultados seguem idênticos àqueles apresentados pela tabela A1 em termos de sinal e significância.

Ao controlar por características dos distritos da capital, a grande diferença de resultado entre as tabelas A1 e A7 se dá no coeficiente da variável escolaridade média em anos de estudo, que é significante e positiva (de acordo com o esperado) em português, mas não era em matemática. Em relação ao índice de pobreza, o coeficiente continua negativo e significante, embora com magnitude de cerca de 20 pontos na escala da Prova Brasil, metade do efeito encontrado para matemática.

Outra diferença é que a variável proporção de livros didáticos devolvidos por aluno apresentou coeficiente positivo (conforme o esperado) e significante. Por fim, temos as variáveis reunião de pais (correção do problema de variáveis omitidas) e escolaridade dos pais dos colegas (efeito de pares) que também não apresentaram resultados distintos daqueles observados na tabela A1.

Os resultados obtidos para o exame da heterogeneidade na resposta dos alunos à violência no contexto das regressões que empregaram as notas de português, estão nas tabelas 
A19 a A24 do apêndice. Assim como em matemática, o efeito da violência é maior na cauda superior da distribuição de notas. 


\section{CONCLUSÕES}

A violência é um assunto cotidianamente veiculado pela mídia e constitui-se em um objeto de debate público. Porém, a violência também tem ocupado espaço notório na pauta de estudos das mais diversas áreas de pesquisa. Isso ocorre, pois a violência é uma atividade contraproducente e quando adquiri caráter sistêmico ela gera sérias conseqüências sociais e econômicas as instituições.

Contudo, a violência também é vista como um fator maléfico a nível individual. De acordo com a literatura especializada, a experiência com atos violentos é extremamente nociva ao bem estar físico e emocional das pessoas, especialmente quando as vítimas (ou testemunhas) são crianças e adolescentes. $\mathrm{O}$ argumento é que a exposição à violência no início do ciclo da vida pode constituir-se não só em um fator degenerativo da saúde, mas também, em um fenômeno que pode minar o acúmulo de capital humano e, portanto, afetar a formação socioeconômica da vítima. Logo, a vitimização na infância pode implicar um potencial detrimento da renda futura do indivíduo. Tendo em vista a importância que a eficiência educacional exerce ao mediar essa conexão entre violência e possibilidade de ganhos remunerados na idade adulta, qual seria a associação entre violência e proficiência escolar no município de São Paulo?

No presente estudo, investigamos essa questão e observamos, surpreendentemente, que alunos de escolas de localidades mais violentas possuem desempenho escolar sensivelmente melhor que alunos de escolas em regiões menos violentas, quando se consideram crimes contra o patrimônio, roubo consumado ou crimes violentos. Para as demais categorias de crimes analisadas, não há efeito algum sobre a proficiência, tanto em matemática como em português. De qualquer modo, os resultados obtidos divergem do que seria esperado: uma relação negativa da violência com a performance dos estudantes. 
Uma possível explicação para esse resultado pode ser o fato de que a subnotificação de crimes é maior em regiões mais violentas, em que estão as piores escolas. Assim, as estatísticas oficiais seriam uma medida com erro da verdadeira criminalidade da região da escola, o que poderia levar ao resultado de não encontrarmos uma relação inversa entre violência e desempenho escolar. Além disso, pode ser que regiões mais centrais recebam um grande fluxo de pessoas que trabalham na mesma, levando a maior ocorrência de crimes. No entanto, como a criminalidade é calculada por habitantes e a região central de São Paulo tem baixa densidade de moradores, as taxas de criminalidade são infladas nessa região.

Um outro ponto relevante e que deixa margem para o desenvolvimento do tema aqui estudado, está ligado ao possível problema de endogeneidade entre a violência e proficiência escolar. Para controlar o problema de simultaneidade utilizamos o conceito mais fraco de endogeneidade (predeterminação). O procedimento ideal seria utilizar variáveis instrumentais, ou seja, utilizar uma variável que seja correlacionada com a violência, mas que seja ortogonal ao termo de erro. No entanto, descobrir uma variável instrumental parece ser uma empreitada bastante árdua, mas de grande estímulo em termos de contribuição acadêmica.

Em relação às demais variáveis explicativas, observamos que a renda desempenha papel preponderante na determinação do desempenho escolar. Em outras palavras, a variável índice de pobreza representada pela fração de pessoas com rendimento de até um salário mínimo teve o maior efeito sobre as notas de português e de matemática. Os resultados também mostram evidências de que combater a reprovação é meta essencial para incrementar o desempenho escolar. Outro resultado interessante sugere que professores e gestores das instituições escolares precisam estar atentos ao estado emocional dos alunos, já que alunos que se sentem "deixados de lado" apresentaram notas muito inferiores se comparados aos demais. 
Por fim, cabe destacar que há um campo enorme a ser preenchido no estudo da relação entre violência e desempenho escolar e o presente trabalho foi apenas o primeiro passo nessa direção. Analisar as relações para alunos de outras séries, outros tipos de crimes e a utilização de pesquisas de vitimização são alguns rumos que a pesquisa futura acerca do tema pode tomar. 


\section{REFERÊNCIAS}

AINSWORTH, James W. Why Does It Take a Village? The Mediation of Neighborhood Effects on Educational Achievement. Social Forces, University of North Carolina (USA), v. 81(1), p. 117-152, sep. 2002.

AISENBERG, Eugene; ELL, Kathleen. Contextualizing community violence and its effects: an ecological model of parent-child interdependent coping. Journal of Interpersonal Violence, v. 20, n. 7, p. 855-871, jul. 2005.

AIZER, Anna. Neighborhood violence and urban youth. Working Paper NBER $\boldsymbol{n}^{\boldsymbol{o}}$. W13773, National Bureau of Economic Research (NBER), New York (USA), p. 1-45, jul. 2007.

AMMERMÜLLER, Andréas. Violence in european schools: victimization and consequences. Discussion Paper $\boldsymbol{n}^{\text {o }}$ 07-004, Centre for European Economic Research (ZEW), Mannheim (Germany), p. 1-40, jan. 2007.

BARROS, R. P. et al. Determinantes do desempenho educacional no Brasil. Texto para discussão n. 834. Instituto de Pesquisa Econômica Aplicada (IPEA), Rio de Janeiro, p. 1-33, out. 2001.

BOWEN, Natasha; BOWEN, Gary L. Effects of crime and violence in neighborhoods and schools behavior and performance of adolescents. Journal of Adolescent Research, v. 14, n. 3, p. 319-342, jul. 1999.

BROOKS-GUNN, Jeanne et al. Do neighborhoods influence child and adolescent development? The American Journal of Sociology, University of Chicago(USA), v. 99, n. 2, p. 353-395, sep. 1993.

BROWNING, Christopher R.; CAGNEY, Kathleen A. Neighborhood structural disadvantage, collective efficacy, and self-rated physical health in an urban setting. Journal of Health and Social Behavior, v. 43, n. 4, p. 383-399, dec. 2002.

CEBALLO, Rosário et al. Inner-city children's exposure to community violence: how much do parents know? Journal of Marriage and the Family, v. 63, n. 4, p. 927-940, nov. 2001.

CENTRO DE ESTUDOS DA METRÓPOLE (CEM). Número de pessoas responsáveis pelos domicílios particulares permanentes com diferentes faixas de rendimento e de escolaridade em anos de estudos. Disponível em: <www.centrodametropole.org.br〉. Acesso em: 18 set. de 2008.

COLEMAN, Beverly E. School violence and student achievement in reading and mathematics among eighth graders. 1998. 47 f. Dissertation (Ph. D) - University of Illinois, Urbana-Champaing (USA), 1998. Disponível em: <http://www.eric.ed.gov/>. Acesso em: 10 jul. 2007. 
DELANEY-BLACK, Virginia et al. Violence Exposure, Trauma, and IQ and/or Reading Deficits Among Urban Children. Arch Pediatr Adolesc Med, v. 156, p. 280-285, mar. 2002.

FERRÃO, Maria Eugênia; BELTRÃO, Kaizô Iwakami; SANTOS, Denis Paulo dos. O impacto de políticas de não-repetência sobre o aprendizado dos alunos da $4^{\text {a }}$ série. Pesquisa $\boldsymbol{e}$ Planejamento Econômico, v. 32(3), p. 495-513, dez. 2002.

FERRIS, J. Stephen; LEUNG, Ambrose. School Size and youth violence. Carleton Working Paper CEP 02-10, Presented at the Canadian Economic Association Meetings, First Draft, p. $1-25$, jul. 2002.

FIGLIO, David N. Boys named sue: disruptive children and their peers. Working Paper NBER $n^{o}$ 11277, National Bureau of Economic Research (NBER), New York (USA), p. 1-20, apr. 2005.

FUNDAÇÃO SISTEMA ESTADUAL DE ANÁLISE DE DADOS (SEADE). Número de ocorrências criminais organizados por distritos policiais, conceitos das categorias criminais, dados demográficos e de contigüidade das escolas em relação ao centro. Disponível em: <www.seade.gov.br>. Acesso em: 20 fev. de 2008.

GORMAN-SMITH, Deborah; TOLAN, Patrick. The role of exposure to community violence and developmental problems among inner-city youth. Development and Psychopathology, Cambridge University (USA), v. 10, p. 101-116, 1998.

GROGGER, Jeff. Local violence, educational attainment, and teacher pay. Working Paper NBER $n^{\circ}$ 6003, National Bureau of Economic Research (NBER), New York (USA), p. 1-50, apr. 1997.

HANUSHEK, Eric A.; WOESSMANN, Ludger. The role of school improvement in economic development. National Bureau of Economic Research, Cambridge (USA), Working Paper n. 12832, p. 1-94, jan. 2007.

HENRICH, Christopher C. et al. The association of community violence exposure with middle-school achievement: a prospective study. Journal of Applied Developmental Psychology, v. 25, ed. 3, p. 327-348, 2004.

HURT, Hallam et al. Exposure to Violence: Psychological and Academic Correlates in Child Witnesses. Arch Pediatr Adolesc, v. 155, p. 1351-1356, dec. 2001.

INSTITUTO DE PESQUISA ECONÔMICA APLICADA (IPEADATA). Dados de homicídios por cem mil habitantes no Brasil entre os anos de 1992 a 2002. Disponível em: <http://www.ipeadata.gov.br/>. Acesso em: 8 jan. de 2009.

INSTITUTO NACIONAL DE ESTUDOS E PESQUISAS EDUCACIONAIS ANÍSIO TEIXEIRA (INEP). Prova Brasil 2005 e Censo Escolar 2005. Disponível em: <http://www.inep.gov.br/>. Acesso em: 11 jan. 2008

JONES, Janine M. Exposure to Chronic Community Violence: Resilience in African American Children. Journal of Black Psychology, v. 33, n. 2, p. 125-149, may 2007. 
KINSLER, Josh. Suspending the right to an education or preserving it? A dynamic equilibrium model of student behavior, achievement, and suspension. Working Paper, Department of Economics, Duke University, Durham (USA), p. 1-56, nov. 2006. Disponível em: <http://www.econ.duke.edu/>. Acesso em: 10 jul. 2007.

KOENKER, Roger; HALLOCK, Kevin F. Quantile Regression. Journal of Economic Perspectives, v. 15, n. 4, p. 143-156, 2001.

KRUEGER, Alan B. Economic considerations and class size. The Economic Journal, n. 113, p. 34-63, feb. 2003 .

LAZEAR, Edward P. Educational Production. Working Paper $\boldsymbol{n}^{\boldsymbol{o}}$. 7349, National Bureau of Economic Research (NBER), Cambridge (USA), p. 1-48, sep. 1999.

MACMILLAN, Ross. Violence and the life course: the consequences of victimization for personal and social development. Annual Reviews Sociology, v. 27, p. 1-22, aug. 2001.

MACMILLAN, Ross; HAGAN, John. Violence in the transition to adulthood: adolescent victimization, education, and socioeconomic attainment in later life. Journal of Research on Adolescence, v. 14(2), p. 127-158, 2004.

MARGOLIN, Gayla; GORDIS, Elana B. The Effects of Family and Community Violence on Children. Annu. Rev. Psychol., v. 51, p. 445-479, 2000.

MENEZES-FILHO, Naercio. Os Determinantes do Desempenho Escolar do Brasil. Texto para discussão, Instituto Futuro Brasil, Ibmec-SP e FEA-USP. 2007. Disponível em: <http://www.ifb.com.br/>. Acesso em: 13 jan. 2009.

OSOFSKY, Joy D. The Impact of Violence on Children. Domestic Violence and Children, v. 9, n. 3, p. 33-49, 1999.

OVERSTREET, Stacy. Exposure to community violence: defining the problem and understanding the consequences. Journal of Child and Family Studies, v. 9, n. 1, p.7-25, 2000 .

PROGRAMA INTERNACIONAL DE AVALIAÇÃO DE ALUNOS (PISA). Dados sobre proficiência escolar em matemática e leitura do PISA 2003 e 2006. Disponível em: <http://www.pisa.oecd.org/>. Acesso em: 7 jan. de 2009.

RATNER, Hilary H. et al. Violence exposure, IQ, academic performance, and children's perception of safety: evidence of protective effects. Merrill-Palmer Quarterly, Detroit (USA), v. 52, n. 2, p. 264-287, apr. 2006.

ROMER, David. Advanced macroeconomics. New York, McGraw-Hill, 3 ed. 2006.

ROSS, Catherine E. Neighborhood Disadvantage and Adult Depression. Journal of Health and Social Behavior, v. 41, n. 2, p. 177-187, jun. 2000. 
SALZINGER, Suzanne et al. An ecological framework for understanding risk for exposure to community violence and the effects of exposure on children and adolescents. Journal of Aggression and Violent Behavior, v. 7, p. 423-451, 2002.

SAMPSON, Robert J.; MORENOFF, Jeffrey D.; GANNON-ROWLEV, Thomas. Assessing "neighborhood effects": social process and new directions in research. Annu. Rev. Sociol.; v. 28, p. 443-478, 2002.

SCARPA, Angela. Community Violence Exposure in Young Adults. Trauma, Violence , \& Abuse, v. 4, n. 3, p. 210-227, jul. 2003.

SECRETARIA DE SEGURANÇA PÚBLICA DE SÃO PAULO. Conceitos das categorias criminais. Disponível em: <www.ssp.sp.gov.br>. Acesso em: 20 fev. de 2008.

SEVERNINI, E. R. A relação entre violência nas escolas e proficiência dos alunos. 2007. 24 f. Dissertação (Mestrado em Economia) - Programa de Pós-Graduação em Economia da PUC-Rio, Rio de Janeiro, 2007. Disponível em: <http://www.maxwell.lambda.ele.pucrio.br>. Acesso em: 5 ago. 2007.

SIEGER, Karin et al. The effects and treatment of community violence in children and adolescents: what should be done? Trauma, Violence, \& Abuse, v. 5, n. 3, p. 243-259, 2004.

WAISELFISZ, Julio J. (2006). Mapa da violência 2006: os jovens do Brasil. Organização dos Estados Ibero-Americanos para a Educação, a Ciência e a Cultura - OEI, p. 1-162. Disponível em: 〈www.oei.org.br/mapa2006.pdf〉. Acesso em: 7 set. 2007

WALTENBERG, Fábio D. Iniqüidade Educacional no Brasil. Uma Avaliação com Dados do PISA 2000. Revista Economia, Brasília (DF), v. 6, n. 1, p. 67-118, jan./jul. 2005.

WARD, C. L. et al. Exposure to violence and its relationship to psychopathology in adolescents. Injury Prevention, v. 7, p. 297-301, 2001.

WINSTON, Gordon C.; ZIMMERMAN. David J. Peer Effects in Higher Education. Discussion Paper n. 64, Williams Project on the Economics of Higher Education, Williamstown (USA), p. 1-40, jan. 2003. 


\section{APÊNDICES}

\subsection{Definições e construção das variáveis explicativas}

Quadro A1 - Lista de variáveis (continua)

\begin{tabular}{|c|c|}
\hline \multicolumn{2}{|r|}{ Características dos alunos } \\
\hline Variável & Especificação \\
\hline Menino & variável dummy que recebe o valor 1 se o aluno for menino e 0 se for menina \\
\hline Branco & $\begin{array}{l}\text { variável dummy que recebe o valor } 1 \text { se o aluno for branco (branco e amarelo) e } 0 \text { caso } \\
\text { contrário (preto, pardo e indígena) }\end{array}$ \\
\hline \multirow{8}{*}{ Idade } & $\begin{array}{l}8 \text { anos ou menos: dummy que recebe o valor } 1 \text { se o aluno tem } 8 \text { anos ou menos e } 0 \text { caso } \\
\text { contrário. }\end{array}$ \\
\hline & 9 anos: dummy que recebe o valor 1 se o aluno tem 9 anos e 0 caso contrário. \\
\hline & 10 anos: \\
\hline & 11 anos: \\
\hline & 12 anos: \\
\hline & 13 anos: \\
\hline & 14 anos: \\
\hline & 15 anos ou mais: \\
\hline Reprovação & dummy que recebe o valor 1 se o aluno já reprovou uma vez ou mais e 0 caso contrário \\
\hline $\begin{array}{l}\text { Tarefas de } \\
\text { matemática }\end{array}$ & $\begin{array}{l}\text { dummy que recebe o valor } 1 \text { se o aluno faz sempre ou quase sempre as tarefas de } \\
\text { matemática e } 0 \text { caso contrário. }\end{array}$ \\
\hline $\begin{array}{l}\text { Tarefas de } \\
\text { português }\end{array}$ & $\begin{array}{l}\text { variável dummy que recebe o valor } 1 \text { se o aluno faz sempre ou quase sempre as tarefas de } \\
\text { português e } 0 \text { caso contrário. }\end{array}$ \\
\hline Tempo de tv & $\begin{array}{l}\text { variável dummy que recebe o valor } 1 \text { se o aluno assiste mais de } 4 \text { horas de tv em dia de } \\
\text { aula e } 0 \text { caso contrário. }\end{array}$ \\
\hline Abandono & $\begin{array}{l}\text { variável dummy que recebe o valor } 1 \text { se o aluno abandonou uma vez ou mais a escola e } \\
\text { ficou afastado durante o ano e } 0 \text { caso contrário. }\end{array}$ \\
\hline $\begin{array}{c}\text { Trabalha fora } \\
\text { de casa }\end{array}$ & variável dummy que recebe o valor 1 se o aluno trabalha fora de casa e 0 caso contrário. \\
\hline $\begin{array}{l}\text { Trabalhos } \\
\text { domésticos }\end{array}$ & $\begin{array}{l}\text { variável dummy que recebe o valor } 1 \text { se o aluno não faz trabalhos domésticos e } 0 \text { caso } \\
\text { contrário. }\end{array}$ \\
\hline \multirow{3}{*}{$\begin{array}{l}\text { Início na } \\
\text { escola }\end{array}$} & $\begin{array}{l}\text { maternal: variável dummy que recebe o valor } 1 \text { se o aluno começou a estudar no maternal } \\
\text { (jardim de infância) e } 0 \text { caso contrário. }\end{array}$ \\
\hline & $\begin{array}{l}\text { pré-escola: variável dummy que recebe o valor } 1 \text { se o aluno começou a estudar na pré- } \\
\text { escola e } 0 \text { caso contrário. }\end{array}$ \\
\hline & $\begin{array}{l}\text { primeira série: variável dummy que recebe o valor } 1 \text { se o aluno começou a estudar na } \\
\text { primeira série e } 0 \text { caso contrário. }\end{array}$ \\
\hline $\begin{array}{c}\text { Estudou na } \\
\text { mesma escola }\end{array}$ & $\begin{array}{l}\text { variável dummy que recebe o valor } 1 \text { se o aluno sempre estudou na mesma escola e } 0 \text { caso } \\
\text { contrário. }\end{array}$ \\
\hline $\begin{array}{l}\text { Mora com pai } \\
\text { ou mãe }\end{array}$ & $\begin{array}{l}\text { variável dummy que recebe o valor } 1 \text { se o aluno mora com a mãe ou com o pai e } 0 \text { caso } \\
\text { contrário. }\end{array}$ \\
\hline \multirow{6}{*}{$\begin{array}{l}\text { Mora com } \\
\text { quantas } \\
\text { pessoas }\end{array}$} & $\begin{array}{l}\text { mora sozinho ou com mais uma pessoa: dummy que recebe o valor } 1 \text { se o aluno mora } \\
\text { sozinho ou com mais uma pessoa e } 0 \text { caso contrário. }\end{array}$ \\
\hline & mora com mais duas pessoas: \\
\hline & mora com mais três pessoas: \\
\hline & mora com mais quatro ou cinco pessoas: \\
\hline & mora com mais seis a oito pessoas: \\
\hline & mora com mais de oito pessoas: \\
\hline
\end{tabular}


Quadro A1 - Lista de variáveis (continuação)

\begin{tabular}{|c|c|}
\hline \multicolumn{2}{|r|}{ Características dos alunos } \\
\hline Variável & Especificação \\
\hline \multirow{4}{*}{$\begin{array}{c}\text { Futuro } \\
\text { (Quando você } \\
\text { terminar o } \\
\text { ensino } \\
\text { fundamental, } \\
\text { você pretende:) }\end{array}$} & $\begin{array}{l}\text { futuro (ainda não sei): dummy que recebe o valor } 1 \text { se o aluno ainda não sabe e } 0 \text { caso } \\
\text { contrário. }\end{array}$ \\
\hline & $\begin{array}{l}\text { futuro (estudar): variável dummy que recebe o valor } 1 \text { se o aluno pretende continuar } \\
\text { estudando e } 0 \text { caso contrário. }\end{array}$ \\
\hline & $\begin{array}{l}\text { futuro (estudar e trabalhar): dummy que recebe o valor } 1 \text { se o aluno(a) quer continuar } \\
\text { estudando e trabalhar e } 0 \text { caso contrário. }\end{array}$ \\
\hline & $\begin{array}{l}\text { futuro (trabalhar): dummy que recebe o valor } 1 \text { se o aluno pretende apenas trabalhar e } 0 \\
\text { caso contrário }\end{array}$ \\
\hline Deixado de lado & $\begin{array}{l}\text { variável dummy que recebe o valor } 1 \text { se o aluno se sente deixado de lado muitas vezes } \\
\text { na sala de aula e } 0 \text { caso contrário. }\end{array}$ \\
\hline Bolsa família & $\begin{array}{l}\text { variável dummy que recebe o valor } 1 \text { se a família do aluno possui a bolsa e } 0 \text { caso } \\
\text { contrário. }\end{array}$ \\
\hline \multicolumn{2}{|r|}{ Background familiar } \\
\hline Variável & Especificação \\
\hline Livros & $\begin{array}{l}\text { variável dummy que recebe o valor } 1 \text { se o aluno tem uma estante com mais de } 20 \text { livros } \\
\text { e } 0 \text { caso contrário. }\end{array}$ \\
\hline Computador & $\begin{array}{l}\text { variável dummy que recebe o valor } 1 \text { caso o aluno possui computador com ou sem } \\
\text { internet e } 0 \text { caso contrário. }\end{array}$ \\
\hline $\begin{array}{l}\text { Apoio aos } \\
\text { estudos }\end{array}$ & $\begin{array}{l}\text { variável dummy que recebe o valor } 1 \text { caso os pais do aluno incentivam ao estudo e } 0 \\
\text { caso contrário. }\end{array}$ \\
\hline \multirow{6}{*}{$\begin{array}{l}\text { Escolaridade da } \\
\text { mãe }\end{array}$} & $\begin{array}{l}\text { mãe nunca estudou ou não completou a } 4^{a} \text { série: dummy que recebe o valor } 1 \text { se a mãe } \\
\text { do aluno nunca estudou ou não completou a } 4^{\text {a }} \text { série e } 0 \text { caso contrário. }\end{array}$ \\
\hline & mãe completou a $4^{a}$ série (antigo primário), mas não completou a $8^{a}$ série: \\
\hline & mãe completou a $8^{a}$ série (antigo ginásio), mas não completou o Ensino Médio: \\
\hline & mãe completou o Ensino Médio (antigo $2^{\circ}$ grau), mas não completou a Faculdade: \\
\hline & completou a Faculdade: \\
\hline & $\begin{array}{l}\text { não sei: } \text { dummy que recebe o valor } 1 \text { se o aluno não sabe a escolaridade da mãe e } 0 \text { caso } \\
\text { contrário. }\end{array}$ \\
\hline \multicolumn{2}{|r|}{ Características das escolas } \\
\hline Variável & Especificação \\
\hline \multirow{8}{*}{ Tamanho da sala } & $\begin{array}{l}\text { tamanho da sala (menos de 10): dummy que recebe o valor } 1 \text { se a sala do aluno tem } \\
\text { menos de } 10 \text { alunos e } 0 \text { caso contrário. }\end{array}$ \\
\hline & $\begin{array}{l}\text { tamanho da sala (11-15): dummy que recebe o valor } 1 \text { se a sala do aluno tem de } 11 \text { a } 15 \\
\text { alunos e } 0 \text { caso contrário. }\end{array}$ \\
\hline & tamanho da sala (16-20): \\
\hline & tamanho da sala (21-25): \\
\hline & tamanho da sala (26-30): \\
\hline & tamanho da sala (31-35): \\
\hline & tamanho da sala (36-40): \\
\hline & tamanho da sala (41-45): \\
\hline Municipal & $\begin{array}{l}\text { variável dummy que recebe o valor } 1 \text { caso a escola do aluno seja municipal e } 0 \text { caso } \\
\text { contrário (estadual). }\end{array}$ \\
\hline Ensino Médio & $\begin{array}{l}\text { variável dummy que recebe o valor } 1 \text { caso a escola do aluno possui ensino médio e } 0 \\
\text { caso contrário. }\end{array}$ \\
\hline $\begin{array}{l}\text { Laboratório de } \\
\text { informática }\end{array}$ & $\begin{array}{l}\text { variável dummy que recebe o valor } 1 \text { caso a escola do aluno possui laboratório de } \\
\text { informática e } 0 \text { caso contrário. }\end{array}$ \\
\hline $\begin{array}{l}\text { Laboratório de } \\
\text { ciências }\end{array}$ & $\begin{array}{l}\text { variável dummy que recebe o valor } 1 \text { caso a escola do aluno possui laboratório de } \\
\text { ciências e } 0 \text { caso contrário. }\end{array}$ \\
\hline Biblioteca & $\begin{array}{l}\text { variável dummy que recebe o valor } 1 \text { caso a escola do aluno possui biblioteca e } 0 \text { caso } \\
\text { contrário. }\end{array}$ \\
\hline Sala de leitura & $\begin{array}{l}\text { variável dummy que recebe o valor } 1 \text { caso a escola do aluno possui sala de leitura e } 0 \\
\text { caso contrário. }\end{array}$ \\
\hline $\begin{array}{c}\text { Uso de } \\
\text { computadores } \\
\text { em sala de aula }\end{array}$ & $\begin{array}{l}\text { variável dummy que recebe o valor } 1 \text { se na escola do aluno é usado computador em sala } \\
\text { de aula e } 0 \text { caso contrário. }\end{array}$ \\
\hline
\end{tabular}


Quadro A1 - Lista de variáveis (conclusão)

\begin{tabular}{|c|c|c|}
\hline \multicolumn{3}{|r|}{ Características das escolas } \\
\hline \multicolumn{2}{|c|}{ Variável } & Especificação \\
\hline \multicolumn{2}{|c|}{ Programas educacionais } & $\begin{array}{l}\text { dummy que recebe o valor } 1 \text { caso a escola participe de pelo menos um dos } \\
\text { seguintes programas: Renda Mínima, TV Escola, PROINFO/MEC e outros } \\
\text { programas educativos, e } 0 \text { caso contrário. }\end{array}$ \\
\hline \multicolumn{2}{|c|}{$\begin{array}{l}\text { Distância em relação ao } \\
\text { centro }\end{array}$} & Distância da escola em relação à Praça da Sé em km. \\
\hline \multicolumn{3}{|r|}{ Características dos professores } \\
\hline \multicolumn{2}{|c|}{ Variável } & Especificação \\
\hline \multicolumn{2}{|c|}{$\begin{array}{l}\text { Corrige tarefas de } \\
\text { matemática }\end{array}$} & $\begin{array}{l}\text { dummy que recebe o valor } 1 \text { caso o professor corrige sempre ou quase sempre as } \\
\text { tarefas de matemática e } 0 \text { caso contrário. }\end{array}$ \\
\hline \multicolumn{2}{|c|}{$\begin{array}{l}\text { Corrige tarefas de } \\
\text { português }\end{array}$} & $\begin{array}{l}\text { variável dummy que recebe o valor } 1 \text { caso o professor corrige sempre ou quase } \\
\text { sempre as tarefas de português e } 0 \text { caso contrário }\end{array}$ \\
\hline \multicolumn{2}{|c|}{$\begin{array}{l}\text { Proporção de } \\
\text { professores com ensino } \\
\text { superior }\end{array}$} & proporção de professores com ensino superior. \\
\hline \multicolumn{3}{|c|}{ Características socioeconômicas dos distritos da capital } \\
\hline \multicolumn{2}{|c|}{ Variável } & Especificação \\
\hline \multicolumn{2}{|c|}{$\begin{array}{l}\text { Escolaridade média em } \\
\text { anos de estudo }\end{array}$} & $\begin{array}{l}\text { escolaridade média em anos de estudo das pessoas responsáveis pelos } \\
\text { domicílios particulares permanentes de cada distrito. }\end{array}$ \\
\hline \multicolumn{2}{|c|}{ Índice de pobreza } & $\begin{array}{l}\text { proporção de pessoas responsáveis pelos domicílios particulares permanentes } \\
\text { que não possuem rendimento ou que possuem rendimento menor do que um } \\
\text { salário mínimo de cada distrito. }\end{array}$ \\
\hline \multicolumn{3}{|r|}{ ets } \\
\hline \multicolumn{2}{|c|}{ Variável } & Especificação \\
\hline \multirow{2}{*}{$\begin{array}{l}\text { Tratamento } \\
\text { do } \\
\text { problema } \\
\text { de } \\
\text { variáveis } \\
\text { omitidas }\end{array}$} & $\begin{array}{c}\text { Reunião } \\
\text { de pais }\end{array}$ & $\begin{array}{l}\text { dummy que recebe o valor } 1 \text { se os pais ou responsáveis vão quase sempre ou } \\
\text { sempre a reunião e } 0 \text { caso contrário. }\end{array}$ \\
\hline & $\begin{array}{c}\text { Taxa de } \\
\text { livros } \\
\text { didáticos } \\
\text { devolvidos } \\
\text { por aluno }\end{array}$ & $\begin{array}{l}\text { taxa de livros didáticos devolvidos por aluno da quarta série no final do ano de } \\
2004 \text {. }\end{array}$ \\
\hline \multicolumn{2}{|c|}{ Peer Effect } & $\begin{array}{l}\text { variável dummy que recebe o valor } 1 \text { se o pai e a mãe completaram a faculdade } \\
\text { e } 0 \text { caso contrário. }\end{array}$ \\
\hline
\end{tabular}


7.2 Tabelas com os resultados obtidos por mínimos quadrados ordinários

Tabela A1 - A associação entre crimes contra a pessoa e notas de matemática (continua)

\begin{tabular}{|c|c|c|c|c|c|c|c|}
\hline Variáveis & Modelo 1 & Modelo 2 & Modelo 3 & Modelo 4 & Modelo 5 & Modelo 6 & Modelo 7 \\
\hline Crimes contra pessoas (2005) & $\begin{array}{c}0,007 * * * * \\
(0,000)\end{array}$ & $\begin{array}{c}0,005 * * * \\
(0,001) \\
\end{array}$ & $\begin{array}{c}0,005^{* * *} * \\
(0,001)\end{array}$ & $\begin{array}{c}0,002^{* * *} \\
(0,001)\end{array}$ & $\begin{array}{c}0,000 \\
(0,001)\end{array}$ & $\begin{array}{c}0,000 \\
(0,001)\end{array}$ & \\
\hline Crimes contra pessoas (2004) & & & & & & & $\begin{array}{c}0,000 \\
(0,001)\end{array}$ \\
\hline menino & & $\begin{array}{c}2,094 * * * \\
(0,277)\end{array}$ & $\begin{array}{c}2,197 * * * \\
(0,278)\end{array}$ & $\begin{array}{c}2,180^{* * * *} \\
(0,276)\end{array}$ & $\begin{array}{c}2,171 * * * \\
(0,275) \\
\end{array}$ & $\begin{array}{c}2,283 * * * \\
(0,277) \\
\end{array}$ & $\begin{array}{c}2,284 * * * * \\
(0,277) \\
\end{array}$ \\
\hline branco & & $\begin{array}{c}4,642 * * * \\
(0,303)\end{array}$ & $\begin{array}{c}4,254 * * * \\
(0,296) \\
\end{array}$ & $\begin{array}{c}3,758^{* * * *} \\
(0,290) \\
\end{array}$ & $\begin{array}{c}3,710 * * * \\
(0,289) \\
\end{array}$ & $\begin{array}{c}3,656^{* * * *} \\
(0,290) \\
\end{array}$ & $\begin{array}{c}3,656 * * * \\
(0,290) \\
\end{array}$ \\
\hline 8 anos & & $\begin{array}{c}-6,934 * * * \\
(2,081)\end{array}$ & $\begin{array}{c}-9,869^{* * *} \\
(2,175)\end{array}$ & $\begin{array}{c}-9,479 * * * \\
(2,171)\end{array}$ & $\begin{array}{c}-9,403^{* * * *} \\
(2,167) \\
\end{array}$ & $\begin{array}{c}-10,235^{* * *} \\
(2,178)\end{array}$ & $\begin{array}{c}-10,237 \text { **** } \\
(2,178) \\
\end{array}$ \\
\hline 9 anos & & $\begin{array}{c}8,849 * * * \\
(1,912)\end{array}$ & $\begin{array}{c}7,630^{* * * *} \\
(1,957) \\
\end{array}$ & $\begin{array}{c}7,157 * * * \\
(1,936) \\
\end{array}$ & $\begin{array}{c}6,983 * * * \\
(1,927) \\
\end{array}$ & $\begin{array}{c}6,278 * * * * \\
(1,932) \\
\end{array}$ & $\begin{array}{c}6,277 * * * * \\
(1,932) \\
\end{array}$ \\
\hline 10 anos & & $\begin{array}{c}12,808 * * * \\
(1,733)\end{array}$ & $\begin{array}{c}11,104^{* * * *} \\
(1,798)\end{array}$ & $\begin{array}{c}10,486^{* * * *} \\
(1,770)\end{array}$ & $\begin{array}{c}10,334 \text { **** } \\
(1,762)\end{array}$ & $\begin{array}{c}9,837 * * * * \\
(1,770) \\
\end{array}$ & $\begin{array}{c}9,836 * * * \\
(1,770) \\
\end{array}$ \\
\hline 11 anos & & $\begin{array}{c}10,515 * * * \\
(1,719)\end{array}$ & $\begin{array}{c}9,131 * * * \\
(1,785)\end{array}$ & $\begin{array}{c}8,709^{* * *} \\
(1,760)\end{array}$ & $\begin{array}{c}8,608^{* * * *} \\
(1,753) \\
\end{array}$ & $\begin{array}{c}8,244 * * * * \\
(1,760) \\
\end{array}$ & $\begin{array}{c}8,244 * * * * \\
(1,760) \\
\end{array}$ \\
\hline 12 anos & & $\begin{array}{c}6,596 * * * \\
(1,765)\end{array}$ & $\begin{array}{c}5,536 * * * \\
(1,829)\end{array}$ & $\begin{array}{c}5,389 * * * \\
(1,808)\end{array}$ & $\begin{array}{c}5,328 * * * \\
(1,802)\end{array}$ & $\begin{array}{c}5,142 * * * \\
(1,810)\end{array}$ & $\begin{array}{c}5,142 * * * \\
(1,810)\end{array}$ \\
\hline 13 anos & & $\begin{array}{c}4,761 * * * \\
(1,832) \\
\end{array}$ & $\begin{array}{l}3,638^{*} \\
(1,911)\end{array}$ & $\begin{array}{l}3,621 * \\
(1,887)\end{array}$ & $\begin{array}{l}3,602 * \\
(1,881)\end{array}$ & $\begin{array}{l}3,503 * \\
(1,890)\end{array}$ & $\begin{array}{l}3,502 * \\
(1,890)\end{array}$ \\
\hline 14 anos & & $\begin{array}{c}5,152 * * \\
(2,223) \\
\end{array}$ & $\begin{array}{c}4,680^{* *} \\
(2,267) \\
\end{array}$ & $\begin{array}{c}4,645^{* *} \\
(2,230)\end{array}$ & $\begin{array}{c}4,633 * * \\
(2,222) \\
\end{array}$ & $\begin{array}{c}4,712 * * \\
(2,217) \\
\end{array}$ & $\begin{array}{c}4,710^{* * *} \\
(2,217)\end{array}$ \\
\hline reprovação & & $\begin{array}{c}-14,648^{* * *} \\
(0,442)\end{array}$ & $\begin{array}{c}-14,167 * * * \\
(0,437)\end{array}$ & $\begin{array}{c}-13,543 * * * * \\
(0,432)\end{array}$ & $\begin{array}{c}-13,566 * * * * \\
(0,431) \\
\end{array}$ & $\begin{array}{c}-13,366^{* * *} \\
(0,431)\end{array}$ & $\begin{array}{c}-13,367 \text { *** } \\
(0,431) \\
\end{array}$ \\
\hline tarefa de matemática & & $\begin{array}{c}9,889 * * * * \\
(0,321) \\
\end{array}$ & $\begin{array}{c}9,244 * * * \\
(0,317) \\
\end{array}$ & $\begin{array}{c}8,403 * * * \\
(0,320) \\
\end{array}$ & $\begin{array}{c}8,422 * * * * \\
(0,319) \\
\end{array}$ & $\begin{array}{c}7,713 * * * * \\
(0,320) \\
\end{array}$ & $\begin{array}{c}7,713 * * * * \\
(0,320) \\
\end{array}$ \\
\hline tempo de tv & & $\begin{array}{c}0,410 \\
(0,309)\end{array}$ & $\begin{array}{c}0,448 \\
(0,307) \\
\end{array}$ & $\begin{array}{c}0,345 \\
(0,302) \\
\end{array}$ & $\begin{array}{c}0,326 \\
(0,302) \\
\end{array}$ & $\begin{array}{c}0,376 \\
(0,301) \\
\end{array}$ & $\begin{array}{c}0,376 \\
(0,302)\end{array}$ \\
\hline abandono & & $\begin{array}{c}-10,490 * * * \\
(0,495)\end{array}$ & $\begin{array}{c}-10,065^{* * *} \\
(0,504)\end{array}$ & $\begin{array}{c}-9,766^{* * * *} \\
(0,503)\end{array}$ & $\begin{array}{c}-9,719 * * * \\
(0,504)\end{array}$ & $\begin{array}{c}-9,208^{* * *} * \\
(0,505)\end{array}$ & $\begin{array}{c}-9,208 * * * \\
(0,505)\end{array}$ \\
\hline trabalha fora de casa & & $\begin{array}{c}-10,723 * * * \\
(0,392)\end{array}$ & $\begin{array}{c}-10,883 * * * \\
(0,403) \\
\end{array}$ & $\begin{array}{c}-10,702 * * * \\
(0,402) \\
\end{array}$ & $\begin{array}{c}-10,609 \text { *** } \\
(0,401) \\
\end{array}$ & $\begin{array}{c}-10,396 * * * \\
(0,398)\end{array}$ & $\begin{array}{c}-10,397 * * * \\
(0,398) \\
\end{array}$ \\
\hline trabalhos domésticos & & $\begin{array}{c}3,311 * * * * \\
(0,291)\end{array}$ & $\begin{array}{c}3,297 * * * * \\
(0,292)\end{array}$ & $\begin{array}{c}3,142^{* * * *} \\
(0,288)\end{array}$ & $\begin{array}{c}3,081 * * * * \\
(0,288) \\
\end{array}$ & $\begin{array}{c}2,922 * * * \\
(0,286) \\
\end{array}$ & $\begin{array}{c}2,922 * * * * \\
(0,286) \\
\end{array}$ \\
\hline maternal & & $\begin{array}{c}11,860 * * * \\
(0,393)\end{array}$ & $\begin{array}{c}10,414^{* * *} \\
(0,388)\end{array}$ & $\begin{array}{c}9,874 * * * \\
(0,382)\end{array}$ & $\begin{array}{c}9,702 * * * \\
(0,382)\end{array}$ & $\begin{array}{c}9,318^{* * * *} \\
(0,383)\end{array}$ & $\begin{array}{c}9,319 * * * \\
(0,383) \\
\end{array}$ \\
\hline pré-escola & & $\begin{array}{c}10,922 * * * \\
(0,346)\end{array}$ & $\begin{array}{c}10,133^{* * * *} \\
(0,345)\end{array}$ & $\begin{array}{c}10,087^{* * * *} \\
(0,348)\end{array}$ & $\begin{array}{c}10,033^{* * * *} \\
(0,349)\end{array}$ & $\begin{array}{c}9,702 * * * * \\
(0,348)\end{array}$ & $\begin{array}{c}9,703 * * * \\
(0,348) \\
\end{array}$ \\
\hline estudou na mesma escola & & $\begin{array}{l}-0,133 \\
(0,290) \\
\end{array}$ & $\begin{array}{l}-0,169 \\
(0,290) \\
\end{array}$ & $\begin{array}{l}-0,250 \\
(0,285) \\
\end{array}$ & $\begin{array}{l}-0,198 \\
(0,283) \\
\end{array}$ & $\begin{array}{l}-0,352 \\
(0,284) \\
\end{array}$ & $\begin{array}{l}-0,351 \\
(0,284) \\
\end{array}$ \\
\hline mora com pai ou mãe & & $\begin{array}{c}-1,278 * * * \\
(0,312)\end{array}$ & $\begin{array}{c}-1,007 * * * \\
(0,315)\end{array}$ & $\begin{array}{c}-1,060 * * * \\
(0,314)\end{array}$ & $\begin{array}{c}-1,077^{* * * *} \\
(0,314)\end{array}$ & $\begin{array}{c}-0,648^{* *} \\
(0,317)\end{array}$ & $\begin{array}{c}-0,648^{* *} \\
(0,317) \\
\end{array}$ \\
\hline $\begin{array}{c}\text { mora sozinho ou com mais } \\
\text { uma pessoa }\end{array}$ & & $\begin{array}{c}7,543 * * * \\
(0,904)\end{array}$ & $\begin{array}{c}7,506^{* * * *} \\
(0,919)\end{array}$ & $\begin{array}{c}7,438 * * * \\
(0,910)\end{array}$ & $\begin{array}{c}7,351 * * * \\
(0,903)\end{array}$ & $\begin{array}{c}6,941 * * * \\
(0,901)\end{array}$ & $\begin{array}{c}6,941 * * * \\
(0,901)\end{array}$ \\
\hline
\end{tabular}


Tabela A1 - A associação entre crimes contra a pessoa e notas de matemática (continuação)

\begin{tabular}{|c|c|c|c|c|c|c|c|}
\hline $\begin{array}{c}\text { Variáveis } \\
\text { mora com mais duas pessoas }\end{array}$ & Modelo 1 & $\begin{array}{c}\text { Modelo } 2 \\
13,628 * * * \\
(0,621) \\
\end{array}$ & $\begin{array}{c}\text { Modelo } 3 \\
13,223 * * * \\
(0,614) \\
\end{array}$ & $\begin{array}{c}\text { Modelo } 4 \\
12,879 * * * \\
(0,610) \\
\end{array}$ & $\begin{array}{c}\text { Modelo } 5 \\
12,773^{* * *} * \\
(0,605)\end{array}$ & $\begin{array}{c}\text { Modelo } 6 \\
12,527 * * * \\
(0,603)\end{array}$ & $\begin{array}{c}\text { Modelo } 7 \\
12,527^{* * *} * \\
(0,604) \\
\end{array}$ \\
\hline mora com mais três pessoas & & $\begin{array}{c}13,419 * * * \\
(0,593)\end{array}$ & $\begin{array}{c}12,839 * * * \\
(0,591)\end{array}$ & $\begin{array}{c}12,624 * * * \\
(0,581)\end{array}$ & $\begin{array}{c}12,547 * * * \\
(0,579)\end{array}$ & $\begin{array}{c}12,276^{* * * *} \\
(0,577)\end{array}$ & $\begin{array}{c}12,276^{* * * *} \\
(0,577)\end{array}$ \\
\hline $\begin{array}{l}\text { mora com mais quatro ou } \\
\text { cinco pessoas }\end{array}$ & & $\begin{array}{c}5,549 * * * \\
(0,526) \\
\end{array}$ & $\begin{array}{c}5,332 * * * \\
(0,525) \\
\end{array}$ & $\begin{array}{c}5,109 * * * \\
(0,518) \\
\end{array}$ & $\begin{array}{c}5,052 * * * \\
(0,515) \\
\end{array}$ & $\begin{array}{c}4,894 * * * \\
(0,513) \\
\end{array}$ & $\begin{array}{c}4,894 * * * \\
(0,513) \\
\end{array}$ \\
\hline $\begin{array}{c}\text { mora com mais seis a oito } \\
\text { pessoas }\end{array}$ & & $\begin{array}{c}2,779 * * * \\
(0,563)\end{array}$ & $\begin{array}{c}2,670 * * * \\
(0,559) \\
\end{array}$ & $\begin{array}{c}2,625^{* * * *} \\
(0,551) \\
\end{array}$ & $\begin{array}{c}2,601 * * * \\
(0,551) \\
\end{array}$ & $\begin{array}{c}2,569 * * * \\
(0,552) \\
\end{array}$ & $\begin{array}{c}2,569 * * * \\
(0,552) \\
\end{array}$ \\
\hline futuro (ainda não sei) & & $\begin{array}{c}5,818 * * * \\
(0,431) \\
\end{array}$ & $\begin{array}{c}6,297 * * * \\
(0,440) \\
\end{array}$ & $\begin{array}{c}5,976^{* * * *} \\
(0,437) \\
\end{array}$ & $\begin{array}{c}5,924 * * * \\
(0,436) \\
\end{array}$ & $\begin{array}{c}5,890 * * * \\
(0,441) \\
\end{array}$ & $\begin{array}{c}5,890 * * * \\
(0,441) \\
\end{array}$ \\
\hline futuro (estudar) & & $\begin{array}{c}5,631 * * * \\
(0,508) \\
\end{array}$ & $\begin{array}{c}5,098 * * * \\
(0,506)\end{array}$ & $\begin{array}{c}4,679 * * * \\
(0,498) \\
\end{array}$ & $\begin{array}{c}4,610^{* * * *} \\
(0,498)\end{array}$ & $\begin{array}{c}4,211 * * * \\
(0,499)\end{array}$ & $\begin{array}{c}4,210 * * * \\
(0,499)\end{array}$ \\
\hline futuro (estudar e trabalhar) & & $\begin{array}{c}11,977 * * * \\
(0,448)\end{array}$ & $\begin{array}{c}11,299 * * * \\
(0,451)\end{array}$ & $\begin{array}{c}11,013 * * * \\
(0,449)\end{array}$ & $\begin{array}{c}10,953 * * * \\
(0,448)\end{array}$ & $\begin{array}{c}10,655^{* * * *} \\
(0,450)\end{array}$ & $\begin{array}{c}10,656^{* * * *} \\
(0,450)\end{array}$ \\
\hline deixado de lado & & $\begin{array}{c}-12,365^{* * * *} \\
(0,359) \\
\end{array}$ & $\begin{array}{c}-12,137 * * * \\
(0,360) \\
\end{array}$ & $\begin{array}{c}-11,888 * * * \\
(0,358) \\
\end{array}$ & $\begin{array}{c}-11,837 * * * \\
(0,357) \\
\end{array}$ & $\begin{array}{c}-11,771 * * * \\
(0,358) \\
\end{array}$ & $\begin{array}{c}-11,770 * * * \\
(0,358) \\
\end{array}$ \\
\hline bolsa família & & $\begin{array}{c}-9,096^{* * *} * \\
(0,345)\end{array}$ & $\begin{array}{c}-8,730 * * * \\
(0,344) \\
\end{array}$ & $\begin{array}{c}-8,501 * * * \\
(0,341) \\
\end{array}$ & $\begin{array}{c}-8,478 * * * \\
(0,338)\end{array}$ & $\begin{array}{c}-8,553 * * * \\
(0,340)\end{array}$ & $\begin{array}{c}-8,553 * * * \\
(0,340)\end{array}$ \\
\hline livros & & & $\begin{array}{c}2,187 * * * \\
(0,282)\end{array}$ & $\begin{array}{c}1,983 * * * \\
(0,279)\end{array}$ & $\begin{array}{c}1,891 * * * \\
(0,278) \\
\end{array}$ & $\begin{array}{c}1,640 * * * \\
(0,276)\end{array}$ & $\begin{array}{c}1,640 * * * \\
(0,276) \\
\end{array}$ \\
\hline computador & & & $\begin{array}{c}3,254 * * * \\
(0,313) \\
\end{array}$ & $\begin{array}{c}2,820 * * * \\
(0,309) \\
\end{array}$ & $\begin{array}{c}2,630 * * * \\
(0,308) \\
\end{array}$ & $\begin{array}{c}2,399 * * * \\
(0,308)\end{array}$ & $\begin{array}{c}2,399 * * * \\
(0,308) \\
\end{array}$ \\
\hline apoio aos estudos & & & $\begin{array}{c}7,815 * * * \\
(0,619) \\
\end{array}$ & $\begin{array}{c}7,477 * * * \\
(0,614) \\
\end{array}$ & $\begin{array}{c}7,429 * * * \\
(0,615)\end{array}$ & $\begin{array}{c}6,977 * * * \\
(0,620)\end{array}$ & $\begin{array}{c}6,977 * * * \\
(0,620) \\
\end{array}$ \\
\hline $\begin{array}{c}\text { mãe nunca estudou ou não } \\
\text { completou a } 4^{\mathrm{a}} \text { série }\end{array}$ & & & $\begin{array}{c}-1,816^{* * * *} \\
(0,521)\end{array}$ & $\begin{array}{c}-1,623 * * * \\
(0,523)\end{array}$ & $\begin{array}{c}-1,467 * * * \\
(0,521)\end{array}$ & $\begin{array}{c}-1,240^{* * *} \\
(0,527)\end{array}$ & $\begin{array}{c}-1,242 * * \\
(0,527)\end{array}$ \\
\hline $\begin{array}{c}\text { mãe completou a } 4^{\mathrm{a}} \text { série } \\
\text { (antigo primário), mas não } \\
\text { completou a } 8^{\mathrm{a}} \text { série }\end{array}$ & & & $\begin{array}{c}2,609 * * * \\
(0,366) \\
\end{array}$ & $\begin{array}{c}2,284 * * * * \\
(0,364)\end{array}$ & $\begin{array}{c}2,368 * * * \\
(0,364) \\
\end{array}$ & $\begin{array}{c}2,544 * * * \\
(0,373)\end{array}$ & $\begin{array}{c}2,543 * * * \\
(0,374) \\
\end{array}$ \\
\hline $\begin{array}{l}\text { mãe completou a } 8^{\mathrm{a}} \text { série } \\
\text { (antigo ginásio), mas não } \\
\text { completou o Ensino Médio }\end{array}$ & & & $\begin{array}{c}3,460 * * * \\
(0,416) \\
\end{array}$ & $\begin{array}{c}3,028 * * * \\
(0,412)\end{array}$ & $\begin{array}{c}3,094 * * * \\
(0,410)\end{array}$ & $\begin{array}{c}3,226^{* * * *} \\
(0,422)\end{array}$ & $\begin{array}{c}3,227 * * * \\
(0,422)\end{array}$ \\
\hline $\begin{array}{l}\text { mãe completou o Ensino } \\
\text { Médio (antigo } 2^{\circ} \text { grau), mas } \\
\text { não completou a Faculdade }\end{array}$ & & & $\begin{array}{c}10,596^{* * * *} \\
(0,430)\end{array}$ & $\begin{array}{c}10,003 * * * \\
(0,424)\end{array}$ & $\begin{array}{c}10,019 * * * \\
(0,425)\end{array}$ & $\begin{array}{c}10,083^{* * * *} \\
(0,429)\end{array}$ & $\begin{array}{c}10,083 * * * \\
(0,429)\end{array}$ \\
\hline tamanho da sala (11-15) & & & & $\begin{array}{l}-6,637 \\
(8,703) \\
\end{array}$ & $\begin{array}{l}-7,162 \\
(8,492) \\
\end{array}$ & $\begin{array}{l}-7,819 \\
(8,397) \\
\end{array}$ & $\begin{array}{c}-7,829 \\
(8,397) \\
\end{array}$ \\
\hline tamanho da sala (16-20) & & & & $\begin{array}{c}-8,880 * * \\
(4,522)\end{array}$ & $\begin{array}{c}-9,346^{* *} \\
(4,261) \\
\end{array}$ & $\begin{array}{c}-9,225^{* *} * \\
(4,256) \\
\end{array}$ & $\begin{array}{c}-9,223 * * \\
(4,259) \\
\end{array}$ \\
\hline tamanho da sala (21-25) & & & & $\begin{array}{c}-8,473 * * \\
(4,295) \\
\end{array}$ & $\begin{array}{c}-9,217 * * \\
(4,019) \\
\end{array}$ & $\begin{array}{c}-9,348 * * \\
(4,011) \\
\end{array}$ & $\begin{array}{c}-9,350 * * \\
(4,013) \\
\end{array}$ \\
\hline tamanho da sala (26-30) & & & & $\begin{array}{c}-5,002 \\
(4,264) \\
\end{array}$ & $\begin{array}{l}-5,666 \\
(3,971) \\
\end{array}$ & $\begin{array}{l}-5,677 \\
(3,968) \\
\end{array}$ & $\begin{array}{l}-5,679 \\
(3,971) \\
\end{array}$ \\
\hline tamanho da sala (31-35) & & & & $\begin{array}{c}-2,504 \\
(4,243) \\
\end{array}$ & $\begin{array}{l}-3,062 \\
(3,959) \\
\end{array}$ & $\begin{array}{l}-3,107 \\
(3,955)\end{array}$ & $\begin{array}{l}-3,105 \\
(3,957) \\
\end{array}$ \\
\hline tamanho da sala (36-40) & & & & $\begin{array}{c}-0,938 \\
(4,274) \\
\end{array}$ & $\begin{array}{c}-1,546 \\
(3,983) \\
\end{array}$ & $\begin{array}{l}-1,598 \\
(3,981) \\
\end{array}$ & $\begin{array}{l}-1,596 \\
(3,983) \\
\end{array}$ \\
\hline tamanho da sala (41-45) & & & & $\begin{array}{l}-1,626 \\
(5,406) \\
\end{array}$ & $\begin{array}{c}-1,623 \\
(5,312) \\
\end{array}$ & $\begin{array}{l}-1,590 \\
(5,272) \\
\end{array}$ & $\begin{array}{c}-1,612 \\
(5,274) \\
\end{array}$ \\
\hline municipal & & & & $\begin{array}{c}-7,206 * * * \\
(0,805)\end{array}$ & $\begin{array}{c}-7,020 * * * \\
(0,801) \\
\end{array}$ & $\begin{array}{c}-6,662 * * * \\
(0,851) \\
\end{array}$ & $\begin{array}{c}-6,657 * * * \\
(0,851) \\
\end{array}$ \\
\hline
\end{tabular}


Tabela A1 - A associação entre crimes contra a pessoa e notas de matemática (conclusão)

\begin{tabular}{|c|c|c|c|c|c|c|c|}
\hline Variáveis & Modelo1 & Modelo 2 & Modelo 3 & Modelo 4 & Modelo 5 & Modelo 6 & Modelo 7 \\
\hline ensino médio & & & & $\begin{array}{c}-3,186 * * * \\
(0,935)\end{array}$ & $\begin{array}{c}-2,622 * * * \\
(0,941) \\
\end{array}$ & $\begin{array}{c}-2,557 * * * \\
(0,937) \\
\end{array}$ & $\begin{array}{c}-2,563 * * * \\
(0,935) \\
\end{array}$ \\
\hline laboratório de informática & & & & $\begin{array}{l}-1,016 \\
(0,798) \\
\end{array}$ & $\begin{array}{l}-1,117 \\
(0,791) \\
\end{array}$ & $\begin{array}{l}-1,003 \\
(0,784) \\
\end{array}$ & $\begin{array}{l}-1,005 \\
(0,784) \\
\end{array}$ \\
\hline laboratório de ciências & & & & $\begin{array}{c}0,765 \\
(0,730) \\
\end{array}$ & $\begin{array}{c}0,405 \\
(0,712) \\
\end{array}$ & $\begin{array}{c}0,387 \\
(0,705) \\
\end{array}$ & $\begin{array}{c}0,389 \\
(0,704)\end{array}$ \\
\hline biblioteca & & & & $\begin{array}{c}0,257 \\
(1,315) \\
\end{array}$ & $\begin{array}{c}0,032 \\
(1,232) \\
\end{array}$ & $\begin{array}{l}-0,036 \\
(1,210) \\
\end{array}$ & $\begin{array}{l}-0,043 \\
(1,207) \\
\end{array}$ \\
\hline sala de leitura & & & & $\begin{array}{c}1,736 * * \\
(0,773) \\
\end{array}$ & $\begin{array}{l}1,387^{*} \\
(0,775) \\
\end{array}$ & $\begin{array}{c}1,242 \\
(0,767) \\
\end{array}$ & $\begin{array}{c}1,246 \\
(0,767) \\
\end{array}$ \\
\hline $\begin{array}{l}\text { uso de computadores em sala } \\
\text { de aula }\end{array}$ & & & & $\begin{array}{l}-0,770 \\
(1,288) \\
\end{array}$ & $\begin{array}{l}-0,660 \\
(1,376) \\
\end{array}$ & $\begin{array}{l}-0,435 \\
(1,364) \\
\end{array}$ & $\begin{array}{l}-0,428 \\
(1,361) \\
\end{array}$ \\
\hline programas educacionais & & & & $\begin{array}{c}1,456 \\
(1,140) \\
\end{array}$ & $\begin{array}{c}0,766 \\
(1,069)\end{array}$ & $\begin{array}{c}0,805 \\
(1,076) \\
\end{array}$ & $\begin{array}{c}0,816 \\
(1,077) \\
\end{array}$ \\
\hline distância em relação ao centro & & & & $\begin{array}{c}-0,357 * * * \\
(0,055) \\
\end{array}$ & $\begin{array}{l}-0,076 \\
(0,073)\end{array}$ & $\begin{array}{l}-0,089 \\
(0,073)\end{array}$ & $\begin{array}{l}-0,088 \\
(0,073)\end{array}$ \\
\hline corrige tarefas de matemática & & & & $\begin{array}{c}1,931 * * * \\
(0,353) \\
\end{array}$ & $\begin{array}{c}1,859 * * * \\
(0,352)\end{array}$ & $\begin{array}{c}1,635 * * * \\
(0,349) \\
\end{array}$ & $\begin{array}{c}1,635 * * * \\
(0,349) \\
\end{array}$ \\
\hline $\begin{array}{l}\text { proporção de professores com } \\
\text { ensino superior }\end{array}$ & & & & $\begin{array}{l}-0,023 \\
(0,038)\end{array}$ & $\begin{array}{l}-0,002 \\
(0,037)\end{array}$ & $\begin{array}{l}-0,009 \\
(0,037)\end{array}$ & $\begin{array}{l}-0,009 \\
(0,037)\end{array}$ \\
\hline $\begin{array}{l}\text { escolaridade média em anos } \\
\text { de estudo }\end{array}$ & & & & & $\begin{array}{c}0,504 \\
(0,470) \\
\end{array}$ & $\begin{array}{c}0,544 \\
(0,472) \\
\end{array}$ & $\begin{array}{c}0,531 \\
(0,471) \\
\end{array}$ \\
\hline índice de pobreza & & & & & $\begin{array}{c}-40,011 * * * \\
(12,198) \\
\end{array}$ & $\begin{array}{c}-38,454 * * * \\
(12,124) \\
\end{array}$ & $\begin{array}{c}-38,288 * * * \\
(12,192)\end{array}$ \\
\hline $\begin{array}{l}\text { escolaridade dos pais dos } \\
\text { colegas }\end{array}$ & & & & & & $\begin{array}{l}1,029 * * \\
(0,402)\end{array}$ & $\begin{array}{l}1,028 * * \\
(0,402)\end{array}$ \\
\hline reunião de pais & & & & & & $\begin{array}{c}5,352 * * * \\
(0,290) \\
\end{array}$ & $\begin{array}{c}5,352 * * * \\
(0,290) \\
\end{array}$ \\
\hline $\begin{array}{c}\text { taxa de livros didáticos } \\
\text { devolvidos por aluno }\end{array}$ & & & & & & $\begin{array}{c}0,080 \\
(0,060) \\
\end{array}$ & $\begin{array}{c}0,080 \\
(0,060) \\
\end{array}$ \\
\hline constante & $\begin{array}{c}170,163 * * * \\
(0,291)\end{array}$ & $\begin{array}{c}138,677 * * * \\
(1,963) \\
\end{array}$ & $\begin{array}{c}130,266^{* * * *} \\
(2,106)\end{array}$ & $\begin{array}{c}146,677 * * * \\
(5,122)\end{array}$ & $\begin{array}{c}149,455^{* * * *} \\
(7,194)\end{array}$ & $\begin{array}{c}146,897 * * * * \\
(7,179)\end{array}$ & $\begin{array}{c}146,825 * * * \\
(7,190)\end{array}$ \\
\hline $\mathrm{R}^{2}$ & 0,005 & 0,199 & 0,212 & 0,221 & 0,222 & 0,226 & 0,226 \\
\hline número de observações & 101436 & 83609 & 81857 & 81402 & 81402 & 81077 & 81077 \\
\hline
\end{tabular}

Fonte: Elaboração própria com base nos dados da SEADE, Prova Brasil 2005, Censo Escolar 2005 e Censo Demográfico 2000.

***significante a $1 \% * *$ significante a $5 \% *$ significante a $10 \%$ 
Tabela A2 - A associação entre crimes contra o patrimônio e notas de matemática (continua)

\begin{tabular}{|c|c|c|c|c|c|c|c|}
\hline Variáveis & Modelo 1 & Modelo 2 & Modelo 3 & Modelo 4 & Modelo 5 & Modelo 6 & Modelo 7 \\
\hline $\begin{array}{l}\text { Crimes contra o patrimônio } \\
\qquad(2005)\end{array}$ & $\begin{array}{c}0,001 * * * \\
(0,000)\end{array}$ & $\begin{array}{c}0,001 * * * \\
(0,000)\end{array}$ & $\begin{array}{c}0,001 * * * \\
(0,000)\end{array}$ & $\begin{array}{c}0,001 * * * \\
(0,000)\end{array}$ & $\begin{array}{l}0,000 * \\
(0,000) \\
\end{array}$ & $\begin{array}{l}0,000 * \\
(0,000) \\
\end{array}$ & \\
\hline $\begin{array}{l}\text { Crimes contra o patrimônio } \\
\text { (2004) }\end{array}$ & & & & & & & $\begin{array}{l}0,000 * \\
(0,000)\end{array}$ \\
\hline menino & & $\begin{array}{c}2,097 * * * \\
(0,277) \\
\end{array}$ & $\begin{array}{c}2,203 * * * \\
(0,278)\end{array}$ & $\begin{array}{c}2,185^{* * * *} \\
(0,276)\end{array}$ & $\begin{array}{c}2,175 * * * \\
(0,275) \\
\end{array}$ & $\begin{array}{c}2,287 * * * \\
(0,277)\end{array}$ & $\begin{array}{c}2,288 * * * \\
(0,277)\end{array}$ \\
\hline branco & & $\begin{array}{c}4,560 * * * \\
(0,307)\end{array}$ & $\begin{array}{c}4,199 * * * \\
(0,299)\end{array}$ & $\begin{array}{c}3,740 * * * \\
(0,290)\end{array}$ & $\begin{array}{c}3,699 * * * \\
(0,289)\end{array}$ & $\begin{array}{c}3,647 * * * \\
(0,290)\end{array}$ & $\begin{array}{c}3,646 * * * \\
(0,290) \\
\end{array}$ \\
\hline 8 anos & & $\begin{array}{c}-6,664 * * * \\
(2,077)\end{array}$ & $\begin{array}{c}-9,589 * * * \\
(2,170)\end{array}$ & $\begin{array}{c}-9,334 * * * \\
(2,167) \\
\end{array}$ & $\begin{array}{c}-9,354 * * * \\
-2,167 \\
\end{array}$ & $\begin{array}{c}-10,190 * * * \\
-2,178 \\
\end{array}$ & $\begin{array}{c}-10,184 * * * \\
(2,178) \\
\end{array}$ \\
\hline 9 anos & & $\begin{array}{c}8,984 * * * \\
(1,918) \\
\end{array}$ & $\begin{array}{c}7,750 * * * \\
(1,951) \\
\end{array}$ & $\begin{array}{c}7,206 * * * \\
(1,933) \\
\end{array}$ & $\begin{array}{c}7,015^{* * * *} \\
(1,927) \\
\end{array}$ & $\begin{array}{c}6,310 * * * \\
-1,932 \\
\end{array}$ & $\begin{array}{c}6,311 * * * \\
(1,933) \\
\end{array}$ \\
\hline 10 anos & & $\begin{array}{c}12,931 * * * \\
(1,741)\end{array}$ & $\begin{array}{c}11,211 * * * \\
(1,791)\end{array}$ & $\begin{array}{c}10,538 * * * \\
(1,767)\end{array}$ & $\begin{array}{c}10,368 * * * \\
(1,762)\end{array}$ & $\begin{array}{c}9,869 * * * \\
(1,770) \\
\end{array}$ & $\begin{array}{c}9,871 * * * \\
(1,770) \\
\end{array}$ \\
\hline 11 anos & & $\begin{array}{c}10,703 * * * \\
(1,722)\end{array}$ & $\begin{array}{c}9,289 * * * \\
(1,776) \\
\end{array}$ & $\begin{array}{c}8,808 * * * \\
(1,756) \\
\end{array}$ & $\begin{array}{c}8,662^{* * * *} \\
(1,752) \\
\end{array}$ & $\begin{array}{c}8,295 * * * \\
(1,760) \\
\end{array}$ & $\begin{array}{c}8,298 * * * \\
(1,760) \\
\end{array}$ \\
\hline 12 anos & & $\begin{array}{c}6,791 * * * \\
(1,767) \\
\end{array}$ & $\begin{array}{c}5,691 * * * \\
(1,820) \\
\end{array}$ & $\begin{array}{c}5,490 * * * \\
(1,803) \\
\end{array}$ & $\begin{array}{c}5,382^{* * * *} \\
(1,801) \\
\end{array}$ & $\begin{array}{c}5,192 * * * \\
(1,809)\end{array}$ & $\begin{array}{c}5,196 * * * \\
(1,810) \\
\end{array}$ \\
\hline 13 anos & & $\begin{array}{c}4,940 * * * \\
(1,837) \\
\end{array}$ & $\begin{array}{c}3,783 * * \\
(1,906) \\
\end{array}$ & $\begin{array}{c}3,707 * * \\
(1,886) \\
\end{array}$ & $\begin{array}{l}3,634 * \\
(1,882) \\
\end{array}$ & $\begin{array}{l}3,531 * \\
(1,891) \\
\end{array}$ & $\begin{array}{l}3,540 * \\
(1,891) \\
\end{array}$ \\
\hline 14 anos & & $\begin{array}{c}5,389 * * \\
(2,228) \\
\end{array}$ & $\begin{array}{c}4,847 * * \\
(2,262) \\
\end{array}$ & $\begin{array}{c}4,770 * * \\
(2,227) \\
\end{array}$ & $\begin{array}{c}4,701 * * \\
(2,222) \\
\end{array}$ & $\begin{array}{c}4,774 * * \\
(2,218) \\
\end{array}$ & $\begin{array}{c}4,769 * * \\
(2,218) \\
\end{array}$ \\
\hline reprovação & & $\begin{array}{c}-14,668 * * * \\
(0,440)\end{array}$ & $\begin{array}{c}-14,189 * * * \\
(0,435)\end{array}$ & $\begin{array}{c}-13,573 * * * \\
(0,431)\end{array}$ & $\begin{array}{c}-13,579 * * * \\
(0,431) \\
\end{array}$ & $\begin{array}{c}-13,379 * * * \\
(0,430)\end{array}$ & $\begin{array}{c}-13,379 * * * * \\
(0,430) \\
\end{array}$ \\
\hline tarefa de matemática & & $\begin{array}{c}9,875 * * * \\
(0,319) \\
\end{array}$ & $\begin{array}{c}9,235 * * * \\
(0,315) \\
\end{array}$ & $\begin{array}{c}8,409^{* * * *} \\
(0,319)\end{array}$ & $\begin{array}{c}8,418 * * * \\
(0,319) \\
\end{array}$ & $\begin{array}{c}7,712^{* * * *} \\
(0,320)\end{array}$ & $\begin{array}{c}7,713 * * * \\
(0,320)\end{array}$ \\
\hline tempo de tv & & $\begin{array}{c}0,366 \\
(0,306) \\
\end{array}$ & $\begin{array}{c}0,407 \\
(0,305) \\
\end{array}$ & $\begin{array}{c}0,343 \\
(0,302) \\
\end{array}$ & $\begin{array}{c}0,329 \\
(0,302) \\
\end{array}$ & $\begin{array}{c}0,379 \\
(0,301) \\
\end{array}$ & $\begin{array}{c}0,379 \\
(0,301) \\
\end{array}$ \\
\hline abandono & & $\begin{array}{c}-10,409 * * * \\
(0,494)\end{array}$ & $\begin{array}{c}-9,980 * * * \\
(0,503)\end{array}$ & $\begin{array}{c}-9,726 * * * \\
(0,503) \\
\end{array}$ & $\begin{array}{c}-9,706^{* * * *} \\
(0,503) \\
\end{array}$ & $\begin{array}{c}-9,196 * * * \\
(0,505) \\
\end{array}$ & $\begin{array}{c}-9,195 * * * \\
(0,505) \\
\end{array}$ \\
\hline trabalha fora de casa & & $\begin{array}{c}-10,712 * * * \\
(0,391)\end{array}$ & $\begin{array}{c}-10,860 * * * \\
(0,402)\end{array}$ & $\begin{array}{c}-10,684 * * * \\
(0,401)\end{array}$ & $\begin{array}{c}-10,614 * * * \\
(0,401)\end{array}$ & $\begin{array}{c}-10,401 * * * \\
(0,398) \\
\end{array}$ & $\begin{array}{c}-10,402 * * * \\
(0,398) \\
\end{array}$ \\
\hline trabalhos domésticos & & $\begin{array}{c}3,234 * * * \\
(0,291) \\
\end{array}$ & $\begin{array}{c}3,234 * * * \\
(0,292) \\
\end{array}$ & $\begin{array}{c}3,116 * * * \\
(0,287) \\
\end{array}$ & $\begin{array}{c}3,076^{* * * *} \\
(0,287) \\
\end{array}$ & $\begin{array}{c}2,918 * * * \\
(0,286)\end{array}$ & $\begin{array}{c}2,917 * * * \\
(0,286)\end{array}$ \\
\hline maternal & & $\begin{array}{c}11,671 * * * \\
(0,398) \\
\end{array}$ & $\begin{array}{c}10,276^{* * * *} \\
(0,392) \\
\end{array}$ & $\begin{array}{c}9,828 * * * \\
(0,382) \\
\end{array}$ & $\begin{array}{c}9,698 * * * \\
(0,382) \\
\end{array}$ & $\begin{array}{c}9,316^{* * * *} \\
(0,383) \\
\end{array}$ & $\begin{array}{c}9,314 * * * \\
(0,383) \\
\end{array}$ \\
\hline pré-escola & & $\begin{array}{c}10,904 * * * \\
(0,345) \\
\end{array}$ & $\begin{array}{c}10,124 * * * \\
(0,345) \\
\end{array}$ & $\begin{array}{c}10,103 * * * \\
(0,348)\end{array}$ & $\begin{array}{c}10,046 * * * \\
(0,349)\end{array}$ & $\begin{array}{c}9,715 * * * \\
(0,348) \\
\end{array}$ & $\begin{array}{c}9,714 * * * \\
(0,348) \\
\end{array}$ \\
\hline estudou na mesma escola & & $\begin{array}{l}-0,104 \\
(0,287)\end{array}$ & $\begin{array}{l}-0,145 \\
(0,288)\end{array}$ & $\begin{array}{l}-0,229 \\
(0,284)\end{array}$ & $\begin{array}{l}-0,190 \\
(0,282)\end{array}$ & $\begin{array}{l}-0,345 \\
(0,283)\end{array}$ & $\begin{array}{l}-0,344 \\
(0,283) \\
\end{array}$ \\
\hline mora com pai ou mãe & & $\begin{array}{c}-1,279 * * * \\
(0,312)\end{array}$ & $\begin{array}{c}-1,014 * * * \\
(0,315) \\
\end{array}$ & $\begin{array}{c}-1,058 * * * \\
(0,313) \\
\end{array}$ & $\begin{array}{c}-1,070 * * * \\
(0,314)\end{array}$ & $\begin{array}{c}-0,643 * * \\
(0,317) \\
\end{array}$ & $\begin{array}{c}-0,642 * * \\
(0,317) \\
\end{array}$ \\
\hline $\begin{array}{c}\text { mora sozinho ou com mais } \\
\text { uma pessoa }\end{array}$ & & $\begin{array}{c}7,508 * * * \\
(0,900) \\
\end{array}$ & $\begin{array}{c}7,458 * * * \\
(0,915) \\
\end{array}$ & $\begin{array}{c}7,401 * * * \\
(0,907)\end{array}$ & $\begin{array}{c}7,355^{* * * *} \\
(0,903) \\
\end{array}$ & $\begin{array}{c}6,944 * * * \\
(0,900)\end{array}$ & $\begin{array}{c}6,941 * * * \\
(0,900) \\
\end{array}$ \\
\hline mora com mais duas pessoas & & $\begin{array}{c}13,561 * * * \\
(0,616)\end{array}$ & $\begin{array}{c}13,161 * * * \\
(0,609)\end{array}$ & $\begin{array}{c}12,843 * * * \\
(0,608)\end{array}$ & $\begin{array}{c}12,780 * * * \\
(0,605)\end{array}$ & $\begin{array}{c}12,534 * * * \\
(0,604)\end{array}$ & $\begin{array}{c}12,531 * * * \\
(0,604)\end{array}$ \\
\hline mora com mais três pessoas & & $\begin{array}{c}13,397 * * * \\
(0,589)\end{array}$ & $\begin{array}{c}12,821 * * * \\
(0,588)\end{array}$ & $\begin{array}{c}12,603 * * * \\
(0,579)\end{array}$ & $\begin{array}{c}12,553 * * * \\
(0,579)\end{array}$ & $\begin{array}{c}12,283 * * * \\
(0,576)\end{array}$ & $\begin{array}{c}12,283^{* * *} \\
(0,576) \\
\end{array}$ \\
\hline
\end{tabular}


Tabela A2 - A associação entre crimes contra o patrimônio e notas de matemática (continuação)

\begin{tabular}{|c|c|c|c|c|c|c|c|}
\hline Variáveis & Modelo 1 & Modelo 2 & Modelo 3 & Modelo 4 & Modelo 5 & Modelo 6 & Modelo 7 \\
\hline $\begin{array}{c}\text { mora com mais quatro ou cince } \\
\text { pessoas }\end{array}$ & & $\begin{array}{c}5,563 * * * \\
(0,524) \\
\end{array}$ & $\begin{array}{c}5,339 * * * \\
(0,523)\end{array}$ & $\begin{array}{c}5,109 * * * \\
(0,516)\end{array}$ & $\begin{array}{c}5,067 * * * \\
(0,515)\end{array}$ & $\begin{array}{c}4,909^{* * * *} \\
(0,512)\end{array}$ & $\begin{array}{c}4,908 * * * \\
(0,512)\end{array}$ \\
\hline $\begin{array}{l}\text { mora com mais seis a oito } \\
\text { pessoas }\end{array}$ & & $\begin{array}{c}2,816^{* * * *} \\
(0,562) \\
\end{array}$ & $\begin{array}{c}2,695 * * * \\
(0,558)\end{array}$ & $\begin{array}{c}2,630 * * * \\
(0,551)\end{array}$ & $\begin{array}{c}2,612 * * * \\
(0,551)\end{array}$ & $\begin{array}{c}2,578 * * * \\
(0,552)\end{array}$ & $\begin{array}{c}2,580 * * * \\
(0,552) \\
\end{array}$ \\
\hline futuro (ainda não sei) & & $\begin{array}{c}5,795 * * * \\
(0,432) \\
\end{array}$ & $\begin{array}{c}6,268 * * * \\
(0,441) \\
\end{array}$ & $\begin{array}{c}5,980 * * * \\
(0,437)\end{array}$ & $\begin{array}{c}5,939 * * * \\
(0,436)\end{array}$ & $\begin{array}{c}5,903 * * * \\
(0,441)\end{array}$ & $\begin{array}{c}5,903 * * * \\
(0,441) \\
\end{array}$ \\
\hline futuro (estudar) & & $\begin{array}{c}5,586 * * * \\
(0,508) \\
\end{array}$ & $\begin{array}{c}5,064 * * * \\
(0,506) \\
\end{array}$ & $\begin{array}{c}4,671^{* * * *} \\
(0,498)\end{array}$ & $\begin{array}{c}4,613 * * * \\
(0,498)\end{array}$ & $\begin{array}{c}4,215^{* * * *} \\
(0,499)\end{array}$ & $\begin{array}{c}4,215 * * * \\
(0,499) \\
\end{array}$ \\
\hline futuro (estudar e trabalhar) & & $\begin{array}{c}11,954 * * * \\
(0,450)\end{array}$ & $\begin{array}{c}11,281 * * * \\
(0,453)\end{array}$ & $\begin{array}{c}11,026 * * * \\
(0,450)\end{array}$ & $\begin{array}{c}10,969 * * * \\
(0,448)\end{array}$ & $\begin{array}{c}10,672 * * * \\
(0,450)\end{array}$ & $\begin{array}{c}10,673 * * * \\
(0,450)\end{array}$ \\
\hline deixado de lado & & $\begin{array}{c}-12,323 * * * \\
(0,361) \\
\end{array}$ & $\begin{array}{c}-12,099 * * * \\
(0,361) \\
\end{array}$ & $\begin{array}{c}-11,867 * * * \\
(0,358) \\
\end{array}$ & $\begin{array}{c}-11,828 * * * \\
(0,358)\end{array}$ & $\begin{array}{c}-11,763 * * * \\
(0,358)\end{array}$ & $\begin{array}{c}-11,762 * * * \\
(0,358) \\
\end{array}$ \\
\hline bolsa família & & $\begin{array}{c}-9,010 * * * \\
(0,346)\end{array}$ & $\begin{array}{c}-8,666^{* * * *} \\
(0,344) \\
\end{array}$ & $\begin{array}{c}-8,467 * * * \\
(0,341) \\
\end{array}$ & $\begin{array}{c}-8,469 * * * \\
(0,338)\end{array}$ & $\begin{array}{c}-8,544 * * * \\
(0,340) \\
\end{array}$ & $\begin{array}{c}-8,545 * * * \\
(0,340) \\
\end{array}$ \\
\hline livros & & & $\begin{array}{c}2,146 * * * \\
(0,283) \\
\end{array}$ & $\begin{array}{c}1,949 * * * \\
(0,280)\end{array}$ & $\begin{array}{c}1,888 * * * \\
(0,278) \\
\end{array}$ & $\begin{array}{c}1,640 * * * \\
(0,276)\end{array}$ & $\begin{array}{c}1,639 * * * \\
(0,276) \\
\end{array}$ \\
\hline computador & & & $\begin{array}{c}3,066^{* * * *} \\
(0,315) \\
\end{array}$ & $\begin{array}{c}2,727 * * * \\
(0,307) \\
\end{array}$ & $\begin{array}{c}2,612 * * * \\
(0,306) \\
\end{array}$ & $\begin{array}{c}2,385 * * * \\
(0,307)\end{array}$ & $\begin{array}{c}2,383 * * * \\
(0,306)\end{array}$ \\
\hline apoio aos estudos & & & $\begin{array}{c}7,793 * * * \\
(0,618)\end{array}$ & $\begin{array}{c}7,469 * * * \\
(0,613) \\
\end{array}$ & $\begin{array}{c}7,431 * * * \\
(0,614)\end{array}$ & $\begin{array}{c}6,980 * * * \\
(0,620)\end{array}$ & $\begin{array}{c}6,978 * * * \\
(0,620) \\
\end{array}$ \\
\hline $\begin{array}{l}\text { mãe nunca estudou ou não } \\
\text { completou a } 4^{\mathrm{a}} \text { série }\end{array}$ & & & $\begin{array}{c}-1,704 * * * \\
(0,520)\end{array}$ & $\begin{array}{c}-1,586 * * * \\
(0,521) \\
\end{array}$ & $\begin{array}{c}-1,474 * * * \\
(0,521)\end{array}$ & $\begin{array}{c}-1,252 * * \\
(0,527)\end{array}$ & $\begin{array}{c}-1,251 * * \\
(0,527) \\
\end{array}$ \\
\hline $\begin{array}{l}\text { mãe completou a } 4^{\mathrm{a}} \text { série } \\
\text { (antigo primário), mas não } \\
\text { completou a } 8^{\mathrm{a}} \text { série }\end{array}$ & & & $\begin{array}{c}2,682 * * * \\
(0,364)\end{array}$ & $\begin{array}{c}2,321 * * * \\
(0,362)\end{array}$ & $\begin{array}{c}2,379 * * * \\
(0,363)\end{array}$ & $\begin{array}{c}2,549 * * * \\
(0,373)\end{array}$ & $\begin{array}{c}2,551 * * * \\
(0,373) \\
\end{array}$ \\
\hline $\begin{array}{l}\text { mãe completou a } 8^{\mathrm{a}} \text { série } \\
\text { (antigo ginásio), mas não } \\
\text { completou o Ensino Médio }\end{array}$ & & & $\begin{array}{c}3,486^{* * * *} \\
(0,416) \\
\end{array}$ & $\begin{array}{c}3,058 * * * \\
(0,412) \\
\end{array}$ & $\begin{array}{c}3,107 * * * \\
(0,410) \\
\end{array}$ & $\begin{array}{c}3,233 * * * \\
(0,422) \\
\end{array}$ & $\begin{array}{c}3,234 * * * \\
(0,422) \\
\end{array}$ \\
\hline $\begin{array}{c}\text { mãe completou o Ensino Médi } \\
\text { (antigo } 2^{\circ} \text { grau), mas não } \\
\text { completou a Faculdade }\end{array}$ & & & $\begin{array}{c}10,581 * * * \\
(0,429)\end{array}$ & $\begin{array}{c}10,005 * * * \\
(0,424)\end{array}$ & $\begin{array}{c}10,020 * * * \\
(0,424)\end{array}$ & $\begin{array}{c}10,080 * * * \\
(0,429)\end{array}$ & $\begin{array}{c}10,082 * * * \\
(0,429) \\
\end{array}$ \\
\hline tamanho da sala (11-15) & & & & $\begin{array}{l}-6,806 \\
(8,606) \\
\end{array}$ & $\begin{array}{c}-7,308 \\
(8,502) \\
\end{array}$ & $\begin{array}{l}-7,969 \\
(8,405) \\
\end{array}$ & $\begin{array}{c}-7,995 \\
(8,402) \\
\end{array}$ \\
\hline tamanho da sala (16-20) & & & & $\begin{array}{c}-8,874 * * \\
(4,440) \\
\end{array}$ & $\begin{array}{c}-9,317 * * \\
(4,286)\end{array}$ & $\begin{array}{c}-9,195 * * \\
(4,282) \\
\end{array}$ & $\begin{array}{c}-9,210 * * \\
(4,280)\end{array}$ \\
\hline tamanho da sala $(21-25)$ & & & & $\begin{array}{c}-8,575^{* *} \\
(4,202) \\
\end{array}$ & $\begin{array}{c}-9,241 * * \\
(4,038)\end{array}$ & $\begin{array}{c}-9,370 * * \\
(4,032)\end{array}$ & $\begin{array}{c}-9,383 * * \\
(4,030) \\
\end{array}$ \\
\hline tamanho da sala (26-30) & & & & $\begin{array}{l}-5,097 \\
(4,166) \\
\end{array}$ & $\begin{array}{l}-5,685 \\
(3,992) \\
\end{array}$ & $\begin{array}{l}-5,693 \\
(3,990) \\
\end{array}$ & $\begin{array}{c}-5,714 \\
(3,988) \\
\end{array}$ \\
\hline tamanho da sala (31-35) & & & & $\begin{array}{l}-2,504 \\
(4,150)\end{array}$ & $\begin{array}{l}-3,026 \\
(3,980) \\
\end{array}$ & $\begin{array}{l}-3,070 \\
(3,977)\end{array}$ & $\begin{array}{l}-3,081 \\
(3,974) \\
\end{array}$ \\
\hline tamanho da sala (36-40) & & & & $\begin{array}{c}-0,962 \\
(4,183) \\
\end{array}$ & $\begin{array}{l}-1,507 \\
(4,007) \\
\end{array}$ & $\begin{array}{l}-1,559 \\
(4,005)\end{array}$ & $\begin{array}{l}-1,568 \\
(4,002) \\
\end{array}$ \\
\hline tamanho da sala (41-45) & & & & $\begin{array}{l}-1,579 \\
(5,359) \\
\end{array}$ & $\begin{array}{l}-1,689 \\
(5,329) \\
\end{array}$ & $\begin{array}{l}-1,647 \\
(5,289) \\
\end{array}$ & $\begin{array}{l}-1,689 \\
(5,291) \\
\end{array}$ \\
\hline municipal & & & & $\begin{array}{c}-6,988 * * * \\
(0,803)\end{array}$ & $\begin{array}{c}-6,950 * * * \\
(0,799) \\
\end{array}$ & $\begin{array}{c}-6,587 * * * * \\
(0,847)\end{array}$ & $\begin{array}{c}-6,580 * * * \\
(0,847) \\
\end{array}$ \\
\hline ensino médio & & & & $\begin{array}{c}-2,938 * * * \\
(0,924)\end{array}$ & $\begin{array}{c}-2,653 * * * \\
(0,933) \\
\end{array}$ & $\begin{array}{c}-2,585 * * * \\
(0,929) \\
\end{array}$ & $\begin{array}{c}-2,574 * * * \\
(0,927)\end{array}$ \\
\hline
\end{tabular}


Tabela A2 - A associação entre crimes contra o patrimônio e notas de matemática (conclusão)

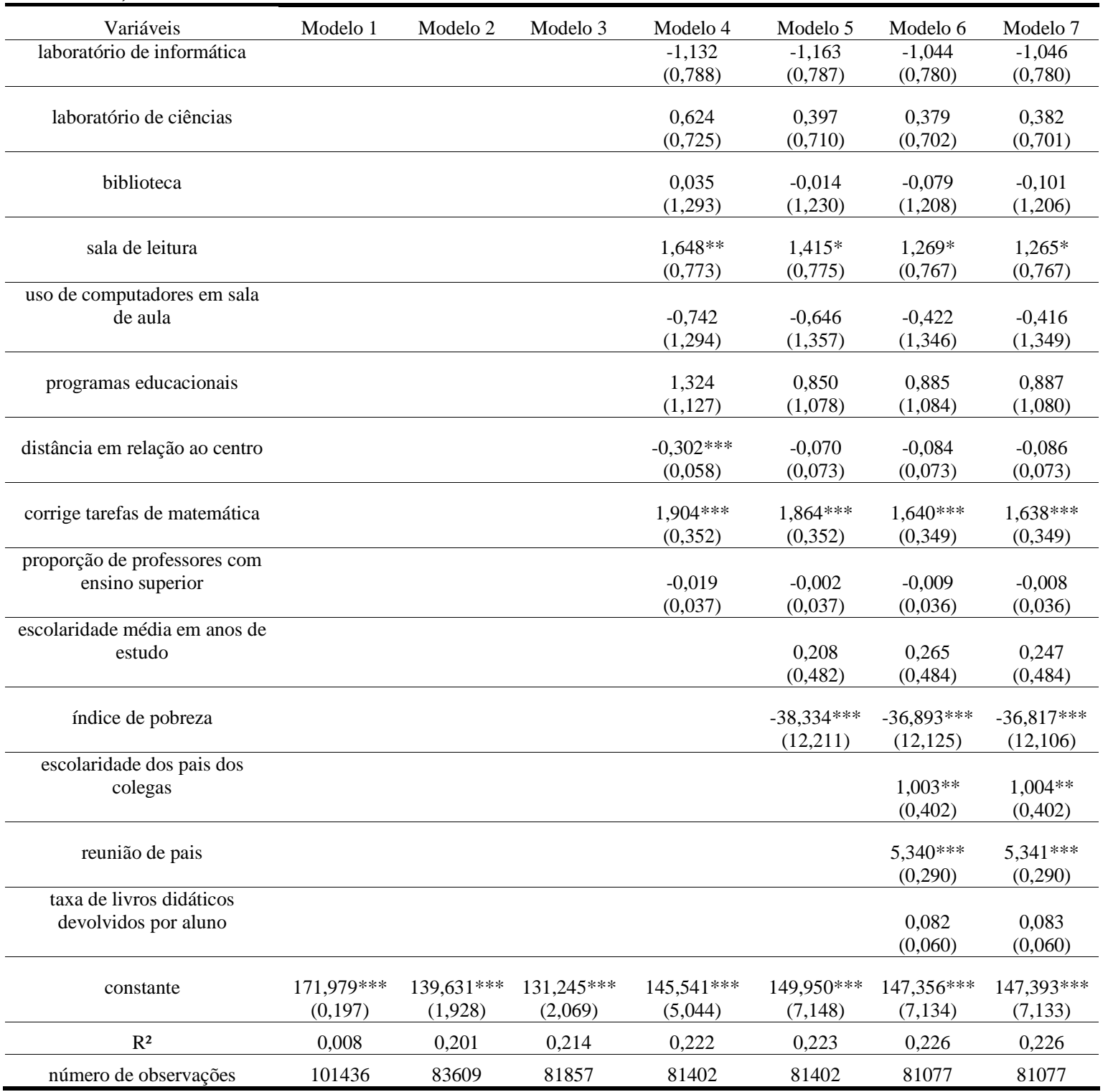

Fonte: Elaboração própria com base nos dados da SEADE, Prova Brasil 2005, Censo Escolar 2005 e Censo Demográfico 2000.

$* * *$ significante a $1 \% * *$ significante a $5 \% *$ significante a $10 \%$ 
Tabela A3 - A associação entre crimes violentos e notas de matemática (continua)

\begin{tabular}{|c|c|c|c|c|c|c|c|}
\hline Variáveis & Modelo 1 & Modelo 2 & Modelo 3 & Modelo 4 & Modelo 5 & Modelo 6 & Modelo 7 \\
\hline Crimes violentos (2005) & $\begin{array}{c}0,004 * * * \\
(0,000)\end{array}$ & $\begin{array}{c}0,003 * * * \\
(0,000) \\
\end{array}$ & $\begin{array}{c}0,003 * * * \\
(0,000)\end{array}$ & $\begin{array}{c}0,002 * * * \\
(0,000)\end{array}$ & $\begin{array}{c}0,001 * * \\
(0,000)\end{array}$ & $\begin{array}{c}0,001 * * \\
(0,000)\end{array}$ & \\
\hline Crimes violentos (2004) & & & & & & & $\begin{array}{c}0,001 * * \\
(0,000)\end{array}$ \\
\hline menino & & $\begin{array}{c}2,095 * * * \\
(0,277) \\
\end{array}$ & $\begin{array}{c}2,202 * * * \\
(0,278) \\
\end{array}$ & $\begin{array}{c}2,184 * * * \\
(0,276) \\
\end{array}$ & $\begin{array}{c}2,174 * * * \\
(0,275)\end{array}$ & $\begin{array}{c}2,286^{* * * *} \\
(0,277)\end{array}$ & $\begin{array}{c}2,290 * * * \\
(0,277)\end{array}$ \\
\hline branco & & $\begin{array}{c}4,589 * * * \\
(0,304)\end{array}$ & $\begin{array}{c}4,224 * * * \\
(0,297) \\
\end{array}$ & $\begin{array}{c}3,749 * * * \\
(0,290) \\
\end{array}$ & $\begin{array}{c}3,703 * * * \\
(0,289) \\
\end{array}$ & $\begin{array}{c}3,651 * * * * \\
(0,290)\end{array}$ & $\begin{array}{c}3,648 * * * \\
(0,290)\end{array}$ \\
\hline 8 anos & & $\begin{array}{c}-6,708^{* * * *} \\
(2,082) \\
\end{array}$ & $\begin{array}{c}-9,605 * * * \\
(2,176) \\
\end{array}$ & $\begin{array}{c}-9,330 * * * \\
(2,170)\end{array}$ & $\begin{array}{c}-9,351 * * * \\
(2,168) \\
\end{array}$ & $\begin{array}{c}-10,187^{* * * *} \\
(2,180) \\
\end{array}$ & $\begin{array}{c}-10,172 * * * \\
(2,180) \\
\end{array}$ \\
\hline 9 anos & & $\begin{array}{c}8,936 * * * \\
(1,917) \\
\end{array}$ & $\begin{array}{c}7,730 * * * \\
(1,954) \\
\end{array}$ & $\begin{array}{c}7,196^{* * * *} \\
(1,934) \\
\end{array}$ & $\begin{array}{c}7,012^{* * * *} \\
(1,928)\end{array}$ & $\begin{array}{c}6,308^{* * * *} \\
(1,933)\end{array}$ & $\begin{array}{c}6,310 * * * \\
(1,934)\end{array}$ \\
\hline 10 anos & & $\begin{array}{c}12,903 * * * \\
(1,740)\end{array}$ & $\begin{array}{c}11,212^{* * * *} \\
(1,794)\end{array}$ & $\begin{array}{c}10,537 * * * \\
(1,768)\end{array}$ & $\begin{array}{c}10,370 * * * \\
(1,763)\end{array}$ & $\begin{array}{c}9,872 * * * \\
(1,771)\end{array}$ & $\begin{array}{c}9,871 * * * \\
(1,771)\end{array}$ \\
\hline 11 anos & & $\begin{array}{c}10,639 * * * \\
(1,722)\end{array}$ & $\begin{array}{c}9,258 * * * \\
(1,780) \\
\end{array}$ & $\begin{array}{c}8,790 * * * \\
(1,758) \\
\end{array}$ & $\begin{array}{c}8,656^{* * * *} \\
(1,753) \\
\end{array}$ & $\begin{array}{c}8,289 * * * \\
(1,761) \\
\end{array}$ & $\begin{array}{c}8,295 * * * \\
(1,761) \\
\end{array}$ \\
\hline 12 anos & & $\begin{array}{c}6,719 * * * \\
(1,768) \\
\end{array}$ & $\begin{array}{c}5,654 * * * \\
(1,824) \\
\end{array}$ & $\begin{array}{c}5,471 * * * \\
(1,805) \\
\end{array}$ & $\begin{array}{c}5,375^{* * * *} \\
(1,802) \\
\end{array}$ & $\begin{array}{c}5,186^{* * * *} \\
(1,811) \\
\end{array}$ & $\begin{array}{c}5,193 * * * \\
(1,811) \\
\end{array}$ \\
\hline 13 anos & & $\begin{array}{c}4,857 \text { *** } \\
(1,836) \\
\end{array}$ & $\begin{array}{l}3,730 * \\
(1,908) \\
\end{array}$ & $\begin{array}{l}3,679 * \\
(1,887) \\
\end{array}$ & $\begin{array}{l}3,620^{*} \\
(1,883)\end{array}$ & $\begin{array}{l}3,518^{*} \\
(1,892) \\
\end{array}$ & $\begin{array}{l}3,532 * \\
(1,892)\end{array}$ \\
\hline 14 anos & & $\begin{array}{c}5,335^{* * *} \\
(2,224) \\
\end{array}$ & $\begin{array}{c}4,822 * * \\
(2,262) \\
\end{array}$ & $\begin{array}{c}4,753 * * \\
(2,228) \\
\end{array}$ & $\begin{array}{c}4,696 * * \\
(2,222) \\
\end{array}$ & $\begin{array}{c}4,769 * * \\
(2,218) \\
\end{array}$ & $\begin{array}{c}4,758 * * \\
(2,217) \\
\end{array}$ \\
\hline reprovação & & $\begin{array}{c}-14,656^{* * * *} \\
(0,440)\end{array}$ & $\begin{array}{c}-14,177 * * * \\
(0,435) \\
\end{array}$ & $\begin{array}{c}-13,562 * * * \\
(0,431)\end{array}$ & $\begin{array}{c}-13,574 * * * \\
(0,431) \\
\end{array}$ & $\begin{array}{c}-13,374 * * * \\
(0,430) \\
\end{array}$ & $\begin{array}{c}-13,372 * * * \\
(0,430) \\
\end{array}$ \\
\hline tarefa de matemática & & $\begin{array}{c}9,898 * * * \\
(0,320) \\
\end{array}$ & $\begin{array}{c}9,256 * * * \\
(0,316) \\
\end{array}$ & $\begin{array}{c}8,422 * * * \\
(0,319) \\
\end{array}$ & $\begin{array}{c}8,425 * * * \\
(0,319) \\
\end{array}$ & $\begin{array}{c}7,718^{* * * *} \\
(0,320)\end{array}$ & $\begin{array}{c}7,726^{* * * *} \\
(0,320) \\
\end{array}$ \\
\hline tempo de tv & & $\begin{array}{c}0,364 \\
(0,306) \\
\end{array}$ & $\begin{array}{c}0,404 \\
(0,305) \\
\end{array}$ & $\begin{array}{c}0,340 \\
(0,301) \\
\end{array}$ & $\begin{array}{c}0,328 \\
(0,302) \\
\end{array}$ & $\begin{array}{c}0,377 \\
(0,301) \\
\end{array}$ & $\begin{array}{c}0,379 \\
(0,301) \\
\end{array}$ \\
\hline abandono & & $\begin{array}{c}-10,408 * * * \\
(0,495)\end{array}$ & $\begin{array}{c}-9,982 * * * \\
(0,504)\end{array}$ & $\begin{array}{c}-9,726 * * * \\
(0,503) \\
\end{array}$ & $\begin{array}{c}-9,705 * * * \\
(0,504)\end{array}$ & $\begin{array}{c}-9,196 * * * \\
(0,505)\end{array}$ & $\begin{array}{c}-9,195 * * * \\
(0,505) \\
\end{array}$ \\
\hline trabalha fora de casa & & $\begin{array}{c}-10,702^{* * * *} \\
(0,390)\end{array}$ & $\begin{array}{c}-10,850 * * * \\
(0,401)\end{array}$ & $\begin{array}{c}-10,679 * * * \\
(0,401)\end{array}$ & $\begin{array}{c}-10,612 * * * \\
(0,400)\end{array}$ & $\begin{array}{c}-10,399 * * * \\
(0,398)\end{array}$ & $\begin{array}{c}-10,400 * * * \\
(0,398)\end{array}$ \\
\hline trabalhos domésticos & & $\begin{array}{c}3,245 \text { **** } \\
(0,290)\end{array}$ & $\begin{array}{c}3,242 * * * \\
(0,291)\end{array}$ & $\begin{array}{c}3,117 * * * \\
(0,287)\end{array}$ & $\begin{array}{c}3,078 * * * \\
(0,287)\end{array}$ & $\begin{array}{c}2,919 * * * \\
(0,286)\end{array}$ & $\begin{array}{c}2,916 * * * \\
(0,286)\end{array}$ \\
\hline maternal & & $\begin{array}{c}11,707 * * * \\
(0,393)\end{array}$ & $\begin{array}{c}10,303 * * * \\
(0,388)\end{array}$ & $\begin{array}{c}9,838 * * * \\
(0,382) \\
\end{array}$ & $\begin{array}{c}9,704 * * * * \\
(0,382)\end{array}$ & $\begin{array}{c}9,322 * * * \\
(0,383)\end{array}$ & $\begin{array}{c}9,318 * * * \\
(0,383)\end{array}$ \\
\hline pré-escola & & $\begin{array}{c}10,916^{* * * *} \\
(0,346)\end{array}$ & $\begin{array}{c}10,135 * * * \\
(0,345)\end{array}$ & $\begin{array}{c}10,113 * * * \\
(0,348)\end{array}$ & $\begin{array}{c}10,052 * * * \\
(0,349)\end{array}$ & $\begin{array}{c}9,720 * * * \\
(0,348)\end{array}$ & $\begin{array}{c}9,720 * * * \\
(0,348) \\
\end{array}$ \\
\hline estudou na mesma escola & & $\begin{array}{c}-0,139 \\
(0,288) \\
\end{array}$ & $\begin{array}{c}-0,178 \\
(0,288) \\
\end{array}$ & $\begin{array}{l}-0,247 \\
(0,284)\end{array}$ & $\begin{array}{l}-0,200 \\
(0,282)\end{array}$ & $\begin{array}{l}-0,354 \\
(0,284)\end{array}$ & $\begin{array}{l}-0,353 \\
(0,283) \\
\end{array}$ \\
\hline mora com pai ou mãe & & $\begin{array}{c}-1,277 * * * \\
(0,312)\end{array}$ & $\begin{array}{c}-1,011 * * * \\
(0,315)\end{array}$ & $\begin{array}{c}-1,058 * * * \\
(0,314)\end{array}$ & $\begin{array}{c}-1,070 * * * \\
(0,314)\end{array}$ & $\begin{array}{c}-0,643^{* *} \\
(0,317)\end{array}$ & $\begin{array}{c}-0,641^{* *} \\
(0,317) \\
\end{array}$ \\
\hline $\begin{array}{c}\text { mora sozinho ou com mais } \\
\text { uma pessoa }\end{array}$ & & $\begin{array}{c}7,510 * * * \\
(0,900) \\
\end{array}$ & $\begin{array}{c}7,456 * * * \\
(0,915) \\
\end{array}$ & $\begin{array}{c}7,398 * * * \\
(0,907) \\
\end{array}$ & $\begin{array}{c}7,355 * * * \\
(0,903) \\
\end{array}$ & $\begin{array}{c}6,945^{* * * *} \\
(0,901) \\
\end{array}$ & $\begin{array}{c}6,936 * * * \\
(0,900) \\
\end{array}$ \\
\hline mora com mais duas pessoas & & $\begin{array}{c}13,568 * * * \\
(0,616) \\
\end{array}$ & $\begin{array}{c}13,164 * * * \\
(0,609)\end{array}$ & $\begin{array}{c}12,841 * * * \\
(0,608)\end{array}$ & $\begin{array}{c}12,781 * * * \\
(0,605)\end{array}$ & $\begin{array}{c}12,535 * * * \\
(0,603)\end{array}$ & $\begin{array}{c}12,525 * * * \\
(0,603)\end{array}$ \\
\hline mora com mais três pessoas & & $\begin{array}{c}13,376^{* * * *} \\
(0,589)\end{array}$ & $\begin{array}{c}12,800 * * * \\
(0,588)\end{array}$ & $\begin{array}{c}12,589 * * * \\
(0,579)\end{array}$ & $\begin{array}{c}12,546^{* * * *} \\
(0,578)\end{array}$ & $\begin{array}{c}12,277 * * * \\
(0,576)\end{array}$ & $\begin{array}{c}12,276^{* * * *} \\
(0,576)\end{array}$ \\
\hline $\begin{array}{c}\text { mora com mais quatro ou cinco } \\
\text { pessoas }\end{array}$ & & $\begin{array}{c}5,543 * * * \\
(0,524)\end{array}$ & $\begin{array}{c}5,320 * * * \\
(0,523)\end{array}$ & $\begin{array}{c}5,098 * * * \\
(0,516)\end{array}$ & $\begin{array}{c}5,062 * * * \\
(0,515)\end{array}$ & $\begin{array}{c}4,905 * * * \\
(0,512)\end{array}$ & $\begin{array}{l}4,902 * * * \\
(0,512)\end{array}$ \\
\hline
\end{tabular}


Tabela A3 - A associação entre crimes violentos e notas de matemática (continuação)

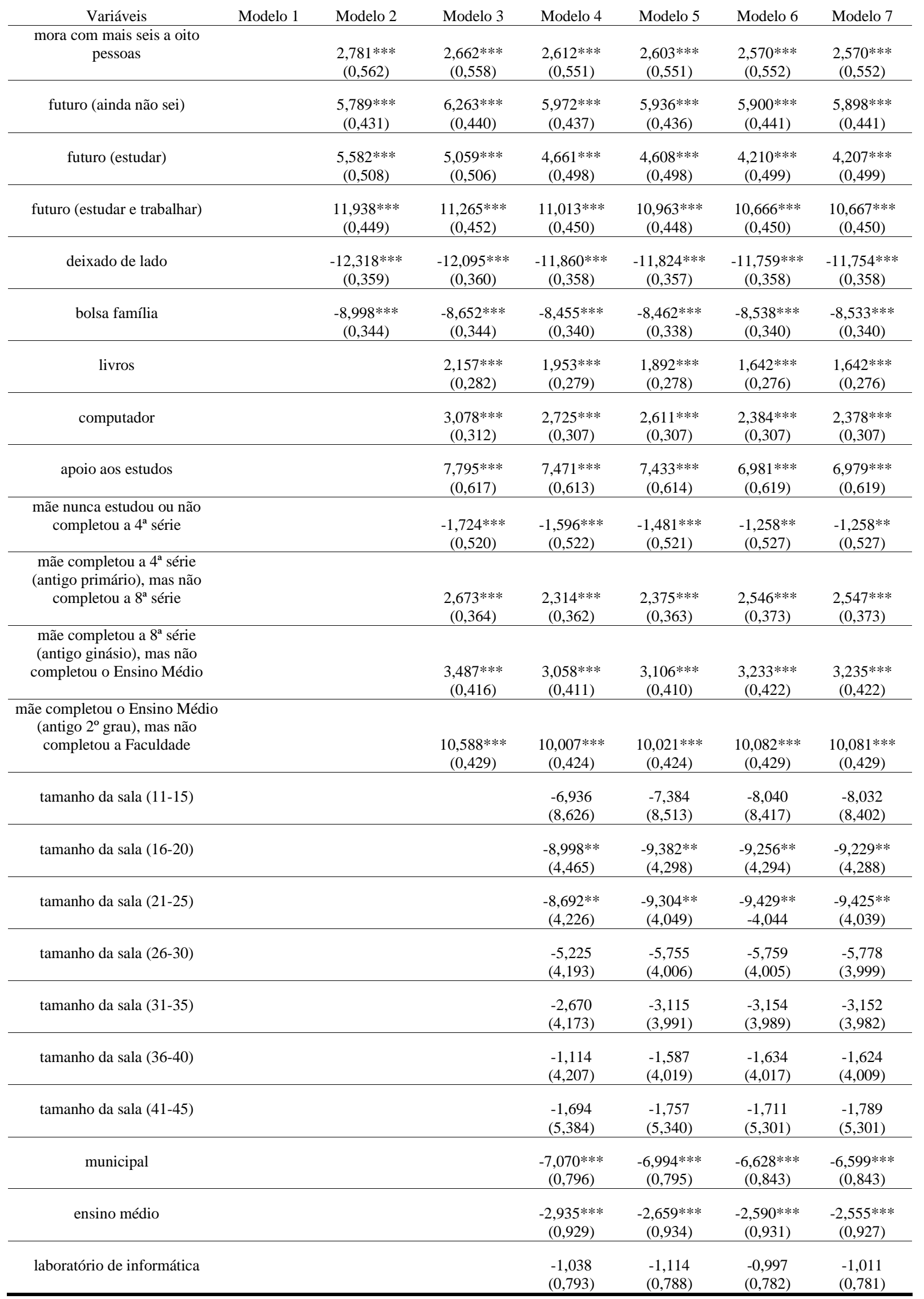


Tabela A3 - A associação entre crimes violentos e notas de matemática (conclusão)

\begin{tabular}{|c|c|c|c|c|c|c|c|}
\hline Variáveis & Modelo 1 & Modelo 2 & Modelo 3 & Modelo 4 & Modelo 5 & Modelo 6 & Modelo 7 \\
\hline laboratório de ciências & & & & $\begin{array}{c}0,553 \\
(0,727) \\
\end{array}$ & $\begin{array}{c}0,361 \\
(0,712) \\
\end{array}$ & $\begin{array}{c}0,345 \\
(0,705) \\
\end{array}$ & $\begin{array}{c}0,327 \\
(0,703) \\
\end{array}$ \\
\hline biblioteca & & & & $\begin{array}{c}0,087 \\
(1,295) \\
\end{array}$ & $\begin{array}{c}0,016 \\
(1,234)\end{array}$ & $\begin{array}{l}-0,051 \\
(1,213)\end{array}$ & $\begin{array}{l}-0,087 \\
(1,210)\end{array}$ \\
\hline sala de leitura & & & & $\begin{array}{l}1,613 * * \\
(0,771)\end{array}$ & $\begin{array}{l}1,399 * \\
(0,775)\end{array}$ & $\begin{array}{c}1,254 \\
(0,767) \\
\end{array}$ & $\begin{array}{c}1,244 \\
(0,766) \\
\end{array}$ \\
\hline $\begin{array}{l}\text { uso de computadores em sala } \\
\text { de aula }\end{array}$ & & & & $\begin{array}{l}-0,724 \\
(1,287) \\
\end{array}$ & $\begin{array}{l}-0,636 \\
(1,350) \\
\end{array}$ & $\begin{array}{l}-0,413 \\
(1,340) \\
\end{array}$ & $\begin{array}{l}-0,407 \\
(1,340) \\
\end{array}$ \\
\hline programas educacionais & & & & $\begin{array}{c}1,234 \\
(1,130) \\
\end{array}$ & $\begin{array}{c}0,811 \\
(1,080)\end{array}$ & $\begin{array}{c}0,848 \\
(1,086)\end{array}$ & $\begin{array}{c}0,869 \\
(1,081)\end{array}$ \\
\hline distância em relação ao centro & & & & $\begin{array}{c}-0,304 * * * \\
(0,055)\end{array}$ & $\begin{array}{l}-0,073 \\
(0,073)\end{array}$ & $\begin{array}{l}-0,087 \\
(0,073)\end{array}$ & $\begin{array}{l}-0,094 \\
(0,073)\end{array}$ \\
\hline corrige tarefas de matemática & & & & $\begin{array}{c}1,903 * * * \\
(0,351)\end{array}$ & $\begin{array}{c}1,864 * * * \\
(0,352)\end{array}$ & $\begin{array}{c}1,640 * * * \\
(0,349)\end{array}$ & $\begin{array}{c}1,635 * * * \\
(0,349)\end{array}$ \\
\hline $\begin{array}{l}\text { proporção de professores com } \\
\text { ensino superior }\end{array}$ & & & & $\begin{array}{l}-0,018 \\
(0,037)\end{array}$ & $\begin{array}{l}-0,002 \\
(0,037)\end{array}$ & $\begin{array}{l}-0,009 \\
(0,036)\end{array}$ & $\begin{array}{l}-0,008 \\
(0,036)\end{array}$ \\
\hline $\begin{array}{l}\text { escolaridade média em anos } \\
\text { de estudo }\end{array}$ & & & & & $\begin{array}{c}0,178 \\
(0,479) \\
\end{array}$ & $\begin{array}{c}0,235 \\
(0,481) \\
\end{array}$ & $\begin{array}{c}0,172 \\
(0,480) \\
\end{array}$ \\
\hline índice de pobreza & & & & & $\begin{array}{c}-38,175 * * * \\
(12,209)\end{array}$ & $\begin{array}{c}-36,739 * * * \\
(12,127)\end{array}$ & $\begin{array}{c}-36,162 * * * \\
-12,109\end{array}$ \\
\hline $\begin{array}{l}\text { escolaridade dos pais dos } \\
\text { colegas }\end{array}$ & & & & & & $\begin{array}{c}1,007 * * \\
(0,402)\end{array}$ & $\begin{array}{l}1,003 * * \\
(0,402)\end{array}$ \\
\hline reunião de pais & & & & & & $\begin{array}{c}5,340 * * * \\
(0,290)\end{array}$ & $\begin{array}{c}5,338 * * * \\
(0,290)\end{array}$ \\
\hline $\begin{array}{l}\text { taxa de livros didáticos } \\
\text { devolvidos por aluno }\end{array}$ & & & & & & $\begin{array}{c}0,082 \\
(0,060) \\
\end{array}$ & $\begin{array}{c}0,083 \\
(0,060) \\
\end{array}$ \\
\hline constante & $\begin{array}{c}169,762 * * * \\
(0,259)\end{array}$ & $\begin{array}{c}138,110 * * * \\
(2,006)\end{array}$ & $\begin{array}{c}129,783 * * * \\
(2,139)\end{array}$ & $\begin{array}{c}144,908 * * * \\
(5,057)\end{array}$ & $\begin{array}{c}149,733 * * * \\
(7,175)\end{array}$ & $\begin{array}{c}147,153 * * * \\
(7,159)\end{array}$ & $\begin{array}{c}147,109 * * * \\
(7,160)\end{array}$ \\
\hline $\mathrm{R}^{2}$ & 0,008 & 0,201 & 0,214 & 0,222 & 0,223 & 0,226 & 0,226 \\
\hline número de observações & 101436 & 83609 & 81857 & 81402 & 81402 & 81077 & 81077 \\
\hline
\end{tabular}

Fonte: Elaboração própria com base nos dados da SEADE, Prova Brasil 2005, Censo Escolar 2005 e Censo Demográfico 2000.

$* * *$ significante a $1 \% * *$ significante a $5 \% *$ significante a $10 \%$ 
Tabela A4 - A associação entre ameaças e notas de matemática (continua)

\begin{tabular}{|c|c|c|c|c|c|c|c|}
\hline Variáveis & Modelo 1 & Modelo 2 & Modelo 3 & Modelo 4 & Modelo 5 & Modelo 6 & Modelo 7 \\
\hline Ameaças (2005) & $\begin{array}{c}0,027 \text { *** } \\
(0,001)\end{array}$ & $\begin{array}{c}0,019 * * * \\
(0,003)\end{array}$ & $\begin{array}{c}0,018^{* * * *} \\
(0,003) \\
\end{array}$ & $\begin{array}{l}0,006^{*} \\
(0,003) \\
\end{array}$ & $\begin{array}{c}0,000 \\
(0,003) \\
\end{array}$ & $\begin{array}{c}0,000 \\
(0,003) \\
\end{array}$ & \\
\hline Ameaças (2004) & & & & & & & $\begin{array}{c}0,001 \\
(0,003) \\
\end{array}$ \\
\hline menino & & $\begin{array}{c}2,091 * * * \\
(0,277) \\
\end{array}$ & $\begin{array}{c}2,193 * * * \\
(0,278) \\
\end{array}$ & $\begin{array}{c}2,178 * * * \\
(0,276) \\
\end{array}$ & $\begin{array}{c}2,171 * * * \\
(0,275)\end{array}$ & $\begin{array}{c}2,283 * * * \\
(0,277) \\
\end{array}$ & $\begin{array}{c}2,284 * * * \\
(0,277) \\
\end{array}$ \\
\hline branco & & $\begin{array}{c}4,643 * * * \\
(0,301) \\
\end{array}$ & $\begin{array}{c}4,252 * * * \\
(0,294) \\
\end{array}$ & $\begin{array}{c}3,759 * * * \\
(0,290)\end{array}$ & $\begin{array}{c}3,710 * * * \\
(0,289)\end{array}$ & $\begin{array}{c}3,656^{* * * *} \\
(0,290) \\
\end{array}$ & $\begin{array}{c}3,655 * * * \\
(0,290) \\
\end{array}$ \\
\hline 8 anos & & $\begin{array}{c}-6,986^{* * * *} \\
(2,082( \\
\end{array}$ & $\begin{array}{c}-9,931 * * * \\
(2,178) \\
\end{array}$ & $\begin{array}{c}-9,500 * * * \\
(2,172)\end{array}$ & $\begin{array}{c}-9,404 * * * \\
(2,167) \\
\end{array}$ & $\begin{array}{c}-10,237 * * * \\
(2,178)\end{array}$ & $\begin{array}{c}-10,242 * * * \\
(2,178)\end{array}$ \\
\hline 9 anos & & $\begin{array}{c}8,839 * * * \\
(1,914) \\
\end{array}$ & $\begin{array}{c}7,608 * * * \\
(1,960) \\
\end{array}$ & $\begin{array}{c}7,145 * * * \\
(1,938) \\
\end{array}$ & $\begin{array}{c}6,981 * * * \\
(1,927) \\
\end{array}$ & $\begin{array}{c}6,277 * * * \\
(1,932) \\
\end{array}$ & $\begin{array}{c}6,271 * * * \\
(1,932) \\
\end{array}$ \\
\hline 10 anos & & $\begin{array}{c}12,802 * * * \\
(1,736)\end{array}$ & $\begin{array}{c}11,087 * * * \\
(1,802)\end{array}$ & $\begin{array}{c}10,477 * * * \\
(1,772)\end{array}$ & $\begin{array}{c}10,333 * * * \\
(1,762)\end{array}$ & $\begin{array}{c}9,836 * * * \\
(1,770) \\
\end{array}$ & $\begin{array}{c}9,830 * * * \\
(1,769) \\
\end{array}$ \\
\hline 11 anos & & $\begin{array}{c}10,466^{* * * *} \\
(1,722)\end{array}$ & $\begin{array}{c}9,075 * * * \\
(1,790) \\
\end{array}$ & $\begin{array}{c}8,688^{* * * *} \\
(1,762) \\
\end{array}$ & $\begin{array}{c}8,607 * * * \\
(1,753) \\
\end{array}$ & $\begin{array}{c}8,242 * * * \\
(1,760) \\
\end{array}$ & $\begin{array}{c}8,238 * * * \\
(1,760) \\
\end{array}$ \\
\hline 12 anos & & $\begin{array}{c}6,544 * * * \\
(1,770) \\
\end{array}$ & $\begin{array}{c}5,480 * * * \\
(1,836) \\
\end{array}$ & $\begin{array}{c}5,371 * * * \\
(1,810) \\
\end{array}$ & $\begin{array}{c}5,327 * * * \\
(1,801) \\
\end{array}$ & $\begin{array}{c}5,141 * * * \\
(1,809) \\
\end{array}$ & $\begin{array}{c}5,136^{* * * *} \\
(1,809) \\
\end{array}$ \\
\hline 13 anos & & $\begin{array}{c}4,762 * * * \\
(1,832) \\
\end{array}$ & $\begin{array}{l}3,629 * \\
(1,912) \\
\end{array}$ & $\begin{array}{l}3,621^{*} \\
(1,888) \\
\end{array}$ & $\begin{array}{l}3,601 * \\
(1,881) \\
\end{array}$ & $\begin{array}{l}3,502 * \\
(1,890) \\
\end{array}$ & $\begin{array}{l}3,499 * \\
(1,890) \\
\end{array}$ \\
\hline 14 anos & & $\begin{array}{c}5,128 * * \\
(2,227) \\
\end{array}$ & $\begin{array}{c}4,657 * * \\
(2,272) \\
\end{array}$ & $\begin{array}{c}4,635^{* * *} \\
(2,231) \\
\end{array}$ & $\begin{array}{c}4,633 * * \\
(2,221) \\
\end{array}$ & $\begin{array}{c}4,711 * * \\
(2,217)\end{array}$ & $\begin{array}{c}4,705 * * \\
(2,217) \\
\end{array}$ \\
\hline reprovação & & $\begin{array}{c}-14,642 * * * \\
(0,443)\end{array}$ & $\begin{array}{c}-14,161 * * * \\
(0,437)\end{array}$ & $\begin{array}{c}- \\
13,537 * * * \\
(0,432) \\
\end{array}$ & $\begin{array}{c}-13,566^{* * * *} \\
(0,431)\end{array}$ & $\begin{array}{c}-13,366 * * * \\
(0,431)\end{array}$ & $\begin{array}{c}-13,367 * * * \\
(0,431)\end{array}$ \\
\hline tarefa de matemática & & $\begin{array}{c}9,882 * * * \\
(0,322) \\
\end{array}$ & $\begin{array}{c}9,237 * * * \\
(0,317) \\
\end{array}$ & $\begin{array}{c}8,403 * * * \\
(0,320) \\
\end{array}$ & $\begin{array}{c}8,422 * * * \\
(0,319) \\
\end{array}$ & $\begin{array}{c}7,713 * * * \\
(0,320) \\
\end{array}$ & $\begin{array}{c}7,712 * * * \\
(0,320) \\
\end{array}$ \\
\hline tempo de tv & & $\begin{array}{c}0,411 \\
(0,308) \\
\end{array}$ & $\begin{array}{c}0,449 \\
(0,307) \\
\end{array}$ & $\begin{array}{c}0,343 \\
(0,302) \\
\end{array}$ & $\begin{array}{c}0,326 \\
(0,302) \\
\end{array}$ & $\begin{array}{c}0,376 \\
(0,301) \\
\end{array}$ & $\begin{array}{c}0,378 \\
(0,302) \\
\end{array}$ \\
\hline abandono & & $\begin{array}{c}-10,487 * * * \\
(0,495)\end{array}$ & $\begin{array}{c}-10,065^{* * * *} \\
(0,505)\end{array}$ & $\begin{array}{c}-9,767 * * * \\
(0,503)\end{array}$ & $\begin{array}{c}-9,719 * * * \\
(0,504) \\
\end{array}$ & $\begin{array}{c}-9,208 * * * \\
(0,505)\end{array}$ & $\begin{array}{c}-9,208 * * * \\
(0,505)\end{array}$ \\
\hline trabalha fora de casa & & $\begin{array}{c}-10,698 * * * \\
(0,393)\end{array}$ & $\begin{array}{c}-10,862 * * * \\
(0,404)\end{array}$ & $\begin{array}{c}- \\
10,697 * * * \\
(0,403)\end{array}$ & $\begin{array}{c}-10,608 * * * \\
(0,400)\end{array}$ & $\begin{array}{c}-10,396 * * * \\
(0,398)\end{array}$ & $\begin{array}{c}-10,396 * * * \\
(0,398)\end{array}$ \\
\hline trabalhos domésticos & & $\begin{array}{c}3,317 * * * * \\
(0,291)\end{array}$ & $\begin{array}{c}3,301 * * * \\
(0,292) \\
\end{array}$ & $\begin{array}{c}3,146^{* * * *} \\
(0,288)\end{array}$ & $\begin{array}{c}3,081 * * * \\
(0,288)\end{array}$ & $\begin{array}{c}2,922 * * * \\
(0,286)\end{array}$ & $\begin{array}{c}2,922 * * * \\
(0,286) \\
\end{array}$ \\
\hline maternal & & $\begin{array}{c}11,854 * * * * \\
(0,392)\end{array}$ & $\begin{array}{c}10,404 * * * \\
(0,387)\end{array}$ & $\begin{array}{c}9,871 * * * \\
(0,382)\end{array}$ & $\begin{array}{c}9,702 * * * \\
(0,382)\end{array}$ & $\begin{array}{c}9,318 * * * \\
(0,383) \\
\end{array}$ & $\begin{array}{c}9,319 * * * \\
(0,383) \\
\end{array}$ \\
\hline pré-escola & & $\begin{array}{c}10,904 * * * \\
(0,346)\end{array}$ & $\begin{array}{c}10,115 * * * \\
(0,345)\end{array}$ & $\begin{array}{c}10,080 * * * \\
(0,348)\end{array}$ & $\begin{array}{c}10,033 * * * \\
(0,349)\end{array}$ & $\begin{array}{c}9,702 * * * \\
(0,348) \\
\end{array}$ & $\begin{array}{c}9,705 * * * \\
(0,348) \\
\end{array}$ \\
\hline estudou na mesma escola & & $\begin{array}{l}-0,131 \\
(0,290) \\
\end{array}$ & $\begin{array}{l}-0,167 \\
(0,290) \\
\end{array}$ & $\begin{array}{l}-0,249 \\
(0,285) \\
\end{array}$ & $\begin{array}{l}-0,197 \\
(0,283) \\
\end{array}$ & $\begin{array}{l}-0,352 \\
(0,284) \\
\end{array}$ & $\begin{array}{c}-0,350 \\
(0,284) \\
\end{array}$ \\
\hline mora com pai ou mãe & & $\begin{array}{c}-1,274 * * * \\
(0,313) \\
\end{array}$ & $\begin{array}{c}-1,001 * * * \\
(0,316)\end{array}$ & $\begin{array}{c}-1,058 * * * \\
(0,314)\end{array}$ & $\begin{array}{c}-1,076^{* * * *} \\
(0,314) \\
\end{array}$ & $\begin{array}{c}-0,648 * * \\
(0,317) \\
\end{array}$ & $\begin{array}{c}-0,647 * * \\
(0,317) \\
\end{array}$ \\
\hline $\begin{array}{l}\text { mora sozinho ou com mais uma } \\
\text { pessoa }\end{array}$ & & $\begin{array}{c}7,549 * * * \\
(0,904) \\
\end{array}$ & $\begin{array}{c}7,515 * * * \\
(0,920) \\
\end{array}$ & $\begin{array}{c}7,440 * * * \\
(0,910)\end{array}$ & $\begin{array}{c}7,351 * * * \\
(0,903) \\
\end{array}$ & $\begin{array}{c}6,941 * * * \\
(0,901)\end{array}$ & $\begin{array}{c}6,939 * * * \\
(0,901) \\
\end{array}$ \\
\hline mora com mais duas pessoas & & $\begin{array}{c}13,635^{* * * *} \\
(0,621) \\
\end{array}$ & $\begin{array}{c}13,235 * * * \\
(0,613)\end{array}$ & $\begin{array}{c}12,882 * * * \\
(0,610)\end{array}$ & $\begin{array}{c}12,773 * * * \\
(0,605)\end{array}$ & $\begin{array}{c}12,527 * * * \\
(0,603)\end{array}$ & $\begin{array}{c}12,526 * * * \\
(0,604)\end{array}$ \\
\hline mora com mais três pessoas & & $\begin{array}{c}13,422 * * * \\
(0,593)\end{array}$ & $\begin{array}{c}12,845 * * * \\
(0,591)\end{array}$ & $\begin{array}{c}12,627 * * * \\
(0,581)\end{array}$ & $\begin{array}{c}12,546 * * * \\
(0,579)\end{array}$ & $\begin{array}{c}12,276 * * * \\
(0,577)\end{array}$ & $\begin{array}{c}12,275^{* * *} * \\
(0,577)\end{array}$ \\
\hline $\begin{array}{c}\text { mora com mais quatro ou cinco } \\
\text { pessoas }\end{array}$ & & $\begin{array}{c}5,542 * * * \\
(0,526) \\
\end{array}$ & $\begin{array}{c}5,329 * * * \\
(0,525) \\
\end{array}$ & $\begin{array}{c}5,107 * * * \\
(0,518) \\
\end{array}$ & $\begin{array}{c}5,051 * * * \\
(0,515) \\
\end{array}$ & $\begin{array}{c}4,894 * * * \\
(0,513) \\
\end{array}$ & $\begin{array}{c}4,893 * * * \\
(0,513) \\
\end{array}$ \\
\hline
\end{tabular}


Tabela A4 - A associação entre ameaças e notas de matemática (continuação)

\begin{tabular}{|c|c|c|c|c|c|c|c|}
\hline Variáveis & Modelo 1 & Modelo 2 & Modelo 3 & Modelo 4 & Modelo 5 & Modelo 6 & Modelo 7 \\
\hline mora com mais seis a oito pessoas & & $\begin{array}{c}2,771 * * * \\
(0,563)\end{array}$ & $\begin{array}{c}2,666^{* * * *} \\
(0,559)\end{array}$ & $\begin{array}{c}2,624 * * * * \\
(0,551)\end{array}$ & $\begin{array}{c}2,601 * * * \\
(0,551)\end{array}$ & $\begin{array}{c}2,569^{* * * *} \\
(0,552)\end{array}$ & $\begin{array}{c}2,568 * * * \\
(0,552)\end{array}$ \\
\hline futuro (ainda não sei) & & $\begin{array}{c}5,829 * * * \\
(0,431)\end{array}$ & $\begin{array}{c}6,308 * * * \\
(0,440)\end{array}$ & $\begin{array}{c}5,977 * * * * \\
(0,437)\end{array}$ & $\begin{array}{c}5,925 * * * \\
(0,436) \\
\end{array}$ & $\begin{array}{c}5,891 * * * \\
(0,441)\end{array}$ & $\begin{array}{c}5,891 * * * \\
(0,441)\end{array}$ \\
\hline futuro (estudar) & & $\begin{array}{c}5,641 * * * \\
(0,508)\end{array}$ & $\begin{array}{c}5,106^{* * * *} * \\
(0,506)\end{array}$ & $\begin{array}{c}4,682 * * * \\
(0,498)\end{array}$ & $\begin{array}{c}4,610^{* * * *} \\
(0,498)\end{array}$ & $\begin{array}{c}4,211 * * * \\
(0,499)\end{array}$ & $\begin{array}{c}4,209 * * * \\
(0,499)\end{array}$ \\
\hline futuro (estudar e trabalhar) & & $\begin{array}{c}11,970 * * * \\
(0,448)\end{array}$ & $\begin{array}{c}11,290 * * * \\
(0,451)\end{array}$ & $\begin{array}{c}11,009 * * * \\
(0,449)\end{array}$ & $\begin{array}{c}10,953 * * * \\
(0,448)\end{array}$ & $\begin{array}{c}10,655^{* * * *} \\
(0,450)\end{array}$ & $\begin{array}{c}10,656^{* * * *} \\
(0,450)\end{array}$ \\
\hline deixado de lado & & $\begin{array}{c}-12,371 * * * \\
(0,359)\end{array}$ & $\begin{array}{c}-12,143^{* * * *} \\
(0,360)\end{array}$ & $\begin{array}{c}-11,891 * * * \\
(0,358)\end{array}$ & $\begin{array}{c}-11,836^{* * * *} \\
(0,357)\end{array}$ & $\begin{array}{c}-11,770 * * * \\
(0,358)\end{array}$ & $\begin{array}{c}-11,769 * * * \\
(0,358)\end{array}$ \\
\hline bolsa família & & $\begin{array}{c}-9,103 * * * \\
(0,346)\end{array}$ & $\begin{array}{c}-8,734 * * * \\
(0,345)\end{array}$ & $\begin{array}{c}-8,503 * * * \\
(0,341)\end{array}$ & $\begin{array}{c}-8,478 * * * \\
(0,338)\end{array}$ & $\begin{array}{c}-8,553 * * * \\
(0,340)\end{array}$ & $\begin{array}{c}-8,553^{* * * *} \\
(0,340)\end{array}$ \\
\hline livros & & & $\begin{array}{c}2,213 * * * \\
(0,282)\end{array}$ & $\begin{array}{c}1,991 * * * \\
(0,279)\end{array}$ & $\begin{array}{c}1,891 * * * \\
(0,278)\end{array}$ & $\begin{array}{c}1,640 * * * \\
(0,276)\end{array}$ & $\begin{array}{c}1,640 * * * \\
(0,276)\end{array}$ \\
\hline computador & & & $\begin{array}{c}3,275 * * * \\
(0,315)\end{array}$ & $\begin{array}{c}2,830 * * * \\
(0,310)\end{array}$ & $\begin{array}{c}2,630 * * * \\
(0,308)\end{array}$ & $\begin{array}{c}2,399 * * * \\
(0,308)\end{array}$ & $\begin{array}{c}2,399 * * * \\
(0,308)\end{array}$ \\
\hline apoio aos estudos & & & $\begin{array}{c}7,810^{* * * *} \\
(0,620)\end{array}$ & $\begin{array}{c}7,478 * * * \\
(0,615) \\
\end{array}$ & $\begin{array}{c}7,429 * * * \\
(0,614)\end{array}$ & $\begin{array}{c}6,977 * * * \\
(0,620)\end{array}$ & $\begin{array}{c}6,976^{* * * *} \\
(0,620)\end{array}$ \\
\hline $\begin{array}{l}\text { mãe nunca estudou ou não } \\
\text { completou a } 4^{\mathrm{a}} \text { série }\end{array}$ & & & $\begin{array}{c}-1,823 * * * \\
(0,521)\end{array}$ & $\begin{array}{c}-1,625 * * * \\
(0,523) \\
\end{array}$ & $\begin{array}{c}-1,468 * * * \\
(0,521)\end{array}$ & $\begin{array}{c}-1,241 * * \\
(0,527)\end{array}$ & $\begin{array}{c}-1,245^{* *} \\
(0,527)\end{array}$ \\
\hline $\begin{array}{l}\text { mãe completou a } 4^{\mathrm{a}} \text { série (antigo } \\
\text { primário), mas não completou a } 8^{\mathrm{a}} \\
\text { série }\end{array}$ & & & $\begin{array}{c}2,601 * * * \\
(0,367)\end{array}$ & $\begin{array}{c}2,278 * * * \\
(0,364)\end{array}$ & $\begin{array}{c}2,368 * * * \\
(0,364)\end{array}$ & $\begin{array}{c}2,544 * * * \\
(0,373)\end{array}$ & $\begin{array}{c}2,542 * * * \\
(0,374)\end{array}$ \\
\hline $\begin{array}{c}\text { mãe completou a } 8^{\mathrm{a}} \text { série (antigo } \\
\text { ginásio), mas não completou o } \\
\text { Ensino Médio }\end{array}$ & & & $\begin{array}{c}3,441 * * * \\
(0,417)\end{array}$ & $\begin{array}{c}3,015^{* * * *} \\
(0,412) \\
\end{array}$ & $\begin{array}{c}3,094 * * * \\
(0,410)\end{array}$ & $\begin{array}{c}3,226 * * * \\
(0,422)\end{array}$ & $\begin{array}{c}3,227 * * * \\
(0,422)\end{array}$ \\
\hline $\begin{array}{l}\text { mãe completou o Ensino Médio } \\
\text { (antigo } 2^{\circ} \text { grau), mas não } \\
\text { completou a Faculdade }\end{array}$ & & & $\begin{array}{c}10,594 * * * \\
(0,429)\end{array}$ & $\begin{array}{c}9,998 * * * \\
(0,424) \\
\end{array}$ & $\begin{array}{c}10,019 * * * \\
(0,425)\end{array}$ & $\begin{array}{c}10,083 * * * \\
(0,429)\end{array}$ & $\begin{array}{c}10,082 * * * \\
(0,429)\end{array}$ \\
\hline tamanho da sala (11-15) & & & & $\begin{array}{l}-6,429 \\
(8,711) \\
\end{array}$ & $\begin{array}{l}-7,156 \\
-8,492 \\
\end{array}$ & $\begin{array}{l}-7,814 \\
(8,398) \\
\end{array}$ & $\begin{array}{l}-7,817 \\
(8,402) \\
\end{array}$ \\
\hline tamanho da sala (16-20) & & & & $\begin{array}{l}-8,842 * \\
(4,540) \\
\end{array}$ & $\begin{array}{c}-9,345^{* *} \\
(4,263)\end{array}$ & $\begin{array}{c}-9,224 * * \\
(4,258)\end{array}$ & $\begin{array}{c}-9,215^{* *} \\
(4,269)\end{array}$ \\
\hline tamanho da sala (21-25) & & & & $\begin{array}{l}-8,353 * \\
(4,319) \\
\end{array}$ & $\begin{array}{c}-9,212 * * \\
(4,022) \\
\end{array}$ & $\begin{array}{c}-9,343 * * \\
(4,014) \\
\end{array}$ & $\begin{array}{c}-9,335 * * \\
(4,025) \\
\end{array}$ \\
\hline tamanho da sala (26-30) & & & & $\begin{array}{l}-4,915 \\
(4,289) \\
\end{array}$ & $\begin{array}{c}-5,661 \\
(3,974) \\
\end{array}$ & $\begin{array}{c}-5,673 \\
(3,972) \\
\end{array}$ & $\begin{array}{c}-5,666 \\
(3,983) \\
\end{array}$ \\
\hline tamanho da sala (31-35) & & & & $\begin{array}{l}-2,452 \\
(4,267)\end{array}$ & $\begin{array}{l}-3,059 \\
(3,962)\end{array}$ & $\begin{array}{l}-3,103 \\
(3,958)\end{array}$ & $\begin{array}{l}-3,092 \\
(3,969)\end{array}$ \\
\hline tamanho da sala (36-40) & & & & $\begin{array}{c}-0,844 \\
(4,298)\end{array}$ & $\begin{array}{l}-1,540 \\
(3,987)\end{array}$ & $\begin{array}{c}-1,592 \\
(3,985) \\
\end{array}$ & $\begin{array}{l}-1,574 \\
(3,996)\end{array}$ \\
\hline tamanho da sala (41-45) & & & & $\begin{array}{l}-1,510 \\
(5,431)\end{array}$ & $\begin{array}{l}-1,620 \\
(5,316)\end{array}$ & $\begin{array}{l}-1,588 \\
(5,276)\end{array}$ & $\begin{array}{l}-1,634 \\
(5,288) \\
\end{array}$ \\
\hline municipal & & & & $\begin{array}{c}-7,294 * * * \\
(0,811) \\
\end{array}$ & $\begin{array}{c}-7,025 * * * \\
(0,804)\end{array}$ & $\begin{array}{c}-6,667 * * * \\
(0,854) \\
\end{array}$ & $\begin{array}{c}-6,662 * * * \\
(0,851)\end{array}$ \\
\hline ensino médio & & & & $\begin{array}{c}-3,209 \text { *** } \\
(0,940)\end{array}$ & $\begin{array}{c}-2,625 * * * \\
(0,940)\end{array}$ & $\begin{array}{c}-2,561 * * * \\
(0,937) \\
\end{array}$ & $\begin{array}{c}-2,572 * * * \\
(0,935)\end{array}$ \\
\hline laboratório de informática & & & & $\begin{array}{c}-0,945 \\
(0,804)\end{array}$ & $\begin{array}{l}-1,112 \\
(0,793)\end{array}$ & $\begin{array}{c}-0,998 \\
(0,786)\end{array}$ & $\begin{array}{c}-1,001 \\
(0,785)\end{array}$ \\
\hline
\end{tabular}


Tabela A4 - A associação entre ameaças e notas de matemática (conclusão)

\begin{tabular}{|c|c|c|c|c|c|c|c|}
\hline Variáveis & Modelo 1 & Modelo 2 & Modelo 3 & Modelo 4 & Modelo 5 & Modelo 6 & Modelo 7 \\
\hline laboratório de ciências & & & & $\begin{array}{c}0,769 \\
(0,732) \\
\end{array}$ & $\begin{array}{c}0,404 \\
(0,712) \\
\end{array}$ & $\begin{array}{c}0,387 \\
(0,704)\end{array}$ & $\begin{array}{c}0,391 \\
(0,704) \\
\end{array}$ \\
\hline biblioteca & & & & $\begin{array}{c}0,315 \\
(1,320) \\
\end{array}$ & $\begin{array}{c}0,034 \\
(1,234) \\
\end{array}$ & $\begin{array}{l}-0,033 \\
(1,212)\end{array}$ & $\begin{array}{l}-0,042 \\
(1,208)\end{array}$ \\
\hline sala de leitura & & & & $\begin{array}{l}1,707 * * \\
(0,775)\end{array}$ & $\begin{array}{l}1,386^{*} \\
(0,775)\end{array}$ & $\begin{array}{c}1,242 \\
(0,766)\end{array}$ & $\begin{array}{c}1,246 \\
(0,766) \\
\end{array}$ \\
\hline $\begin{array}{l}\text { uso de computadores em sala de } \\
\text { aula }\end{array}$ & & & & $\begin{array}{l}-0,820 \\
(1,288) \\
\end{array}$ & $\begin{array}{l}-0,662 \\
(1,375) \\
\end{array}$ & $\begin{array}{l}-0,437 \\
(1,363) \\
\end{array}$ & $\begin{array}{l}-0,425 \\
(1,357) \\
\end{array}$ \\
\hline programas educacionais & & & & $\begin{array}{c}1,445 \\
(1,133) \\
\end{array}$ & $\begin{array}{c}0,766 \\
(1,069)\end{array}$ & $\begin{array}{c}0,807 \\
(1,077)\end{array}$ & $\begin{array}{c}0,823 \\
(1,075)\end{array}$ \\
\hline distância em relação ao centro & & & & $\begin{array}{c}-0,364 * * * \\
(0,055) \\
\end{array}$ & $\begin{array}{l}-0,075 \\
(0,074) \\
\end{array}$ & $\begin{array}{l}-0,088 \\
(0,073) \\
\end{array}$ & $\begin{array}{l}-0,085 \\
(0,072)\end{array}$ \\
\hline corrige tarefas de matemática & & & & $\begin{array}{c}1,931 * * * \\
(0,353)\end{array}$ & $\begin{array}{c}1,860 * * * \\
(0,352)\end{array}$ & $\begin{array}{c}1,635 * * * \\
(0,349)\end{array}$ & $\begin{array}{c}1,636^{* * * *} \\
(0,349)\end{array}$ \\
\hline $\begin{array}{l}\text { proporção de professores com } \\
\text { ensino superior }\end{array}$ & & & & $\begin{array}{l}-0,023 \\
(0,039)\end{array}$ & $\begin{array}{l}-0,002 \\
(0,037)\end{array}$ & $\begin{array}{l}-0,009 \\
(0,037)\end{array}$ & $\begin{array}{l}-0,008 \\
(0,037)\end{array}$ \\
\hline $\begin{array}{c}\text { escolaridade média em anos de } \\
\text { estudo }\end{array}$ & & & & & $\begin{array}{c}0,505 \\
(0,469) \\
\end{array}$ & $\begin{array}{c}0,544 \\
(0,471) \\
\end{array}$ & $\begin{array}{c}0,528 \\
(0,470) \\
\end{array}$ \\
\hline índice de pobreza & & & & & $\begin{array}{c}-39,987 * * * \\
(12,148) \\
\end{array}$ & $\begin{array}{c}-38,417 * * * \\
-12,082 \\
\end{array}$ & $\begin{array}{c}-38,034 * * * \\
-12,178 \\
\end{array}$ \\
\hline escolaridade dos pais dos colegas & & & & & & $\begin{array}{c}1,029 * * \\
(0,402) \\
\end{array}$ & $\begin{array}{l}1,027 * * \\
(0,402) \\
\end{array}$ \\
\hline reunião de pais & & & & & & $\begin{array}{l}5,352 * * * \\
(0,290)\end{array}$ & $\begin{array}{l}5,354 * * * \\
(0,290)\end{array}$ \\
\hline $\begin{array}{l}\text { taxa de livros didáticos } \\
\text { devolvidos por aluno }\end{array}$ & & & & & & $\begin{array}{c}0,080 \\
(0,060)\end{array}$ & $\begin{array}{c}0,080 \\
(0,060)\end{array}$ \\
\hline constante & $\begin{array}{l}170,157 * * * \\
(0,299)\end{array}$ & $\begin{array}{c}138,695 * * * \\
(1,966)\end{array}$ & $\begin{array}{l}130,284 * * * \\
(2,116)\end{array}$ & $\begin{array}{c}146,939 * * * \\
(5,138)\end{array}$ & $\begin{array}{c}149,403 * * * \\
(7,192)\end{array}$ & $\begin{array}{c}146,837 * * * \\
(7,182)\end{array}$ & $\begin{array}{c}146,621 * * * \\
(7,207)\end{array}$ \\
\hline $\mathrm{R}^{2}$ & 0,005 & 0,199 & 0,212 & 0,221 & 0,222 & 0,226 & 0,226 \\
\hline número de observações & 101436 & 83609 & 81857 & 81402 & 81402 & 81077 & 81077 \\
\hline
\end{tabular}

Fonte: Elaboração própria com base nos dados da SEADE, Prova Brasil 2005, Censo Escolar 2005 e Censo Demográfico 2000.

$* * *$ significante a $1 \% * *$ significante a $5 \% *$ significante a $10 \%$ 
Tabela A5 - A associação entre roubo consumado e notas de matemática (continua)

\begin{tabular}{|c|c|c|c|c|c|c|c|}
\hline Variáveis & Modelo 1 & Modelo 2 & Modelo 3 & Modelo 4 & Modelo 5 & Modelo 6 & Modelo 7 \\
\hline Roubo consumado (2005) & $\begin{array}{c}0,005 * * * \\
(0,000) \\
\end{array}$ & $\begin{array}{c}0,004 * * * \\
(0,001)\end{array}$ & $\begin{array}{c}0,003 * * * \\
(0,001) \\
\end{array}$ & $\begin{array}{c}0,002^{* * * *} \\
(0,001)\end{array}$ & $\begin{array}{c}0,001 \\
(0,001) \\
\end{array}$ & $\begin{array}{c}0,001 \\
(0,001) \\
\end{array}$ & \\
\hline Roubo consumado (2004) & & & & & & & $\begin{array}{l}0,001^{*} \\
(0,001) \\
\end{array}$ \\
\hline menino & & $\begin{array}{c}2,089 * * * \\
(0,277) \\
\end{array}$ & $\begin{array}{c}2,194 * * * * \\
(0,279) \\
\end{array}$ & $\begin{array}{c}2,181 * * * \\
(0,276) \\
\end{array}$ & $\begin{array}{c}2,172 * * * \\
(0,275)\end{array}$ & $\begin{array}{c}2,284 * * * \\
(0,277) \\
\end{array}$ & $\begin{array}{c}2,286 * * * \\
(0,277) \\
\end{array}$ \\
\hline branco & & $\begin{array}{c}4,684 * * * \\
(0,305) \\
\end{array}$ & $\begin{array}{c}4,307 * * * \\
(0,298) \\
\end{array}$ & $\begin{array}{c}3,767 * * * \\
(0,290)\end{array}$ & $\begin{array}{c}3,711 * * * * \\
(0,290)\end{array}$ & $\begin{array}{c}3,658 * * * \\
(0,290) \\
\end{array}$ & $\begin{array}{c}3,658 * * * \\
(0,290)\end{array}$ \\
\hline 8 anos & & $\begin{array}{c}-6,711 * * * \\
(2,086) \\
\end{array}$ & $\begin{array}{c}-9,625 * * * \\
(2,179)\end{array}$ & $\begin{array}{c}-9,323 * * * \\
(2,172) \\
\end{array}$ & $\begin{array}{c}-9,354 * * * \\
(2,169) \\
\end{array}$ & $\begin{array}{c}-10,190 * * * \\
(2,181)\end{array}$ & $\begin{array}{c}-10,180 * * * \\
(2,181)\end{array}$ \\
\hline 9 anos & & $\begin{array}{c}8,966 * * * \\
(1,917) \\
\end{array}$ & $\begin{array}{c}7,745 * * * \\
(1,954) \\
\end{array}$ & $\begin{array}{c}7,228 * * * \\
(1,935) \\
\end{array}$ & $\begin{array}{c}7,016^{* * * *} \\
(1,929) \\
\end{array}$ & $\begin{array}{c}6,310^{* * * *} \\
(1,934) \\
\end{array}$ & $\begin{array}{c}6,312 * * * \\
(1,934) \\
\end{array}$ \\
\hline 10 anos & & $\begin{array}{c}12,960 * * * \\
(1,741)\end{array}$ & $\begin{array}{c}11,253 * * * \\
(1,795) \\
\end{array}$ & $\begin{array}{c}10,567 * * * \\
(1,770) \\
\end{array}$ & $\begin{array}{c}10,373 * * * \\
(1,764)\end{array}$ & $\begin{array}{c}9,874 * * * \\
(1,772) \\
\end{array}$ & $\begin{array}{c}9,875^{* * * *} \\
(1,772) \\
\end{array}$ \\
\hline 11 anos & & $\begin{array}{c}10,710 * * * \\
(1,723)\end{array}$ & $\begin{array}{c}9,315 * * * \\
(1,781) \\
\end{array}$ & $\begin{array}{c}8,809 * * * \\
(1,759) \\
\end{array}$ & $\begin{array}{c}8,654 * * * \\
(1,754) \\
\end{array}$ & $\begin{array}{c}8,287 * * * \\
(1,762) \\
\end{array}$ & $\begin{array}{c}8,289 * * * \\
(1,762) \\
\end{array}$ \\
\hline 12 anos & & $\begin{array}{c}6,775 * * * \\
(1,768) \\
\end{array}$ & $\begin{array}{c}5,698 * * * \\
(1,824) \\
\end{array}$ & $\begin{array}{c}5,479 * * * \\
(1,806) \\
\end{array}$ & $\begin{array}{c}5,370 * * * \\
(1,803) \\
\end{array}$ & $\begin{array}{c}5,180 * * * \\
(1,811) \\
\end{array}$ & $\begin{array}{c}5,183 * * * \\
(1,811) \\
\end{array}$ \\
\hline 13 anos & & $\begin{array}{c}4,928 * * * \\
(1,837) \\
\end{array}$ & $\begin{array}{c}3,790 * * \\
(1,909) \\
\end{array}$ & $\begin{array}{l}3,697^{*} \\
(1,889) \\
\end{array}$ & $\begin{array}{l}3,624^{*} \\
(1,883) \\
\end{array}$ & $\begin{array}{l}3,523^{*} \\
(1,892) \\
\end{array}$ & $\begin{array}{l}3,531 * \\
(1,893) \\
\end{array}$ \\
\hline 14 anos & & $\begin{array}{c}5,404 * * \\
(2,226) \\
\end{array}$ & $\begin{array}{c}4,886 * * \\
(2,264) \\
\end{array}$ & $\begin{array}{c}4,753 * * \\
(2,229) \\
\end{array}$ & $\begin{array}{c}4,687 * * \\
(2,223) \\
\end{array}$ & $\begin{array}{c}4,761 * * \\
(2,219) \\
\end{array}$ & $\begin{array}{c}4,756 * * \\
(2,218) \\
\end{array}$ \\
\hline reprovação & & $\begin{array}{c}-14,696 * * * \\
(0,439)\end{array}$ & $\begin{array}{c}-14,213 * * * \\
(0,434)\end{array}$ & $\begin{array}{c}-13,567 * * * \\
(0,431) \\
\end{array}$ & $\begin{array}{c}-13,576^{* * * *} \\
(0,431) \\
\end{array}$ & $\begin{array}{c}-13,376^{* * * *} \\
(0,430) \\
\end{array}$ & $\begin{array}{c}-13,374 * * * \\
(0,430)\end{array}$ \\
\hline tarefa de matemática & & $\begin{array}{c}9,902 * * * \\
(0,321) \\
\end{array}$ & $\begin{array}{c}9,259 * * * \\
(0,316) \\
\end{array}$ & $\begin{array}{c}8,419 * * * \\
(0,320) \\
\end{array}$ & $\begin{array}{c}8,423 * * * \\
(0,319) \\
\end{array}$ & $\begin{array}{c}7,716 * * * \\
(0,320) \\
\end{array}$ & $\begin{array}{c}7,721 * * * \\
(0,320) \\
\end{array}$ \\
\hline tempo de tv & & $\begin{array}{c}0,384 \\
(0,307) \\
\end{array}$ & $\begin{array}{c}0,424 \\
(0,306) \\
\end{array}$ & $\begin{array}{c}0,339 \\
(0,302) \\
\end{array}$ & $\begin{array}{c}0,326 \\
(0,302) \\
\end{array}$ & $\begin{array}{c}0,376 \\
(0,301) \\
\end{array}$ & $\begin{array}{c}0,377 \\
(0,301) \\
\end{array}$ \\
\hline abandono & & $\begin{array}{c}-10,436^{* * * *} \\
(0,495)\end{array}$ & $\begin{array}{c}-10,008 * * * \\
(0,504)\end{array}$ & $\begin{array}{c}-9,731 * * * \\
(0,503)\end{array}$ & $\begin{array}{c}-9,708 * * * \\
(0,504)\end{array}$ & $\begin{array}{c}-9,198 * * * \\
(0,505)\end{array}$ & $\begin{array}{c}-9,198 * * * \\
(0,505)\end{array}$ \\
\hline trabalha fora de casa & & $\begin{array}{c}-10,716^{* * * *} \\
(0,391)\end{array}$ & $\begin{array}{c}-10,866^{* * * *} \\
(0,401)\end{array}$ & $\begin{array}{c}-10,687 * * * \\
(0,401)\end{array}$ & $\begin{array}{c}-10,613^{* * * *} \\
(0,400)\end{array}$ & $\begin{array}{c}-10,400^{* * *} \\
(0,398)\end{array}$ & $\begin{array}{c}-10,402 * * * \\
(0,398)\end{array}$ \\
\hline trabalhos domésticos & & $\begin{array}{c}3,300 * * * \\
(0,291) \\
\end{array}$ & $\begin{array}{c}3,290 * * * \\
(0,292) \\
\end{array}$ & $\begin{array}{c}3,129 * * * \\
(0,287) \\
\end{array}$ & $\begin{array}{c}3,082 * * * \\
(0,288)\end{array}$ & $\begin{array}{c}2,923 * * * * \\
(0,286)\end{array}$ & $\begin{array}{c}2,921 * * * \\
(0,286) \\
\end{array}$ \\
\hline maternal & & $\begin{array}{c}11,802^{* * * *} \\
(0,395)\end{array}$ & $\begin{array}{c}10,383^{* * * *} \\
(0,390)\end{array}$ & $\begin{array}{c}9,848 * * * \\
(0,382) \\
\end{array}$ & $\begin{array}{c}9,703 * * * \\
(0,382) \\
\end{array}$ & $\begin{array}{c}9,320 * * * \\
(0,383) \\
\end{array}$ & $\begin{array}{c}9,319 * * * \\
(0,383) \\
\end{array}$ \\
\hline pré-escola & & $\begin{array}{c}10,921 * * * \\
(0,345)\end{array}$ & $\begin{array}{c}10,135^{* * *} * \\
(0,345)\end{array}$ & $\begin{array}{c}10,108^{* * *} * \\
(0,348)\end{array}$ & $\begin{array}{c}10,045^{* * *} * \\
(0,349)\end{array}$ & $\begin{array}{c}9,713 * * * \\
(0,348) \\
\end{array}$ & $\begin{array}{c}9,713 * * * \\
(0,348) \\
\end{array}$ \\
\hline estudou na mesma escola & & $\begin{array}{l}-0,152 \\
(0,288)\end{array}$ & $\begin{array}{l}-0,190 \\
(0,289) \\
\end{array}$ & $\begin{array}{l}-0,252 \\
(0,284)\end{array}$ & $\begin{array}{l}-0,200 \\
(0,282)\end{array}$ & $\begin{array}{l}-0,354 \\
(0,283) \\
\end{array}$ & $\begin{array}{l}-0,355 \\
(0,283)\end{array}$ \\
\hline mora com pai ou mãe & & $\begin{array}{c}-1,269 * * * \\
(0,311)\end{array}$ & $\begin{array}{c}-0,999 * * * \\
(0,315)\end{array}$ & $\begin{array}{c}-1,062 * * * \\
(0,313) \\
\end{array}$ & $\begin{array}{c}-1,073 * * * \\
(0,314) \\
\end{array}$ & $\begin{array}{c}-0,645^{* * *} \\
(0,317)\end{array}$ & $\begin{array}{c}-0,645^{* * *} \\
(0,317) \\
\end{array}$ \\
\hline $\begin{array}{l}\text { mora sozinho ou com mais uma } \\
\text { pessoa }\end{array}$ & & $\begin{array}{c}7,495 * * * \\
(0,901) \\
\end{array}$ & $\begin{array}{c}7,443 * * * \\
(0,916) \\
\end{array}$ & $\begin{array}{c}7,402 * * * \\
(0,907) \\
\end{array}$ & $\begin{array}{c}7,355^{* * * *} \\
(0,903) \\
\end{array}$ & $\begin{array}{c}6,945^{* * *} * \\
(0,901) \\
\end{array}$ & $\begin{array}{c}6,940 * * * \\
(0,901) \\
\end{array}$ \\
\hline mora com mais duas pessoas & & $\begin{array}{c}13,572 * * * \\
(0,617)\end{array}$ & $\begin{array}{c}13,168 * * * \\
(0,610)\end{array}$ & $\begin{array}{c}12,842 * * * \\
(0,608)\end{array}$ & $\begin{array}{c}12,779 * * * \\
(0,605)\end{array}$ & $\begin{array}{c}12,532 * * * \\
(0,603)\end{array}$ & $\begin{array}{c}12,526^{* * * *} \\
(0,604)\end{array}$ \\
\hline mora com mais três pessoas & & $\begin{array}{c}13,372 * * * \\
(0,589)\end{array}$ & $\begin{array}{c}12,796 * * * \\
(0,588)\end{array}$ & $\begin{array}{c}12,593 * * * \\
(0,580)\end{array}$ & $\begin{array}{c}12,547 * * * \\
(0,579)\end{array}$ & $\begin{array}{c}12,277 * * * \\
(0,576)\end{array}$ & $\begin{array}{c}12,277 * * * \\
(0,576)\end{array}$ \\
\hline $\begin{array}{l}\text { mora com mais quatro ou cinco } \\
\text { pessoas }\end{array}$ & & $\begin{array}{c}5,530 * * * \\
(0,524)\end{array}$ & $\begin{array}{c}5,310 * * * \\
(0,523) \\
\end{array}$ & $\begin{array}{c}5,101 * * * \\
(0,516) \\
\end{array}$ & $\begin{array}{c}5,061 * * * \\
(0,515)\end{array}$ & $\begin{array}{c}4,904 * * * \\
(0,512)\end{array}$ & $\begin{array}{c}4,903 * * * \\
(0,512) \\
\end{array}$ \\
\hline
\end{tabular}


Tabela A5 - A associação entre roubo consumado e notas de matemática (continuação)

\begin{tabular}{|c|c|c|c|c|c|c|c|}
\hline Variáveis & Modelo 1 & Modelo 2 & Modelo 3 & Modelo 4 & Modelo 5 & Modelo 6 & Modelo 7 \\
\hline $\begin{array}{c}\text { mora com mais seis a oito } \\
\text { pessoas }\end{array}$ & & $\begin{array}{c}2,775 * * * \\
(0,563) \\
\end{array}$ & $\begin{array}{c}2,660 * * * \\
(0,559) \\
\end{array}$ & $\begin{array}{c}2,621 * * * \\
(0,551) \\
\end{array}$ & $\begin{array}{c}2,606 * * * \\
(0,551) \\
\end{array}$ & $\begin{array}{c}2,574 * * * \\
(0,552)\end{array}$ & $\begin{array}{c}2,574 * * * \\
(0,552) \\
\end{array}$ \\
\hline futuro (ainda não sei) & & $\begin{array}{c}5,808 * * * \\
(0,432) \\
\end{array}$ & $\begin{array}{c}6,282 * * * \\
(0,441)\end{array}$ & $\begin{array}{c}5,971 * * * \\
(0,437)\end{array}$ & $\begin{array}{c}5,933 * * * \\
(0,436) \\
\end{array}$ & $\begin{array}{c}5,897 * * * \\
(0,441)\end{array}$ & $\begin{array}{c}5,897 * * * \\
(0,441)\end{array}$ \\
\hline futuro (estudar) & & $\begin{array}{c}5,638 * * * \\
(0,510) \\
\end{array}$ & $\begin{array}{c}5,111 * * * \\
(0,508)\end{array}$ & $\begin{array}{c}4,676^{* * * *} \\
(0,498)\end{array}$ & $\begin{array}{c}4,613 * * * \\
(0,498)\end{array}$ & $\begin{array}{c}4,214 * * * \\
(0,499)\end{array}$ & $\begin{array}{c}4,214 * * * \\
(0,499)\end{array}$ \\
\hline futuro (estudar e trabalhar) & & $\begin{array}{c}11,989 * * * \\
(0,449)\end{array}$ & $\begin{array}{c}11,312 * * * \\
(0,452)\end{array}$ & $\begin{array}{c}11,023 * * * \\
(0,449)\end{array}$ & $\begin{array}{c}10,965 * * * \\
(0,448)\end{array}$ & $\begin{array}{c}10,667 * * * \\
(0,450)\end{array}$ & $\begin{array}{c}10,668 * * * \\
(0,450)\end{array}$ \\
\hline deixado de lado & & $\begin{array}{c}-12,360 * * * \\
(0,360)\end{array}$ & $\begin{array}{c}-12,132 * * * \\
(0,360) \\
\end{array}$ & $\begin{array}{c}-11,872 * * * \\
(0,358) \\
\end{array}$ & $\begin{array}{c}-11,830 * * * \\
(0,357)\end{array}$ & $\begin{array}{c}-11,764 * * * \\
(0,358) \\
\end{array}$ & $\begin{array}{c}-11,762 * * * \\
(0,358) \\
\end{array}$ \\
\hline bolsa família & & $\begin{array}{c}-9,017 * * * \\
(0,345)\end{array}$ & $\begin{array}{c}-8,665^{* * * *} \\
(0,344)\end{array}$ & $\begin{array}{c}-8,454 * * * \\
(0,340) \\
\end{array}$ & $\begin{array}{c}-8,464 * * * \\
(0,338)\end{array}$ & $\begin{array}{c}-8,540 * * * \\
(0,340) \\
\end{array}$ & $\begin{array}{c}-8,535 * * * \\
(0,340) \\
\end{array}$ \\
\hline livros & & & $\begin{array}{c}2,139 * * * \\
(0,282)\end{array}$ & $\begin{array}{c}1,953 * * * \\
(0,279)\end{array}$ & $\begin{array}{c}1,889 * * * \\
(0,278)\end{array}$ & $\begin{array}{c}1,639 * * * \\
(0,276)\end{array}$ & $\begin{array}{c}1,639 * * * \\
(0,276)\end{array}$ \\
\hline computador & & & $\begin{array}{c}3,157 * * * \\
(0,314) \\
\end{array}$ & $\begin{array}{c}2,737 * * * \\
(0,308)\end{array}$ & $\begin{array}{c}2,615^{* * * *} \\
(0,307) \\
\end{array}$ & $\begin{array}{c}2,386^{* * * *} \\
(0,307) \\
\end{array}$ & $\begin{array}{c}2,384 * * * * \\
(0,307)\end{array}$ \\
\hline apoio aos estudos & & & $\begin{array}{c}7,834 * * * \\
(0,618) \\
\end{array}$ & $\begin{array}{c}7,480 * * * \\
(0,613)\end{array}$ & $\begin{array}{c}7,435 * * * \\
(0,614) \\
\end{array}$ & $\begin{array}{c}6,983 * * * \\
(0,620)\end{array}$ & $\begin{array}{c}6,982 * * * \\
(0,620)\end{array}$ \\
\hline $\begin{array}{l}\text { mãe nunca estudou ou não } \\
\text { completou a } 4^{\mathrm{a}} \text { série }\end{array}$ & & & $\begin{array}{c}-1,772 * * * \\
(0,521) \\
\end{array}$ & $\begin{array}{c}-1,600 * * * \\
(0,522) \\
\end{array}$ & $\begin{array}{c}-1,476^{* * * *} \\
(0,521)\end{array}$ & $\begin{array}{c}-1,252 * * \\
(0,527)\end{array}$ & $\begin{array}{c}-1,253 * * \\
(0,527) \\
\end{array}$ \\
\hline $\begin{array}{c}\text { mãe completou a } 4^{\mathrm{a}} \text { série (anti } \\
\text { primário), mas não completou } \\
8^{\mathrm{a}} \text { série }\end{array}$ & & & $\begin{array}{c}2,639 * * * \\
(0,365) \\
\end{array}$ & $\begin{array}{c}2,304 * * * \\
(0,363) \\
\end{array}$ & $\begin{array}{c}2,372 * * * \\
(0,363) \\
\end{array}$ & $\begin{array}{c}2,546 * * * \\
(0,373) \\
\end{array}$ & $\begin{array}{c}2,547 * * * \\
(0,373) \\
\end{array}$ \\
\hline $\begin{array}{c}\text { mãe completou a } 8^{\mathrm{a}} \text { série (anti } \\
\text { ginásio), mas não completou } \\
\text { Ensino Médio }\end{array}$ & & & $\begin{array}{c}3,448 * * * \\
(0,417)\end{array}$ & $\begin{array}{c}3,040 * * * \\
(0,412)\end{array}$ & $\begin{array}{c}3,099 * * * \\
(0,410)\end{array}$ & $\begin{array}{c}3,228 * * * \\
(0,422)\end{array}$ & $\begin{array}{c}3,229 * * * \\
(0,422)\end{array}$ \\
\hline $\begin{array}{l}\text { mãe completou o Ensino Méd } \\
\text { (antigo } 2^{\circ} \text { grau), mas não } \\
\text { completou a Faculdade }\end{array}$ & & & $\begin{array}{c}10,577 * * * \\
(0,429)\end{array}$ & $\begin{array}{c}10,001 * * * \\
(0,424)\end{array}$ & $\begin{array}{c}10,019 * * * \\
(0,425)\end{array}$ & $\begin{array}{c}10,080 * * * \\
(0,429)\end{array}$ & $\begin{array}{c}10,082 * * * \\
(0,429)\end{array}$ \\
\hline tamanho da sala (11-15) & & & & $\begin{array}{l}-6,811 \\
(8,610) \\
\end{array}$ & $\begin{array}{l}-7,322 \\
(8,498) \\
\end{array}$ & $\begin{array}{l}-7,977 \\
(8,403) \\
\end{array}$ & $\begin{array}{l}-8,002 \\
(8,395) \\
\end{array}$ \\
\hline tamanho da sala (16-20) & & & & $\begin{array}{c}-8,839 * * \\
(4,450) \\
\end{array}$ & $\begin{array}{c}-9,320 * * \\
(4,279) \\
\end{array}$ & $\begin{array}{c}-9,199 * * \\
(4,275) \\
\end{array}$ & $\begin{array}{c}-9,170 * * \\
(4,269)\end{array}$ \\
\hline tamanho da sala (21-25) & & & & $\begin{array}{c}-8,617 * * \\
(4,217) \\
\end{array}$ & $\begin{array}{c}-9,288 * * \\
(4,033) \\
\end{array}$ & $\begin{array}{c}-9,414^{* * *} \\
(4,027)\end{array}$ & $\begin{array}{c}-9,414 * * \\
(4,022)\end{array}$ \\
\hline tamanho da sala (26-30) & & & & $\begin{array}{l}-5,148 \\
(4,183) \\
\end{array}$ & $\begin{array}{l}-5,735 \\
(3,989) \\
\end{array}$ & $\begin{array}{l}-5,741 \\
(3,987) \\
\end{array}$ & $\begin{array}{l}-5,739 \\
(3,982) \\
\end{array}$ \\
\hline tamanho da sala (31-35) & & & & $\begin{array}{l}-2,613 \\
(4,163) \\
\end{array}$ & $\begin{array}{l}-3,105 \\
(3,974) \\
\end{array}$ & $\begin{array}{l}-3,145 \\
(3,971) \\
\end{array}$ & $\begin{array}{l}-3,134 \\
(3,966) \\
\end{array}$ \\
\hline tamanho da sala (36-40) & & & & $\begin{array}{l}-1,108 \\
(4,195) \\
\end{array}$ & $\begin{array}{l}-1,603 \\
(4,000) \\
\end{array}$ & $\begin{array}{l}-1,650 \\
(3,998) \\
\end{array}$ & $\begin{array}{c}-1,638 \\
(3,992) \\
\end{array}$ \\
\hline tamanho da sala (41-45) & & & & $\begin{array}{l}-1,660 \\
(5,348) \\
\end{array}$ & $\begin{array}{c}-1,731 \\
(5,318) \\
\end{array}$ & $\begin{array}{c}-1,688 \\
(5,279) \\
\end{array}$ & $\begin{array}{l}-1,697 \\
(5,276) \\
\end{array}$ \\
\hline municipal & & & & $\begin{array}{c}-7,059 * * * \\
(0,801) \\
\end{array}$ & $\begin{array}{c}-6,990 * * * \\
(0,798) \\
\end{array}$ & $\begin{array}{c}-6,627 * * * \\
(0,847) \\
\end{array}$ & $\begin{array}{c}-6,600 * * * \\
(0,847) \\
\end{array}$ \\
\hline ensino médio & & & & $\begin{array}{c}-2,908 * * * \\
(0,925)\end{array}$ & $\begin{array}{c}-2,631 * * * \\
(0,933)\end{array}$ & $\begin{array}{c}-2,565 * * * \\
(0,930) \\
\end{array}$ & $\begin{array}{c}-2,537 * * * \\
(0,927) \\
\end{array}$ \\
\hline laboratório de informática & & & & $\begin{array}{l}-1,090 \\
(0,793)\end{array}$ & $\begin{array}{l}-1,143 \\
(0,789)\end{array}$ & $\begin{array}{l}-1,025 \\
(0,783)\end{array}$ & $\begin{array}{l}-1,036 \\
(0,782)\end{array}$ \\
\hline
\end{tabular}


Tabela A5 - A associação entre roubo consumado e notas de matemática (conclusão)

\begin{tabular}{|c|c|c|c|c|c|c|c|}
\hline Variáveis & Modelo 1 & Modelo 2 & Modelo 3 & Modelo 4 & Modelo 5 & Modelo 6 & Modelo 7 \\
\hline laboratório de ciências & & & & $\begin{array}{c}0,603 \\
(0,728) \\
\end{array}$ & $\begin{array}{c}0,381 \\
(0,711)\end{array}$ & $\begin{array}{c}0,364 \\
(0,704)\end{array}$ & $\begin{array}{c}0,346 \\
(0,703) \\
\end{array}$ \\
\hline biblioteca & & & & $\begin{array}{c}0,028 \\
(1,313)\end{array}$ & $\begin{array}{c}-0,012 \\
(1,236)\end{array}$ & $\begin{array}{c}-0,077 \\
(1,214)\end{array}$ & $\begin{array}{l}-0,097 \\
(1,214)\end{array}$ \\
\hline sala de leitura & & & & $\begin{array}{l}1,666^{* *} \\
(0,775)\end{array}$ & $\begin{array}{l}1,414 * \\
(0,776)\end{array}$ & $\begin{array}{l}1,268^{*} \\
(0,768)\end{array}$ & $\begin{array}{l}1,271^{*} \\
(0,767)\end{array}$ \\
\hline $\begin{array}{l}\text { uso de computadores em sala de } \\
\text { aula }\end{array}$ & & & & $\begin{array}{l}-0,709 \\
(1,297)\end{array}$ & $\begin{array}{c}-0,627 \\
(1,360)\end{array}$ & $\begin{array}{c}-0,404 \\
(1,349)\end{array}$ & $\begin{array}{l}-0,395 \\
(1,349)\end{array}$ \\
\hline programas educacionais & & & & $\begin{array}{c}1,211 \\
(1,134)\end{array}$ & $\begin{array}{c}0,776 \\
(1,076)\end{array}$ & $\begin{array}{c}0,816 \\
-1,082 \\
\end{array}$ & $\begin{array}{c}0,808 \\
(1,082)\end{array}$ \\
\hline distância em relação ao centro & & & & $\begin{array}{c}-0,340 * * * \\
(0,053) \\
\end{array}$ & $\begin{array}{l}-0,081 \\
(0,073)\end{array}$ & $\begin{array}{l}-0,094 \\
(0,073)\end{array}$ & $\begin{array}{l}-0,098 \\
(0,073)\end{array}$ \\
\hline corrige tarefas de matemática & & & & $\begin{array}{c}1,905^{* * *} * \\
(0,352)\end{array}$ & $\begin{array}{c}1,862 * * * \\
(0,352)\end{array}$ & $\begin{array}{c}1,638 * * * \\
(0,349)\end{array}$ & $\begin{array}{c}1,637 * * * \\
(0,349)\end{array}$ \\
\hline $\begin{array}{l}\text { proporção de professores com } \\
\text { ensino superior }\end{array}$ & & & & $\begin{array}{l}-0,022 \\
(0,037)\end{array}$ & $\begin{array}{l}-0,003 \\
(0,037)\end{array}$ & $\begin{array}{l}-0,010 \\
(0,036)\end{array}$ & $\begin{array}{l}-0,010 \\
(0,036)\end{array}$ \\
\hline $\begin{array}{c}\text { escolaridade média em anos de } \\
\text { estudo }\end{array}$ & & & & & $\begin{array}{c}0,210 \\
(0,488)\end{array}$ & $\begin{array}{c}0,266 \\
(0,490)\end{array}$ & $\begin{array}{c}0,197 \\
(0,491)\end{array}$ \\
\hline índice de pobreza & & & & & $\begin{array}{c}-40,241 * * * \\
(12,110)\end{array}$ & $\begin{array}{c}-38,682 * * * \\
(12,036)\end{array}$ & $\begin{array}{c}-38,919 * * * * \\
(12,008)\end{array}$ \\
\hline escolaridade dos pais dos colegas & & & & & & $\begin{array}{l}1,014 * * \\
(0,402)\end{array}$ & $\begin{array}{l}1,014 * * \\
(0,402)\end{array}$ \\
\hline reunião de pais & & & & & & $\begin{array}{c}5,344 * * * \\
(0,290)\end{array}$ & $\begin{array}{c}5,343 * * * \\
(0,290)\end{array}$ \\
\hline $\begin{array}{l}\text { taxa de livros didáticos } \\
\text { devolvidos por aluno }\end{array}$ & & & & & & $\begin{array}{c}0,081 \\
(0,060)\end{array}$ & $\begin{array}{c}0,082 \\
(0,060)\end{array}$ \\
\hline constante & $\begin{array}{c}172,353 * * * * \\
(0,205)\end{array}$ & $\begin{array}{c}139,782^{* * * *} \\
(1,955)\end{array}$ & $\begin{array}{c}131,349 * * * \\
(2,095) \\
\end{array}$ & $\begin{array}{c}146,579 * * * \\
(4,979) \\
\end{array}$ & $\begin{array}{c}150,825^{* * *} \\
(7,155) \\
\end{array}$ & $\begin{array}{c}148,179^{* * *} \\
(7,144)\end{array}$ & $\begin{array}{c}148,473 * * * \\
(7,134) \\
\end{array}$ \\
\hline $\mathrm{R}^{2}$ & 0,006 & 0,200 & 0,213 & 0,222 & 0,223 & 0,226 & 0,226 \\
\hline número de observações & 101436 & 83609 & 81857 & 81402 & 81402 & 81077 & 81077 \\
\hline
\end{tabular}


Tabela A6 - A associação entre furto consumado e notas de matemática (continua)

\begin{tabular}{|c|c|c|c|c|c|c|c|}
\hline Variáveis & Modelo 1 & Modelo 2 & Modelo 3 & Modelo 4 & Modelo 5 & Modelo 6 & Modelo 7 \\
\hline Furto consumado (2005) & $\begin{array}{c}0,002 * * * \\
(0,000)\end{array}$ & $\begin{array}{c}0,002 * * \\
(0,001)\end{array}$ & $\begin{array}{c}0,002 * * \\
(0,001)\end{array}$ & $\begin{array}{c}0,001 \\
(0,001) \\
\end{array}$ & $\begin{array}{c}0,000 \\
(0,000) \\
\end{array}$ & $\begin{array}{c}0,000 \\
(0,000) \\
\end{array}$ & \\
\hline Furto consumado (2004) & & & & & & & $\begin{array}{c}0,000 \\
(0,000) \\
\end{array}$ \\
\hline menino & & $\begin{array}{c}2,091 * * * \\
(0,277)\end{array}$ & $\begin{array}{c}2,191 * * * \\
(0,279) \\
\end{array}$ & $\begin{array}{c}2,180 * * * \\
(0,276)\end{array}$ & $\begin{array}{c}2,172 * * * \\
(0,275) \\
\end{array}$ & $\begin{array}{c}2,284 * * * \\
(0,277)\end{array}$ & $\begin{array}{c}2,284 * * * \\
(0,277)\end{array}$ \\
\hline branco & & $\begin{array}{c}4,737 * * * \\
(0,308)\end{array}$ & $\begin{array}{c}4,341^{* * * *} \\
(0,299)\end{array}$ & $\begin{array}{c}3,763 * * * \\
(0,290) \\
\end{array}$ & $\begin{array}{c}3,709 * * * \\
(0,290)\end{array}$ & $\begin{array}{c}3,656^{* * * *} \\
(0,290) \\
\end{array}$ & $\begin{array}{c}3,655^{* * * *} \\
(0,290)\end{array}$ \\
\hline 8 anos & & $\begin{array}{c}-6,840 * * * \\
(2,081)\end{array}$ & $\begin{array}{c}-9,810 * * * \\
(2,175)\end{array}$ & $\begin{array}{c}-9,426 * * * \\
(2,170) \\
\end{array}$ & $\begin{array}{c}-9,394 * * * \\
(2,167) \\
\end{array}$ & $\begin{array}{c}-10,227 * * * \\
(2,178)\end{array}$ & $\begin{array}{c}-10,225^{* * * *} \\
(2,178) \\
\end{array}$ \\
\hline 9 anos & & $\begin{array}{c}8,981 * * * \\
(1,914) \\
\end{array}$ & $\begin{array}{c}7,707 * * * \\
(1,953)\end{array}$ & $\begin{array}{c}7,211 * * * \\
(1,935)\end{array}$ & $\begin{array}{c}6,994 * * * \\
(1,928)\end{array}$ & $\begin{array}{c}6,289 * * * \\
(1,933)\end{array}$ & $\begin{array}{c}6,289 * * * \\
(1,933)\end{array}$ \\
\hline 10 anos & & $\begin{array}{c}12,973 * * * \\
(1,738)\end{array}$ & $\begin{array}{c}11,213 * * * \\
(1,796)\end{array}$ & $\begin{array}{c}10,536^{* * * *} \\
(1,770)\end{array}$ & $\begin{array}{c}10,344^{* * * *} \\
(1,762)\end{array}$ & $\begin{array}{c}9,847 * * * \\
(1,770)\end{array}$ & $\begin{array}{c}9,848 * * * \\
(1,771)\end{array}$ \\
\hline 11 anos & & $\begin{array}{c}10,733^{* * *} \\
(1,720)\end{array}$ & $\begin{array}{c}9,289 * * * \\
(1,781) \\
\end{array}$ & $\begin{array}{c}8,765^{* * * *} \\
(1,759) \\
\end{array}$ & $\begin{array}{c}8,622^{* * * *} * \\
(1,753)\end{array}$ & $\begin{array}{c}8,256^{* * * *} \\
(1,760) \\
\end{array}$ & $\begin{array}{c}8,258 * * * \\
(1,760)\end{array}$ \\
\hline 12 anos & & $\begin{array}{c}6,813 * * * \\
(1,765) \\
\end{array}$ & $\begin{array}{c}5,687 * * * \\
(1,825) \\
\end{array}$ & $\begin{array}{c}5,443 * * * \\
(1,807)\end{array}$ & $\begin{array}{c}5,342^{* * * *} \\
(1,802)\end{array}$ & $\begin{array}{c}5,154 * * * \\
(1,810)\end{array}$ & $\begin{array}{c}5,156^{* * * *} \\
(1,810) \\
\end{array}$ \\
\hline 13 anos & & $\begin{array}{c}5,005^{* * * *} \\
(1,832) \\
\end{array}$ & $\begin{array}{c}3,827 * * \\
(1,908)\end{array}$ & $\begin{array}{l}3,685^{*} \\
(1,887) \\
\end{array}$ & $\begin{array}{l}3,613^{*} \\
(1,882)\end{array}$ & $\begin{array}{l}3,512 * \\
(1,891)\end{array}$ & $\begin{array}{l}3,515^{*} \\
(1,891) \\
\end{array}$ \\
\hline 14 anos & & $\begin{array}{c}5,442 * * \\
(2,228) \\
\end{array}$ & $\begin{array}{c}4,904 * * \\
(2,267)\end{array}$ & $\begin{array}{c}4,715 * * \\
(2,230)\end{array}$ & $\begin{array}{c}4,654 * * \\
(2,223)\end{array}$ & $\begin{array}{c}4,731 * * \\
(2,218)\end{array}$ & $\begin{array}{c}4,731 * * \\
-2,218\end{array}$ \\
\hline reprovação & & $\begin{array}{c}-14,721 * * * \\
(0,440)\end{array}$ & $\begin{array}{c}-14,231 * * * \\
(0,435)\end{array}$ & $\begin{array}{c}-13,556^{* * * *} \\
(0,432)\end{array}$ & $\begin{array}{c}-13,571 * * * \\
(0,431)\end{array}$ & $\begin{array}{c}-13,371 * * * \\
(0,431)\end{array}$ & $\begin{array}{c}-13,371 * * * \\
(0,431)\end{array}$ \\
\hline tarefa de matemática, & & $\begin{array}{c}9,883^{* * * *} \\
(0,321) \\
\end{array}$ & $\begin{array}{c}9,237 * * * \\
(0,316) \\
\end{array}$ & $\begin{array}{c}8,403 * * * \\
(0,320) \\
\end{array}$ & $\begin{array}{c}8,420 * * * \\
(0,319) \\
\end{array}$ & $\begin{array}{c}7,712 * * * \\
(0,320)\end{array}$ & $\begin{array}{c}7,711^{* * * *} \\
(0,320)\end{array}$ \\
\hline tempo de tv & & $\begin{array}{c}0,401 \\
(0,309) \\
\end{array}$ & $\begin{array}{c}0,441 \\
(0,308) \\
\end{array}$ & $\begin{array}{c}0,336 \\
(0,302) \\
\end{array}$ & $\begin{array}{c}0,326 \\
(0,302) \\
\end{array}$ & $\begin{array}{c}0,376 \\
(0,302) \\
\end{array}$ & $\begin{array}{c}0,376 \\
(0,302) \\
\end{array}$ \\
\hline abandono & & $\begin{array}{c}-10,483^{* * * *} \\
(0,494)\end{array}$ & $\begin{array}{c}-10,054 * * * \\
(0,503)\end{array}$ & $\begin{array}{c}-9,749 * * * \\
(0,502)\end{array}$ & $\begin{array}{c}-9,716^{* * * *} \\
(0,503)\end{array}$ & $\begin{array}{c}-9,205 * * * \\
(0,504)\end{array}$ & $\begin{array}{c}-9,204 * * * \\
(0,504)\end{array}$ \\
\hline trabalha fora de casa & & $\begin{array}{c}-10,722 * * * \\
(0,392)\end{array}$ & $\begin{array}{c}-10,885^{* * * *} \\
(0,403)\end{array}$ & $\begin{array}{c}-10,699 * * * \\
(0,402)\end{array}$ & $\begin{array}{c}-10,610 * * * \\
(0,401)\end{array}$ & $\begin{array}{c}-10,397 \text { **** } \\
(0,398)\end{array}$ & $\begin{array}{c}-10,398 * * * \\
(0,398) \\
\end{array}$ \\
\hline trabalhos domésticos & & $\begin{array}{c}3,366^{* * * *} \\
(0,294)\end{array}$ & $\begin{array}{c}3,346^{* * * *} \\
(0,294)\end{array}$ & $\begin{array}{c}3,145^{* * * *} \\
(0,288)\end{array}$ & $\begin{array}{c}3,082^{* * * *} * \\
(0,288)\end{array}$ & $\begin{array}{c}2,923 * * * \\
(0,286)\end{array}$ & $\begin{array}{c}2,923 * * * \\
(0,286)\end{array}$ \\
\hline maternal & & $\begin{array}{c}11,915^{* * * *} \\
(0,402)\end{array}$ & $\begin{array}{c}10,464 * * * \\
(0,394)\end{array}$ & $\begin{array}{c}9,860 * * * \\
(0,382)\end{array}$ & $\begin{array}{c}9,701 * * * \\
(0,382)\end{array}$ & $\begin{array}{c}9,317 * * * \\
(0,383) \\
\end{array}$ & $\begin{array}{c}9,317 * * * \\
(0,383)\end{array}$ \\
\hline pré-escola & & $\begin{array}{c}10,887 * * * \\
(0,344)\end{array}$ & $\begin{array}{c}10,097 * * * \\
(0,344)\end{array}$ & $\begin{array}{c}10,078 * * * \\
(0,348)\end{array}$ & $\begin{array}{c}10,034 * * * * \\
(0,349)\end{array}$ & $\begin{array}{c}9,703 * * * \\
(0,348)\end{array}$ & $\begin{array}{c}9,703 * * * \\
(0,348) \\
\end{array}$ \\
\hline estudou na mesma escola & & $\begin{array}{c}-0,144 \\
(0,289) \\
\end{array}$ & $\begin{array}{c}-0,178 \\
(0,290) \\
\end{array}$ & $\begin{array}{l}-0,248 \\
(0,285) \\
\end{array}$ & $\begin{array}{l}-0,195 \\
(0,282) \\
\end{array}$ & $\begin{array}{l}-0,350 \\
(0,284) \\
\end{array}$ & $\begin{array}{l}-0,349 \\
(0,283) \\
\end{array}$ \\
\hline mora com pai ou mãe & & $\begin{array}{c}-1,250 * * * \\
(0,311) \\
\end{array}$ & $\begin{array}{c}-0,973 * * * \\
(0,314)\end{array}$ & $\begin{array}{c}-1,056 * * * \\
(0,313) \\
\end{array}$ & $\begin{array}{c}-1,075 * * * \\
(0,314)\end{array}$ & $\begin{array}{c}-0,647 * * \\
(0,317)\end{array}$ & $\begin{array}{c}-0,647 * * \\
(0,317) \\
\end{array}$ \\
\hline $\begin{array}{l}\text { mora sozinho ou com mais uma } \\
\text { pessoa }\end{array}$ & & $\begin{array}{c}7,528 * * * \\
(0,904) \\
\end{array}$ & $\begin{array}{c}7,493 * * * \\
(0,920)\end{array}$ & $\begin{array}{c}7,437 * * * \\
(0,909) \\
\end{array}$ & $\begin{array}{c}7,354 * * * \\
(0,903) \\
\end{array}$ & $\begin{array}{c}6,943 * * * \\
(0,901) \\
\end{array}$ & $\begin{array}{c}6,943 * * * \\
(0,901) \\
\end{array}$ \\
\hline mora com mais duas pessoas & & $\begin{array}{c}13,636^{* * * *} \\
(0,619)\end{array}$ & $\begin{array}{c}13,237 * * * \\
(0,612)\end{array}$ & $\begin{array}{c}12,878^{* * * *} \\
(0,609)\end{array}$ & $\begin{array}{c}12,776^{* * * *} \\
(0,605)\end{array}$ & $\begin{array}{c}12,529 * * * \\
(0,604)\end{array}$ & $\begin{array}{c}12,529 * * * \\
(0,604)\end{array}$ \\
\hline mora com mais três pessoas & & $\begin{array}{c}13,432 * * * \\
(0,592)\end{array}$ & $\begin{array}{c}12,858 * * * \\
(0,590)\end{array}$ & $\begin{array}{c}12,631 * * * \\
(0,581)\end{array}$ & $\begin{array}{c}12,549 * * * \\
(0,579)\end{array}$ & $\begin{array}{c}12,279 * * * \\
(0,577)\end{array}$ & $\begin{array}{c}12,279 * * * \\
(0,577)\end{array}$ \\
\hline $\begin{array}{c}\text { mora com mais quatro ou cinco } \\
\text { pessoas }\end{array}$ & & $\begin{array}{l}5,551^{* * * *} \\
(0,526)\end{array}$ & $\begin{array}{c}5,339 * * * \\
(0,525)\end{array}$ & $\begin{array}{c}5,119 * * * \\
(0,517)\end{array}$ & $\begin{array}{c}5,057 * * * \\
(0,515)\end{array}$ & $\begin{array}{c}4,899 * * * \\
(0,513)\end{array}$ & $\begin{array}{c}4,899 * * * \\
(0,513)\end{array}$ \\
\hline
\end{tabular}


Tabela A6 - A associação entre furto consumado e notas de matemática (continuação)

\begin{tabular}{|c|c|c|c|c|c|c|c|}
\hline Variáveis & Modelo 1 & Modelo 2 & Modelo 3 & Modelo 4 & Modelo 5 & Modelo 6 & Modelo 7 \\
\hline $\begin{array}{l}\text { mora com mais seis a oito } \\
\text { pessoas }\end{array}$ & & $\begin{array}{c}2,790 * * * \\
(0,564)\end{array}$ & $\begin{array}{c}2,685 * * * \\
(0,559)\end{array}$ & $\begin{array}{c}2,639 * * * \\
(0,551)\end{array}$ & $\begin{array}{c}2,606 * * * \\
(0,551)\end{array}$ & $\begin{array}{c}2,573 * * * \\
(0,552)\end{array}$ & $\begin{array}{c}2,574 * * * \\
(0,552)\end{array}$ \\
\hline futuro (ainda não sei) & & $\begin{array}{c}5,845 * * * \\
(0,433) \\
\end{array}$ & $\begin{array}{c}6,322 * * * \\
(0,441)\end{array}$ & $\begin{array}{c}5,979 * * * \\
(0,437) \\
\end{array}$ & $\begin{array}{c}5,929 * * * \\
(0,436)\end{array}$ & $\begin{array}{c}5,894 * * * \\
(0,441) \\
\end{array}$ & $\begin{array}{c}5,894 * * * \\
(0,441)\end{array}$ \\
\hline futuro (estudar) & & $\begin{array}{c}5,696^{* * *} * \\
(0,511)\end{array}$ & $\begin{array}{c}5,162 * * * \\
(0,508)\end{array}$ & $\begin{array}{c}4,690 * * * \\
(0,498)\end{array}$ & $\begin{array}{c}4,612 * * * \\
(0,498)\end{array}$ & $\begin{array}{c}4,213 * * * \\
(0,499)\end{array}$ & $\begin{array}{c}4,213 * * * \\
(0,499)\end{array}$ \\
\hline futuro (estudar e trabalhar) & & $\begin{array}{c}12,038 * * * \\
(0,450)\end{array}$ & $\begin{array}{c}11,356^{* * * *} \\
(0,453)\end{array}$ & $\begin{array}{c}11,026^{* * * *} \\
(0,449)\end{array}$ & $\begin{array}{c}10,959 * * * \\
(0,448)\end{array}$ & $\begin{array}{c}10,661 * * * \\
(0,450)\end{array}$ & $\begin{array}{c}10,662 * * * \\
(0,450)\end{array}$ \\
\hline deixado de lado & & $\begin{array}{c}-12,403 * * * * \\
(0,362)\end{array}$ & $\begin{array}{c}-12,172 * * * \\
(0,363)\end{array}$ & $\begin{array}{c}-11,889 * * * \\
(0,358)\end{array}$ & $\begin{array}{c}-11,835 * * * \\
(0,358) \\
\end{array}$ & $\begin{array}{c}-11,769 * * * \\
(0,358)\end{array}$ & $\begin{array}{c}-11,769 * * * \\
(0,358)\end{array}$ \\
\hline bolsa família & & $\begin{array}{c}-9,124 * * * \\
(0,347) \\
\end{array}$ & $\begin{array}{c}-8,754 * * * \\
(0,345)\end{array}$ & $\begin{array}{c}-8,498 * * * * \\
(0,341)\end{array}$ & $\begin{array}{c}-8,478 * * * \\
(0,338)\end{array}$ & $\begin{array}{c}-8,553 * * * \\
(0,340) \\
\end{array}$ & $\begin{array}{c}-8,553 * * * * \\
(0,340)\end{array}$ \\
\hline livros & & & $\begin{array}{c}2,166 * * * \\
(0,284)\end{array}$ & $\begin{array}{c}1,979 * * * \\
(0,280)\end{array}$ & $\begin{array}{c}1,891 * * * \\
(0,278)\end{array}$ & $\begin{array}{c}1,640 * * * \\
(0,276)\end{array}$ & $\begin{array}{c}1,640 * * * \\
(0,276)\end{array}$ \\
\hline computador & & & $\begin{array}{c}3,317 * * * \\
(0,321)\end{array}$ & $\begin{array}{c}2,804 * * * \\
(0,309)\end{array}$ & $\begin{array}{c}2,627 * * * \\
(0,307)\end{array}$ & $\begin{array}{c}2,396 * * * * \\
(0,307)\end{array}$ & $\begin{array}{c}2,396 * * * \\
(0,307)\end{array}$ \\
\hline apoio aos estudos & & & $\begin{array}{c}7,876^{* * *} \\
(0,619)\end{array}$ & $\begin{array}{c}7,487 * * * \\
(0,614) \\
\end{array}$ & $\begin{array}{c}7,432 * * * \\
(0,615) \\
\end{array}$ & $\begin{array}{c}6,980 * * * \\
(0,620)\end{array}$ & $\begin{array}{c}6,979 * * * \\
(0,620)\end{array}$ \\
\hline $\begin{array}{l}\text { mãe nunca estudou ou não } \\
\text { completou a } 4^{\mathrm{a}} \text { série }\end{array}$ & & & $\begin{array}{c}-1,812 * * * \\
(0,521)\end{array}$ & $\begin{array}{c}-1,603 * * * \\
(0,522)\end{array}$ & $\begin{array}{c}-1,468 * * * \\
(0,521)\end{array}$ & $\begin{array}{c}-1,242 * * \\
(0,527)\end{array}$ & $\begin{array}{c}-1,243 * * \\
(0,527)\end{array}$ \\
\hline $\begin{array}{l}\text { mãe completou a } 4^{\mathrm{a}} \text { série (antigo } \\
\text { primário), mas não completou a } \\
8^{\mathrm{a}} \text { série }\end{array}$ & & & $\begin{array}{c}2,608 * * * \\
(0,365)\end{array}$ & $\begin{array}{c}2,294 * * * \\
(0,363)\end{array}$ & $\begin{array}{c}2,370 * * * \\
(0,364) \\
\end{array}$ & $\begin{array}{c}2,545^{* * * *} \\
(0,373)\end{array}$ & $\begin{array}{c}2,545 * * * \\
(0,373)\end{array}$ \\
\hline $\begin{array}{c}\text { mãe completou a } 8^{\text {a }} \text { série (antigo } \\
\text { ginásio), mas não completou o } \\
\text { Ensino Médio }\end{array}$ & & & $\begin{array}{c}3,403 * * * \\
(0,418)\end{array}$ & $\begin{array}{c}3,016^{* * *} * \\
(0,413)\end{array}$ & $\begin{array}{c}3,094 * * * \\
(0,411)\end{array}$ & $\begin{array}{c}3,226 * * * \\
(0,422) \\
\end{array}$ & $\begin{array}{c}3,226 * * * \\
(0,422) \\
\end{array}$ \\
\hline $\begin{array}{l}\text { mãe completou o Ensino Médio } \\
\text { (antigo } 2^{\circ} \text { grau), mas não } \\
\text { completou a Faculdade }\end{array}$ & & & $\begin{array}{c}10,566 * * * \\
(0,429) \\
\end{array}$ & $\begin{array}{c}9,994 * * * \\
(0,424)\end{array}$ & $\begin{array}{c}10,019 * * * \\
(0,425)\end{array}$ & $\begin{array}{c}10,082 * * * \\
(0,429)\end{array}$ & $\begin{array}{c}10,082 * * * \\
(0,429)\end{array}$ \\
\hline tamanho da sala (11-15) & & & & $\begin{array}{c}-6,483 \\
(8,651) \\
\end{array}$ & $\begin{array}{l}-7,185 \\
(8,493) \\
\end{array}$ & $\begin{array}{l}-7,847 \\
(8,397)\end{array}$ & $\begin{array}{l}-7,857 \\
(8,398)\end{array}$ \\
\hline tamanho da sala (16-20) & & & & $\begin{array}{l}-8,737 * \\
(4,479) \\
\end{array}$ & $\begin{array}{c}-9,316^{* * *} \\
(4,267) \\
\end{array}$ & $\begin{array}{c}-9,195 * * \\
(4,262) \\
\end{array}$ & $\begin{array}{c}-9,197 * * \\
(4,262) \\
\end{array}$ \\
\hline tamanho da sala (21-25) & & & & $\begin{array}{c}-8,424 * * \\
(4,254)\end{array}$ & $\begin{array}{c}-9,221 * * \\
(4,022) \\
\end{array}$ & $\begin{array}{c}-9,351 * * \\
(4,015) \\
\end{array}$ & $\begin{array}{c}-9,353 * * \\
(4,015) \\
\end{array}$ \\
\hline tamanho da sala (26-30) & & & & $\begin{array}{c}-4,973 \\
(4,220)\end{array}$ & $\begin{array}{l}-5,665 \\
(3,975) \\
\end{array}$ & $\begin{array}{l}-5,675 \\
(3,972) \\
\end{array}$ & $\begin{array}{l}-5,677 \\
(3,972)\end{array}$ \\
\hline tamanho da sala (31-35) & & & & $\begin{array}{l}-2,458 \\
(4,201)\end{array}$ & $\begin{array}{l}-3,046 \\
(3,963)\end{array}$ & $\begin{array}{l}-3,089 \\
(3,959)\end{array}$ & $\begin{array}{c}-3,088 \\
(3,959)\end{array}$ \\
\hline tamanho da sala (36-40) & & & & $\begin{array}{l}-0,916 \\
(4,231)\end{array}$ & $\begin{array}{c}-1,534 \\
(3,987)\end{array}$ & $\begin{array}{l}-1,585 \\
(3,985)\end{array}$ & $\begin{array}{l}-1,585 \\
(3,985)\end{array}$ \\
\hline tamanho da sala (41-45) & & & & $\begin{array}{l}-1,462 \\
(5,341)\end{array}$ & $\begin{array}{l}-1,623 \\
(5,313)\end{array}$ & $\begin{array}{l}-1,587 \\
(5,273)\end{array}$ & $\begin{array}{l}-1,602 \\
(5,273)\end{array}$ \\
\hline municipal & & & & $\begin{array}{c}-7,168 * * * \\
(0,810) \\
\end{array}$ & $\begin{array}{c}-7,012 * * * * \\
(0,801)\end{array}$ & $\begin{array}{c}-6,649 * * * \\
(0,851)\end{array}$ & $\begin{array}{c}-6,642 * * * * \\
(0,852) \\
\end{array}$ \\
\hline ensino médio & & & & $\begin{array}{c}-3,075^{* * *} * \\
(0,927)\end{array}$ & $\begin{array}{c}-2,633 * * * * \\
(0,936) \\
\end{array}$ & $\begin{array}{c}-2,567 * * * \\
(0,933)\end{array}$ & $\begin{array}{c}-2,565 * * * \\
(0,932)\end{array}$ \\
\hline laboratório de informática & & & & $\begin{array}{l}-1,059 \\
(0,796)\end{array}$ & $\begin{array}{l}-1,125 \\
(0,790)\end{array}$ & $\begin{array}{l}-1,009 \\
(0,783)\end{array}$ & $\begin{array}{c}-1,014 \\
(0,783)\end{array}$ \\
\hline
\end{tabular}


Tabela A6 - A associação entre furto consumado e notas de matemática (conclusão)

\begin{tabular}{|c|c|c|c|c|c|c|c|}
\hline Variáveis & Modelo 1 & Modelo 2 & Modelo 3 & Modelo 4 & Modelo 5 & Modelo 6 & Modelo 7 \\
\hline laboratório de ciências & & & & $\begin{array}{c}0,782 \\
(0,728) \\
\end{array}$ & $\begin{array}{c}0,416 \\
(0,711) \\
\end{array}$ & $\begin{array}{c}0,398 \\
(0,703) \\
\end{array}$ & $\begin{array}{c}0,402 \\
(0,703) \\
\end{array}$ \\
\hline biblioteca & & & & $\begin{array}{c}0,159 \\
(1,322)\end{array}$ & $\begin{array}{c}0,012 \\
(1,230) \\
\end{array}$ & $\begin{array}{l}-0,054 \\
(1,208)\end{array}$ & $\begin{array}{l}-0,061 \\
(1,207)\end{array}$ \\
\hline sala de leitura & & & & $\begin{array}{l}1,725 * * \\
(0,776)\end{array}$ & $\begin{array}{l}1,401 * \\
(0,774)\end{array}$ & $\begin{array}{c}1,256 \\
(0,766)\end{array}$ & $\begin{array}{c}1,255 \\
(0,766)\end{array}$ \\
\hline $\begin{array}{l}\text { uso de computadores em sala de } \\
\text { aula }\end{array}$ & & & & $\begin{array}{l}-0,767 \\
(1,302)\end{array}$ & $\begin{array}{l}-0,651 \\
(1,372)\end{array}$ & $\begin{array}{l}-0,426 \\
(1,360)\end{array}$ & $\begin{array}{l}-0,425 \\
(1,360)\end{array}$ \\
\hline programas educacionais & & & & $\begin{array}{c}1,437 \\
(1,138) \\
\end{array}$ & $\begin{array}{c}0,796 \\
(1,071) \\
\end{array}$ & $\begin{array}{c}0,834 \\
(1,078) \\
\end{array}$ & $\begin{array}{c}0,835 \\
(1,078) \\
\end{array}$ \\
\hline distância em relação ao centro & & & & $\begin{array}{c}-0,377 * * * \\
(0,053) \\
\end{array}$ & $\begin{array}{l}-0,075 \\
(0,073)\end{array}$ & $\begin{array}{l}-0,088 \\
(0,073)\end{array}$ & $\begin{array}{l}-0,088 \\
(0,073)\end{array}$ \\
\hline corrige tarefas de matemática & & & & $\begin{array}{c}1,912 * * * \\
(0,353)\end{array}$ & $\begin{array}{c}1,859 * * * \\
(0,352)\end{array}$ & $\begin{array}{c}1,635^{* * * *} \\
(0,349)\end{array}$ & $\begin{array}{c}1,635 * * * \\
(0,349) \\
\end{array}$ \\
\hline $\begin{array}{l}\text { proporção de professores com } \\
\text { ensino superior }\end{array}$ & & & & $\begin{array}{l}-0,028 \\
(0,038)\end{array}$ & $\begin{array}{l}-0,003 \\
(0,037) \\
\end{array}$ & $\begin{array}{l}-0,009 \\
(0,037)\end{array}$ & $\begin{array}{l}-0,009 \\
(0,037) \\
\end{array}$ \\
\hline $\begin{array}{l}\text { escolaridade média em anos de } \\
\text { estudo }\end{array}$ & & & & & $\begin{array}{c}0,450 \\
(0,466) \\
\end{array}$ & $\begin{array}{c}0,492 \\
(0,469) \\
\end{array}$ & $\begin{array}{c}0,478 \\
(0,469) \\
\end{array}$ \\
\hline índice de pobreza & & & & & $\begin{array}{c}-39,967 * * * \\
(12,133) \\
\end{array}$ & $\begin{array}{c}-38,410 * * * \\
(12,057)\end{array}$ & $\begin{array}{c}-38,539 * * * \\
(12,041)\end{array}$ \\
\hline escolaridade dos pais dos colegas & & & & & & $\begin{array}{l}1,023 * * \\
(0,402) \\
\end{array}$ & $\begin{array}{l}1,023 * * \\
(0,402) \\
\end{array}$ \\
\hline reunião de pais & & & & & & $\begin{array}{c}5,350 * * * \\
(0,290) \\
\end{array}$ & $\begin{array}{c}5,351 * * * \\
(0,290) \\
\end{array}$ \\
\hline $\begin{array}{l}\text { taxa de livros didáticos } \\
\text { devolvidos por aluno }\end{array}$ & & & & & & $\begin{array}{c}0,081 \\
(0,060) \\
\end{array}$ & $\begin{array}{c}0,081 \\
(0,060) \\
\end{array}$ \\
\hline constante & $\begin{array}{c}174,539 * * * \\
(0,166) \\
\end{array}$ & $\begin{array}{c}141,147 * * * \\
(1,909)\end{array}$ & $\begin{array}{c}132,595 * * * \\
(2,055)\end{array}$ & $\begin{array}{c}147,856^{* * * *} \\
(5,009) \\
\end{array}$ & $\begin{array}{c}149,614 * * * \\
(7,136) \\
\end{array}$ & $\begin{array}{c}147,038 * * * \\
(7,124) \\
\end{array}$ & $\begin{array}{c}147,135 * * * \\
(7,116) \\
\end{array}$ \\
\hline $\mathrm{R}^{2}$ & 0,003 & 0,199 & 0,211 & 0,221 & 0,223 & 0,226 & 0,226 \\
\hline número de observações & 101436 & 83609 & 81857 & 81402 & 81402 & 81077 & 81077 \\
\hline
\end{tabular}

Fonte: Elaboração própria com base nos dados da SEADE, Prova Brasil 2005, Censo Escolar 2005 e Censo Demográfico 2000.

$* * *$ significante a $1 \% * *$ significante a $5 \% *$ significante a $10 \%$ 
Tabela A7 - A associação entre crimes contra a pessoa e notas de português (continua)

\begin{tabular}{|c|c|c|c|c|c|c|c|}
\hline Variáveis & Modelo 1 & Modelo 2 & Modelo 3 & Modelo 4 & Modelo 5 & Modelo 6 & Modelo 7 \\
\hline Crimes contra a pessoa (2005) & $\begin{array}{c}0,008 * * * \\
(0,000)\end{array}$ & $\begin{array}{c}0,006 * * * \\
(0,001) \\
\end{array}$ & $\begin{array}{c}0,006^{* * * *} \\
(0,001)\end{array}$ & $\begin{array}{c}0,002 * * * \\
(0,001) \\
\end{array}$ & $\begin{array}{c}0,001 \\
(0,001)\end{array}$ & $\begin{array}{c}0,001 \\
(0,001)\end{array}$ & \\
\hline Crimes contra a pessoa (2004) & & & & & & & $\begin{array}{c}0,001 \\
(0,001)\end{array}$ \\
\hline menino & & $\begin{array}{c}-6,352 * * * \\
(0,294)\end{array}$ & $\begin{array}{c}-6,338^{* * *} * \\
(0,293)\end{array}$ & $\begin{array}{c}-6,385^{* * *} * \\
(0,289)\end{array}$ & $\begin{array}{c}-6,394 * * * \\
(0,289)\end{array}$ & $\begin{array}{c}-6,291 * * * \\
(0,290)\end{array}$ & $\begin{array}{c}-6,290 * * * \\
(0,290)\end{array}$ \\
\hline branco & & $\begin{array}{c}4,708 * * * \\
(0,324)\end{array}$ & $\begin{array}{c}4,216 * * * \\
(0,315)\end{array}$ & $\begin{array}{c}3,612 * * * \\
(0,309) \\
\end{array}$ & $\begin{array}{c}3,589 * * * \\
(0,308)\end{array}$ & $\begin{array}{c}3,500 * * * \\
(0,308)\end{array}$ & $\begin{array}{c}3,502 * * * \\
(0,308)\end{array}$ \\
\hline 8 anos & & $\begin{array}{c}-6,539 * * * \\
(2,008)\end{array}$ & $\begin{array}{c}-9,062 * * * \\
-2,095\end{array}$ & $\begin{array}{c}-9,115^{* * *} \\
(2,131)\end{array}$ & $\begin{array}{c}-9,020 * * * \\
(2,130)\end{array}$ & $\begin{array}{c}-9,629 * * * \\
(2,134)\end{array}$ & $\begin{array}{c}-9,640 * * * \\
(2,134)\end{array}$ \\
\hline 9 anos & & $\begin{array}{c}9,070 \text { *** } \\
(1,983)\end{array}$ & $\begin{array}{c}8,086^{* * * *} \\
(2,049)\end{array}$ & $\begin{array}{c}6,787 * * * \\
(2,086)\end{array}$ & $\begin{array}{c}6,670 \text { **** } \\
(2,081)\end{array}$ & $\begin{array}{c}5,960 * * * \\
(2,086)\end{array}$ & $\begin{array}{c}5,954 * * * \\
(2,086)\end{array}$ \\
\hline 10 anos & & $\begin{array}{c}12,665^{* * * *} \\
(1,756) \\
\end{array}$ & $\begin{array}{c}11,069^{* * *} \\
(1,835) \\
\end{array}$ & $\begin{array}{c}9,815^{* * * *} \\
(1,858) \\
\end{array}$ & $\begin{array}{c}9,709 * * * * \\
(1,853) \\
\end{array}$ & $\begin{array}{c}9,142 * * * \\
(1,859)\end{array}$ & $\begin{array}{c}9,137 * * * \\
(1,860)\end{array}$ \\
\hline 11 anos & & $\begin{array}{c}10,008 * * * \\
(1,746)\end{array}$ & $\begin{array}{c}8,843^{* * * *} \\
(1,838) \\
\end{array}$ & $\begin{array}{c}8,042 * * * \\
(1,862) \\
\end{array}$ & $\begin{array}{c}7,983 * * * \\
(1,857) \\
\end{array}$ & $\begin{array}{c}7,552^{* * * *} \\
(1,860)\end{array}$ & $\begin{array}{c}7,551 * * * \\
(1,861)\end{array}$ \\
\hline 12 anos & & $\begin{array}{c}5,649 * * * \\
(1,790) \\
\end{array}$ & $\begin{array}{c}4,803 * * \\
(1,867)\end{array}$ & $\begin{array}{c}4,594 * * \\
(1,901) \\
\end{array}$ & $\begin{array}{c}4,558 * * \\
(1,897) \\
\end{array}$ & $\begin{array}{c}4,326 * * \\
(1,901) \\
\end{array}$ & $\begin{array}{c}4,324 * * \\
(1,901) \\
\end{array}$ \\
\hline 13 anos & & $\begin{array}{c}3,965^{* * *} \\
(1,876)\end{array}$ & $\begin{array}{c}3,028 \\
(1,959)\end{array}$ & $\begin{array}{c}2,945 \\
(1,973)\end{array}$ & $\begin{array}{c}2,946 \\
(1,969)\end{array}$ & $\begin{array}{c}2,662 \\
(1,969)\end{array}$ & $\begin{array}{c}2,659 \\
(1,969)\end{array}$ \\
\hline 14 anos & & $\begin{array}{c}5,387 * * * \\
(2,240) \\
\end{array}$ & $\begin{array}{c}5,034^{* * *} \\
(2,342) \\
\end{array}$ & $\begin{array}{c}4,788 * * \\
(2,328) \\
\end{array}$ & $\begin{array}{c}4,772 * * \\
(2,327) \\
\end{array}$ & $\begin{array}{c}4,817 * * \\
(2,316) \\
\end{array}$ & $\begin{array}{c}4,804 * * \\
(2,317) \\
\end{array}$ \\
\hline reprovação & & $\begin{array}{c}-17,542 * * * \\
(0,425)\end{array}$ & $\begin{array}{c}-16,947 * * * \\
(0,425)\end{array}$ & $\begin{array}{c}-16,045^{* * * *} \\
(0,418)\end{array}$ & $\begin{array}{c}-16,076^{* * * *} \\
(0,419)\end{array}$ & $\begin{array}{c}-15,801 * * * * \\
(0,419)\end{array}$ & $\begin{array}{c}-15,803 * * * \\
(0,419)\end{array}$ \\
\hline tarefa de português & & $\begin{array}{c}11,617 \text { *** } \\
(0,336)\end{array}$ & $\begin{array}{c}10,711 * * * \\
(0,334)\end{array}$ & $\begin{array}{c}10,117 \text { *** } \\
(0,331)\end{array}$ & $\begin{array}{c}10,092 * * * * \\
(0,332)\end{array}$ & $\begin{array}{c}9,249 * * * \\
(0,331)\end{array}$ & $\begin{array}{c}9,251 * * * \\
(0,331)\end{array}$ \\
\hline tempo de tv & & $\begin{array}{c}0,474 \\
(0,323) \\
\end{array}$ & $\begin{array}{c}0,478 \\
(0,320) \\
\end{array}$ & $\begin{array}{c}0,344 \\
(0,313) \\
\end{array}$ & $\begin{array}{c}0,337 \\
(0,312) \\
\end{array}$ & $\begin{array}{c}0,377 \\
(0,310) \\
\end{array}$ & $\begin{array}{c}0,379 \\
(0,310) \\
\end{array}$ \\
\hline abandono & & $\begin{array}{c}-10,562 * * * \\
(0,484)\end{array}$ & $\begin{array}{c}-9,948 * * * \\
(0,497)\end{array}$ & $\begin{array}{c}-9,868 * * * \\
(0,498) \\
\end{array}$ & $\begin{array}{c}-9,836 * * * \\
(0,499) \\
\end{array}$ & $\begin{array}{c}-9,247 * * * * \\
(0,502)\end{array}$ & $\begin{array}{c}-9,248 * * * \\
(0,502)\end{array}$ \\
\hline trabalha fora de casa & & $\begin{array}{c}-13,573 * * * \\
(0,400)\end{array}$ & $\begin{array}{c}-13,781 * * * \\
(0,408)\end{array}$ & $\begin{array}{c}-13,611 * * * \\
(0,405)\end{array}$ & $\begin{array}{c}-13,532 * * * \\
(0,404)\end{array}$ & $\begin{array}{c}-13,316^{* * * *} \\
(0,404)\end{array}$ & $\begin{array}{c}-13,318 * * * \\
(0,404) \\
\end{array}$ \\
\hline trabalhos domésticos & & $\begin{array}{c}3,948 * * * \\
(0,318)\end{array}$ & $\begin{array}{c}3,957 * * * \\
(0,314)\end{array}$ & $\begin{array}{c}3,834 * * * \\
(0,312)\end{array}$ & $\begin{array}{c}3,776 \text { *** } \\
(0,311)\end{array}$ & $\begin{array}{c}3,604 * * * \\
(0,310)\end{array}$ & $\begin{array}{c}3,606 * * * \\
(0,310)\end{array}$ \\
\hline maternal & & $\begin{array}{c}12,885^{* * *} * \\
(0,408)\end{array}$ & $\begin{array}{c}11,150 * * * \\
(0,407)\end{array}$ & $\begin{array}{c}10,719 * * * \\
(0,403)\end{array}$ & $\begin{array}{c}10,590 * * * \\
(0,402)\end{array}$ & $\begin{array}{c}10,165^{* * *} \\
(0,399)\end{array}$ & $\begin{array}{c}10,168 * * * \\
(0,399)\end{array}$ \\
\hline pré-escola & & $\begin{array}{c}11,324 * * * \\
(0,371)\end{array}$ & $\begin{array}{c}10,342 * * * \\
(0,373)\end{array}$ & $\begin{array}{c}10,505^{* * *} \\
(0,374)\end{array}$ & $\begin{array}{c}10,485^{* * *} * \\
(0,374)\end{array}$ & $\begin{array}{c}10,111 * * * \\
(0,373)\end{array}$ & $\begin{array}{c}10,117 * * * * \\
(0,373)\end{array}$ \\
\hline estudou na mesma escola & & $\begin{array}{c}-0,969 * * * \\
(0,310)\end{array}$ & $\begin{array}{c}-1,005^{* * *} \\
(0,308)\end{array}$ & $\begin{array}{c}-0,998 * * * \\
(0,303)\end{array}$ & $\begin{array}{c}-0,958 * * * \\
(0,302)\end{array}$ & $\begin{array}{c}-1,166^{* * * *} \\
(0,302)\end{array}$ & $\begin{array}{c}-1,164 * * * \\
(0,302)\end{array}$ \\
\hline mora com pai ou mãe & & $\begin{array}{c}-1,842 * * * \\
(0,306)\end{array}$ & $\begin{array}{c}-1,510 * * * \\
(0,310)\end{array}$ & $\begin{array}{c}-1,593 * * * \\
(0,309)\end{array}$ & $\begin{array}{c}-1,613 * * * \\
(0,308)\end{array}$ & $\begin{array}{c}-1,105^{* * * *} \\
(0,308)\end{array}$ & $\begin{array}{c}-1,102 * * * \\
(0,308)\end{array}$ \\
\hline $\begin{array}{l}\text { mora sozinho ou com mais uma } \\
\text { pessoa }\end{array}$ & & $\begin{array}{c}11,866^{* * *} \\
(0,915)\end{array}$ & $\begin{array}{c}11,817 * * * \\
(0,931)\end{array}$ & $\begin{array}{c}11,610^{* * * *} \\
(0,909)\end{array}$ & $\begin{array}{c}11,508 * * * \\
(0,904)\end{array}$ & $\begin{array}{c}11,017 * * * * \\
(0,908)\end{array}$ & $\begin{array}{c}11,012^{* * * *} \\
(0,908)\end{array}$ \\
\hline mora com mais duas pessoas & & $\begin{array}{c}18,703^{* * * *} \\
(0,639)\end{array}$ & $\begin{array}{c}18,289 * * * \\
(0,635)\end{array}$ & $\begin{array}{c}17,777 * * * \\
(0,625)\end{array}$ & $\begin{array}{c}17,661 * * * \\
(0,622)\end{array}$ & $\begin{array}{c}17,346 * * * \\
(0,622)\end{array}$ & $\begin{array}{c}17,344 * * * \\
(0,623)\end{array}$ \\
\hline mora com mais três pessoas & & $\begin{array}{c}17,130 * * * \\
(0,574)\end{array}$ & $\begin{array}{c}16,390 * * * \\
(0,578)\end{array}$ & $\begin{array}{c}15,997 * * * \\
(0,569)\end{array}$ & $\begin{array}{c}15,911^{* * * *} \\
(0,566)\end{array}$ & $\begin{array}{c}15,575^{* * * *} \\
(0,563)\end{array}$ & $\begin{array}{c}15,575 * * * \\
(0,563)\end{array}$ \\
\hline $\begin{array}{c}\text { mora com mais quatro ou cinco } \\
\text { pessoas }\end{array}$ & & $\begin{array}{c}7,867 * * * \\
(0,508)\end{array}$ & $\begin{array}{c}7,583 * * * \\
(0,508)\end{array}$ & $\begin{array}{c}7,205 * * * \\
(0,501)\end{array}$ & $\begin{array}{c}7,141^{* * *} * \\
(0,499)\end{array}$ & $\begin{array}{c}6,928^{* * *} \\
(0,495)\end{array}$ & $\begin{array}{c}6,927 * * * \\
(0,496)\end{array}$ \\
\hline
\end{tabular}


Tabela A7 - A associação entre crimes contra a pessoa e notas de português (continuação)

\begin{tabular}{|c|c|c|c|c|c|c|c|}
\hline Variáveis & Modelo 1 & Modelo 2 & Modelo 3 & Modelo 4 & Modelo 5 & Modelo 6 & Modelo 7 \\
\hline mora com mais seis a oito pessoas & & $\begin{array}{c}4,343 * * * \\
(0,560)\end{array}$ & $\begin{array}{c}4,231 * * * \\
(0,562)\end{array}$ & $\begin{array}{c}4,110 * * * \\
(0,557)\end{array}$ & $\begin{array}{c}4,077 * * * \\
(0,557) \\
\end{array}$ & $\begin{array}{c}4,016^{* * * *} \\
(0,558)\end{array}$ & $\begin{array}{c}4,017 * * * \\
(0,558)\end{array}$ \\
\hline futuro (ainda não sei) & & $\begin{array}{c}6,242^{* * * *} \\
(0,477)\end{array}$ & $\begin{array}{c}6,807 * * * * \\
(0,494)\end{array}$ & $\begin{array}{c}6,487 * * * * \\
(0,488) \\
\end{array}$ & $\begin{array}{c}6,439 * * * \\
(0,486) \\
\end{array}$ & $\begin{array}{c}6,356^{* * * *} \\
(0,486) \\
\end{array}$ & $\begin{array}{c}6,353 * * * \\
(0,486) \\
\end{array}$ \\
\hline futuro (estudar) & & $\begin{array}{c}6,441^{* * * *} \\
(0,529) \\
\end{array}$ & $\begin{array}{c}5,791 * * * * \\
(0,532)\end{array}$ & $\begin{array}{c}5,341 * * * \\
(0,525) \\
\end{array}$ & $\begin{array}{c}5,285^{* * * *} \\
(0,524) \\
\end{array}$ & $\begin{array}{c}4,788 * * * \\
(0,524) \\
\end{array}$ & $\begin{array}{c}4,786 * * * \\
(0,523) \\
\end{array}$ \\
\hline futuro (estudar e trabalhar) & & $\begin{array}{c}13,303 * * * \\
(0,468)\end{array}$ & $\begin{array}{c}12,479 * * * \\
(0,483)\end{array}$ & $\begin{array}{c}12,287 * * * \\
(0,476)\end{array}$ & $\begin{array}{c}12,245^{* * * *} \\
(0,473)\end{array}$ & $\begin{array}{c}11,881^{* * * *} \\
(0,473)\end{array}$ & $\begin{array}{c}11,884 * * * \\
(0,474)\end{array}$ \\
\hline deixado de lado & & $\begin{array}{c}-12,829 * * * \\
(0,365)\end{array}$ & $\begin{array}{c}-12,526^{* * * *} \\
(0,365)\end{array}$ & $\begin{array}{c}-12,132 * * * \\
(0,360)\end{array}$ & $\begin{array}{c}-12,091 * * * \\
(0,358)\end{array}$ & $\begin{array}{c}-11,979 * * * \\
(0,358)\end{array}$ & $\begin{array}{c}-11,977 * * * \\
(0,358) \\
\end{array}$ \\
\hline bolsa família & & $\begin{array}{c}-10,081 * * * \\
(0,369)\end{array}$ & $\begin{array}{c}-9,730 * * * \\
(0,374)\end{array}$ & $\begin{array}{c}-9,449 * * * \\
(0,365)\end{array}$ & $\begin{array}{c}-9,408 * * * \\
(0,363)\end{array}$ & $\begin{array}{c}-9,487 * * * \\
(0,362)\end{array}$ & $\begin{array}{c}-9,486 * * * \\
(0,362) \\
\end{array}$ \\
\hline livros & & & $\begin{array}{c}2,682 * * * \\
(0,288)\end{array}$ & $\begin{array}{c}2,330 * * * \\
(0,285) \\
\end{array}$ & $\begin{array}{c}2,245^{* * * *} \\
(0,284)\end{array}$ & $\begin{array}{c}1,963 * * * \\
(0,284)\end{array}$ & $\begin{array}{c}1,962 * * * \\
(0,284)\end{array}$ \\
\hline computador & & & $\begin{array}{c}4,204 * * * * \\
(0,341)\end{array}$ & $\begin{array}{c}3,743 * * * \\
(0,340)\end{array}$ & $\begin{array}{c}3,566^{* * * *} \\
(0,340)\end{array}$ & $\begin{array}{c}3,370^{* * * *} \\
(0,338)\end{array}$ & $\begin{array}{c}3,369 * * * \\
(0,338)\end{array}$ \\
\hline apoio aos estudos & & & $\begin{array}{c}10,979 * * * \\
(0,584)\end{array}$ & $\begin{array}{c}10,751 * * * \\
(0,584)\end{array}$ & $\begin{array}{c}10,713 * * * \\
(0,583)\end{array}$ & $\begin{array}{c}10,032 * * * \\
(0,584)\end{array}$ & $\begin{array}{c}10,032 * * * \\
(0,584)\end{array}$ \\
\hline $\begin{array}{l}\text { mãe nunca estudou ou não } \\
\text { completou a } 4^{\mathrm{a}} \text { série }\end{array}$ & & & $\begin{array}{c}-2,251 * * * \\
(0,520) \\
\end{array}$ & $\begin{array}{c}-2,125^{* * * *} \\
(0,523)\end{array}$ & $\begin{array}{c}-2,004 * * * \\
(0,519)\end{array}$ & $\begin{array}{c}-1,764 * * * \\
(0,521) \\
\end{array}$ & $\begin{array}{c}-1,770 * * * \\
(0,521) \\
\end{array}$ \\
\hline $\begin{array}{l}\text { mãe completou a } 4^{\mathrm{a}} \text { série (antigo } \\
\text { primário), mas não completou a } 8^{\mathrm{a}} \\
\text { série }\end{array}$ & & & $\begin{array}{c}2,972 * * * \\
(0,374)\end{array}$ & $\begin{array}{c}2,404 * * * \\
(0,368) \\
\end{array}$ & $\begin{array}{c}2,466^{* * * *} \\
(0,367) \\
\end{array}$ & $\begin{array}{c}2,657 * * * \\
(0,373) \\
\end{array}$ & $\begin{array}{c}2,653 * * * \\
(0,373) \\
\end{array}$ \\
\hline $\begin{array}{c}\text { mãe completou a } 8^{\mathrm{a}} \text { série (antigo } \\
\text { ginásio), mas não completou o } \\
\text { Ensino Médio }\end{array}$ & & & $\begin{array}{c}3,729 * * * \\
(0,435)\end{array}$ & $\begin{array}{c}2,964 * * * \\
(0,427)\end{array}$ & $\begin{array}{c}3,022 * * * \\
(0,426) \\
\end{array}$ & $\begin{array}{c}3,199 * * * \\
(0,437) \\
\end{array}$ & $\begin{array}{c}3,200 * * * \\
(0,437)\end{array}$ \\
\hline $\begin{array}{l}\text { mãe completou o Ensino Médio } \\
\left.\text { (antigo } 2^{\circ} \text { grau }\right) \text {, mas não } \\
\text { completou a Faculdade }\end{array}$ & & & $\begin{array}{c}11,745^{* * * *} \\
(0,455)\end{array}$ & $\begin{array}{c}10,878 * * * \\
(0,446)\end{array}$ & $\begin{array}{c}10,893 * * * \\
(0,447)\end{array}$ & $\begin{array}{c}10,921^{* * * *} \\
(0,455)\end{array}$ & $\begin{array}{c}10,919 * * * \\
(0,454)\end{array}$ \\
\hline tamanho da sala (11-15) & & & & $\begin{array}{c}0,141 \\
(5,623) \\
\end{array}$ & $\begin{array}{l}-0,227 \\
(5,529)\end{array}$ & $\begin{array}{l}-1,173 \\
(5,396)\end{array}$ & $\begin{array}{l}-1,179 \\
(5,387)\end{array}$ \\
\hline tamanho da sala (16-20) & & & & $\begin{array}{l}-6,038^{*} \\
(3,331) \\
\end{array}$ & $\begin{array}{l}-6,374 * \\
(3,282) \\
\end{array}$ & $\begin{array}{l}-6,086 * \\
(3,332) \\
\end{array}$ & $\begin{array}{l}-6,073 * \\
(3,340) \\
\end{array}$ \\
\hline tamanho da sala (21-25) & & & & $\begin{array}{l}-1,480 \\
(3,103) \\
\end{array}$ & $\begin{array}{l}-1,987 \\
(3,045)\end{array}$ & $\begin{array}{l}-2,023 \\
(3,091) \\
\end{array}$ & $\begin{array}{l}-2,035 \\
(3,099)\end{array}$ \\
\hline tamanho da sala (26-30) & & & & $\begin{array}{c}1,133 \\
(2,963) \\
\end{array}$ & $\begin{array}{c}0,704 \\
(2,892) \\
\end{array}$ & $\begin{array}{c}0,796 \\
(2,950) \\
\end{array}$ & $\begin{array}{c}0,779 \\
(2,958) \\
\end{array}$ \\
\hline tamanho da sala (31-35) & & & & $\begin{array}{c}3,319 \\
(2,973) \\
\end{array}$ & $\begin{array}{c}2,974 \\
(2,918) \\
\end{array}$ & $\begin{array}{c}3,075 \\
(2,973) \\
\end{array}$ & $\begin{array}{c}3,075 \\
(2,980) \\
\end{array}$ \\
\hline tamanho da sala (36-40) & & & & $\begin{array}{l}5,147 * \\
(3,019)\end{array}$ & $\begin{array}{c}4,732 \\
(2,965)\end{array}$ & $\begin{array}{c}4,813 \\
(3,020) \\
\end{array}$ & $\begin{array}{c}4,814 \\
(3,027) \\
\end{array}$ \\
\hline tamanho da sala (41-45) & & & & $\begin{array}{c}6,099 \\
(4,047) \\
\end{array}$ & $\begin{array}{c}6,177 \\
(4,147) \\
\end{array}$ & $\begin{array}{c}6,706 \\
(4,146) \\
\end{array}$ & $\begin{array}{c}6,597 \\
(4,158) \\
\end{array}$ \\
\hline municipal & & & & $\begin{array}{c}-10,732 * * * \\
(0,784)\end{array}$ & $\begin{array}{c}-10,508 * * * \\
(0,778)\end{array}$ & $\begin{array}{c}-9,847 * * * * \\
(0,832)\end{array}$ & $\begin{array}{c}-9,815^{* * *} * \\
(0,833) \\
\end{array}$ \\
\hline ensino médio & & & & $\begin{array}{c}-2,232 * * \\
(1,009)\end{array}$ & $\begin{array}{l}-1,639 \\
(1,021) \\
\end{array}$ & $\begin{array}{l}-1,489 \\
(1,011) \\
\end{array}$ & $\begin{array}{c}-1,490 \\
(1,011) \\
\end{array}$ \\
\hline laboratório de informática & & & & $\begin{array}{l}-0,806 \\
(0,829)\end{array}$ & $\begin{array}{l}-0,882 \\
(0,812)\end{array}$ & $\begin{array}{l}-0,759 \\
(0,805)\end{array}$ & $\begin{array}{l}-0,782 \\
(0,805)\end{array}$ \\
\hline
\end{tabular}


Tabela A7 - A associação entre crimes contra a pessoa e notas de português (conclusão)

\begin{tabular}{|c|c|c|c|c|c|c|c|}
\hline$\frac{\text { Variáveis }}{\text { laboratório de ciências }}$ & Modelo 1 & Modelo 2 & Modelo 3 & $\begin{array}{c}\text { Modelo } 4 \\
0,690 \\
(0,709) \\
\end{array}$ & $\begin{array}{c}\text { Modelo } 5 \\
0,343 \\
(0,702) \\
\end{array}$ & $\begin{array}{c}\text { Modelo } 6 \\
0,313 \\
(0,690) \\
\end{array}$ & $\begin{array}{c}\text { Modelo } 7 \\
0,321 \\
(0,688) \\
\end{array}$ \\
\hline biblioteca & & & & $\begin{array}{c}0,008 \\
(1,182)\end{array}$ & $\begin{array}{l}-0,297 \\
(1,155)\end{array}$ & $\begin{array}{l}-0,315 \\
(1,132)\end{array}$ & $\begin{array}{r}-0,366 \\
(1,126)\end{array}$ \\
\hline sala de leitura & & & & $\begin{array}{l}1,322 * \\
(0,712)\end{array}$ & $\begin{array}{c}1,004 \\
(0,716)\end{array}$ & $\begin{array}{c}0,884 \\
(0,702)\end{array}$ & $\begin{array}{c}0,893 \\
(0,702)\end{array}$ \\
\hline $\begin{array}{l}\text { uso de computadores em sala de } \\
\text { aula }\end{array}$ & & & & $\begin{array}{c}1,392 \\
(1,254) \\
\end{array}$ & $\begin{array}{c}1,475 \\
(1,321) \\
\end{array}$ & $\begin{array}{c}1,698 \\
(1,306) \\
\end{array}$ & $\begin{array}{c}1,736 \\
(1,301) \\
\end{array}$ \\
\hline programas educacionais & & & & $\begin{array}{c}1,404 \\
(1,102)\end{array}$ & $\begin{array}{c}0,759 \\
(1,057)\end{array}$ & $\begin{array}{c}0,792 \\
(1,049)\end{array}$ & $\begin{array}{c}0,824 \\
(1,047)\end{array}$ \\
\hline distância em relação ao centro & & & & $\begin{array}{c}-0,318 * * * \\
(0,052)\end{array}$ & $\begin{array}{c}-0,086 \\
(0,070)\end{array}$ & $\begin{array}{l}-0,105 \\
(0,069) \\
\end{array}$ & $\begin{array}{c}-0,103 \\
(0,069)\end{array}$ \\
\hline corrige tarefas de português & & & & $\begin{array}{c}1,157 * * * \\
(0,369)\end{array}$ & $\begin{array}{c}1,108 * * * \\
(0,367)\end{array}$ & $\begin{array}{c}0,780^{* *} \\
(0,368)\end{array}$ & $\begin{array}{c}0,778^{* *} \\
(0,369)\end{array}$ \\
\hline $\begin{array}{l}\text { proporção de professores com } \\
\text { ensino superior }\end{array}$ & & & & $\begin{array}{c}-0,018 \\
(0,038)\end{array}$ & $\begin{array}{c}0,004 \\
(0,037)\end{array}$ & $\begin{array}{c}-0,005 \\
(0,036)\end{array}$ & $\begin{array}{c}-0,004 \\
(0,036)\end{array}$ \\
\hline $\begin{array}{l}\text { escolaridade média em anos de } \\
\text { estudo }\end{array}$ & & & & & $\begin{array}{c}0,993^{* *} \\
(0,455)\end{array}$ & $\begin{array}{l}1,027 * * \\
(0,455)\end{array}$ & $\begin{array}{c}0,985^{* *} \\
(0,454)\end{array}$ \\
\hline índice de pobreza & & & & & $\begin{array}{l}-21,616^{*} \\
(11,862) \\
\end{array}$ & $\begin{array}{l}-19,944 * \\
(11,692) \\
\end{array}$ & $\begin{array}{l}-19,371 * \\
(11,741) \\
\end{array}$ \\
\hline escolaridade dos pais dos colegas & & & & & & $\begin{array}{c}1,045^{* *} \\
(0,415)\end{array}$ & $\begin{array}{l}1,042 * * \\
(0,414)\end{array}$ \\
\hline reunião de pais & & & & & & $\begin{array}{c}6,448 * * * * \\
(0,297)\end{array}$ & $\begin{array}{c}6,451 * * * \\
(0,297)\end{array}$ \\
\hline $\begin{array}{l}\text { taxa de livros didáticos } \\
\text { devolvidos por aluno }\end{array}$ & & & & & & $\begin{array}{c}0,147 * * \\
(0,057)\end{array}$ & $\begin{array}{c}0,147 * * \\
(0,057)\end{array}$ \\
\hline constante & $\begin{array}{c}164,039 * * * \\
(0,313)\end{array}$ & $\begin{array}{c}134,654 * * * \\
(1,997)\end{array}$ & $\begin{array}{c}122,798 * * * \\
(2,144)\end{array}$ & $\begin{array}{c}136,130 * * * \\
(4,151)\end{array}$ & $\begin{array}{c}132,414 * * * \\
(6,346)\end{array}$ & $\begin{array}{c}129,094 * * * \\
(6,350)\end{array}$ & $\begin{array}{c}128,981 * * * \\
(6,370)\end{array}$ \\
\hline $\mathrm{R}^{2}$ & 0,006 & 0,242 & 0,257 & 0,269 & 0,270 & 0,275 & 0,275 \\
\hline número de observações & 101436 & 83587 & 81834 & 81414 & 81414 & 81099 & 81099 \\
\hline
\end{tabular}

Fonte: Elaboração própria com base nos dados da SEADE, Prova Brasil 2005, Censo Escolar 2005 e Censo Demográfico 2000.

$* * *$ significante a $1 \% * *$ significante a $5 \% *$ significante a $10 \%$ 
Tabela A8 - A associação entre crimes contra o patrimônio e notas de português (continua)

\begin{tabular}{|c|c|c|c|c|c|c|c|}
\hline Variáveis & Modelo 1 & Modelo 2 & Modelo 3 & Modelo 4 & Modelo 5 & Modelo 6 & Modelo 7 \\
\hline $\begin{array}{l}\text { Crimes contra o patrimônio } \\
(2005)\end{array}$ & $\begin{array}{c}0,002 * * * \\
(0,000)\end{array}$ & $\begin{array}{c}0,001 * * * \\
(0,000)\end{array}$ & $\begin{array}{c}0,001 * * * \\
(0,000)\end{array}$ & $\begin{array}{c}0,001 * * * \\
(0,000)\end{array}$ & $\begin{array}{c}0,000 * * \\
(0,000)\end{array}$ & $\begin{array}{c}0,000 * * \\
(0,000)\end{array}$ & \\
\hline $\begin{array}{l}\text { Crimes contra o patrimônio } \\
(2004)\end{array}$ & & & & & & & $\begin{array}{c}0,000 * * \\
(0,000)\end{array}$ \\
\hline menino & & $\begin{array}{c}-6,351 * * * \\
(0,295)\end{array}$ & $\begin{array}{c}-6,333 * * * \\
(0,293)\end{array}$ & $\begin{array}{c}-6,381 * * * * \\
(0,289)\end{array}$ & $\begin{array}{c}-6,391 * * * \\
(0,289)\end{array}$ & $\begin{array}{c}-6,288 * * * \\
(0,290)\end{array}$ & $\begin{array}{c}-6,287 * * * \\
(0,290)\end{array}$ \\
\hline branco & & $\begin{array}{c}4,640 * * * \\
(0,331)\end{array}$ & $\begin{array}{c}4,177 * * * \\
(0,320)\end{array}$ & $\begin{array}{c}3,598 * * * \\
(0,309)\end{array}$ & $\begin{array}{c}3,581 * * * \\
(0,308)\end{array}$ & $\begin{array}{c}3,493 * * * \\
(0,308)\end{array}$ & $\begin{array}{c}3,491 * * * \\
(0,308)\end{array}$ \\
\hline 8 anos & & $\begin{array}{c}-6,251 * * * \\
(2,009)\end{array}$ & $\begin{array}{c}-8,766 * * * \\
-2,097 \\
\end{array}$ & $\begin{array}{c}-8,967 * * * * \\
(2,130)\end{array}$ & $\begin{array}{c}-8,962 * * * \\
(2,130)\end{array}$ & $\begin{array}{c}-9,574 * * * \\
(2,134)\end{array}$ & $\begin{array}{c}-9,567 * * * \\
(2,135)\end{array}$ \\
\hline 9 anos & & $\begin{array}{c}9,215^{* * * *} \\
(1,993)\end{array}$ & $\begin{array}{c}8,213 * * * \\
(2,051)\end{array}$ & $\begin{array}{c}6,839 * * * \\
(2,085)\end{array}$ & $\begin{array}{c}6,706 * * * \\
(2,082)\end{array}$ & $\begin{array}{c}5,994 * * * \\
(2,086)\end{array}$ & $\begin{array}{c}5,996 * * * * \\
(2,087)\end{array}$ \\
\hline 10 anos & & $\begin{array}{c}12,811 * * * \\
-1,768\end{array}$ & $\begin{array}{c}11,197 * * * \\
-1,835\end{array}$ & $\begin{array}{c}9,873 * * * \\
(1,857) \\
\end{array}$ & $\begin{array}{c}9,748 * * * \\
(1,854)\end{array}$ & $\begin{array}{c}9,180 * * * \\
(1,860)\end{array}$ & $\begin{array}{c}9,182 * * * \\
(1,861)\end{array}$ \\
\hline 11 anos & & $\begin{array}{c}10,228 * * * \\
-1,754 \\
\end{array}$ & $\begin{array}{c}9,030 * * * \\
-1,838\end{array}$ & $\begin{array}{c}8,148 * * * \\
(1,862)\end{array}$ & $\begin{array}{c}8,043 * * * \\
(1,858)\end{array}$ & $\begin{array}{c}7,609 * * * \\
(1,861)\end{array}$ & $\begin{array}{c}7,615 * * * \\
(1,862)\end{array}$ \\
\hline 12 anos & & $\begin{array}{c}5,878 * * * \\
(1,794)\end{array}$ & $\begin{array}{c}4,988 * * * \\
(1,864)\end{array}$ & $\begin{array}{c}4,700 * * \\
(1,899)\end{array}$ & $\begin{array}{c}4,616^{* *} \\
(1,897)\end{array}$ & $\begin{array}{c}4,382 * * \\
(1,902)\end{array}$ & $\begin{array}{c}4,389 * * \\
(1,902)\end{array}$ \\
\hline 13 anos & & $\begin{array}{c}4,181 * * \\
-1,882 \\
\end{array}$ & $\begin{array}{c}3,209 \\
(1,956)\end{array}$ & $\begin{array}{c}3,045 \\
(1,971)\end{array}$ & $\begin{array}{c}2,992 \\
(1,969)\end{array}$ & $\begin{array}{c}2,704 \\
(1,970)\end{array}$ & $\begin{array}{c}2,716 \\
(1,970) \\
\end{array}$ \\
\hline 14 anos & & $\begin{array}{c}5,653^{* * *} \\
-2,246\end{array}$ & $\begin{array}{c}5,229 * * \\
(2,339) \\
\end{array}$ & $\begin{array}{c}4,908 * * \\
(2,326)\end{array}$ & $\begin{array}{c}4,840 * * \\
(2,328)\end{array}$ & $\begin{array}{c}4,880 * * \\
(2,317) \\
\end{array}$ & $\begin{array}{c}4,874 * * \\
(2,316) \\
\end{array}$ \\
\hline reprovação & & $\begin{array}{c}-17,569 * * * \\
(0,424)\end{array}$ & $\begin{array}{c}-16,974 * * * \\
(0,424)\end{array}$ & $\begin{array}{c}-16,073 * * * \\
(0,418)\end{array}$ & $\begin{array}{c}-16,086^{* * * *} \\
(0,419)\end{array}$ & $\begin{array}{c}-15,812 * * * * \\
(0,418)\end{array}$ & $\begin{array}{c}-15,812 * * * \\
(0,418)\end{array}$ \\
\hline tarefa de português & & $\begin{array}{c}11,588 * * * \\
(0,334)\end{array}$ & $\begin{array}{c}10,692 * * * * \\
(0,332)\end{array}$ & $\begin{array}{c}10,119 * * * \\
(0,331)\end{array}$ & $\begin{array}{c}10,096^{* * *} \\
(0,331)\end{array}$ & $\begin{array}{c}9,255 * * * \\
(0,331)\end{array}$ & $\begin{array}{c}9,258 * * * \\
(0,331) \\
\end{array}$ \\
\hline tempo de tv & & $\begin{array}{c}0,427 \\
(0,321)\end{array}$ & $\begin{array}{c}0,436 \\
(0,318)\end{array}$ & $\begin{array}{c}0,338 \\
(0,312)\end{array}$ & $\begin{array}{c}0,335 \\
(0,312) \\
\end{array}$ & $\begin{array}{c}0,375 \\
(0,310)\end{array}$ & $\begin{array}{c}0,375 \\
(0,310) \\
\end{array}$ \\
\hline abandono & & $\begin{array}{c}-10,481 * * * \\
(0,484)\end{array}$ & $\begin{array}{c}-9,864 * * * \\
(0,496)\end{array}$ & $\begin{array}{c}-9,826 * * * \\
(0,498)\end{array}$ & $\begin{array}{c}-9,818^{* * *} * \\
(0,499)\end{array}$ & $\begin{array}{c}-9,232 * * * \\
(0,502)\end{array}$ & $\begin{array}{c}-9,231 * * * \\
(0,502)\end{array}$ \\
\hline trabalha fora de casa & & $\begin{array}{c}-13,562 * * * \\
(0,399)\end{array}$ & $\begin{array}{c}-13,758 * * * \\
(0,407)\end{array}$ & $\begin{array}{c}-13,595 * * * \\
(0,404)\end{array}$ & $\begin{array}{c}-13,535 * * * \\
(0,403)\end{array}$ & $\begin{array}{c}-13,319 * * * \\
(0,404)\end{array}$ & $\begin{array}{c}-13,321 * * * \\
(0,404)\end{array}$ \\
\hline trabalhos domésticos & & $\begin{array}{c}3,877 * * * \\
(0,319)\end{array}$ & $\begin{array}{c}3,901 * * * \\
(0,315) \\
\end{array}$ & $\begin{array}{c}3,808 * * * \\
(0,312) \\
\end{array}$ & $\begin{array}{c}3,770 * * * \\
(0,311) \\
\end{array}$ & $\begin{array}{c}3,599 * * * \\
(0,310)\end{array}$ & $\begin{array}{c}3,598 * * * \\
(0,310) \\
\end{array}$ \\
\hline maternal & & $\begin{array}{c}12,704 * * * \\
(0,415)\end{array}$ & $\begin{array}{c}11,021 * * * \\
(0,412)\end{array}$ & $\begin{array}{c}10,669 * * * \\
(0,403)\end{array}$ & $\begin{array}{c}10,579 * * * \\
(0,402)\end{array}$ & $\begin{array}{c}10,155^{* * *} * \\
(0,399)\end{array}$ & $\begin{array}{c}10,153 * * * * \\
(0,399)\end{array}$ \\
\hline pré-escola & & $\begin{array}{c}11,301 * * * \\
(0,369)\end{array}$ & $\begin{array}{c}10,328 * * * \\
(0,372)\end{array}$ & $\begin{array}{c}10,513 * * * \\
(0,374)\end{array}$ & $\begin{array}{c}10,490 * * * \\
(0,374)\end{array}$ & $\begin{array}{c}10,117 \text { *** } \\
(0,373)\end{array}$ & $\begin{array}{c}10,116 \text { **** } \\
(0,373)\end{array}$ \\
\hline estudou na mesma escola & & $\begin{array}{c}-0,942 * * * * \\
(0,309)\end{array}$ & $\begin{array}{c}-0,983 * * * \\
(0,307) \\
\end{array}$ & $\begin{array}{c}-0,980 * * * \\
(0,302)\end{array}$ & $\begin{array}{c}-0,952 * * * \\
(0,302)\end{array}$ & $\begin{array}{c}-1,160 * * * \\
(0,302)\end{array}$ & $\begin{array}{c}-1,158^{* * * *} \\
(0,302)\end{array}$ \\
\hline mora com pai ou mãe & & $\begin{array}{c}-1,839 * * * * \\
(0,307)\end{array}$ & $\begin{array}{c}-1,512 * * * \\
(0,312)\end{array}$ & $\begin{array}{c}-1,588^{* * * *} \\
(0,309)\end{array}$ & $\begin{array}{c}-1,606^{* * * *} \\
(0,308)\end{array}$ & $\begin{array}{c}-1,099 * * * \\
(0,308)\end{array}$ & $\begin{array}{c}-1,098 * * * \\
(0,308)\end{array}$ \\
\hline $\begin{array}{c}\text { mora sozinho ou com mais uma } \\
\text { pessoa }\end{array}$ & & $\begin{array}{c}11,835 * * * \\
(0,910)\end{array}$ & $\begin{array}{c}11,773 * * * \\
(0,925)\end{array}$ & $\begin{array}{c}11,574 * * * \\
(0,906)\end{array}$ & $\begin{array}{c}11,508 * * * \\
(0,904)\end{array}$ & $\begin{array}{c}11,017 * * * \\
(0,907)\end{array}$ & $\begin{array}{c}11,013 * * * \\
(0,907)\end{array}$ \\
\hline mora com mais duas pessoas & & $\begin{array}{c}18,645^{* * * *} \\
(0,635)\end{array}$ & $\begin{array}{c}18,236^{* * * *} \\
(0,631)\end{array}$ & $\begin{array}{c}17,744 * * * \\
(0,624)\end{array}$ & $\begin{array}{c}17,665 * * * \\
(0,622)\end{array}$ & $\begin{array}{c}17,349 * * * \\
(0,622)\end{array}$ & $\begin{array}{c}17,347 * * * \\
(0,622)\end{array}$ \\
\hline mora com mais três pessoas & & $\begin{array}{c}17,115 * * * \\
(0,571)\end{array}$ & $\begin{array}{c}16,379 * * * \\
(0,576)\end{array}$ & $\begin{array}{c}15,981 * * * \\
(0,567)\end{array}$ & $\begin{array}{c}15,918 * * * \\
(0,566)\end{array}$ & $\begin{array}{c}15,582 * * * \\
(0,564)\end{array}$ & $\begin{array}{c}15,583 * * * \\
(0,564)\end{array}$ \\
\hline
\end{tabular}


Tabela A8 - A associação entre crimes contra o patrimônio e notas de português (continuação)

\begin{tabular}{|c|c|c|c|c|c|c|c|}
\hline Variáveis & Modelo 1 & Modelo 2 & Modelo 3 & Modelo 4 & Modelo 5 & Modelo 6 & Modelo 7 \\
\hline $\begin{array}{l}\text { mora com mais quatro ou cinco } \\
\text { pessoas }\end{array}$ & & $\begin{array}{c}7,883 * * * \\
(0,505) \\
\end{array}$ & $\begin{array}{c}7,592 * * * \\
(0,506) \\
\end{array}$ & $\begin{array}{c}7,206 * * * \\
(0,500) \\
\end{array}$ & $\begin{array}{c}7,153 * * * \\
(0,499) \\
\end{array}$ & $\begin{array}{c}6,940^{* * * *} \\
(0,495)\end{array}$ & $\begin{array}{c}6,941^{* * * *} \\
(0,495)\end{array}$ \\
\hline mora com mais seis a oito pessoas & & $\begin{array}{c}4,382 * * * \\
(0,559) \\
\end{array}$ & $\begin{array}{c}4,258 * * * \\
(0,561) \\
\end{array}$ & $\begin{array}{c}4,118 * * * \\
(0,556)\end{array}$ & $\begin{array}{c}4,088 * * * \\
(0,557)\end{array}$ & $\begin{array}{c}4,026 * * * \\
(0,558)\end{array}$ & $\begin{array}{c}4,029 * * * \\
(0,558) \\
\end{array}$ \\
\hline futuro (ainda não sei) & & $\begin{array}{c}6,221 * * * \\
(0,477)\end{array}$ & $\begin{array}{c}6,781 * * * \\
(0,494)\end{array}$ & $\begin{array}{c}6,489 * * * \\
(0,487)\end{array}$ & $\begin{array}{c}6,450^{* * * *} \\
(0,485)\end{array}$ & $\begin{array}{c}6,364 * * * \\
(0,486)\end{array}$ & $\begin{array}{c}6,366 * * * \\
(0,486) \\
\end{array}$ \\
\hline futuro (estudar) & & $\begin{array}{c}6,407 * * * \\
(0,528)\end{array}$ & $\begin{array}{c}5,767 * * * \\
(0,531)\end{array}$ & $\begin{array}{c}5,337 * * * \\
(0,525)\end{array}$ & $\begin{array}{c}5,290 * * * \\
(0,524)\end{array}$ & $\begin{array}{c}4,794 * * * \\
(0,523)\end{array}$ & $\begin{array}{c}4,794 * * * \\
(0,523)\end{array}$ \\
\hline futuro (estudar e trabalhar) & & $\begin{array}{c}13,286^{* * * *} \\
(0,470) \\
\end{array}$ & $\begin{array}{c}12,467 * * * * \\
(0,483)\end{array}$ & $\begin{array}{c}12,300 * * * \\
(0,475)\end{array}$ & $\begin{array}{c}12,258 * * * \\
(0,473)\end{array}$ & $\begin{array}{c}11,895 * * * \\
(0,473) \\
\end{array}$ & $\begin{array}{c}11,898 * * * \\
(0,474)\end{array}$ \\
\hline deixado de lado & & $\begin{array}{c}-12,792 * * * \\
(0,365) \\
\end{array}$ & $\begin{array}{c}-12,494 * * * * \\
(0,365)\end{array}$ & $\begin{array}{c}-12,113 * * * \\
(0,359) \\
\end{array}$ & $\begin{array}{c}-12,084 * * * * \\
(0,358) \\
\end{array}$ & $\begin{array}{c}-11,973^{* * * *} \\
(0,358) \\
\end{array}$ & $\begin{array}{c}-11,971 * * * \\
(0,357) \\
\end{array}$ \\
\hline bolsa família & & $\begin{array}{c}-9,995 * * * \\
(0,369)\end{array}$ & $\begin{array}{c}-9,667 * * * \\
(0,374)\end{array}$ & $\begin{array}{c}-9,413 * * * \\
(0,364) \\
\end{array}$ & $\begin{array}{c}-9,397 * * * \\
(0,363)\end{array}$ & $\begin{array}{c}-9,477 * * * \\
(0,362)\end{array}$ & $\begin{array}{c}-9,477 * * * \\
(0,362) \\
\end{array}$ \\
\hline livros & & & $\begin{array}{c}2,639 * * * \\
(0,290) \\
\end{array}$ & $\begin{array}{c}2,297 * * * * \\
(0,286) \\
\end{array}$ & $\begin{array}{c}2,240 * * * \\
(0,284) \\
\end{array}$ & $\begin{array}{c}1,961 * * * * \\
(0,284)\end{array}$ & $\begin{array}{c}1,960 * * * \\
(0,284)\end{array}$ \\
\hline computador & & & $\begin{array}{c}4,031 * * * \\
(0,343) \\
\end{array}$ & $\begin{array}{c}3,652 * * * \\
(0,339) \\
\end{array}$ & $\begin{array}{c}3,543 * * * \\
(0,338) \\
\end{array}$ & $\begin{array}{c}3,352 * * * \\
(0,337) \\
\end{array}$ & $\begin{array}{c}3,349 * * * \\
(0,337) \\
\end{array}$ \\
\hline apoio aos estudos & & & $\begin{array}{c}10,967 * * * \\
(0,582)\end{array}$ & $\begin{array}{c}10,745^{* * * *} \\
(0,582)\end{array}$ & $\begin{array}{c}10,715^{* * * *} \\
(0,582)\end{array}$ & $\begin{array}{c}10,035 * * * \\
(0,583) \\
\end{array}$ & $\begin{array}{c}10,033^{* * *} * \\
(0,583)\end{array}$ \\
\hline $\begin{array}{c}\text { mãe nunca estudou ou não } \\
\text { completou a } 4^{\mathrm{a}} \text { série }\end{array}$ & & & $\begin{array}{c}-2,138 * * * \\
(0,521)\end{array}$ & $\begin{array}{c}-2,081 * * * \\
(0,522)\end{array}$ & $\begin{array}{c}-1,999 * * * \\
(0,519)\end{array}$ & $\begin{array}{c}-1,764 * * * \\
(0,522)\end{array}$ & $\begin{array}{c}-1,763 * * * \\
(0,522) \\
\end{array}$ \\
\hline $\begin{array}{l}\text { mãe completou a } 4^{\mathrm{a}} \text { série (antigo } \\
\text { primário), mas não completou a } 8^{\mathrm{a}} \\
\text { série }\end{array}$ & & & $\begin{array}{c}3,044 * * * \\
(0,373) \\
\end{array}$ & $\begin{array}{c}2,443 * * * \\
(0,367) \\
\end{array}$ & $\begin{array}{c}2,480 * * * \\
(0,367) \\
\end{array}$ & $\begin{array}{c}2,666^{* * * *} \\
(0,373) \\
\end{array}$ & $\begin{array}{c}2,668 * * * \\
(0,372) \\
\end{array}$ \\
\hline $\begin{array}{c}\text { mãe completou a } 8^{\mathrm{a}} \text { série (antigo } \\
\text { ginásio), mas não completou o } \\
\text { Ensino Médio }\end{array}$ & & & $\begin{array}{c}3,748 * * * \\
(0,435) \\
\end{array}$ & $\begin{array}{c}2,987 * * * \\
(0,427) \\
\end{array}$ & $\begin{array}{c}3,029 * * * \\
(0,425)\end{array}$ & $\begin{array}{c}3,201 * * * \\
(0,436)\end{array}$ & $\begin{array}{c}3,203 * * * \\
(0,436) \\
\end{array}$ \\
\hline $\begin{array}{c}\text { mãe completou o Ensino Médio } \\
\text { (antigo } 2^{\circ} \text { grau), mas não } \\
\text { completou a Faculdade }\end{array}$ & & & $\begin{array}{c}11,724 * * * \\
(0,454)\end{array}$ & $\begin{array}{c}10,876 * * * \\
(0,446) \\
\end{array}$ & $\begin{array}{c}10,890 * * * \\
(0,446)\end{array}$ & $\begin{array}{c}10,915 * * * \\
(0,454)\end{array}$ & $\begin{array}{c}10,916^{* * * *} \\
(0,454)\end{array}$ \\
\hline tamanho da sala (11-15) & & & & $\begin{array}{c}0,060 \\
(5,539) \\
\end{array}$ & $\begin{array}{c}-0,278 \\
(5,519) \\
\end{array}$ & $\begin{array}{l}-1,222 \\
(5,387) \\
\end{array}$ & $\begin{array}{c}-1,266 \\
(5,387) \\
\end{array}$ \\
\hline tamanho da sala (16-20) & & & & $\begin{array}{l}-6,017 * \\
(3,323) \\
\end{array}$ & $\begin{array}{l}-6,335^{*} \\
(3,303) \\
\end{array}$ & $\begin{array}{l}-6,048^{*} \\
(3,352) \\
\end{array}$ & $\begin{array}{l}-6,067 * \\
(3,352)\end{array}$ \\
\hline tamanho da sala (21-25) & & & & $\begin{array}{l}-1,560 \\
(3,095) \\
\end{array}$ & $\begin{array}{l}-1,996 \\
(3,068) \\
\end{array}$ & $\begin{array}{l}-2,031 \\
(3,112) \\
\end{array}$ & $\begin{array}{l}-2,051 \\
(3,112) \\
\end{array}$ \\
\hline tamanho da sala (26-30) & & & & $\begin{array}{c}1,036 \\
(2,948) \\
\end{array}$ & $\begin{array}{c}0,680 \\
(2,913) \\
\end{array}$ & $\begin{array}{c}0,774 \\
(2,970) \\
\end{array}$ & $\begin{array}{c}0,746 \\
(2,970) \\
\end{array}$ \\
\hline tamanho da sala (31-35) & & & & $\begin{array}{c}3,305 \\
(2,965) \\
\end{array}$ & $\begin{array}{c}2,992 \\
(2,939) \\
\end{array}$ & $\begin{array}{c}3,092 \\
(2,992) \\
\end{array}$ & $\begin{array}{c}3,078 \\
(2,991) \\
\end{array}$ \\
\hline tamanho da sala (36-40) & & & & $\begin{array}{l}5,111^{*} \\
(3,013) \\
\end{array}$ & $\begin{array}{c}4,753 \\
(2,988) \\
\end{array}$ & $\begin{array}{c}4,833 \\
(3,041) \\
\end{array}$ & $\begin{array}{c}4,821 \\
(3,040) \\
\end{array}$ \\
\hline tamanho da sala (41-45) & & & & $\begin{array}{c}6,198 \\
(4,053) \\
\end{array}$ & $\begin{array}{c}6,178 \\
(4,152) \\
\end{array}$ & $\begin{array}{c}6,713 \\
(4,152) \\
\end{array}$ & $\begin{array}{c}6,655 \\
(4,155) \\
\end{array}$ \\
\hline municipal & & & & $\begin{array}{c}-10,511^{* * * *} \\
(0,781)\end{array}$ & $\begin{array}{c}-10,429 * * * \\
(0,775)\end{array}$ & $\begin{array}{c}-9,768 * * * \\
(0,828) \\
\end{array}$ & $\begin{array}{c}-9,756^{* * * *} \\
(0,827) \\
\end{array}$ \\
\hline ensino médio & & & & $\begin{array}{l}-1,932 * \\
(0,996) \\
\end{array}$ & $\begin{array}{c}-1,598 \\
(1,009) \\
\end{array}$ & $\begin{array}{c}-1,446 \\
(1,000) \\
\end{array}$ & $\begin{array}{l}-1,435 \\
(0,996) \\
\end{array}$ \\
\hline laboratório de informática & & & & $\begin{array}{c}-0,934 \\
(0,816) \\
\end{array}$ & $\begin{array}{l}-0,941 \\
(0,807)\end{array}$ & $\begin{array}{c}-0,814 \\
(0,800)\end{array}$ & $\begin{array}{c}-0,820 \\
(0,799)\end{array}$ \\
\hline
\end{tabular}


Tabela A8 - A associação entre crimes contra o patrimônio e notas de português (conclusão)

\begin{tabular}{|c|c|c|c|c|c|c|c|}
\hline Variáveis & Modelo 1 & Modelo 2 & Modelo 3 & Modelo 4 & Modelo 5 & Modelo 6 & Modelo 7 \\
\hline laboratório de ciências & & & & $\begin{array}{c}0,547 \\
(0,706) \\
\end{array}$ & $\begin{array}{c}0,322 \\
(0,700) \\
\end{array}$ & $\begin{array}{c}0,293 \\
(0,688) \\
\end{array}$ & $\begin{array}{c}0,295 \\
(0,686) \\
\end{array}$ \\
\hline biblioteca & & & & $\begin{array}{l}-0,215 \\
(1,165) \\
\end{array}$ & $\begin{array}{l}-0,355 \\
(1,152) \\
\end{array}$ & $\begin{array}{l}-0,370 \\
(1,130) \\
\end{array}$ & $\begin{array}{l}-0,399 \\
(1,127) \\
\end{array}$ \\
\hline sala de leitura & & & & $\begin{array}{l}1,213^{*} \\
(0,712)\end{array}$ & $\begin{array}{c}1,001 \\
(0,716) \\
\end{array}$ & $\begin{array}{c}0,880 \\
(0,703) \\
\end{array}$ & $\begin{array}{c}0,877 \\
(0,703) \\
\end{array}$ \\
\hline $\begin{array}{l}\text { uso de computadores em sala de } \\
\text { aula }\end{array}$ & & & & $\begin{array}{c}1,401 \\
(1,259)\end{array}$ & $\begin{array}{c}1,476 \\
(1,314) \\
\end{array}$ & $\begin{array}{c}1,697 \\
(1,301)\end{array}$ & $\begin{array}{c}1,704 \\
(1,306)\end{array}$ \\
\hline programas educacionais & & & & $\begin{array}{c}1,238 \\
(1,093) \\
\end{array}$ & $\begin{array}{c}0,787 \\
(1,063) \\
\end{array}$ & $\begin{array}{c}0,814 \\
(1,054) \\
\end{array}$ & $\begin{array}{c}0,823 \\
(1,053) \\
\end{array}$ \\
\hline distância em relação ao centro & & & & $\begin{array}{c}-0,279 * * * \\
(0,056) \\
\end{array}$ & $\begin{array}{l}-0,091 \\
(0,070) \\
\end{array}$ & $\begin{array}{l}-0,110 \\
(0,069) \\
\end{array}$ & $\begin{array}{l}-0,111 \\
(0,069) \\
\end{array}$ \\
\hline corrige tarefas de português & & & & $\begin{array}{c}1,132 * * * \\
(0,368) \\
\end{array}$ & $\begin{array}{c}1,104 * * * \\
(0,368) \\
\end{array}$ & $\begin{array}{c}0,777 * * \\
(0,368) \\
\end{array}$ & $\begin{array}{c}0,776 * * \\
(0,369) \\
\end{array}$ \\
\hline $\begin{array}{l}\text { proporção de professores com } \\
\text { ensino superior }\end{array}$ & & & & $\begin{array}{l}-0,015 \\
(0,037) \\
\end{array}$ & $\begin{array}{c}0,002 \\
(0,036) \\
\end{array}$ & $\begin{array}{l}-0,006 \\
(0,036) \\
\end{array}$ & $\begin{array}{l}-0,006 \\
(0,036) \\
\end{array}$ \\
\hline $\begin{array}{l}\text { escolaridade média em anos de } \\
\text { estudo }\end{array}$ & & & & & $\begin{array}{c}0,735 \\
(0,464) \\
\end{array}$ & $\begin{array}{l}0,787 * \\
(0,463) \\
\end{array}$ & $\begin{array}{c}0,747 \\
(0,463) \\
\end{array}$ \\
\hline índice de pobreza & & & & & $\begin{array}{l}-20,710^{*} \\
(11,850) \\
\end{array}$ & $\begin{array}{l}-19,163 \\
(11,668) \\
\end{array}$ & $\begin{array}{l}-18,961 \\
(11,638) \\
\end{array}$ \\
\hline escolaridade dos pais dos colegas & & & & & & $\begin{array}{l}1,023 * * \\
(0,414) \\
\end{array}$ & $\begin{array}{l}1,022 * * \\
(0,414) \\
\end{array}$ \\
\hline reunião de pais & & & & & & $\begin{array}{c}6,433 * * * \\
(0,297) \\
\end{array}$ & $\begin{array}{c}6,432 * * * \\
(0,297) \\
\end{array}$ \\
\hline $\begin{array}{c}\text { taxa de livros didáticos } \\
\text { devolvidos por aluno }\end{array}$ & & & & & & $\begin{array}{c}0,148 * * * \\
(0,057) \\
\end{array}$ & $\begin{array}{c}0,148 * * * \\
(0,057) \\
\end{array}$ \\
\hline constante & $\begin{array}{c}166,361 * * * \\
(0,212) \\
\end{array}$ & $\begin{array}{c}136,031 * * * \\
(1,969)\end{array}$ & $\begin{array}{c}124,191 * * * \\
(2,125) \\
\end{array}$ & $\begin{array}{c}135,811 * * * \\
(4,140) \\
\end{array}$ & $\begin{array}{c}133,627 * * * \\
(6,277) \\
\end{array}$ & $\begin{array}{c}130,286^{* * * *} \\
(6,284) \\
\end{array}$ & $\begin{array}{c}130,361 * * * \\
(6,279) \\
\end{array}$ \\
\hline $\mathrm{R}^{2}$ & 0,009 & 0,243 & 0,258 & 0,270 & 0,270 & 0,275 & 0,275 \\
\hline número de observações & 101436 & 83587 & 81834 & 81414 & 81414 & 81099 & 81099 \\
\hline
\end{tabular}

Fonte: Elaboração própria com base nos dados da SEADE, Prova Brasil 2005, Censo Escolar 2005 e Censo Demográfico 2000.

$* * *$ significante a $1 \% * *$ significante a $5 \% *$ significante a $10 \%$ 
Tabela A9 - A associação entre crimes violentos e notas de português (continua)

\begin{tabular}{|c|c|c|c|c|c|c|c|}
\hline Variáveis & Modelo 1 & Modelo 2 & Modelo 3 & Modelo 4 & Modelo 5 & Modelo 6 & Modelo 7 \\
\hline Crimes violentos (2005) & $\begin{array}{c}0,004 * * * \\
(0,000)\end{array}$ & $\begin{array}{c}0,003 * * * \\
(0,000)\end{array}$ & $\begin{array}{c}0,003 * * * \\
(0,000)\end{array}$ & $\begin{array}{c}0,002 * * * \\
(0,000)\end{array}$ & $\begin{array}{c}0,001 * * \\
(0,000)\end{array}$ & $\begin{array}{c}0,001 * * \\
(0,000) \\
\end{array}$ & \\
\hline Crimes violentos (2004) & & & & & & & $\begin{array}{c}0,001 * * * \\
(0,000)\end{array}$ \\
\hline menino & & $\begin{array}{c}-6,353 * * * \\
(0,294) \\
\end{array}$ & $\begin{array}{c}-6,334 * * * \\
(0,293)\end{array}$ & $\begin{array}{c}-6,382 * * * \\
(0,289)\end{array}$ & $\begin{array}{c}-6,392^{* * * *} \\
(0,289)\end{array}$ & $\begin{array}{c}-6,289 * * * \\
(0,290)\end{array}$ & $\begin{array}{c}-6,285^{* * *} * \\
(0,290) \\
\end{array}$ \\
\hline branco & & $\begin{array}{c}4,678 * * * \\
(0,327)\end{array}$ & $\begin{array}{c}4,210 * * * \\
(0,317)\end{array}$ & $\begin{array}{c}3,608 * * * \\
(0,309)\end{array}$ & $\begin{array}{c}3,586 * * * \\
(0,308)\end{array}$ & $\begin{array}{c}3,498 * * * \\
(0,308)\end{array}$ & $\begin{array}{c}3,495 * * * \\
(0,307)\end{array}$ \\
\hline 8 anos & & $\begin{array}{c}-6,299 * * * \\
(2,009)\end{array}$ & $\begin{array}{c}-8,786^{* * * *} \\
(2,096)\end{array}$ & $\begin{array}{c}-8,967 * * * \\
(2,130)\end{array}$ & $\begin{array}{c}-8,962 * * * * \\
(2,130)\end{array}$ & $\begin{array}{c}-9,574 * * * \\
(2,134)\end{array}$ & $\begin{array}{c}-9,560 * * * \\
(2,135) \\
\end{array}$ \\
\hline 9 anos & & $\begin{array}{c}9,168 * * * * \\
(1,988) \\
\end{array}$ & $\begin{array}{c}8,195 * * * * \\
(2,049) \\
\end{array}$ & $\begin{array}{c}6,828 * * * \\
(2,084) \\
\end{array}$ & $\begin{array}{c}6,700^{* * * *} \\
(2,082)\end{array}$ & $\begin{array}{c}5,990 * * * \\
(2,086) \\
\end{array}$ & $\begin{array}{c}5,990 * * * \\
(2,088)\end{array}$ \\
\hline 10 anos & & $\begin{array}{c}12,787 * * * * \\
(1,762)\end{array}$ & $\begin{array}{c}11,203 * * * \\
(1,834)\end{array}$ & $\begin{array}{c}9,872 * * * \\
(1,856) \\
\end{array}$ & $\begin{array}{c}9,748 * * * \\
(1,853) \\
\end{array}$ & $\begin{array}{c}9,180 * * * \\
(1,860) \\
\end{array}$ & $\begin{array}{c}9,178 * * * \\
(1,861) \\
\end{array}$ \\
\hline 11 anos & & $\begin{array}{c}10,165^{* * * *} \\
(1,750)\end{array}$ & $\begin{array}{c}9,002^{* * * *} \\
(1,837)\end{array}$ & $\begin{array}{c}8,127 * * * \\
(1,861) \\
\end{array}$ & $\begin{array}{c}8,032 * * * \\
(1,858) \\
\end{array}$ & $\begin{array}{c}7,599 * * * \\
(1,861) \\
\end{array}$ & $\begin{array}{c}7,604 * * * \\
(1,863) \\
\end{array}$ \\
\hline 12 anos & & $\begin{array}{c}5,808 * * * \\
(1,792) \\
\end{array}$ & $\begin{array}{c}4,955^{* * * *} \\
(1,864) \\
\end{array}$ & $\begin{array}{c}4,679 * * \\
(1,899)\end{array}$ & $\begin{array}{c}4,605^{* *} * \\
(1,897) \\
\end{array}$ & $\begin{array}{c}4,372 * * \\
(1,901) \\
\end{array}$ & $\begin{array}{c}4,378 * * \\
(1,903) \\
\end{array}$ \\
\hline 13 anos & & $\begin{array}{c}4,100 * * \\
(1,879) \\
\end{array}$ & $\begin{array}{c}3,160 \\
(1,955) \\
\end{array}$ & $\begin{array}{c}3,014 \\
(1,971) \\
\end{array}$ & $\begin{array}{c}2,975 \\
(1,969)\end{array}$ & $\begin{array}{c}2,689 \\
(1,969)\end{array}$ & $\begin{array}{c}2,702 \\
(1,971) \\
\end{array}$ \\
\hline 14 anos & & $\begin{array}{l}5,602 * * \\
(2,241)\end{array}$ & $\begin{array}{c}5,209 * * \\
(2,338)\end{array}$ & $\begin{array}{c}4,890 * * \\
(2,326) \\
\end{array}$ & $\begin{array}{c}4,830 * * \\
(2,327)\end{array}$ & $\begin{array}{c}4,870 * * \\
(2,316) \\
\end{array}$ & $\begin{array}{c}4,854 * * \\
(2,316) \\
\end{array}$ \\
\hline reprovação & & $\begin{array}{c}-17,557 * * * \\
(0,424)\end{array}$ & $\begin{array}{c}-16,963 * * * \\
(0,424)\end{array}$ & $\begin{array}{c}-16,060 * * * \\
(0,418)\end{array}$ & $\begin{array}{c}-16,079 * * * \\
(0,419)\end{array}$ & $\begin{array}{c}-15,805^{* * * *} \\
(0,419)\end{array}$ & $\begin{array}{c}-15,802^{* * * *} \\
(0,418)\end{array}$ \\
\hline tarefa de português & & $\begin{array}{c}11,609 * * * \\
(0,335)\end{array}$ & $\begin{array}{c}10,710 * * * \\
(0,333)\end{array}$ & $\begin{array}{c}10,127 * * * \\
(0,331)\end{array}$ & $\begin{array}{c}10,101 * * * \\
(0,331)\end{array}$ & $\begin{array}{c}9,259 * * * \\
(0,331)\end{array}$ & $\begin{array}{c}9,268 * * * \\
(0,331) \\
\end{array}$ \\
\hline tempo de tv & & $\begin{array}{c}0,427 \\
(0,321) \\
\end{array}$ & $\begin{array}{c}0,435 \\
(0,318) \\
\end{array}$ & $\begin{array}{c}0,335 \\
(0,312) \\
\end{array}$ & $\begin{array}{c}0,333 \\
(0,312) \\
\end{array}$ & $\begin{array}{c}0,373 \\
(0,310) \\
\end{array}$ & $\begin{array}{c}0,374 \\
(0,310) \\
\end{array}$ \\
\hline abandono & & $\begin{array}{c}-10,483^{* * * *} \\
(0,485)\end{array}$ & $\begin{array}{c}-9,869^{* * * *} \\
(0,498) \\
\end{array}$ & $\begin{array}{c}-9,827 * * * \\
(0,499) \\
\end{array}$ & $\begin{array}{c}-9,818^{* * * *} \\
(0,500)\end{array}$ & $\begin{array}{c}-9,233 \text { *** } \\
(0,502)\end{array}$ & $\begin{array}{c}-9,231 * * * \\
(0,502)\end{array}$ \\
\hline trabalha fora de casa & & $\begin{array}{c}-13,552 * * * \\
(0,398)\end{array}$ & $\begin{array}{c}-13,748 * * * \\
(0,406)\end{array}$ & $\begin{array}{c}-13,590 * * * \\
(0,404)\end{array}$ & $\begin{array}{c}-13,533 * * * \\
(0,403)\end{array}$ & $\begin{array}{c}-13,316^{* * * *} \\
(0,404)\end{array}$ & $\begin{array}{c}-13,318^{* * * *} \\
(0,404)\end{array}$ \\
\hline trabalhos domésticos & & $\begin{array}{c}3,892 * * * \\
(0,318) \\
\end{array}$ & $\begin{array}{c}3,913 * * * \\
(0,315) \\
\end{array}$ & $\begin{array}{c}3,810 * * * \\
(0,312) \\
\end{array}$ & $\begin{array}{c}3,772 * * * \\
(0,311) \\
\end{array}$ & $\begin{array}{c}3,601 * * * \\
(0,310)\end{array}$ & $\begin{array}{c}3,596 * * * \\
(0,310) \\
\end{array}$ \\
\hline maternal & & $\begin{array}{c}12,754 * * * \\
(0,409) \\
\end{array}$ & $\begin{array}{c}11,059 \text { *** } \\
(0,408)\end{array}$ & $\begin{array}{c}10,682 * * * \\
(0,402)\end{array}$ & $\begin{array}{c}10,586^{* * * *} \\
(0,401)\end{array}$ & $\begin{array}{c}10,161 * * * \\
(0,399)\end{array}$ & $\begin{array}{c}10,158 * * * \\
(0,399)\end{array}$ \\
\hline pré-escola & & $\begin{array}{c}11,314 * * * * \\
(0,370)\end{array}$ & $\begin{array}{c}10,338 * * * \\
(0,372)\end{array}$ & $\begin{array}{c}10,523 * * * \\
(0,374)\end{array}$ & $\begin{array}{c}10,496^{* * * *} \\
(0,374)\end{array}$ & $\begin{array}{c}10,121 * * * \\
(0,373)\end{array}$ & $\begin{array}{c}10,122 * * * \\
(0,373)\end{array}$ \\
\hline estudou na mesma escola & & $\begin{array}{c}-0,980 * * * \\
(0,309) \\
\end{array}$ & $\begin{array}{c}-1,020 * * * \\
(0,307)\end{array}$ & $\begin{array}{c}-0,999 * * * \\
(0,302)\end{array}$ & $\begin{array}{c}-0,962 * * * \\
(0,302)\end{array}$ & $\begin{array}{c}-1,170^{* * * *} \\
(0,302)\end{array}$ & $\begin{array}{c}-1,169 * * * \\
(0,302)\end{array}$ \\
\hline mora com pai ou mãe & & $\begin{array}{c}-1,836^{* * * *} \\
(0,307) \\
\end{array}$ & $\begin{array}{c}-1,508 * * * \\
(0,311)\end{array}$ & $\begin{array}{c}-1,589 * * * \\
(0,309)\end{array}$ & $\begin{array}{c}-1,606^{* * * *} \\
(0,308)\end{array}$ & $\begin{array}{c}-1,099^{* * * *} \\
(0,308)\end{array}$ & $\begin{array}{c}-1,097 * * * \\
(0,308)\end{array}$ \\
\hline $\begin{array}{l}\text { mora sozinho ou com mais uma } \\
\text { pessoa }\end{array}$ & & $\begin{array}{c}11,838 * * * * \\
(0,910)\end{array}$ & $\begin{array}{c}11,772 * * * \\
(0,926)\end{array}$ & $\begin{array}{c}11,572 * * * \\
(0,906)\end{array}$ & $\begin{array}{c}11,507 * * * \\
(0,904)\end{array}$ & $\begin{array}{c}11,017 * * * * \\
(0,907)\end{array}$ & $\begin{array}{c}11,007 * * * \\
(0,907)\end{array}$ \\
\hline mora com mais duas pessoas & & $\begin{array}{c}18,654 * * * \\
(0,636)\end{array}$ & $\begin{array}{c}18,241 * * * \\
(0,632)\end{array}$ & $\begin{array}{c}17,743 * * * \\
(0,624)\end{array}$ & $\begin{array}{c}17,665^{* * * *} \\
(0,622)\end{array}$ & $\begin{array}{c}17,350 * * * \\
(0,622)\end{array}$ & $\begin{array}{c}17,341 * * * \\
(0,622)\end{array}$ \\
\hline mora com mais três pessoas & & $\begin{array}{c}17,092 * * * * \\
(0,571)\end{array}$ & $\begin{array}{c}16,356^{* * * *} \\
(0,577)\end{array}$ & $\begin{array}{c}15,967 * * * \\
(0,568)\end{array}$ & $\begin{array}{c}15,910 * * * \\
(0,566)\end{array}$ & $\begin{array}{c}15,575 * * * \\
(0,564)\end{array}$ & $\begin{array}{c}15,574 * * * \\
(0,564)\end{array}$ \\
\hline $\begin{array}{c}\text { mora com mais quatro ou cinco } \\
\text { pessoas }\end{array}$ & & $\begin{array}{c}7,859 * * * \\
(0,505) \\
\end{array}$ & $\begin{array}{c}7,569 * * * \\
(0,506) \\
\end{array}$ & $\begin{array}{c}7,193 * * * \\
(0,500) \\
\end{array}$ & $\begin{array}{c}7,147 * * * \\
(0,499) \\
\end{array}$ & $\begin{array}{c}6,935 * * * \\
(0,495) \\
\end{array}$ & $\begin{array}{c}6,933 * * * \\
(0,496) \\
\end{array}$ \\
\hline
\end{tabular}


Tabela A9 - A associação entre crimes violentos e notas de português (continuação)

\begin{tabular}{|c|c|c|c|c|c|c|c|}
\hline Variáveis & Modelo 1 & Modelo 2 & Modelo 3 & Modelo 4 & Modelo 5 & Modelo 6 & Modelo 7 \\
\hline $\begin{array}{c}\text { mora com mais seis a oito } \\
\text { pessoas }\end{array}$ & & $\begin{array}{c}4,341 * * * \\
(0,558) \\
\end{array}$ & $\begin{array}{c}4,221 * * * \\
(0,561) \\
\end{array}$ & $\begin{array}{c}4,098 * * * \\
(0,556) \\
\end{array}$ & $\begin{array}{c}4,078 * * * \\
(0,557) \\
\end{array}$ & $\begin{array}{c}4,016^{* * * *} \\
(0,558) \\
\end{array}$ & $\begin{array}{c}4,017 * * * \\
(0,558) \\
\end{array}$ \\
\hline futuro (ainda não sei) & & $\begin{array}{c}6,217 * * * \\
(0,476) \\
\end{array}$ & $\begin{array}{c}6,779 * * * \\
(0,493) \\
\end{array}$ & $\begin{array}{c}6,481 * * * \\
(0,487) \\
\end{array}$ & $\begin{array}{c}6,446^{* * * *} \\
(0,486) \\
\end{array}$ & $\begin{array}{c}6,360 * * * \\
(0,486) \\
\end{array}$ & $\begin{array}{c}6,359 * * * \\
(0,486) \\
\end{array}$ \\
\hline futuro (estudar) & & $\begin{array}{c}6,408 * * * \\
(0,528) \\
\end{array}$ & $\begin{array}{c}5,768 * * * \\
(0,532) \\
\end{array}$ & $\begin{array}{c}5,328 * * * \\
(0,525) \\
\end{array}$ & $\begin{array}{c}5,286 * * * \\
(0,524) \\
\end{array}$ & $\begin{array}{c}4,789 * * * \\
(0,524)\end{array}$ & $\begin{array}{c}4,786^{* * * *} \\
(0,523) \\
\end{array}$ \\
\hline futuro (estudar e trabalhar) & & $\begin{array}{c}13,271 * * * \\
(0,468)\end{array}$ & $\begin{array}{c}12,454 * * * \\
(0,482) \\
\end{array}$ & $\begin{array}{c}12,287 * * * \\
(0,475)\end{array}$ & $\begin{array}{c}12,251 * * * * \\
(0,473)\end{array}$ & $\begin{array}{c}11,888 * * * \\
(0,474)\end{array}$ & $\begin{array}{c}11,890 * * * \\
(0,474)\end{array}$ \\
\hline deixado de lado & & $\begin{array}{c}-12,791 * * * \\
(0,365) \\
\end{array}$ & $\begin{array}{c}-12,494 * * * * \\
(0,365)\end{array}$ & $\begin{array}{c}-12,107 * * * \\
(0,359) \\
\end{array}$ & $\begin{array}{c}-12,081 * * * \\
(0,358) \\
\end{array}$ & $\begin{array}{c}-11,970 * * * \\
(0,358) \\
\end{array}$ & $\begin{array}{c}-11,963 * * * \\
(0,357) \\
\end{array}$ \\
\hline bolsa família & & $\begin{array}{c}-9,987 * * * \\
(0,369) \\
\end{array}$ & $\begin{array}{c}-9,657 * * * \\
(0,374) \\
\end{array}$ & $\begin{array}{c}-9,403 * * * \\
(0,364) \\
\end{array}$ & $\begin{array}{c}-9,391 * * * \\
(0,363) \\
\end{array}$ & $\begin{array}{c}-9,471 * * * \\
(0,362)\end{array}$ & $\begin{array}{c}-9,466 * * * \\
(0,362)\end{array}$ \\
\hline livros & & & $\begin{array}{c}2,651 * * * \\
(0,288) \\
\end{array}$ & $\begin{array}{c}2,303 * * * \\
(0,285)\end{array}$ & $\begin{array}{c}2,244 * * * \\
(0,284)\end{array}$ & $\begin{array}{c}1,964 * * * \\
(0,284)\end{array}$ & $\begin{array}{c}1,963 * * * \\
(0,284)\end{array}$ \\
\hline computador & & & $\begin{array}{c}4,055 * * * \\
(0,339) \\
\end{array}$ & $\begin{array}{c}3,653 * * * \\
(0,338) \\
\end{array}$ & $\begin{array}{c}3,544 * * * \\
(0,338) \\
\end{array}$ & $\begin{array}{c}3,352 * * * \\
(0,337) \\
\end{array}$ & $\begin{array}{c}3,345 * * * \\
(0,336) \\
\end{array}$ \\
\hline apoio aos estudos & & & $\begin{array}{c}10,973 * * * \\
(0,581)\end{array}$ & $\begin{array}{c}10,749 * * * \\
(0,582)\end{array}$ & $\begin{array}{c}10,717 * * * * \\
(0,582)\end{array}$ & $\begin{array}{c}10,037 * * * \\
(0,583)\end{array}$ & $\begin{array}{c}10,035 * * * \\
(0,583)\end{array}$ \\
\hline $\begin{array}{l}\text { mãe nunca estudou ou não } \\
\text { completou a } 4^{\mathrm{a}} \text { série }\end{array}$ & & & $\begin{array}{c}-2,163^{* * * *} \\
(0,520)\end{array}$ & $\begin{array}{c}-2,091 * * * \\
(0,522) \\
\end{array}$ & $\begin{array}{c}-2,005 * * * \\
(0,519)\end{array}$ & $\begin{array}{c}-1,768 * * * \\
(0,522)\end{array}$ & $\begin{array}{c}-1,770 * * * \\
(0,522) \\
\end{array}$ \\
\hline $\begin{array}{l}\text { mãe completou a } 4^{\mathrm{a}} \text { série } \\
\text { (antigo primário), mas não } \\
\text { completou a } 8^{\mathrm{a}} \text { série }\end{array}$ & & & $\begin{array}{c}3,031 * * * \\
(0,373) \\
\end{array}$ & $\begin{array}{c}2,434 * * * \\
(0,367) \\
\end{array}$ & $\begin{array}{c}2,475 * * * \\
(0,367) \\
\end{array}$ & $\begin{array}{c}2,663 * * * \\
(0,373) \\
\end{array}$ & $\begin{array}{c}2,664 * * * \\
(0,372) \\
\end{array}$ \\
\hline $\begin{array}{l}\text { mãe completou a } 8^{\mathrm{a}} \text { série } \\
\text { (antigo ginásio), mas não } \\
\text { completou o Ensino Médio }\end{array}$ & & & $\begin{array}{c}3,747 * * * \\
(0,434) \\
\end{array}$ & $\begin{array}{c}2,985 * * * \\
(0,426)\end{array}$ & $\begin{array}{c}3,028 * * * \\
(0,425) \\
\end{array}$ & $\begin{array}{c}3,201 * * * \\
(0,436)\end{array}$ & $\begin{array}{c}3,202 * * * \\
(0,436) \\
\end{array}$ \\
\hline $\begin{array}{c}\text { mãe completou o Ensino Médi } \\
\text { (antigo } 2^{\circ} \text { grau), mas não } \\
\text { completou a Faculdade }\end{array}$ & & & $\begin{array}{c}11,732 * * * \\
(0,453)\end{array}$ & $\begin{array}{c}10,878 * * * \\
(0,445)\end{array}$ & $\begin{array}{c}10,892 * * * \\
(0,446)\end{array}$ & $\begin{array}{c}10,917 * * * \\
(0,454)\end{array}$ & $\begin{array}{c}10,916^{* * * *} \\
(0,454)\end{array}$ \\
\hline tamanho da sala (11-15) & & & & $\begin{array}{l}-0,060 \\
(5,528) \\
\end{array}$ & $\begin{array}{l}-0,344 \\
(5,507) \\
\end{array}$ & $\begin{array}{l}-1,281 \\
(5,379) \\
\end{array}$ & $\begin{array}{l}-1,289 \\
(5,361) \\
\end{array}$ \\
\hline tamanho da sala (16-20) & & & & $\begin{array}{c}-6,145^{*} \\
(3,305) \\
\end{array}$ & $\begin{array}{l}-6,404^{*} \\
(3,284) \\
\end{array}$ & $\begin{array}{c}-6,114^{*} \\
(3,335) \\
\end{array}$ & $\begin{array}{l}-6,091^{*} \\
(3,337) \\
\end{array}$ \\
\hline tamanho da sala (21-25) & & & & $\begin{array}{l}-1,676 \\
(3,070) \\
\end{array}$ & $\begin{array}{l}-2,059 \\
(3,044) \\
\end{array}$ & $\begin{array}{l}-2,090 \\
(3,092) \\
\end{array}$ & $\begin{array}{l}-2,095 \\
(3,095) \\
\end{array}$ \\
\hline tamanho da sala (26-30) & & & & $\begin{array}{c}0,908 \\
(2,928) \\
\end{array}$ & $\begin{array}{c}0,609 \\
(2,892) \\
\end{array}$ & $\begin{array}{c}0,707 \\
(2,953) \\
\end{array}$ & $\begin{array}{c}0,676 \\
(2,955) \\
\end{array}$ \\
\hline tamanho da sala (31-35) & & & & $\begin{array}{c}3,132 \\
(2,939) \\
\end{array}$ & $\begin{array}{c}2,897 \\
(2,915) \\
\end{array}$ & $\begin{array}{c}3,002 \\
(2,972) \\
\end{array}$ & $\begin{array}{c}2,996 \\
(2,973) \\
\end{array}$ \\
\hline tamanho da sala (36-40) & & & & $\begin{array}{l}4,954^{*} \\
(2,988) \\
\end{array}$ & $\begin{array}{c}4,667 \\
(2,964) \\
\end{array}$ & $\begin{array}{c}4,751 \\
(3,021) \\
\end{array}$ & $\begin{array}{c}4,755 \\
(3,021) \\
\end{array}$ \\
\hline tamanho da sala (41-45) & & & & $\begin{array}{c}6,082 \\
(4,038) \\
\end{array}$ & $\begin{array}{c}6,114 \\
(4,136) \\
\end{array}$ & $\begin{array}{c}6,651 \\
(4,137) \\
\end{array}$ & $\begin{array}{c}6,554 \\
(4,145) \\
\end{array}$ \\
\hline municipal & & & & $\begin{array}{c}-10,604 * * * \\
(0,775) \\
\end{array}$ & $\begin{array}{c}-10,481 * * * \\
(0,773)\end{array}$ & $\begin{array}{c}-9,819 * * * \\
(0,826) \\
\end{array}$ & $\begin{array}{c}-9,785^{* * * *} \\
(0,824) \\
\end{array}$ \\
\hline ensino médio & & & & $\begin{array}{c}-1,934 * \\
(0,998) \\
\end{array}$ & $\begin{array}{l}-1,601 \\
(1,009) \\
\end{array}$ & $\begin{array}{c}-1,449 \\
(1,000) \\
\end{array}$ & $\begin{array}{l}-1,413 \\
(0,994) \\
\end{array}$ \\
\hline laboratório de informática & & & & $\begin{array}{l}-0,831 \\
(0,826)\end{array}$ & $\begin{array}{l}-0,885 \\
(0,812)\end{array}$ & $\begin{array}{l}-0,762 \\
(0,804)\end{array}$ & $\begin{array}{l}-0,777 \\
(0,804)\end{array}$ \\
\hline
\end{tabular}


Tabela A9 - A associação entre crimes violentos e notas de português (conclusão)

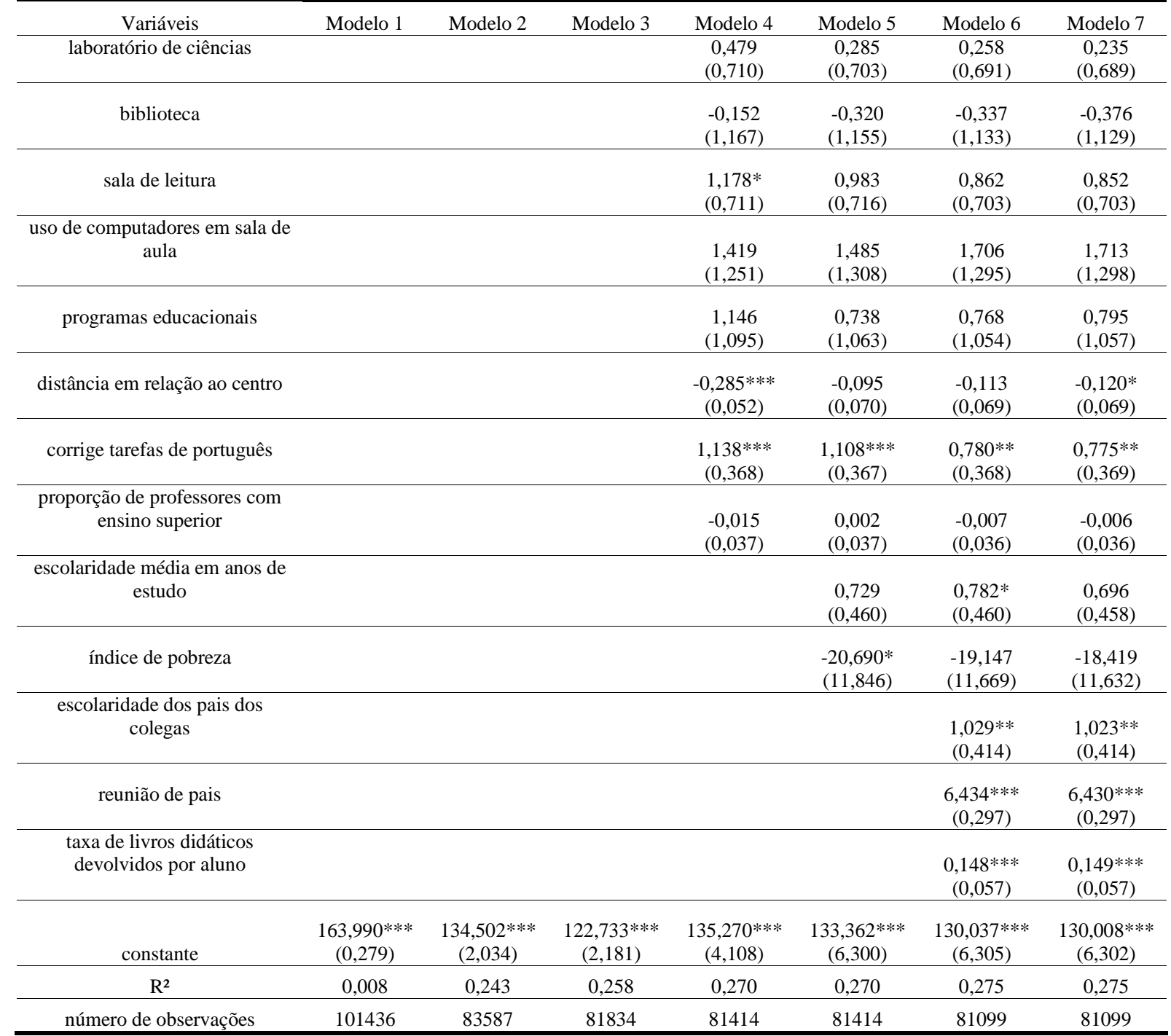

Fonte: Elaboração própria com base nos dados da SEADE, Prova Brasil 2005, Censo Escolar 2005 e Censo Demográfico 2000.

$* * *$ significante a $1 \% * *$ significante a $5 \% *$ significante a $10 \%$ 
Tabela A10 - A associação entre ameaças e notas de português (continua)

\begin{tabular}{|c|c|c|c|c|c|c|c|}
\hline Variáveis & Modelo 1 & Modelo 2 & Modelo 3 & Modelo 4 & Modelo 5 & Modelo 6 & Modelo 7 \\
\hline Ameaças (2005) & $\begin{array}{c}0,031 * * * \\
(0,001)\end{array}$ & $\begin{array}{c}0,021 * * * \\
(0,003)\end{array}$ & $\begin{array}{c}0,020 * * * \\
(0,003)\end{array}$ & $\begin{array}{c}0,008 * * * \\
(0,003) \\
\end{array}$ & $\begin{array}{c}0,003 \\
(0,003) \\
\end{array}$ & $\begin{array}{c}0,003 \\
(0,003) \\
\end{array}$ & \\
\hline Ameaças (2004) & & & & & & & $\begin{array}{c}0,004 \\
(0,003)\end{array}$ \\
\hline menino & & $\begin{array}{c}-6,357 * * * \\
(0,294) \\
\end{array}$ & $\begin{array}{c}-6,344 * * * \\
(0,293) \\
\end{array}$ & $\begin{array}{c}-6,388^{* * * *} \\
(0,289) \\
\end{array}$ & $\begin{array}{c}-6,395 * * * \\
(0,289) \\
\end{array}$ & $\begin{array}{c}-6,292 * * * \\
(0,290) \\
\end{array}$ & $\begin{array}{c}-6,291 * * * \\
(0,290) \\
\end{array}$ \\
\hline branco & & $\begin{array}{c}4,716^{* * * *} \\
(0,322)\end{array}$ & $\begin{array}{c}4,219 * * * \\
(0,313) \\
\end{array}$ & $\begin{array}{c}3,612 * * * \\
(0,309)\end{array}$ & $\begin{array}{c}3,589 * * * \\
(0,308)\end{array}$ & $\begin{array}{c}3,499 * * * \\
(0,308)\end{array}$ & $\begin{array}{c}3,500 * * * \\
(0,308) \\
\end{array}$ \\
\hline 8 anos & & $\begin{array}{c}-6,600 * * * \\
(2,007) \\
\end{array}$ & $\begin{array}{c}-9,135 * * * \\
(2,095) \\
\end{array}$ & $\begin{array}{c}-9,145^{* * * *} \\
(2,131) \\
\end{array}$ & $\begin{array}{c}-9,029 * * * \\
(2,130) \\
\end{array}$ & $\begin{array}{c}-9,638 * * * \\
(2,134) \\
\end{array}$ & $\begin{array}{c}-9,650 * * * \\
(2,135) \\
\end{array}$ \\
\hline 9 anos & & $\begin{array}{c}9,053 * * * \\
(1,980) \\
\end{array}$ & $\begin{array}{c}8,056 * * * \\
(2,047) \\
\end{array}$ & $\begin{array}{c}6,769 * * * \\
(2,086) \\
\end{array}$ & $\begin{array}{c}6,661 * * * \\
(2,081) \\
\end{array}$ & $\begin{array}{c}5,951 * * * \\
(2,085)\end{array}$ & $\begin{array}{c}5,934 * * * \\
(2,086) \\
\end{array}$ \\
\hline 10 anos & & $\begin{array}{c}12,655^{* * * *} \\
(1,754)\end{array}$ & $\begin{array}{c}11,046^{* * * *} \\
(1,834)\end{array}$ & $\begin{array}{c}9,800 * * * \\
(1,857) \\
\end{array}$ & $\begin{array}{c}9,702^{* * * *} \\
(1,852)\end{array}$ & $\begin{array}{c}9,134 * * * \\
(1,859) \\
\end{array}$ & $\begin{array}{c}9,118 * * * \\
(1,860) \\
\end{array}$ \\
\hline 11 anos & & $\begin{array}{c}9,951 * * * \\
(1,745) \\
\end{array}$ & $\begin{array}{c}8,778 * * * \\
(1,838) \\
\end{array}$ & $\begin{array}{c}8,012 * * * \\
(1,862) \\
\end{array}$ & $\begin{array}{c}7,971 * * * \\
(1,857) \\
\end{array}$ & $\begin{array}{c}7,540 * * * \\
(1,860) \\
\end{array}$ & $\begin{array}{c}7,530 * * * \\
(1,861) \\
\end{array}$ \\
\hline 12 anos & & $\begin{array}{c}5,590 * * * \\
(1,790) \\
\end{array}$ & $\begin{array}{c}4,737 * * \\
(1,868) \\
\end{array}$ & $\begin{array}{c}4,568 * * \\
(1,902) \\
\end{array}$ & $\begin{array}{c}4,547 * * \\
(1,897) \\
\end{array}$ & $\begin{array}{c}4,316^{* * *} \\
(1,901) \\
\end{array}$ & $\begin{array}{c}4,304 * * \\
(1,902) \\
\end{array}$ \\
\hline 13 anos & & $\begin{array}{c}3,963 * * \\
(1,874) \\
\end{array}$ & $\begin{array}{c}3,015 \\
(1,958) \\
\end{array}$ & $\begin{array}{c}2,944 \\
(1,972) \\
\end{array}$ & $\begin{array}{c}2,944 \\
(1,968) \\
\end{array}$ & $\begin{array}{c}2,660 \\
(1,968) \\
\end{array}$ & $\begin{array}{c}2,654 \\
(1,969) \\
\end{array}$ \\
\hline 14 anos & & $\begin{array}{c}5,361 * * \\
(2,241) \\
\end{array}$ & $\begin{array}{c}5,009 * * \\
(2,342) \\
\end{array}$ & $\begin{array}{c}4,779 * * \\
(2,328) \\
\end{array}$ & $\begin{array}{c}4,769 * * \\
(2,327) \\
\end{array}$ & $\begin{array}{c}4,813^{* * *} \\
(2,316) \\
\end{array}$ & $\begin{array}{c}4,790 * * \\
(2,316) \\
\end{array}$ \\
\hline reprovação & & $\begin{array}{c}-17,542 * * * \\
(0,425)\end{array}$ & $\begin{array}{c}-16,946 \text { *** } \\
(0,426)\end{array}$ & $\begin{array}{c}-16,040 * * * \\
(0,419)\end{array}$ & $\begin{array}{c}-16,075^{* * * *} \\
(0,420)\end{array}$ & $\begin{array}{c}-15,800 * * * \\
(0,419) \\
\end{array}$ & $\begin{array}{c}-15,802 * * * \\
(0,419) \\
\end{array}$ \\
\hline tarefa de português & & $\begin{array}{c}11,595 * * * \\
(0,337)\end{array}$ & $\begin{array}{c}10,687 * * * \\
(0,335)\end{array}$ & $\begin{array}{c}10,108 * * * \\
(0,332)\end{array}$ & $\begin{array}{c}10,088 * * * \\
(0,332)\end{array}$ & $\begin{array}{c}9,244 * * * \\
(0,331) \\
\end{array}$ & $\begin{array}{c}9,244 * * * \\
(0,331) \\
\end{array}$ \\
\hline tempo de tv & & $\begin{array}{c}0,475 \\
(0,323) \\
\end{array}$ & $\begin{array}{c}0,479 \\
(0,320) \\
\end{array}$ & $\begin{array}{c}0,342 \\
(0,312) \\
\end{array}$ & $\begin{array}{c}0,338 \\
(0,312) \\
\end{array}$ & $\begin{array}{c}0,378 \\
(0,310) \\
\end{array}$ & $\begin{array}{c}0,379 \\
(0,310) \\
\end{array}$ \\
\hline abandono & & $\begin{array}{c}-10,564 * * * \\
(0,484)\end{array}$ & $\begin{array}{c}-9,955^{* * * *} \\
(0,497) \\
\end{array}$ & $\begin{array}{c}-9,873 \text { **** } \\
(0,498)\end{array}$ & $\begin{array}{c}-9,836 * * * \\
(0,499) \\
\end{array}$ & $\begin{array}{c}-9,248 * * * \\
(0,502)\end{array}$ & $\begin{array}{c}-9,248 * * * \\
(0,502) \\
\end{array}$ \\
\hline trabalha fora de casa & & $\begin{array}{c}-13,545^{* * * *} \\
(0,400)\end{array}$ & $\begin{array}{c}-13,758 * * * \\
(0,408)\end{array}$ & $\begin{array}{c}-13,603 * * * \\
(0,405)\end{array}$ & $\begin{array}{c}-13,528 * * * \\
(0,403)\end{array}$ & $\begin{array}{c}-13,311 * * * \\
(0,404)\end{array}$ & $\begin{array}{c}-13,312 * * * * \\
(0,404)\end{array}$ \\
\hline trabalhos domésticos & & $\begin{array}{c}3,959 * * * \\
(0,318) \\
\end{array}$ & $\begin{array}{c}3,964 * * * \\
(0,315) \\
\end{array}$ & $\begin{array}{c}3,838 * * * \\
(0,312) \\
\end{array}$ & $\begin{array}{c}3,775 * * * \\
(0,311)\end{array}$ & $\begin{array}{c}3,604 * * * \\
(0,310) \\
\end{array}$ & $\begin{array}{c}3,605 * * * \\
(0,310) \\
\end{array}$ \\
\hline maternal & & $\begin{array}{c}12,890 \text { *** } \\
(0,408)\end{array}$ & $\begin{array}{c}11,147 * * * \\
(0,407)\end{array}$ & $\begin{array}{c}10,718^{* * *} * \\
(0,403)\end{array}$ & $\begin{array}{c}10,588 * * * \\
(0,402)\end{array}$ & $\begin{array}{c}10,162 * * * \\
(0,399)\end{array}$ & $\begin{array}{c}10,164 * * * \\
(0,399)\end{array}$ \\
\hline pré-escola & & $\begin{array}{c}11,304 * * * \\
(0,370)\end{array}$ & $\begin{array}{c}10,321 * * * \\
(0,373)\end{array}$ & $\begin{array}{c}10,496 * * * \\
(0,374) \\
\end{array}$ & $\begin{array}{c}10,483 * * * \\
(0,374)\end{array}$ & $\begin{array}{c}10,109^{* * * *} \\
(0,373)\end{array}$ & $\begin{array}{c}10,115^{* * * *} \\
(0,373)\end{array}$ \\
\hline estudou na mesma escola & & $\begin{array}{c}-0,968 * * * \\
(0,311) \\
\end{array}$ & $\begin{array}{c}-1,003 * * * \\
(0,308)\end{array}$ & $\begin{array}{c}-0,997 * * * \\
(0,303)\end{array}$ & $\begin{array}{c}-0,956^{* * * *} \\
(0,302) \\
\end{array}$ & $\begin{array}{c}-1,164 * * * \\
(0,303) \\
\end{array}$ & $\begin{array}{c}-1,161 * * * \\
(0,303)\end{array}$ \\
\hline mora com pai ou mãe & & $\begin{array}{c}-1,837 * * * \\
(0,306) \\
\end{array}$ & $\begin{array}{c}-1,503 \text { *** } \\
(0,311) \\
\end{array}$ & $\begin{array}{c}-1,591 * * * \\
(0,309) \\
\end{array}$ & $\begin{array}{c}-1,613 * * * \\
(0,308)\end{array}$ & $\begin{array}{c}-1,104 * * * \\
(0,308) \\
\end{array}$ & $\begin{array}{c}-1,102 * * * \\
(0,308)\end{array}$ \\
\hline $\begin{array}{l}\text { mora sozinho ou com mais uma } \\
\text { pessoa }\end{array}$ & & $\begin{array}{c}11,873 * * * \\
(0,915) \\
\end{array}$ & $\begin{array}{c}11,828 * * * \\
(0,932)\end{array}$ & $\begin{array}{c}11,613 * * * \\
(0,910)\end{array}$ & $\begin{array}{c}11,506 * * * \\
(0,904)\end{array}$ & $\begin{array}{c}11,015^{* * * *} \\
(0,908)\end{array}$ & $\begin{array}{c}11,007 * * * \\
(0,908)\end{array}$ \\
\hline mora com mais duas pessoas & & $\begin{array}{c}18,713 * * * \\
(0,640)\end{array}$ & $\begin{array}{c}18,303 * * * \\
(0,635) \\
\end{array}$ & $\begin{array}{c}17,782 * * * \\
(0,625)\end{array}$ & $\begin{array}{c}17,660 * * * \\
(0,622)\end{array}$ & $\begin{array}{c}17,345^{* * * *} \\
(0,622)\end{array}$ & $\begin{array}{c}17,341 * * * \\
(0,623)\end{array}$ \\
\hline mora com mais três pessoas & & $\begin{array}{c}17,133 * * * \\
(0,574) \\
\end{array}$ & $\begin{array}{c}16,398 * * * \\
(0,578)\end{array}$ & $\begin{array}{c}16,001 * * * \\
(0,569)\end{array}$ & $\begin{array}{c}15,909 * * * \\
(0,566)\end{array}$ & $\begin{array}{c}15,573 * * * \\
(0,563)\end{array}$ & $\begin{array}{c}15,571 * * * \\
(0,563)\end{array}$ \\
\hline $\begin{array}{c}\text { mora com mais quatro ou cinco } \\
\text { pessoas }\end{array}$ & & $\begin{array}{c}7,857 * * * \\
(0,508) \\
\end{array}$ & $\begin{array}{c}7,578 * * * \\
(0,508) \\
\end{array}$ & $\begin{array}{c}7,203 * * * \\
(0,501) \\
\end{array}$ & $\begin{array}{c}7,138 * * * \\
(0,499) \\
\end{array}$ & $\begin{array}{c}6,926 * * * \\
(0,495) \\
\end{array}$ & $\begin{array}{c}6,923 * * * \\
(0,496) \\
\end{array}$ \\
\hline
\end{tabular}


Tabela A10 - A associação entre ameaças e notas de português (continuação)

\begin{tabular}{|c|c|c|c|c|c|c|c|}
\hline Variáveis & Modelo 1 & Modelo 2 & Modelo 3 & Modelo 4 & Modelo 5 & Modelo 6 & Modelo 7 \\
\hline mora com mais seis a oito pessoas & & $\begin{array}{c}4,330^{* * * *} \\
(0,559)\end{array}$ & $\begin{array}{c}4,225 * * * \\
(0,561)\end{array}$ & $\begin{array}{c}4,108 * * * \\
(0,556)\end{array}$ & $\begin{array}{c}4,075 * * * \\
(0,557)\end{array}$ & $\begin{array}{c}4,014 * * * \\
(0,558)\end{array}$ & $\begin{array}{c}4,013^{* * * *} \\
(0,558)\end{array}$ \\
\hline futuro (ainda não sei) & & $\begin{array}{c}6,255^{* * * *} \\
(0,478)\end{array}$ & $\begin{array}{c}6,820 * * * \\
(0,495) \\
\end{array}$ & $\begin{array}{c}6,487 * * * \\
(0,488)\end{array}$ & $\begin{array}{c}6,439 * * * \\
(0,486)\end{array}$ & $\begin{array}{c}6,356^{* * * *} \\
(0,486) \\
\end{array}$ & $\begin{array}{c}6,353^{* * * *} \\
(0,486)\end{array}$ \\
\hline futuro (estudar) & & $\begin{array}{c}6,459 * * * \\
(0,530)\end{array}$ & $\begin{array}{c}5,805 * * * \\
(0,533) \\
\end{array}$ & $\begin{array}{c}5,344 * * * \\
(0,526)\end{array}$ & $\begin{array}{c}5,285^{* * * *} \\
(0,524)\end{array}$ & $\begin{array}{c}4,788^{* * * *} * \\
(0,524)\end{array}$ & $\begin{array}{c}4,784 * * * \\
(0,523)\end{array}$ \\
\hline futuro (estudar e trabalhar) & & $\begin{array}{c}13,297 * * * \\
(0,470)\end{array}$ & $\begin{array}{c}12,472 * * * \\
(0,483)\end{array}$ & $\begin{array}{c}12,281^{* * * *} \\
(0,476)\end{array}$ & $\begin{array}{c}12,242 * * * \\
(0,473)\end{array}$ & $\begin{array}{c}11,879 * * * \\
(0,474)\end{array}$ & $\begin{array}{c}11,879 * * * \\
(0,474)\end{array}$ \\
\hline deixado de lado & & $\begin{array}{c}-12,840 * * * \\
(0,366)\end{array}$ & $\begin{array}{c}-12,536 * * * \\
(0,366) \\
\end{array}$ & $\begin{array}{c}-12,135^{* * * *} \\
(0,360)\end{array}$ & $\begin{array}{c}-12,091 * * * \\
(0,358)\end{array}$ & $\begin{array}{c}-11,978 * * * \\
(0,358)\end{array}$ & $\begin{array}{c}-11,976^{* * * *} \\
(0,358)\end{array}$ \\
\hline bolsa família & & $\begin{array}{c}-10,093^{* * * *} \\
(0,370)\end{array}$ & $\begin{array}{c}-9,738 * * * \\
(0,375)\end{array}$ & $\begin{array}{c}-9,452 \text { **** } \\
(0,365)\end{array}$ & $\begin{array}{c}-9,408 * * * \\
(0,363) \\
\end{array}$ & $\begin{array}{c}-9,487 * * * \\
(0,362) \\
\end{array}$ & $\begin{array}{c}-9,488 * * * \\
(0,362)\end{array}$ \\
\hline livros & & & $\begin{array}{c}2,712 * * * \\
(0,288) \\
\end{array}$ & $\begin{array}{c}2,341 * * * * \\
(0,285)\end{array}$ & $\begin{array}{c}2,246 * * * \\
(0,284)\end{array}$ & $\begin{array}{c}1,965 * * * \\
(0,284) \\
\end{array}$ & $\begin{array}{c}1,963 * * * \\
(0,284)\end{array}$ \\
\hline computador & & & $\begin{array}{c}4,237 * * * \\
(0,343)\end{array}$ & $\begin{array}{c}3,757 * * * * \\
(0,341) \\
\end{array}$ & $\begin{array}{c}3,566^{* * * *} \\
(0,340) \\
\end{array}$ & $\begin{array}{c}3,370 * * * \\
(0,338) \\
\end{array}$ & $\begin{array}{c}3,367 * * * * \\
(0,338) \\
\end{array}$ \\
\hline apoio aos estudos & & & $\begin{array}{c}10,976^{* * * *} \\
(0,585)\end{array}$ & $\begin{array}{c}10,753 * * * \\
(0,584)\end{array}$ & $\begin{array}{c}10,713 \text { *** } \\
(0,583)\end{array}$ & $\begin{array}{c}10,030 * * * \\
(0,584)\end{array}$ & $\begin{array}{c}10,029 * * * \\
(0,584)\end{array}$ \\
\hline $\begin{array}{l}\text { mãe nunca estudou ou não } \\
\text { completou a } 4^{\mathrm{a}} \text { série }\end{array}$ & & & $\begin{array}{c}-2,261 * * * \\
(0,521)\end{array}$ & $\begin{array}{c}-2,127 * * * \\
(0,523)\end{array}$ & $\begin{array}{c}-2,004 * * * \\
(0,519)\end{array}$ & $\begin{array}{c}-1,764 * * * \\
(0,521)\end{array}$ & $\begin{array}{c}-1,767 * * * \\
(0,521)\end{array}$ \\
\hline $\begin{array}{l}\text { mãe completou a } 4^{\mathrm{a}} \text { série (antigo } \\
\text { primário), mas não completou a } 8^{\mathrm{a}} \\
\text { série }\end{array}$ & & & $\begin{array}{c}2,960 * * * \\
(0,375)\end{array}$ & $\begin{array}{c}2,395 * * * \\
(0,368)\end{array}$ & $\begin{array}{c}2,463^{* * * *} \\
(0,368)\end{array}$ & $\begin{array}{c}2,655^{* * * *} \\
(0,373)\end{array}$ & $\begin{array}{c}2,651 * * * \\
(0,373)\end{array}$ \\
\hline $\begin{array}{c}\text { mãe completou a } 8^{\mathrm{a}} \text { série (antigo } \\
\text { ginásio), mas não completou o } \\
\text { Ensino Médio }\end{array}$ & & & $\begin{array}{c}3,705 * * * \\
(0,435) \\
\end{array}$ & $\begin{array}{c}2,947 * * * \\
(0,427)\end{array}$ & $\begin{array}{c}3,019 * * * \\
(0,426)\end{array}$ & $\begin{array}{c}3,196 * * * \\
(0,437)\end{array}$ & $\begin{array}{c}3,197 * * * \\
(0,437)\end{array}$ \\
\hline $\begin{array}{c}\text { mãe completou o Ensino Médio } \\
\text { (antigo } 2^{\circ} \text { grau), mas não } \\
\text { completou a Faculdade }\end{array}$ & & & $\begin{array}{c}11,741 * * * \\
(0,455)\end{array}$ & $\begin{array}{c}10,871 * * * \\
(0,446)\end{array}$ & $\begin{array}{c}10,891 * * * \\
(0,447)\end{array}$ & $\begin{array}{c}10,920 * * * \\
(0,455)\end{array}$ & $\begin{array}{c}10,916^{* * * *} \\
(0,454)\end{array}$ \\
\hline tamanho da sala (11-15) & & & & $\begin{array}{c}0,430 \\
(5,618)\end{array}$ & $\begin{array}{l}-0,143 \\
(5,528)\end{array}$ & $\begin{array}{l}-1,084 \\
(5,397)\end{array}$ & $\begin{array}{l}-1,071 \\
(5,390)\end{array}$ \\
\hline tamanho da sala (16-20) & & & & $\begin{array}{l}-5,982^{*} \\
(3,343) \\
\end{array}$ & $\begin{array}{l}-6,361^{*} \\
(3,287) \\
\end{array}$ & $\begin{array}{l}-6,075^{*} \\
(3,336) \\
\end{array}$ & $\begin{array}{l}-6,047 * \\
(3,351) \\
\end{array}$ \\
\hline tamanho da sala $(21-25)$ & & & & $\begin{array}{l}-1,310 \\
(3,122) \\
\end{array}$ & $\begin{array}{l}-1,937 \\
(3,054) \\
\end{array}$ & $\begin{array}{l}-1,972 \\
(3,098) \\
\end{array}$ & $\begin{array}{l}-1,967 \\
(3,116) \\
\end{array}$ \\
\hline tamanho da sala (26-30) & & & & $\begin{array}{c}1,260 \\
(2,984)\end{array}$ & $\begin{array}{c}0,744 \\
(2,900) \\
\end{array}$ & $\begin{array}{c}0,836 \\
(2,957) \\
\end{array}$ & $\begin{array}{c}0,830 \\
(2,976)\end{array}$ \\
\hline tamanho da sala (31-35) & & & & $\begin{array}{c}3,397 \\
(2,994) \\
\end{array}$ & $\begin{array}{c}3,001 \\
(2,926) \\
\end{array}$ & $\begin{array}{c}3,102 \\
(2,979) \\
\end{array}$ & $\begin{array}{c}3,105 \\
(2,997) \\
\end{array}$ \\
\hline tamanho da sala (36-40) & & & & $\begin{array}{l}5,285^{*} \\
(3,039) \\
\end{array}$ & $\begin{array}{c}4,779 \\
(2,974) \\
\end{array}$ & $\begin{array}{c}4,860 \\
(3,028)\end{array}$ & $\begin{array}{c}4,873 \\
(3,045)\end{array}$ \\
\hline tamanho da sala (41-45) & & & & $\begin{array}{c}6,266 \\
(4,074) \\
\end{array}$ & $\begin{array}{c}6,232 \\
(4,164) \\
\end{array}$ & $\begin{array}{c}6,756 \\
(4,162) \\
\end{array}$ & $\begin{array}{c}6,611 \\
(4,184) \\
\end{array}$ \\
\hline municipal & & & & $\begin{array}{c}-10,856^{* * * *} \\
(0,792)\end{array}$ & $\begin{array}{c}-10,546^{* * * *} \\
(0,782)\end{array}$ & $\begin{array}{c}-9,891 * * * \\
(0,837) \\
\end{array}$ & $\begin{array}{c}-9,850^{* * * *} \\
(0,835)\end{array}$ \\
\hline ensino médio & & & & $\begin{array}{c}-2,267^{* * *} \\
(1,016)\end{array}$ & $\begin{array}{l}-1,644 \\
(1,023) \\
\end{array}$ & $\begin{array}{l}-1,499 \\
(1,014) \\
\end{array}$ & $\begin{array}{l}-1,483 \\
(1,012)\end{array}$ \\
\hline laboratório de informática & & & & $\begin{array}{l}-0,704 \\
(0,839)\end{array}$ & $\begin{array}{l}-0,845 \\
(0,817)\end{array}$ & $\begin{array}{l}-0,722 \\
(0,809)\end{array}$ & $\begin{array}{l}-0,760 \\
(0,808)\end{array}$ \\
\hline
\end{tabular}


Tabela A10 - A associação entre ameaças e notas de português (conclusão)

\begin{tabular}{|c|c|c|c|c|c|c|c|}
\hline Variáveis & Modelo 1 & Modelo 2 & Modelo 3 & Modelo 4 & Modelo 5 & Modelo 6 & Modelo 7 \\
\hline laboratório de ciências & & & & $\begin{array}{c}0,695 \\
(0,711) \\
\end{array}$ & $\begin{array}{c}0,336 \\
(0,703) \\
\end{array}$ & $\begin{array}{c}0,307 \\
(0,691) \\
\end{array}$ & $\begin{array}{c}0,317 \\
(0,689) \\
\end{array}$ \\
\hline biblioteca & & & & $\begin{array}{c}0,090 \\
(1,194)\end{array}$ & $\begin{array}{l}-0,277 \\
(1,161)\end{array}$ & $\begin{array}{l}-0,294 \\
(1,138)\end{array}$ & $\begin{array}{l}-0,344 \\
(1,129)\end{array}$ \\
\hline sala de leitura & & & & $\begin{array}{l}1,282 * \\
(0,714)\end{array}$ & $\begin{array}{c}0,986 \\
(0,715)\end{array}$ & $\begin{array}{c}0,866 \\
(0,702)\end{array}$ & $\begin{array}{c}0,870 \\
(0,702)\end{array}$ \\
\hline $\begin{array}{l}\text { uso de computadores em sala de } \\
\text { aula }\end{array}$ & & & & $\begin{array}{c}1,321 \\
(1,246) \\
\end{array}$ & $\begin{array}{c}1,453 \\
(1,318) \\
\end{array}$ & $\begin{array}{c}1,676 \\
(1,303) \\
\end{array}$ & $\begin{array}{c}1,720 \\
(1,295) \\
\end{array}$ \\
\hline programas educacionais & & & & $\begin{array}{c}1,391 \\
(1,094) \\
\end{array}$ & $\begin{array}{c}0,746 \\
(1,054) \\
\end{array}$ & $\begin{array}{c}0,780 \\
(1,046)\end{array}$ & $\begin{array}{c}0,797 \\
(1,043)\end{array}$ \\
\hline distância em relação ao centro & & & & $\begin{array}{c}-0,326 * * * \\
(0,052)\end{array}$ & $\begin{array}{l}-0,082 \\
(0,071) \\
\end{array}$ & $\begin{array}{l}-0,100 \\
(0,070)\end{array}$ & $\begin{array}{l}-0,099 \\
(0,069) \\
\end{array}$ \\
\hline corrige tarefas de matemática & & & & $\begin{array}{c}1,154 * * * \\
(0,369)\end{array}$ & $\begin{array}{c}1,107 * * * \\
(0,367)\end{array}$ & $\begin{array}{c}0,779 * * \\
(0,368)\end{array}$ & $\begin{array}{c}0,774 * * \\
(0,369)\end{array}$ \\
\hline $\begin{array}{l}\text { proporção de professores com } \\
\text { ensino superior }\end{array}$ & & & & $\begin{array}{l}-0,017 \\
(0,038)\end{array}$ & $\begin{array}{c}0,005 \\
(0,037)\end{array}$ & $\begin{array}{l}-0,004 \\
(0,036)\end{array}$ & $\begin{array}{l}-0,003 \\
(0,036)\end{array}$ \\
\hline $\begin{array}{l}\text { escolaridade média em anos de } \\
\text { estudo }\end{array}$ & & & & & $\begin{array}{l}1,023 * * \\
(0,455)\end{array}$ & $\begin{array}{l}1,056 * * \\
(0,454) \\
\end{array}$ & $\begin{array}{l}1,033 * * \\
(0,452) \\
\end{array}$ \\
\hline índice de pobreza & & & & & $\begin{array}{l}-21,706^{*} \\
(11,826)\end{array}$ & $\begin{array}{l}-20,006^{*} \\
(11,665)\end{array}$ & $\begin{array}{l}-19,280 \\
(11,729)\end{array}$ \\
\hline escolaridade dos pais dos colegas & & & & & & $\begin{array}{l}1,048 * * \\
(0,415)\end{array}$ & $\begin{array}{l}1,044 * * \\
(0,415)\end{array}$ \\
\hline reunião de pais & & & & & & $\begin{array}{c}6,452 * * * \\
(0,297)\end{array}$ & $\begin{array}{c}6,455 * * * \\
(0,297)\end{array}$ \\
\hline $\begin{array}{l}\text { taxa de livros didáticos } \\
\text { devolvidos por aluno }\end{array}$ & & & & & & $\begin{array}{c}0,146 * * \\
(0,057) \\
\end{array}$ & $\begin{array}{c}0,147 * * \\
(0,057)\end{array}$ \\
\hline constante & $\begin{array}{c}164,150 * * * \\
(0,322)\end{array}$ & $\begin{array}{c}134,849 * * * * \\
(1,998)\end{array}$ & $\begin{array}{c}122,965^{* * * *} \\
(2,148)\end{array}$ & $\begin{array}{c}136,432 * * * \\
(4,188)\end{array}$ & $\begin{array}{c}132,174 * * * \\
(6,353)\end{array}$ & $\begin{array}{c}128,834 * * * \\
(6,361)\end{array}$ & $\begin{array}{c}128,690 * * * \\
(6,394)\end{array}$ \\
\hline $\mathrm{R}^{2}$ & 0,006 & 0,241 & 0,256 & 0,269 & 0,270 & 0,274 & 0,275 \\
\hline número de observações & 101436 & 83587 & 81834 & 81414 & 81414 & 81099 & 81099 \\
\hline
\end{tabular}

Fonte: Elaboração própria com base nos dados da SEADE, Prova Brasil 2005, Censo Escolar 2005 e Censo Demográfico 2000.

$* * *$ significante a $1 \% * *$ significante a $5 \% *$ significante a $10 \%$ 
Tabela A11 - A associação entre roubo consumado e notas de português (continua)

\begin{tabular}{|c|c|c|c|c|c|c|c|}
\hline Variáveis & Modelo 1 & Modelo 2 & Modelo 3 & Modelo 4 & Modelo 5 & Modelo 6 & Modelo 7 \\
\hline Roubo consumado (2005) & $\begin{array}{c}0,005^{* * *} * \\
(0,000)\end{array}$ & $\begin{array}{c}0,004 * * * \\
(0,001)\end{array}$ & $\begin{array}{c}0,004 * * * \\
(0,001)\end{array}$ & $\begin{array}{c}0,002 * * * \\
(0,001)\end{array}$ & $\begin{array}{l}0,001 * \\
(0,001)\end{array}$ & $\begin{array}{l}0,001 * \\
(0,001)\end{array}$ & \\
\hline Roubo consumado (2004) & & & & & & & $\begin{array}{c}0,001 * * \\
(0,001)\end{array}$ \\
\hline menino & & $\begin{array}{c}-6,359 * * * \\
(0,295) \\
\end{array}$ & $\begin{array}{c}-6,342 * * * \\
(0,294)\end{array}$ & $\begin{array}{c}-6,386 * * * \\
(0,289) \\
\end{array}$ & $\begin{array}{c}-6,394 * * * \\
(0,289)\end{array}$ & $\begin{array}{c}-6,291 * * * \\
(0,290)\end{array}$ & $\begin{array}{c}-6,289 * * * * \\
(0,290)\end{array}$ \\
\hline branco & & $\begin{array}{c}4,774 * * * \\
(0,327)\end{array}$ & $\begin{array}{c}4,293 * * * \\
(0,317) \\
\end{array}$ & $\begin{array}{c}3,627 * * * \\
(0,309)\end{array}$ & $\begin{array}{c}3,594 * * * \\
(0,308)\end{array}$ & $\begin{array}{c}3,505^{* * * *} \\
(0,307)\end{array}$ & $\begin{array}{c}3,505^{* * * *} \\
(0,307)\end{array}$ \\
\hline 8 anos & & $\begin{array}{c}-6,289 * * * \\
(2,014)\end{array}$ & $\begin{array}{c}-8,791 * * * \\
(2,100)\end{array}$ & $\begin{array}{c}-8,948 * * * \\
-2,132 \\
\end{array}$ & $\begin{array}{c}-8,959 * * * \\
(2,132)\end{array}$ & $\begin{array}{c}-9,572 * * * \\
(2,136)\end{array}$ & $\begin{array}{c}-9,561 * * * \\
(2,137)\end{array}$ \\
\hline 9 anos & & $\begin{array}{c}9,207 * * * \\
(1,988)\end{array}$ & $\begin{array}{c}8,218 * * * \\
(2,049) \\
\end{array}$ & $\begin{array}{c}6,864 * * * \\
(2,084) \\
\end{array}$ & $\begin{array}{c}6,707 * * * \\
(2,082)\end{array}$ & $\begin{array}{c}5,994 * * * \\
(2,087)\end{array}$ & $\begin{array}{c}5,996^{* * * *} \\
(2,088) \\
\end{array}$ \\
\hline 10 anos & & $\begin{array}{c}12,856^{* * *} * \\
(1,763)\end{array}$ & $\begin{array}{c}11,255^{* * * *} \\
(1,835)\end{array}$ & $\begin{array}{c}9,908 * * * \\
(1,857)\end{array}$ & $\begin{array}{c}9,755^{* * * *} \\
(1,854)\end{array}$ & $\begin{array}{c}9,186^{* * * *} \\
(1,861)\end{array}$ & $\begin{array}{c}9,187 * * * \\
(1,862)\end{array}$ \\
\hline 11 anos & & $\begin{array}{c}10,249 * * * \\
(1,751)\end{array}$ & $\begin{array}{c}9,071 * * * \\
(1,837) \\
\end{array}$ & $\begin{array}{c}8,154 * * * \\
(1,861) \\
\end{array}$ & $\begin{array}{c}8,034 * * * \\
(1,859)\end{array}$ & $\begin{array}{c}7,600 * * * \\
(1,862)\end{array}$ & $\begin{array}{c}7,604 * * * \\
(1,863)\end{array}$ \\
\hline 12 anos & & $\begin{array}{c}5,876^{* * * *} \\
(1,792) \\
\end{array}$ & $\begin{array}{c}5,009 * * * \\
(1,864) \\
\end{array}$ & $\begin{array}{c}4,694 * * \\
(1,899)\end{array}$ & $\begin{array}{c}4,604 * * \\
(1,898)\end{array}$ & $\begin{array}{c}4,370 * * \\
(1,902)\end{array}$ & $\begin{array}{c}4,373 * * \\
(1,903) \\
\end{array}$ \\
\hline 13 anos & & $\begin{array}{c}4,182 * * \\
(1,880) \\
\end{array}$ & $\begin{array}{l}3,230 * \\
(1,956)\end{array}$ & $\begin{array}{c}3,038 \\
(1,971) \\
\end{array}$ & $\begin{array}{c}2,982 \\
(1,969) \\
\end{array}$ & $\begin{array}{c}2,696 \\
(1,970) \\
\end{array}$ & $\begin{array}{c}2,706 \\
(1,971) \\
\end{array}$ \\
\hline 14 anos & & $\begin{array}{c}5,685 * * \\
(2,241)\end{array}$ & $\begin{array}{c}5,285 * * \\
(2,339)\end{array}$ & $\begin{array}{c}4,899 * * \\
(2,326)\end{array}$ & $\begin{array}{c}4,827 * * \\
(2,328)\end{array}$ & $\begin{array}{c}4,867 * * \\
(2,318)\end{array}$ & $\begin{array}{c}4,860 * * \\
(2,317)\end{array}$ \\
\hline reprovação & & $\begin{array}{c}-17,598 * * * \\
(0,423)\end{array}$ & $\begin{array}{c}-16,999 * * * \\
(0,424)\end{array}$ & $\begin{array}{c}-16,068 * * * \\
(0,418)\end{array}$ & $\begin{array}{c}-16,083 * * * \\
(0,419)\end{array}$ & $\begin{array}{c}-15,808 * * * \\
(0,419)\end{array}$ & $\begin{array}{c}-15,806^{* * * *} \\
(0,419)\end{array}$ \\
\hline tarefa de português & & $\begin{array}{c}11,611^{* * * *} \\
(0,336)\end{array}$ & $\begin{array}{c}10,710 * * * \\
(0,333)\end{array}$ & $\begin{array}{c}10,122 * * * \\
(0,331)\end{array}$ & $\begin{array}{c}10,096^{* * * *} \\
(0,331)\end{array}$ & $\begin{array}{c}9,254 * * * \\
(0,331) \\
\end{array}$ & $\begin{array}{c}9,261 * * * \\
(0,331) \\
\end{array}$ \\
\hline tempo de tv & & $\begin{array}{c}0,447 \\
(0,322) \\
\end{array}$ & $\begin{array}{c}0,454 \\
(0,319) \\
\end{array}$ & $\begin{array}{c}0,334 \\
(0,312) \\
\end{array}$ & $\begin{array}{c}0,332 \\
(0,312) \\
\end{array}$ & $\begin{array}{c}0,371 \\
(0,310) \\
\end{array}$ & $\begin{array}{c}0,373 \\
(0,310) \\
\end{array}$ \\
\hline abandono & & $\begin{array}{c}-10,509 * * * \\
(0,486)\end{array}$ & $\begin{array}{c}-9,894 * * * \\
(0,498)\end{array}$ & $\begin{array}{c}-9,831 * * * \\
(0,499)\end{array}$ & $\begin{array}{c}-9,821 * * * \\
(0,499)\end{array}$ & $\begin{array}{c}-9,235 * * * \\
(0,502)\end{array}$ & $\begin{array}{c}-9,235^{* * * *} * \\
(0,502)\end{array}$ \\
\hline trabalha fora de casa & & $\begin{array}{c}-13,567 * * * \\
(0,399)\end{array}$ & $\begin{array}{c}-13,764 * * * \\
(0,407)\end{array}$ & $\begin{array}{c}-13,597 * * * * \\
(0,404)\end{array}$ & $\begin{array}{c}-13,534 * * * \\
(0,403) \\
\end{array}$ & $\begin{array}{c}-13,317 * * * \\
(0,404)\end{array}$ & $\begin{array}{c}-13,320 * * * \\
(0,404)\end{array}$ \\
\hline trabalhos domésticos & & $\begin{array}{c}3,948 * * * \\
(0,319) \\
\end{array}$ & $\begin{array}{c}3,961 * * * \\
(0,316)\end{array}$ & $\begin{array}{c}3,822 * * * \\
(0,312)\end{array}$ & $\begin{array}{c}3,776^{* * * *} \\
(0,311)\end{array}$ & $\begin{array}{c}3,605^{* * *} * \\
(0,310)\end{array}$ & $\begin{array}{c}3,603 * * * \\
(0,310)\end{array}$ \\
\hline maternal & & $\begin{array}{c}12,847 * * * \\
(0,410)\end{array}$ & $\begin{array}{c}11,137 * * * \\
(0,409)\end{array}$ & $\begin{array}{c}10,691 * * * \\
(0,403) \\
\end{array}$ & $\begin{array}{c}10,584^{* * * *} \\
(0,402)\end{array}$ & $\begin{array}{c}10,160 * * * \\
(0,399)\end{array}$ & $\begin{array}{c}10,159 * * * \\
(0,399) \\
\end{array}$ \\
\hline pré-escola & & $\begin{array}{c}11,320 * * * \\
(0,369)\end{array}$ & $\begin{array}{c}10,340 * * * \\
(0,372)\end{array}$ & $\begin{array}{c}10,520 * * * \\
(0,374)\end{array}$ & $\begin{array}{c}10,489 * * * \\
(0,374)\end{array}$ & $\begin{array}{c}10,115^{* * * *} \\
(0,373)\end{array}$ & $\begin{array}{c}10,116^{* * * *} \\
(0,373)\end{array}$ \\
\hline estudou na mesma escola & & $\begin{array}{c}-0,993 * * * \\
(0,310) \\
\end{array}$ & $\begin{array}{c}-1,031 * * * \\
(0,308) \\
\end{array}$ & $\begin{array}{c}-1,004 * * * \\
(0,302) \\
\end{array}$ & $\begin{array}{c}-0,963 * * * \\
(0,302)\end{array}$ & $\begin{array}{c}-1,170 * * * \\
(0,302)\end{array}$ & $\begin{array}{c}-1,172 * * * * \\
(0,302)\end{array}$ \\
\hline mora com pai ou mãe & & $\begin{array}{c}-1,829 * * * \\
(0,306)\end{array}$ & $\begin{array}{c}-1,497 * * * \\
(0,311) \\
\end{array}$ & $\begin{array}{c}-1,593 * * * \\
(0,309) \\
\end{array}$ & $\begin{array}{c}-1,609 * * * \\
(0,308)\end{array}$ & $\begin{array}{c}-1,101 * * * \\
(0,308)\end{array}$ & $\begin{array}{c}-1,101 * * * \\
(0,308)\end{array}$ \\
\hline $\begin{array}{l}\text { mora sozinho ou com mais uma } \\
\text { pessoa }\end{array}$ & & $\begin{array}{c}11,822 * * * \\
(0,912)\end{array}$ & $\begin{array}{c}11,759 * * * \\
(0,928)\end{array}$ & $\begin{array}{c}11,575^{* * * *} \\
(0,907)\end{array}$ & $\begin{array}{c}11,508 * * * \\
(0,904)\end{array}$ & $\begin{array}{c}11,017 * * * \\
(0,907)\end{array}$ & $\begin{array}{c}11,011^{* * * *} \\
(0,907)\end{array}$ \\
\hline mora com mais duas pessoas & & $\begin{array}{c}18,656^{* * * *} \\
(0,636)\end{array}$ & $\begin{array}{c}18,243 * * * \\
(0,633)\end{array}$ & $\begin{array}{c}17,742 * * * \\
(0,624)\end{array}$ & $\begin{array}{c}17,663 * * * \\
(0,622) \\
\end{array}$ & $\begin{array}{c}17,348 * * * \\
(0,622) \\
\end{array}$ & $\begin{array}{c}17,341^{* * * *} \\
(0,623)\end{array}$ \\
\hline mora com mais três pessoas & & $\begin{array}{c}17,087 * * * \\
(0,572)\end{array}$ & $\begin{array}{c}16,351 * * * \\
(0,577) \\
\end{array}$ & $\begin{array}{c}15,969 * * * \\
(0,568)\end{array}$ & $\begin{array}{c}15,911^{* * * *} \\
(0,566)\end{array}$ & $\begin{array}{c}15,576 * * * \\
(0,564)\end{array}$ & $\begin{array}{c}15,575^{* * *} * \\
(0,564)\end{array}$ \\
\hline $\begin{array}{l}\text { mora com mais quatro ou cinco } \\
\text { pessoas }\end{array}$ & & $\begin{array}{l}7,847 * * * \\
(0,505)\end{array}$ & $\begin{array}{l}7,560 * * * \\
(0,506)\end{array}$ & $\begin{array}{c}7,196 * * * \\
(0,500)\end{array}$ & $\begin{array}{c}7,147 * * * \\
(0,499)\end{array}$ & $\begin{array}{c}6,934 * * * \\
(0,495)\end{array}$ & $\begin{array}{c}6,934 * * * \\
(0,495)\end{array}$ \\
\hline
\end{tabular}


Tabela A11 - A associação entre roubo consumado e notas de português (continuação)

\begin{tabular}{|c|c|c|c|c|c|c|c|}
\hline $\begin{array}{c}\text { Variáveis } \\
\text { mora com mais seis a oito pessoas }\end{array}$ & Modelo 1 & $\begin{array}{c}\text { Modelo } 2 \\
4,338^{* * * *} \\
(0,559) \\
\end{array}$ & $\begin{array}{c}\text { Modelo } 3 \\
4,221 * * * \\
(0,562) \\
\end{array}$ & $\begin{array}{c}\text { Modelo } 4 \\
4,108^{* * * *} \\
(0,556) \\
\end{array}$ & $\begin{array}{c}\text { Modelo } 5 \\
4,082^{* * *} * \\
(0,557) \\
\end{array}$ & $\begin{array}{c}\text { Modelo } 6 \\
4,021^{* * *} \\
(0,558) \\
\end{array}$ & $\begin{array}{c}\text { Modelo } 7 \\
4,022^{* * *} \\
(0,558) \\
\end{array}$ \\
\hline futuro (ainda não sei) & & $\begin{array}{c}6,235^{* * *} \\
(0,476)\end{array}$ & $\begin{array}{c}6,796 * * * \\
(0,494)\end{array}$ & $\begin{array}{c}6,479 * * * \\
(0,487)\end{array}$ & $\begin{array}{c}6,442 * * * \\
(0,486)\end{array}$ & $\begin{array}{c}6,357 * * * \\
(0,486)\end{array}$ & $\begin{array}{c}6,358 * * * \\
(0,486)\end{array}$ \\
\hline futuro (estudar) & & $\begin{array}{c}6,463 * * * \\
(0,529) \\
\end{array}$ & $\begin{array}{c}5,818 * * * \\
(0,533)\end{array}$ & $\begin{array}{c}5,342 * * * \\
(0,525)\end{array}$ & $\begin{array}{c}5,290 * * * \\
(0,524)\end{array}$ & $\begin{array}{c}4,793 * * * \\
(0,524)\end{array}$ & $\begin{array}{c}4,794 * * * \\
(0,524)\end{array}$ \\
\hline futuro (estudar e trabalhar) & & $\begin{array}{c}13,322^{* * * *} \\
(0,468)\end{array}$ & $\begin{array}{c}12,500^{* * * *} \\
(0,482)\end{array}$ & $\begin{array}{c}12,296^{* * * *} \\
(0,475)\end{array}$ & $\begin{array}{c}12,253^{* * * *} \\
(0,473)\end{array}$ & $\begin{array}{c}11,889 * * * \\
(0,473)\end{array}$ & $\begin{array}{c}11,892^{* * *} \\
(0,474)\end{array}$ \\
\hline deixado de lado & & $\begin{array}{c}-12,832 * * * \\
(0,365)\end{array}$ & $\begin{array}{c}-12,530 * * * \\
(0,365)\end{array}$ & $\begin{array}{c}-12,119 * * * \\
(0,360)\end{array}$ & $\begin{array}{c}-12,086^{* * * *} \\
(0,358)\end{array}$ & $\begin{array}{c}-11,975^{* * * *} \\
(0,358)\end{array}$ & $\begin{array}{c}-11,972 * * * \\
(0,358)\end{array}$ \\
\hline bolsa família & & $\begin{array}{c}-10,002 * * * \\
(0,369)\end{array}$ & $\begin{array}{c}-9,666^{* * * *} \\
(0,374)\end{array}$ & $\begin{array}{c}-9,399 * * * \\
(0,364)\end{array}$ & $\begin{array}{c}-9,392 * * * \\
(0,363)\end{array}$ & $\begin{array}{c}-9,472 * * * \\
(0,362)\end{array}$ & $\begin{array}{c}-9,466 * * * \\
(0,362)\end{array}$ \\
\hline livros & & & $\begin{array}{c}2,631 * * * * \\
(0,289) \\
\end{array}$ & $\begin{array}{c}2,301 * * * \\
(0,285) \\
\end{array}$ & $\begin{array}{c}2,241 * * * \\
(0,284) \\
\end{array}$ & $\begin{array}{c}1,961 * * * \\
(0,284) \\
\end{array}$ & $\begin{array}{c}1,960 * * * \\
(0,284)\end{array}$ \\
\hline computador & & & $\begin{array}{c}4,130 * * * * \\
(0,341) \\
\end{array}$ & $\begin{array}{c}3,661 * * * \\
(0,339) \\
\end{array}$ & $\begin{array}{c}3,547 * * * * \\
(0,338) \\
\end{array}$ & $\begin{array}{c}3,353 * * * * \\
(0,337) \\
\end{array}$ & $\begin{array}{c}3,350 * * * \\
(0,337) \\
\end{array}$ \\
\hline apoio aos estudos & & & $\begin{array}{c}11,013 * * * * \\
(0,582)\end{array}$ & $\begin{array}{c}10,758 * * * \\
(0,582)\end{array}$ & $\begin{array}{c}10,720 * * * \\
(0,582)\end{array}$ & $\begin{array}{c}10,040 * * * \\
(0,583)\end{array}$ & $\begin{array}{c}10,038^{* * *} \\
(0,583)\end{array}$ \\
\hline $\begin{array}{l}\text { mãe nunca estudou ou não } \\
\text { completou a } 4^{\mathrm{a}} \text { série }\end{array}$ & & & $\begin{array}{c}-2,211 * * * \\
(0,521)\end{array}$ & $\begin{array}{c}-2,096 * * * \\
(0,522)\end{array}$ & $\begin{array}{c}-2,001 * * * \\
(0,519)\end{array}$ & $\begin{array}{c}-1,763 * * * \\
(0,522)\end{array}$ & $\begin{array}{c}-1,765 * * * \\
(0,522)\end{array}$ \\
\hline $\begin{array}{l}\text { mãe completou a } 4^{\mathrm{a}} \text { série (antigo } \\
\text { primário), mas não completou a } 8^{\mathrm{a}} \\
\text { série }\end{array}$ & & & $\begin{array}{c}2,998 * * * \\
(0,373)\end{array}$ & $\begin{array}{c}2,425 * * * \\
(0,367) \\
\end{array}$ & $\begin{array}{c}2,473 * * * \\
(0,367) \\
\end{array}$ & $\begin{array}{c}2,662 * * * \\
(0,373)\end{array}$ & $\begin{array}{c}2,663 * * * \\
(0,372) \\
\end{array}$ \\
\hline $\begin{array}{l}\text { mãe completou a } 8^{\text {a }} \text { série (antigo } \\
\text { ginásio), mas não completou o } \\
\text { Ensino Médio }\end{array}$ & & & $\begin{array}{c}3,709 * * * \\
(0,435)\end{array}$ & $\begin{array}{c}2,969 * * * \\
(0,427) \\
\end{array}$ & $\begin{array}{c}3,021 * * * \\
(0,425)\end{array}$ & $\begin{array}{c}3,195 * * * \\
(0,437)\end{array}$ & $\begin{array}{c}3,197 \text { *** } \\
(0,436)\end{array}$ \\
\hline $\begin{array}{l}\text { mãe completou o Ensino Médio } \\
\text { (antigo } 2^{\circ} \text { grau), mas não } \\
\text { completou a Faculdade }\end{array}$ & & & $\begin{array}{c}11,720^{* * *} \\
(0,454)\end{array}$ & $\begin{array}{c}10,872 * * * \\
(0,445)\end{array}$ & $\begin{array}{c}10,889 * * * \\
(0,446)\end{array}$ & $\begin{array}{c}10,915^{* * *} * \\
(0,454)\end{array}$ & $\begin{array}{c}10,917 * * * \\
(0,454)\end{array}$ \\
\hline tamanho da sala (11-15) & & & & $\begin{array}{c}0,047 \\
(5,494)\end{array}$ & $\begin{array}{c}-0,292 \\
(5,487) \\
\end{array}$ & $\begin{array}{l}-1,228 \\
(5,358) \\
\end{array}$ & $\begin{array}{l}-1,270 \\
(5,353) \\
\end{array}$ \\
\hline tamanho da sala (16-20) & & & & $\begin{array}{l}-5,976^{*} \\
(3,291)\end{array}$ & $\begin{array}{l}-6,337 * \\
(3,276)\end{array}$ & $\begin{array}{l}-6,050^{*} \\
(3,326)\end{array}$ & $\begin{array}{l}-6,017 * \\
(3,327) \\
\end{array}$ \\
\hline tamanho da sala (21-25) & & & & $\begin{array}{c}-1,607 \\
(3,063) \\
\end{array}$ & $\begin{array}{c}-2,047 \\
(3,038) \\
\end{array}$ & $\begin{array}{c}-2,078 \\
(3,085) \\
\end{array}$ & $\begin{array}{c}-2,085 \\
(3,088) \\
\end{array}$ \\
\hline tamanho da sala (26-30) & & & & $\begin{array}{c}0,981 \\
(2,920)\end{array}$ & $\begin{array}{c}0,626 \\
(2,885) \\
\end{array}$ & $\begin{array}{c}0,723 \\
(2,944) \\
\end{array}$ & $\begin{array}{c}0,718 \\
(2,947) \\
\end{array}$ \\
\hline tamanho da sala (31-35) & & & & $\begin{array}{c}3,189 \\
(2,931) \\
\end{array}$ & $\begin{array}{c}2,906 \\
(2,908) \\
\end{array}$ & $\begin{array}{c}3,010 \\
(2,963) \\
\end{array}$ & $\begin{array}{c}3,018 \\
(2,966) \\
\end{array}$ \\
\hline tamanho da sala (36-40) & & & & $\begin{array}{l}4,954^{*} \\
(2,978) \\
\end{array}$ & $\begin{array}{c}4,647 \\
(2,955)\end{array}$ & $\begin{array}{c}4,732 \\
(3,010) \\
\end{array}$ & $\begin{array}{c}4,741 \\
(3,013) \\
\end{array}$ \\
\hline tamanho da sala (41-45) & & & & $\begin{array}{c}6,110 \\
(4,000)\end{array}$ & $\begin{array}{c}6,135 \\
(4,120) \\
\end{array}$ & $\begin{array}{c}6,671 \\
(4,121) \\
\end{array}$ & $\begin{array}{c}6,650 \\
(4,125) \\
\end{array}$ \\
\hline municipal & & & & $\begin{array}{c}-10,585^{* * *} * \\
(0,779) \\
\end{array}$ & $\begin{array}{c}-10,474 * * * \\
(0,775) \\
\end{array}$ & $\begin{array}{c}-9,815 * * * \\
(0,828) \\
\end{array}$ & $\begin{array}{c}-9,781 * * * \\
(0,827)\end{array}$ \\
\hline ensino médio & & & & $\begin{array}{l}-1,898^{*} \\
(0,997)\end{array}$ & $\begin{array}{c}-1,573 \\
(1,010)\end{array}$ & $\begin{array}{l}-1,423 \\
(1,001)\end{array}$ & $\begin{array}{c}-1,392 \\
(0,996)\end{array}$ \\
\hline laboratório de informática & & & & $\begin{array}{l}-0,890 \\
(0,823)\end{array}$ & $\begin{array}{l}-0,917 \\
(0,811)\end{array}$ & $\begin{array}{l}-0,792 \\
(0,803)\end{array}$ & $\begin{array}{l}-0,807 \\
(0,802)\end{array}$ \\
\hline
\end{tabular}


Tabela A11 - A associação entre roubo consumado e notas de português (conclusão)

\begin{tabular}{|c|c|c|c|c|c|c|c|}
\hline Variáveis & Modelo 1 & Modelo 2 & Modelo 3 & Modelo 4 & Modelo 5 & Modelo 6 & Modelo 7 \\
\hline laboratório de ciências & & & & $\begin{array}{c}0,522 \\
(0,709) \\
\end{array}$ & $\begin{array}{c}0,305 \\
(0,702) \\
\end{array}$ & $\begin{array}{c}0,276 \\
(0,689) \\
\end{array}$ & $\begin{array}{c}0,253 \\
(0,689) \\
\end{array}$ \\
\hline biblioteca & & & & $\begin{array}{l}-0,227 \\
(1,182)\end{array}$ & $\begin{array}{l}-0,353 \\
(1,158) \\
\end{array}$ & $\begin{array}{l}-0,368 \\
(1,136)\end{array}$ & $\begin{array}{l}-0,393 \\
(1,136) \\
\end{array}$ \\
\hline sala de leitura & & & & $\begin{array}{l}1,232 * \\
(0,713)\end{array}$ & $\begin{array}{c}1,000 \\
(0,717)\end{array}$ & $\begin{array}{c}0,878 \\
(0,704)\end{array}$ & $\begin{array}{c}0,884 \\
(0,703)\end{array}$ \\
\hline $\begin{array}{l}\text { uso de computadores em sala de } \\
\text { aula }\end{array}$ & & & & $\begin{array}{c}1,439 \\
(1,253)\end{array}$ & $\begin{array}{c}1,496 \\
(1,314)\end{array}$ & $\begin{array}{c}1,717 \\
(1,300)\end{array}$ & $\begin{array}{c}1,729 \\
(1,301)\end{array}$ \\
\hline programas educacionais & & & & $\begin{array}{c}1,114 \\
(1,095)\end{array}$ & $\begin{array}{c}0,704 \\
(1,059)\end{array}$ & $\begin{array}{c}0,736 \\
(1,050)\end{array}$ & $\begin{array}{c}0,729 \\
(1,054)\end{array}$ \\
\hline distância em relação ao centro & & & & $\begin{array}{c}-0,319^{* * *} \\
(0,051)\end{array}$ & $\begin{array}{l}-0,103 \\
(0,070)\end{array}$ & $\begin{array}{r}-0,121^{*} \\
(0,070)\end{array}$ & $\begin{array}{l}-0,126^{*} \\
(0,070)\end{array}$ \\
\hline corrige tarefas de português & & & & $\begin{array}{c}1,137 * * * \\
(0,368)\end{array}$ & $\begin{array}{c}1,106^{* * * *} \\
(0,368)\end{array}$ & $\begin{array}{c}0,778^{* *} \\
(0,368)\end{array}$ & $\begin{array}{c}0,777 * * \\
(0,369) \\
\end{array}$ \\
\hline $\begin{array}{l}\text { proporção de professores com } \\
\text { ensino superior }\end{array}$ & & & & $\begin{array}{l}-0,019 \\
(0,037)\end{array}$ & $\begin{array}{c}0,001 \\
(0,037) \\
\end{array}$ & $\begin{array}{l}-0,008 \\
(0,036) \\
\end{array}$ & $\begin{array}{l}-0,008 \\
(0,036)\end{array}$ \\
\hline $\begin{array}{l}\text { escolaridade média em anos de } \\
\text { estudo }\end{array}$ & & & & & $\begin{array}{c}0,742 \\
(0,470) \\
\end{array}$ & $\begin{array}{l}0,796^{*} \\
(0,469) \\
\end{array}$ & $\begin{array}{c}0,694 \\
(0,469) \\
\end{array}$ \\
\hline índice de pobreza & & & & & $\begin{array}{l}-22,846^{*} \\
(11,734) \\
\end{array}$ & $\begin{array}{l}-21,177 * \\
(11,566) \\
\end{array}$ & $\begin{array}{l}-21,462 * \\
(11,517) \\
\end{array}$ \\
\hline escolaridade dos pais dos colegas & & & & & & $\begin{array}{c}1,036^{* *} \\
(0,415)\end{array}$ & $\begin{array}{c}1,034 * * \\
(0,415)\end{array}$ \\
\hline reunião de pais & & & & & & $\begin{array}{c}6,438 * * * \\
(0,297) \\
\end{array}$ & $\begin{array}{c}6,436^{* * * *} \\
(0,297)\end{array}$ \\
\hline $\begin{array}{l}\text { taxa de livros didáticos devolvidos } \\
\text { por aluno }\end{array}$ & & & & & & $\begin{array}{c}0,147 * * * \\
(0,057)\end{array}$ & $\begin{array}{c}0,148 * * * \\
(0,057)\end{array}$ \\
\hline constante & $\begin{array}{c}166,744 * * * \\
(0,221)\end{array}$ & $\begin{array}{c}136,188 \text { *** } \\
(1,989)\end{array}$ & $\begin{array}{c}124,300 \text { *** } \\
(2,144)\end{array}$ & $\begin{array}{c}136,885^{* * * *} \\
(4,038)\end{array}$ & $\begin{array}{c}134,587 * * * \\
(6,269)\end{array}$ & $\begin{array}{c}131,188 \text { *** } \\
(6,279)\end{array}$ & $\begin{array}{c}131,622 \text { *** } \\
(6,261)\end{array}$ \\
\hline $\mathrm{R}^{2}$ & 0,006 & 0,242 & 0,257 & 0,270 & 0,270 & 0,275 & 0,275 \\
\hline número de observações & 101436 & 83587 & 81834 & 81414 & 81414 & 81099 & 81099 \\
\hline
\end{tabular}

Fonte: Elaboração própria com base nos dados da SEADE, Prova Brasil 2005, Censo Escolar 2005 e Censo Demográfico 2000.

$* * *$ significante a $1 \% * *$ significante a $5 \% *$ significante a $10 \%$ 
Tabela A12 - A associação entre furto consumado e notas de português (continua)

\begin{tabular}{|c|c|c|c|c|c|c|c|}
\hline Variáveis & Modelo 1 & Modelo 2 & Modelo 3 & Modelo 4 & Modelo 5 & Modelo 6 & Modelo 7 \\
\hline Furto consumado (2005) & $\begin{array}{c}0,003^{* * * *} \\
(0,000)\end{array}$ & $\begin{array}{c}0,002 * * \\
(0,001)\end{array}$ & $\begin{array}{c}0,002 * * \\
(0,001) \\
\end{array}$ & $\begin{array}{l}0,001 * \\
(0,001) \\
\end{array}$ & $\begin{array}{c}0,000 \\
(0,000) \\
\end{array}$ & $\begin{array}{c}0,000 \\
(0,000) \\
\end{array}$ & \\
\hline Furto consumado (2004) & & & & & & & $\begin{array}{c}0,000 \\
(0,000)\end{array}$ \\
\hline menino & & $\begin{array}{c}-6,356 * * * \\
(0,295)\end{array}$ & $\begin{array}{c}-6,346^{* * * *} \\
(0,294)\end{array}$ & $\begin{array}{c}-6,385^{* * * *} \\
(0,289)\end{array}$ & $\begin{array}{c}-6,394 * * * \\
(0,289)\end{array}$ & $\begin{array}{c}-6,291 * * * \\
(0,290)\end{array}$ & $\begin{array}{c}-6,292 * * * \\
(0,290)\end{array}$ \\
\hline branco & & $\begin{array}{c}4,820 * * * \\
(0,332)\end{array}$ & $\begin{array}{c}4,320 * * * \\
(0,320)\end{array}$ & $\begin{array}{c}3,621 * * * \\
(0,309)\end{array}$ & $\begin{array}{c}3,591 * * * * \\
(0,308)\end{array}$ & $\begin{array}{c}3,502 * * * \\
(0,308)\end{array}$ & $\begin{array}{c}3,501 * * * \\
(0,308)\end{array}$ \\
\hline 8 anos & & $\begin{array}{c}-6,422 * * * \\
-2,011\end{array}$ & $\begin{array}{c}-8,981 * * * \\
(2,099)\end{array}$ & $\begin{array}{c}-9,048 * * * \\
(2,133) \\
\end{array}$ & $\begin{array}{c}-8,995^{* * * *} \\
(2,130) \\
\end{array}$ & $\begin{array}{c}-9,606 * * * \\
(2,134)\end{array}$ & $\begin{array}{c}-9,602 * * * \\
(2,135)\end{array}$ \\
\hline 9 anos & & $\begin{array}{c}9,229 * * * \\
-1,986 \\
\end{array}$ & $\begin{array}{c}8,184 * * * \\
(2,049)\end{array}$ & $\begin{array}{c}6,854 * * * \\
(2,086) \\
\end{array}$ & $\begin{array}{c}6,692 * * * \\
(2,082) \\
\end{array}$ & $\begin{array}{c}5,981 * * * \\
(2,086)\end{array}$ & $\begin{array}{c}5,981 * * * \\
(2,086)\end{array}$ \\
\hline 10 anos & & $\begin{array}{c}12,868 * * * \\
(1,762)\end{array}$ & $\begin{array}{c}11,209 * * * \\
(1,836)\end{array}$ & $\begin{array}{c}9,879 * * * \\
(1,858) \\
\end{array}$ & $\begin{array}{c}9,731 * * * \\
(1,853) \\
\end{array}$ & $\begin{array}{c}9,164 * * * \\
(1,860) \\
\end{array}$ & $\begin{array}{c}9,166^{* * * *} \\
(1,860) \\
\end{array}$ \\
\hline 11 anos & & $\begin{array}{c}10,273 * * * \\
(1,750)\end{array}$ & $\begin{array}{c}9,041 * * * \\
(1,839)\end{array}$ & $\begin{array}{c}8,113 * * * \\
(1,863)\end{array}$ & $\begin{array}{c}8,009 * * * \\
(1,858)\end{array}$ & $\begin{array}{c}7,577 * * * \\
(1,861)\end{array}$ & $\begin{array}{c}7,581 * * * \\
(1,862)\end{array}$ \\
\hline 12 anos & & $\begin{array}{c}5,911 * * * \\
(1,792)\end{array}$ & $\begin{array}{c}4,991 * * * \\
(1,866) \\
\end{array}$ & $\begin{array}{c}4,661 * * \\
(1,901)\end{array}$ & $\begin{array}{c}4,583 * * \\
(1,898) \\
\end{array}$ & $\begin{array}{c}4,351 * * \\
(1,902)\end{array}$ & $\begin{array}{c}4,355^{* * *} \\
(1,902)\end{array}$ \\
\hline 13 anos & & $\begin{array}{c}4,263 * * \\
(1,879)\end{array}$ & $\begin{array}{l}3,265^{*} \\
(1,958)\end{array}$ & $\begin{array}{c}3,033 \\
(1,972)\end{array}$ & $\begin{array}{c}2,977 \\
(1,969)\end{array}$ & $\begin{array}{c}2,692 \\
(1,969)\end{array}$ & $\begin{array}{c}2,697 \\
(1,970)\end{array}$ \\
\hline 14 anos & & $\begin{array}{c}5,731 * * \\
(2,246) \\
\end{array}$ & $\begin{array}{c}5,305 * * \\
(2,344) \\
\end{array}$ & $\begin{array}{c}4,876^{* * *} \\
(2,329) \\
\end{array}$ & $\begin{array}{c}4,807 * * \\
(2,329) \\
\end{array}$ & $\begin{array}{c}4,852^{* *} \\
(2,318) \\
\end{array}$ & $\begin{array}{c}4,852^{* * *} \\
(2,318) \\
\end{array}$ \\
\hline reprovação & & $\begin{array}{c}-17,625 * * * \\
(0,423)\end{array}$ & $\begin{array}{c}-17,019 * * * \\
(0,424)\end{array}$ & $\begin{array}{c}-16,062 * * * \\
(0,418)\end{array}$ & $\begin{array}{c}-16,083 * * * \\
(0,419)\end{array}$ & $\begin{array}{c}-15,808 * * * \\
(0,419)\end{array}$ & $\begin{array}{c}-15,809^{* * * *} \\
(0,419)\end{array}$ \\
\hline tarefa de português & & $\begin{array}{c}11,608 * * * \\
(0,336)\end{array}$ & $\begin{array}{c}10,699 * * * \\
(0,333)\end{array}$ & $\begin{array}{c}10,113 * * * \\
(0,331)\end{array}$ & $\begin{array}{c}10,090 * * * \\
(0,332)\end{array}$ & $\begin{array}{c}9,247 * * * \\
(0,331)\end{array}$ & $\begin{array}{c}9,247 * * * \\
(0,331)\end{array}$ \\
\hline tempo de tv & & $\begin{array}{c}0,464 \\
(0,323) \\
\end{array}$ & $\begin{array}{c}0,470 \\
(0,320) \\
\end{array}$ & $\begin{array}{c}0,330 \\
(0,312) \\
\end{array}$ & $\begin{array}{c}0,332 \\
(0,312) \\
\end{array}$ & $\begin{array}{c}0,372 \\
(0,310) \\
\end{array}$ & $\begin{array}{c}0,372 \\
(0,310) \\
\end{array}$ \\
\hline abandono & & $\begin{array}{c}-10,557 * * * \\
(0,483)\end{array}$ & $\begin{array}{c}-9,938 * * * \\
(0,496)\end{array}$ & $\begin{array}{c}-9,850 * * * \\
(0,497)\end{array}$ & $\begin{array}{c}-9,828^{* * * *} \\
(0,499) \\
\end{array}$ & $\begin{array}{c}-9,241 * * * \\
(0,502)\end{array}$ & $\begin{array}{c}-9,239 * * * \\
(0,502) \\
\end{array}$ \\
\hline trabalha fora de casa & & $\begin{array}{c}-13,572 * * * \\
(0,400)\end{array}$ & $\begin{array}{c}-13,783^{* * * *} \\
(0,408)\end{array}$ & $\begin{array}{c}-13,608 * * * \\
(0,405)\end{array}$ & $\begin{array}{c}-13,531 * * * \\
(0,404)\end{array}$ & $\begin{array}{c}-13,315 * * * \\
(0,404)\end{array}$ & $\begin{array}{c}-13,316^{* * * *} \\
(0,404) \\
\end{array}$ \\
\hline trabalhos domésticos & & $\begin{array}{c}4,016^{* * * *} \\
(0,321)\end{array}$ & $\begin{array}{c}4,017 * * * \\
(0,317)\end{array}$ & $\begin{array}{c}3,839 * * * \\
(0,312)\end{array}$ & $\begin{array}{c}3,777 * * * \\
(0,311) \\
\end{array}$ & $\begin{array}{c}3,606^{* * * *} \\
(0,310) \\
\end{array}$ & $\begin{array}{c}3,606 * * * \\
(0,310)\end{array}$ \\
\hline maternal & & $\begin{array}{c}12,953 * * * \\
(0,419)\end{array}$ & $\begin{array}{c}11,210 * * * \\
(0,415)\end{array}$ & $\begin{array}{c}10,703 * * * \\
(0,403) \\
\end{array}$ & $\begin{array}{c}10,582 * * * \\
(0,402)\end{array}$ & $\begin{array}{c}10,157 * * * \\
(0,399)\end{array}$ & $\begin{array}{c}10,156^{* * * *} \\
(0,399)\end{array}$ \\
\hline pré-escola & & $\begin{array}{c}11,284 * * * \\
(0,368)\end{array}$ & $\begin{array}{c}10,301 * * * \\
(0,371)\end{array}$ & $\begin{array}{c}10,490 * * * \\
(0,374)\end{array}$ & $\begin{array}{c}10,479 * * * \\
(0,374)\end{array}$ & $\begin{array}{c}10,106^{* * * *} \\
(0,373)\end{array}$ & $\begin{array}{c}10,105 * * * \\
(0,373) \\
\end{array}$ \\
\hline estudou na mesma escola & & $\begin{array}{c}-0,982 * * * \\
(0,312)\end{array}$ & $\begin{array}{c}-1,015 * * * \\
(0,309)\end{array}$ & $\begin{array}{c}-0,997 * * * \\
(0,303) \\
\end{array}$ & $\begin{array}{c}-0,956^{* * * *} \\
(0,302) \\
\end{array}$ & $\begin{array}{c}-1,164 * * * \\
(0,302)\end{array}$ & $\begin{array}{c}-1,163 * * * \\
(0,302) \\
\end{array}$ \\
\hline mora com pai ou mãe & & $\begin{array}{c}-1,809 * * * \\
(0,306)\end{array}$ & $\begin{array}{c}-1,471 * * * \\
(0,311)\end{array}$ & $\begin{array}{c}-1,587 * * * \\
(0,309)\end{array}$ & $\begin{array}{c}-1,610^{* * * *} \\
(0,308)\end{array}$ & $\begin{array}{c}-1,102 * * * \\
(0,308)\end{array}$ & $\begin{array}{c}-1,102 * * * \\
(0,308)\end{array}$ \\
\hline $\begin{array}{l}\text { mora sozinho ou com mais uma } \\
\text { pessoa }\end{array}$ & & $\begin{array}{c}11,853 * * * \\
(0,916)\end{array}$ & $\begin{array}{c}11,808 * * * \\
(0,932) \\
\end{array}$ & $\begin{array}{c}11,613 * * * \\
(0,909)\end{array}$ & $\begin{array}{c}11,509 * * * \\
(0,904)\end{array}$ & $\begin{array}{c}11,018 * * * \\
(0,907) \\
\end{array}$ & $\begin{array}{c}11,017 * * * \\
(0,908)\end{array}$ \\
\hline mora com mais duas pessoas & & $\begin{array}{c}18,717 * * * \\
(0,637) \\
\end{array}$ & $\begin{array}{c}18,310 * * * \\
(0,634)\end{array}$ & $\begin{array}{c}17,780 * * * \\
(0,625)\end{array}$ & $\begin{array}{c}17,663 * * * \\
(0,622)\end{array}$ & $\begin{array}{c}17,347 * * * \\
(0,622)\end{array}$ & $\begin{array}{c}17,347 * * * \\
(0,622)\end{array}$ \\
\hline mora com mais três pessoas & & $\begin{array}{c}17,148 * * * \\
(0,573)\end{array}$ & $\begin{array}{c}16,416 * * * \\
(0,578)\end{array}$ & $\begin{array}{c}16,010 * * * \\
(0,568)\end{array}$ & $\begin{array}{c}15,916 * * * \\
(0,566)\end{array}$ & $\begin{array}{c}15,580 * * * \\
(0,563)\end{array}$ & $\begin{array}{c}15,580 * * * \\
(0,563)\end{array}$ \\
\hline $\begin{array}{c}\text { mora com mais quatro ou cinco } \\
\text { pessoas }\end{array}$ & & $\begin{array}{c}7,871 * * * \\
(0,507)\end{array}$ & $\begin{array}{c}7,594 * * * \\
(0,507)\end{array}$ & $\begin{array}{c}7,219 * * * \\
(0,501)\end{array}$ & $\begin{array}{c}7,147 * * * \\
(0,499)\end{array}$ & $\begin{array}{c}6,935^{* * *} * \\
(0,495)\end{array}$ & $\begin{array}{c}6,936 * * * \\
(0,495) \\
\end{array}$ \\
\hline
\end{tabular}


Tabela A12 - A associação entre furto consumado e notas de português (continuação)

\begin{tabular}{|c|c|c|c|c|c|c|c|}
\hline Variáveis & Modelo 1 & Modelo 2 & Modelo 3 & Modelo 4 & Modelo 5 & Modelo 6 & Modelo 7 \\
\hline mora com mais seis a oito pessoas & & $\begin{array}{c}4,358 * * * \\
(0,561)\end{array}$ & $\begin{array}{c}4,251 * * * \\
(0,563)\end{array}$ & $\begin{array}{c}4,130 * * * \\
(0,557)\end{array}$ & $\begin{array}{c}4,085 * * * \\
(0,557) \\
\end{array}$ & $\begin{array}{c}4,024 * * * \\
(0,558)\end{array}$ & $\begin{array}{c}4,026^{* * * *} \\
(0,558)\end{array}$ \\
\hline futuro (ainda não sei) & & $\begin{array}{c}6,271 * * * \\
(0,478) \\
\end{array}$ & $\begin{array}{c}6,835^{* * * *} \\
(0,495) \\
\end{array}$ & $\begin{array}{c}6,487 * * * \\
(0,488)\end{array}$ & $\begin{array}{c}6,440 * * * \\
(0,486) \\
\end{array}$ & $\begin{array}{c}6,357 * * * \\
(0,486) \\
\end{array}$ & $\begin{array}{c}6,357 * * * \\
(0,486) \\
\end{array}$ \\
\hline futuro (estudar) & & $\begin{array}{c}6,516^{* * * *} \\
(0,532) \\
\end{array}$ & $\begin{array}{c}5,863^{* * * *} \\
(0,534) \\
\end{array}$ & $\begin{array}{c}5,354 * * * \\
(0,526)\end{array}$ & $\begin{array}{c}5,289 * * * \\
(0,524)\end{array}$ & $\begin{array}{c}4,793^{* * * *} \\
(0,524)\end{array}$ & $\begin{array}{c}4,794 * * * \\
(0,524) \\
\end{array}$ \\
\hline futuro (estudar e trabalhar) & & $\begin{array}{c}13,371 * * * \\
(0,470)\end{array}$ & $\begin{array}{c}12,543 * * * \\
(0,484)\end{array}$ & $\begin{array}{c}12,300 * * * \\
(0,476)\end{array}$ & $\begin{array}{c}12,250 * * * \\
(0,473)\end{array}$ & $\begin{array}{c}11,887 * * * * \\
(0,473)\end{array}$ & $\begin{array}{c}11,889 \text { *** } \\
(0,474)\end{array}$ \\
\hline deixado de lado & & $\begin{array}{c}-12,874 * * * \\
(0,367)\end{array}$ & $\begin{array}{c}-12,568 * * * \\
(0,367)\end{array}$ & $\begin{array}{c}-12,136^{* * * *} \\
(0,360)\end{array}$ & $\begin{array}{c}-12,091 * * * \\
(0,358)\end{array}$ & $\begin{array}{c}-11,979 * * * * \\
(0,358)\end{array}$ & $\begin{array}{c}-11,979 * * * \\
(0,358)\end{array}$ \\
\hline bolsa família & & $\begin{array}{c}-10,112 * * * \\
(0,372)\end{array}$ & $\begin{array}{c}-9,755^{* * * *} \\
(0,376)\end{array}$ & $\begin{array}{c}-9,445^{* * * *} \\
(0,364)\end{array}$ & $\begin{array}{c}-9,407 * * * \\
(0,363) \\
\end{array}$ & $\begin{array}{c}-9,486 * * * \\
(0,362) \\
\end{array}$ & $\begin{array}{c}-9,486 * * * \\
(0,362) \\
\end{array}$ \\
\hline livros & & & $\begin{array}{c}2,660 * * * \\
(0,291) \\
\end{array}$ & $\begin{array}{c}2,327 * * * \\
(0,286) \\
\end{array}$ & $\begin{array}{c}2,243 * * * \\
(0,284) \\
\end{array}$ & $\begin{array}{c}1,962 * * * \\
(0,284)\end{array}$ & $\begin{array}{c}1,961 * * * \\
(0,284) \\
\end{array}$ \\
\hline computador & & & $\begin{array}{c}4,281^{* * * *} \\
(0,350)\end{array}$ & $\begin{array}{c}3,726^{* * * *} \\
(0,340)\end{array}$ & $\begin{array}{c}3,558 * * * * \\
(0,339)\end{array}$ & $\begin{array}{c}3,363 * * * \\
(0,337) \\
\end{array}$ & $\begin{array}{c}3,362 * * * \\
(0,337)\end{array}$ \\
\hline apoio aos estudos & & & $\begin{array}{c}11,049 * * * \\
(0,584)\end{array}$ & $\begin{array}{c}10,765^{* * * *} \\
(0,583)\end{array}$ & $\begin{array}{c}10,719 * * * \\
(0,583)\end{array}$ & $\begin{array}{c}10,038 * * * \\
(0,584)\end{array}$ & $\begin{array}{c}10,036^{* * * *} \\
(0,584)\end{array}$ \\
\hline $\begin{array}{l}\text { mãe nunca estudou ou não } \\
\text { completou a } 4^{\mathrm{a}} \text { série }\end{array}$ & & & $\begin{array}{c}-2,248 * * * \\
(0,522) \\
\end{array}$ & $\begin{array}{c}-2,097 * * * \\
(0,523) \\
\end{array}$ & $\begin{array}{c}-1,994 * * * \\
(0,519)\end{array}$ & $\begin{array}{c}-1,755^{* * * *} \\
(0,522)\end{array}$ & $\begin{array}{c}-1,756 * * * \\
(0,522) \\
\end{array}$ \\
\hline $\begin{array}{l}\text { mãe completou a } 4^{\mathrm{a}} \text { série (antigo } \\
\text { primário), mas não completou a } 8^{\mathrm{a}} \\
\text { série }\end{array}$ & & & $\begin{array}{c}2,969 * * * \\
(0,374)\end{array}$ & $\begin{array}{c}2,416 * * * \\
(0,367) \\
\end{array}$ & $\begin{array}{c}2,471 * * * \\
(0,367)\end{array}$ & $\begin{array}{c}2,662 * * * \\
(0,373)\end{array}$ & $\begin{array}{c}2,662 * * * \\
(0,373) \\
\end{array}$ \\
\hline $\begin{array}{c}\text { mãe completou a } 8^{\mathrm{a}} \text { série (antigo } \\
\text { ginásio), mas não completou o } \\
\text { Ensino Médio }\end{array}$ & & & $\begin{array}{c}3,664 * * * \\
(0,437) \\
\end{array}$ & $\begin{array}{c}2,944 * * * \\
(0,428)\end{array}$ & $\begin{array}{c}3,017 * * * \\
(0,426) \\
\end{array}$ & $\begin{array}{c}3,193 * * * \\
(0,437)\end{array}$ & $\begin{array}{c}3,193 * * * \\
(0,437) \\
\end{array}$ \\
\hline $\begin{array}{c}\text { mãe completou o Ensino Médio } \\
\text { (antigo } 2^{\circ} \text { grau), mas não completou } \\
\text { a Faculdade }\end{array}$ & & & $\begin{array}{c}11,706^{* * * *} \\
(0,454)\end{array}$ & $\begin{array}{c}10,864 * * * \\
(0,446)\end{array}$ & $\begin{array}{c}10,888 * * * \\
(0,446)\end{array}$ & $\begin{array}{c}10,916^{* * * *} \\
(0,454) \\
\end{array}$ & $\begin{array}{c}10,916^{* * * *} \\
(0,454) \\
\end{array}$ \\
\hline tamanho da sala (11-15) & & & & $\begin{array}{c}0,375 \\
(5,536) \\
\end{array}$ & $\begin{array}{l}-0,167 \\
(5,506) \\
\end{array}$ & $\begin{array}{l}-1,117 \\
(5,371) \\
\end{array}$ & $\begin{array}{l}-1,138 \\
(5,375) \\
\end{array}$ \\
\hline tamanho da sala (16-20) & & & & $\begin{array}{l}-5,851 * \\
(3,310) \\
\end{array}$ & $\begin{array}{l}-6,310^{*} \\
(3,285)\end{array}$ & $\begin{array}{l}-6,021 * \\
(3,334)\end{array}$ & $\begin{array}{l}-6,024 * \\
(3,335) \\
\end{array}$ \\
\hline tamanho da sala $(21-25)$ & & & & $\begin{array}{l}-1,406 \\
(3,091)\end{array}$ & $\begin{array}{l}-1,977 \\
(3,052)\end{array}$ & $\begin{array}{l}-2,013 \\
(3,096)\end{array}$ & $\begin{array}{l}-2,017 \\
(3,096)\end{array}$ \\
\hline tamanho da sala (26-30) & & & & $\begin{array}{c}1,172 \\
(2,947) \\
\end{array}$ & $\begin{array}{c}0,705 \\
(2,896) \\
\end{array}$ & $\begin{array}{c}0,798 \\
(2,953) \\
\end{array}$ & $\begin{array}{c}0,794 \\
(2,954) \\
\end{array}$ \\
\hline tamanho da sala (31-35) & & & & $\begin{array}{c}3,371 \\
(2,959) \\
\end{array}$ & $\begin{array}{c}2,986 \\
(2,921) \\
\end{array}$ & $\begin{array}{c}3,089 \\
(2,974) \\
\end{array}$ & $\begin{array}{c}3,090 \\
(2,975) \\
\end{array}$ \\
\hline tamanho da sala (36-40) & & & & $\begin{array}{l}5,169^{*} \\
(3,003) \\
\end{array}$ & $\begin{array}{c}4,733 \\
(2,969) \\
\end{array}$ & $\begin{array}{c}4,815 \\
(3,022) \\
\end{array}$ & $\begin{array}{c}4,816 \\
(3,023) \\
\end{array}$ \\
\hline tamanho da sala (41-45) & & & & $\begin{array}{c}6,329 \\
(3,987) \\
\end{array}$ & $\begin{array}{c}6,249 \\
(4,137) \\
\end{array}$ & $\begin{array}{c}6,781 \\
(4,135) \\
\end{array}$ & $\begin{array}{c}6,751 \\
(4,137) \\
\end{array}$ \\
\hline municipal & & & & $\begin{array}{c}-10,690^{* * * *} \\
(0,790)\end{array}$ & $\begin{array}{c}-10,492 * * * \\
(0,778)\end{array}$ & $\begin{array}{c}-9,827 * * * \\
(0,833) \\
\end{array}$ & $\begin{array}{c}-9,813 \text { *** } \\
(0,833) \\
\end{array}$ \\
\hline ensino médio & & & & $\begin{array}{c}-2,077 * * \\
(0,999)\end{array}$ & $\begin{array}{c}-1,589 \\
(1,014) \\
\end{array}$ & $\begin{array}{c}-1,439 \\
(1,005) \\
\end{array}$ & $\begin{array}{c}-1,437 \\
(1,004) \\
\end{array}$ \\
\hline laboratório de informática & & & & $\begin{array}{l}-0,861 \\
(0,825)\end{array}$ & $\begin{array}{l}-0,904 \\
(0,810)\end{array}$ & $\begin{array}{l}-0,780 \\
(0,803)\end{array}$ & $\begin{array}{l}-0,791 \\
(0,802)\end{array}$ \\
\hline
\end{tabular}


Tabela A12 - A associação entre furto consumado e notas de português (conclusão)

\begin{tabular}{|c|c|c|c|c|c|c|c|}
\hline Variáveis & Modelo 1 & Modelo 2 & Modelo 3 & Modelo 4 & Modelo 5 & Modelo 6 & Modelo 7 \\
\hline laboratório de ciências & & & & $\begin{array}{c}0,716 \\
(0,704)\end{array}$ & $\begin{array}{c}0,353 \\
(0,700)\end{array}$ & $\begin{array}{c}0,323 \\
(0,687)\end{array}$ & $\begin{array}{c}0,332 \\
(0,687)\end{array}$ \\
\hline biblioteca & & & & $\begin{array}{c}-0,109 \\
(1,190)\end{array}$ & $\begin{array}{c}-0,341 \\
(1,154)\end{array}$ & $\begin{array}{c}-0,358 \\
(1,131)\end{array}$ & $\begin{array}{c}-0,373 \\
(1,129)\end{array}$ \\
\hline sala de leitura & & & & $\begin{array}{l}1,302 * \\
(0,711)\end{array}$ & $\begin{array}{c}1,000 \\
(0,714)\end{array}$ & $\begin{array}{c}0,879 \\
(0,701)\end{array}$ & $\begin{array}{c}0,879 \\
(0,702)\end{array}$ \\
\hline uso de computadores em sala de aula & & & & $\begin{array}{c}1,385 \\
(1,272)\end{array}$ & $\begin{array}{c}1,477 \\
(1,329)\end{array}$ & $\begin{array}{c}1,700 \\
(1,314)\end{array}$ & $\begin{array}{c}1,703 \\
(1,315)\end{array}$ \\
\hline programas educacionais & & & & $\begin{array}{c}1,369 \\
(1,101)\end{array}$ & $\begin{array}{c}0,753 \\
(1,057)\end{array}$ & $\begin{array}{c}0,785 \\
(1,049)\end{array}$ & $\begin{array}{c}0,788 \\
(1,049)\end{array}$ \\
\hline distância em relação ao centro & & & & $\begin{array}{c}-0,352^{* * * *} \\
(0,052)\end{array}$ & $\begin{array}{c}-0,094 \\
(0,070)\end{array}$ & $\begin{array}{l}-0,113 \\
(0,070)\end{array}$ & $\begin{array}{c}-0,112 \\
(0,070)\end{array}$ \\
\hline corrige tarefas de matemática & & & & $\begin{array}{c}1,132 * * * \\
(0,369)\end{array}$ & $\begin{array}{c}1,099 * * * \\
(0,368)\end{array}$ & $\begin{array}{c}0,772 * * \\
(0,369)\end{array}$ & $\begin{array}{c}0,771 * * \\
(0,369)\end{array}$ \\
\hline $\begin{array}{l}\text { proporção de professores com ensino } \\
\text { superior }\end{array}$ & & & & $\begin{array}{c}-0,025 \\
(0,037)\end{array}$ & $\begin{array}{c}0,001 \\
(0,037)\end{array}$ & $\begin{array}{l}-0,007 \\
(0,036)\end{array}$ & $\begin{array}{c}-0,007 \\
(0,036)\end{array}$ \\
\hline $\begin{array}{l}\text { escolaridade média em anos de } \\
\text { estudo }\end{array}$ & & & & & $\begin{array}{c}0,961 * * \\
(0,452)\end{array}$ & $\begin{array}{c}0,996 * * \\
(0,452)\end{array}$ & $\begin{array}{c}0,966 * * \\
(0,453)\end{array}$ \\
\hline índice de pobreza & & & & & $\begin{array}{l}-22,437 * \\
(11,766) \\
\end{array}$ & $\begin{array}{r}-20,767 * \\
(11,594) \\
\end{array}$ & $\begin{array}{l}-21,018^{*} \\
(11,565)\end{array}$ \\
\hline escolaridade dos pais dos colegas & & & & & & $\begin{array}{c}1,042 * * \\
(0,415)\end{array}$ & $\begin{array}{l}1,042 * * \\
(0,415)\end{array}$ \\
\hline reunião de pais & & & & & & $\begin{array}{c}6,444 * * * \\
(0,297)\end{array}$ & $\begin{array}{c}6,445^{* * * *} \\
(0,297)\end{array}$ \\
\hline $\begin{array}{l}\text { taxa de livros didáticos devolvidos } \\
\text { por aluno }\end{array}$ & & & & & & $\begin{array}{c}0,148 * * * \\
(0,057) \\
\end{array}$ & $\begin{array}{c}0,148 * * * \\
(0,057)\end{array}$ \\
\hline constante & $\begin{array}{c}169,109 * * * \\
(0,179)\end{array}$ & $\begin{array}{c}137,552 * * * \\
(1,969)\end{array}$ & $\begin{array}{c}125,525 * * * \\
(2,129)\end{array}$ & $\begin{array}{c}138,022 * * * \\
(4,091)\end{array}$ & $\begin{array}{c}133,327 * * * \\
(6,271)\end{array}$ & $\begin{array}{c}129,999 * * * \\
(6,280)\end{array}$ & $\begin{array}{c}130,195^{* * * *} \\
(6,270)\end{array}$ \\
\hline $\mathrm{R}^{2}$ & 0,003 & 0,241 & 0,256 & 0,269 & 0,270 & 0,275 & 0,275 \\
\hline número de observações & 101436 & 83587 & 81834 & 81414 & 81414 & 81099 & 81099 \\
\hline
\end{tabular}

Fonte: Elaboração própria com base nos dados da SEADE, Prova Brasil 2005, Censo Escolar 2005 e Censo Demográfico 2000.

$* * *$ significante a $1 \% * *$ significante a $5 \% *$ significante a $10 \%$

\subsection{Tabelas com os resultados obtidos pelas regressões quantílicas}

Tabela A13 - Relação entre crimes contra a pessoa e proficiência escolar em matemática ao longo da distribuição de notas (continua)

\begin{tabular}{cc}
\hline Quantil (proficiência escolar) & Coeficiente \\
\hline 0,05 & 0,0006686 \\
& $(0,001)$ \\
\hline 0,10 & 0,0009734 \\
& $(0,001)$ \\
\hline 0,25 & $-0,0001713$ \\
& $(0,001)$ \\
\hline 0,50 & $-0,0003707$ \\
& $(0,000)$ \\
\hline
\end{tabular}


Tabela A13 - Relação entre crimes contra a pessoa e proficiência escolar em matemática ao longo da distribuição de notas (conclusão)

\begin{tabular}{|c|c|}
\hline Quantil (proficiência escolar) & Coeficiente \\
\hline 0,75 & $\begin{array}{c}-0,0002979 \\
(0,001)\end{array}$ \\
\hline 0,90 & $\begin{array}{c}-0,0000935 \\
(0,001)\end{array}$ \\
\hline 0,95 & $\begin{array}{c}0,0013605 \\
(0,001)\end{array}$ \\
\hline MQO (modelo 6) & $\begin{array}{c}0,000064 \\
(0,001)\end{array}$ \\
\hline
\end{tabular}

Tabela A14 - Relação entre crimes contra o patrimônio e proficiência escolar em matemática ao longo da distribuição de notas

\begin{tabular}{|c|c|}
\hline Quantil (proficiência escolar) & Coeficiente \\
\hline 0,05 & $\begin{array}{c}0,0002412 \\
(0,000)\end{array}$ \\
\hline 0,10 & $\begin{array}{c}0,0002963^{* *} \\
(0,000)\end{array}$ \\
\hline 0,25 & $\begin{array}{c}0,0002044 * * \\
(0,000)\end{array}$ \\
\hline 0,50 & $\begin{array}{c}0,0002629 * * * \\
(0,000)\end{array}$ \\
\hline 0,75 & $\begin{array}{c}0,0003297 * * * \\
(0,000)\end{array}$ \\
\hline 0,90 & $\begin{array}{c}0,00055 * * * \\
(0,000)\end{array}$ \\
\hline 0,95 & $\begin{array}{c}0,0006829 * * * \\
(0,000)\end{array}$ \\
\hline MQO (modelo 6) & $\begin{array}{c}0,0003017 * \\
(0,000)\end{array}$ \\
\hline
\end{tabular}

Fonte: Elaboração própria com base nos dados da SEADE, Prova Brasil 2005, Censo Escolar 2005 e Censo Demográfico 2000.

$* * *$ significante a $1 \% * *$ significante a $5 \% *$ significante a $10 \%$

Tabela A15 - Relação entre crimes violentos e proficiência escolar em matemática ao longo da distribuição de notas (continua)

\begin{tabular}{|c|c|}
\hline Quantil (proficiência escolar) & Coeficiente \\
\hline 0,05 & $\begin{array}{c}0,0006408^{*} \\
(0,000)\end{array}$ \\
\hline 0,10 & $\begin{array}{c}0,000818 * * * \\
(0,000)\end{array}$ \\
\hline 0,25 & $\begin{array}{c}0,0005946 * * * \\
(0,000)\end{array}$ \\
\hline 0,50 & $\begin{array}{c}0,0007261 \text { *** } \\
(0,000)\end{array}$ \\
\hline 0,75 & $\begin{array}{c}0,0007978 * * * \\
(0,000)\end{array}$ \\
\hline 0,90 & $\begin{array}{c}0,0013088 * * * \\
(0,000)\end{array}$ \\
\hline
\end{tabular}


Tabela A15 - Relação entre crimes violentos e proficiência escolar em matemática ao longo da distribuição de notas (conclusão)

\begin{tabular}{lc}
\hline \multicolumn{1}{c}{ Quantil (proficiência escolar) } & Coeficiente \\
\hline 0,95 & $0,0016257^{* * *}$ \\
& $(0,000)$ \\
\hline MQO (modelo 6) & $0,0008077^{* *}$ \\
& $(0,000)$ \\
\hline Fonte: Elaboração própria com base nos dados da SEADE, Prova Brasil 2005, Censo Escolar 2005 e Censo \\
$\begin{array}{l}\text { Demográfico 2000. } \\
\text { ***significante a 1\% } * * \text { significante a 5\% *significante a 10\% }\end{array}$
\end{tabular}

Tabela A16 - Relação entre ameaças e proficiência escolar em matemática ao longo da distribuição de notas

\begin{tabular}{|c|c|}
\hline Quantil (proficiência escolar) & Coeficiente \\
\hline 0,05 & $\begin{array}{c}0,0000201 \\
(0,003)\end{array}$ \\
\hline 0,10 & $\begin{array}{c}0,0026278 \\
(0,003)\end{array}$ \\
\hline 0,25 & $\begin{array}{c}-0,0010213 \\
(0,002)\end{array}$ \\
\hline 0,50 & $\begin{array}{c}-0,0010701 \\
(0,002)\end{array}$ \\
\hline 0,75 & $\begin{array}{c}-0,0000642 \\
(0,002)\end{array}$ \\
\hline 0,90 & $\begin{array}{c}-0,0000864 \\
(0,003)\end{array}$ \\
\hline 0,95 & $\begin{array}{c}0,0042957 \\
(0,004)\end{array}$ \\
\hline MQO (modelo 6) & $\begin{array}{c}0,0003637 \\
(0,003)\end{array}$ \\
\hline
\end{tabular}

Tabela A17 - Relação entre roubo consumado e proficiência escolar em matemática ao longo da distribuição de notas (continua)

\begin{tabular}{cc}
\hline Quantil (proficiência escolar) & Coeficiente \\
\hline 0,05 & 0,0004771 \\
& $(0,001)$ \\
\hline 0,10 & $0,0008843 * *$ \\
& $(0,000)$ \\
\hline 0,25 & $0,0006146^{*}$ \\
& $(0,000)$ \\
\hline 0,50 & $0,0007852^{* * *}$ \\
& $(0,000)$ \\
\hline 0,75 & $0,0008076^{* *}$ \\
& $(0,000)$ \\
\hline 0,90 & $0,0016533^{* * *}$ \\
& $(0,000)$ \\
\hline 0,95 & $0,0021071^{* * *}$ \\
& $(0,001)$ \\
\hline
\end{tabular}


Tabela A17 - Relação entre roubo consumado e proficiência escolar em matemática ao longo da distribuição de notas (conclusão)

$\begin{array}{cc}\text { Quantil (proficiência escolar) } & \text { Coeficiente } \\ \text { MQO (modelo 6) } & 0,0008532\end{array}$

$(0,001)$

Fonte: Elaboração própria com base nos dados da SEADE, Prova Brasil 2005, Censo Escolar 2005 e Censo Demográfico 2000.

$* * *$ significante a $1 \% * *$ significante a $5 \% *$ significante a $10 \%$

Tabela A18 - Relação entre furto consumado e proficiência escolar em matemática ao longo da distribuição de notas

\begin{tabular}{cc}
\hline Quantil (proficiência escolar) & Coeficiente \\
\hline 0,05 & 0,0001326 \\
& $(0,000)$ \\
\hline 0,10 & 0,0004107 \\
& $(0,000)$ \\
\hline 0,25 & 0,0001425 \\
& $(0,000)$ \\
\hline 0,50 & 0,0001209 \\
& $(0,000)$ \\
\hline 0,75 & 0,0003599 \\
& $(0,000)$ \\
\hline 0,90 & $0,0006802 * *$ \\
& $(0,000)$ \\
\hline 0,95 & $0,0009044 * * *$ \\
& $(0,000)$ \\
\hline MQO (modelo 6) & 0,0002221 \\
& $(0,000)$ \\
\hline
\end{tabular}

Fonte: Elaboração própria com base nos dados da SEADE, Prova Brasil 2005, Censo Escolar 2005 e Censo Demográfico 2000.

$* * *$ significante a $1 \% * *$ significante a $5 \% *$ significante a $10 \%$

Tabela A19 - Relação entre crimes contra a pessoa e proficiência escolar em português ao longo da distribuição de notas

\begin{tabular}{cc}
\hline Quantil (proficiência escolar) & Coeficiente \\
\hline 0,05 & 0,0002115 \\
$(0,001)$ \\
\hline 0,10 & $0,00113^{*}$ \\
& $(0,001)$ \\
\hline 0,25 & 0,0004729 \\
& $(0,001)$ \\
\hline 0,50 & 0,0005265 \\
& $(0,001)$ \\
\hline 0,75 & $0,000988^{*}$ \\
& $(0,001)$ \\
\hline 0,90 & 0,0007543 \\
& $(0,001)$ \\
\hline 0,95 & 0,0013198 \\
& $(0,001)$ \\
\hline MQO (modelo 6) & 0,0008434 \\
& $(0,001)$ \\
\hline
\end{tabular}

Fonte: Elaboração própria com base nos dados da SEADE, Prova Brasil 2005, Censo Escolar 2005 e Censo Demográfico 2000.

$* * *$ significante a $1 \% * *$ significante a $5 \% *$ significante a $10 \%$ 
Tabela A20 - Relação entre crimes contra o patrimônio e proficiência escolar em português ao longo da distribuição de notas

\begin{tabular}{lc}
\hline Quantil (proficiência escolar) & Coeficiente \\
\hline 0,05 & 0,0000609 \\
& $(0,000)$ \\
\hline 0,10 & $0,0004012^{* * *}$ \\
& $(0,000)$ \\
\hline 0,25 & $0,0002667 * * *$ \\
& $(0,000)$ \\
\hline 0,50 & $0,00035 * * *$ \\
& $(0,000)$ \\
\hline 0,75 & $0,0003912 * * *$ \\
& $(0,000)$ \\
\hline 0,90 & $0,0005009^{* * *}$ \\
& $(0,000)$ \\
\hline 0,95 & $0,0005399^{* * *}$ \\
& $(0,000)$ \\
\hline MQO (modelo 6) & $0,0003406 * *$ \\
& $(0,000)$ \\
\hline Fonte: Elaboração própria com base nos dados da SEADE, Prova Brasil 2005, Censo Escolar 2005 e Censo \\
Demográfico 2000. \\
***significante a 1\% **significante a 5\% *significante a 10\%
\end{tabular}

Tabela A21 - Relação entre crimes violentos e proficiência escolar em português ao longo da distribuição de notas

\begin{tabular}{|c|c|}
\hline Quantil (proficiência escolar) & Coeficiente \\
\hline 0,05 & $\begin{array}{c}0,0001351 \\
(0,000)\end{array}$ \\
\hline 0,10 & $\begin{array}{c}0,0008868 * * * \\
(0,000)\end{array}$ \\
\hline 0,25 & $\begin{array}{c}0,0005389 * * \\
(0,000)\end{array}$ \\
\hline 0,50 & $\begin{array}{c}0,0008169 * * * \\
(0,000)\end{array}$ \\
\hline 0,75 & $\begin{array}{c}0,0010339 * * * \\
(0,000)\end{array}$ \\
\hline 0,90 & $\begin{array}{c}0,0013101 * * * \\
(0,000)\end{array}$ \\
\hline 0,95 & $\begin{array}{c}0,0013766^{* * * *} \\
(0,000)\end{array}$ \\
\hline MQO (modelo 6) & $\begin{array}{c}0,0008403 * * \\
(0,000)\end{array}$ \\
\hline
\end{tabular}

Fonte: Elaboração própria com base nos dados da SEADE, Prova Brasil 2005, Censo Escolar 2005 e Censo Demográfico 2000.

$* * *$ significante a $1 \% * *$ significante a $5 \% *$ significante a $10 \%$

Tabela A22 - Relação entre ameaças e notas de português ao longo da distribuição de notas (continua)

\begin{tabular}{cc}
\hline Quantil (proficiência escolar) & Coeficiente \\
\hline 0,05 & $-0,0005935$ \\
& $(0,003)$ \\
\hline 0,10 & 0,0026186 \\
& $(0,003)$ \\
\hline 0,25 & 0,0018293 \\
& $(0,002)$ \\
\hline
\end{tabular}


Tabela A22 - Relação entre ameaças e notas de português ao longo da distribuição de notas (conclusão)

\begin{tabular}{cc}
\hline Quantil (proficiência escolar) & Coeficiente \\
\hline 0,50 & 0,0018567 \\
& $(0,002)$ \\
\hline 0,75 & $0,0035067 *$ \\
& $(0,002)$ \\
\hline 0,90 & $0,0048357^{*}$ \\
& $(0,003)$ \\
\hline 0,95 & 0,0048285 \\
& $(0,004)$ \\
\hline MQO (modelo 6) & 0,0031125 \\
& $(0,003)$ \\
\hline
\end{tabular}

Fonte: Elaboração própria com base nos dados da SEADE, Prova Brasil 2005, Censo Escolar 2005 e Censo Demográfico 2000.

$* * *$ significante a $1 \% * *$ significante a $5 \% *$ significante a $10 \%$

Tabela A23 - Relação entre roubo consumado e proficiência escolar em português ao longo da distribuição de notas

\begin{tabular}{cc}
\hline Quantil (proficiência escolar) & Coeficiente \\
\hline 0,05 & 0,0000694 \\
$(0,000)$ & $0,000838^{*}$ \\
& $(0,000)$ \\
\hline 0,10 & 0,0004892 \\
& $(0,000)$ \\
\hline 0,25 & $0,0009911^{* * *}$ \\
& $(0,000)$ \\
\hline 0,50 & $0,0012105^{* * *}$ \\
& $(0,000)$ \\
\hline 0,75 & $0,0015307 * * *$ \\
& $(0,000)$ \\
\hline 0,90 & $0,0018601 * * *$ \\
& $(0,001)$ \\
\hline MQO (modelo 6) & $0,0009443^{*}$ \\
& $(0,001)$ \\
\hline
\end{tabular}

Fonte: Elaboração própria com base nos dados da SEADE, Prova Brasil 2005, Censo Escolar 2005 e Censo Demográfico 2000.

$* * *$ significante a $1 \% * *$ significante a $5 \% *$ significante a $10 \%$

Tabela A24 - Relação entre furto consumado e proficiência escolar em português ao longo da distribuição de notas (continua)

\begin{tabular}{cc}
\hline Quantil (proficiência escolar) & Coeficiente \\
\hline 0,05 & $-0,0000633$ \\
& $(0,000)$ \\
\hline 0,10 & 0,0002746 \\
& $(0,000)$ \\
\hline 0,25 & 0,0002381 \\
& $(0,000)$ \\
\hline 0,50 & $0,0004521^{*}$ \\
& $(0,000)$ \\
\hline 0,75 & $0,000526^{* *}$ \\
& $(0,000)$ \\
\hline 0,90 & $0,0006616^{* *}$ \\
& $(0,000)$ \\
\hline
\end{tabular}


Tabela A24 - Relação entre furto consumado e proficiência escolar em português ao longo da distribuição de notas (conclusão)

\begin{tabular}{lc}
\hline \multicolumn{1}{c}{ Quantil (proficiência escolar) } & Coeficiente \\
\hline 0,95 & $0,0007721^{* *}$ \\
& $(0,000)$ \\
\hline MQO (modelo 6) & 0,0004356 \\
& $(0,000)$ \\
\hline Fonte: Elaboração própria com base nos dados da SEADE, Prova Brasil 2005, Censo Escolar 2005 e Censo \\
$\begin{array}{l}\text { Demográfico 2000. } \\
* * * \text { significante a 1\% } \% \text { significante a 5\% *significante a 10\% }\end{array}$
\end{tabular}

